\title{
ANÁLISE DO COMPORTAMENTO TERMOELÁSTICO DE UM FREIO A TAMBOR, UTILIZANDO O MÉTODO DOS ELEMENTOS FINITOS
}

Dissertação apresentada à Escola de Engenharia de São Carlos da Universidade de São Paulo para obtenção do título de Mestre em Ciências.

Área de concentração: Projeto Mecânico.

Orientadora: Profa. Dra. Zilda de Castro Silveira

ESTE EXEMPLAR TRATA-SE DA VERSÃO CORRIGIDA. A VERSÃO ORIGINAL ENCONTRASE DISPONÍVEL JUNTO AO DEPARTAMENTO DE ENGENHARIA MECANICA DA EESC-USP. 
AUTORIZO A REPRODUÇÃO TOTAL OU PARCIAL DESTE TRABALHO, POR QUALQUER MEIO CONVENCIONAL OU ELETRÔNICO, PARA FINS DE ESTUDO E PESQUISA, DESDE QUE CITADA A FONTE.

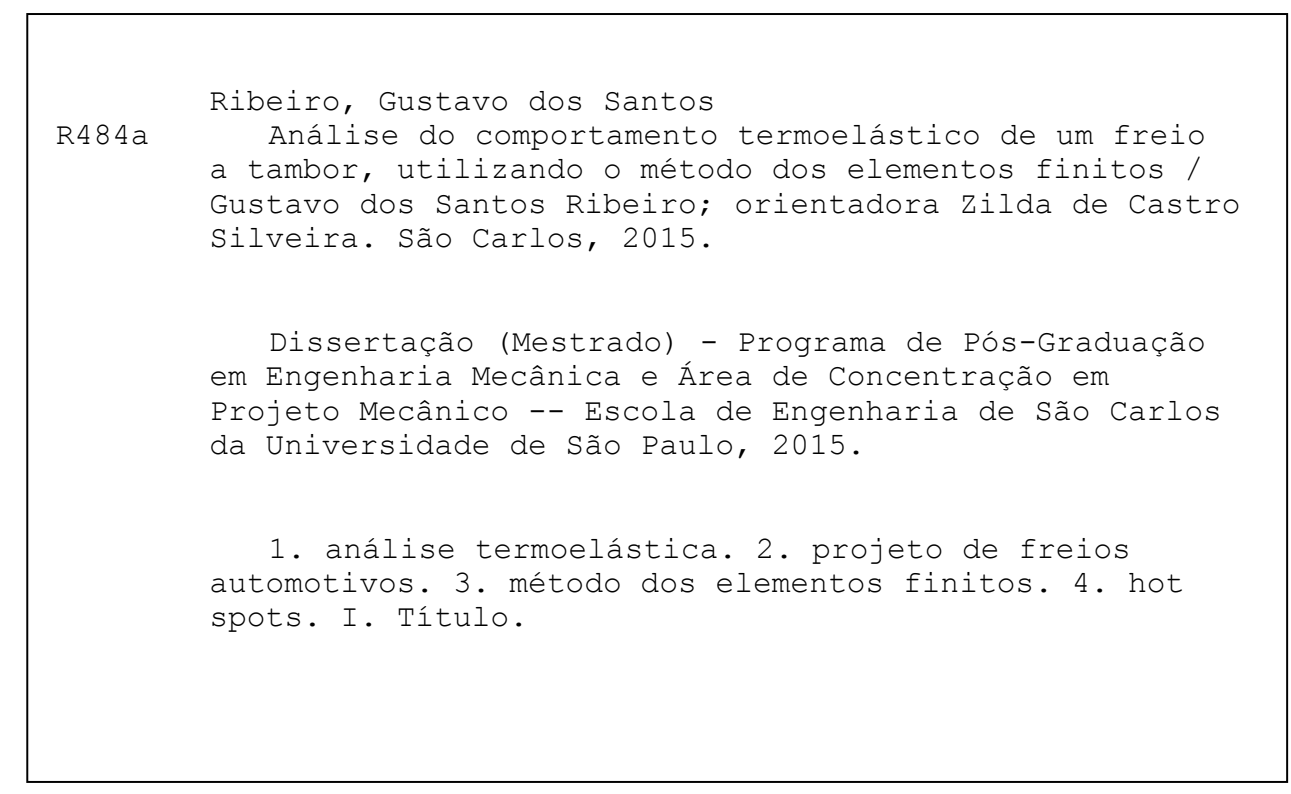




\section{FOLHA DE JULGAMENTO}

Candidato: Engenheiro GUSTAVO DOS SANTOS RIBEIRO.

Título da dissertação: "Análise do comportamento termoelástico de um freio a tambor, utilizando o método dos elementos finitos".

Data da defesa: 15/07/2015

Comissão Julgadora:

Profa. Dra. Zilda de Castro Silveira (Orientadora)

(Escola de Engenharia de São Carlos/EESC)

Prof. Associado Gilberto Francisco Martha de Souza (Escola Politécnica/EP-USP)

Prof. Dr. Flavio Yukio Watanabe

(Universidade Federal de São Carlos/UFSCar)
Resultado:
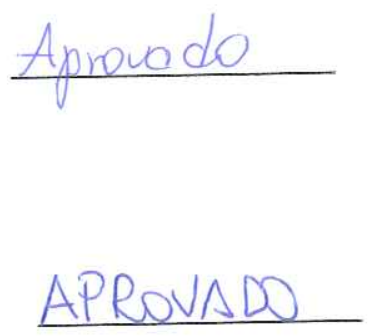

APROVADO

Coordenador do Programa de Pós-Graduação em Engenheira Mecânica: Prof. Associado Gherhardt Ribatski

Presidente da Comissão de Pós-Graduação:

Prof. Associado Paulo César Lima Segantine 



\section{AGRADECIMENTOS}

À professora Zilda de Castro Silveira, pela excelente orientação durante este trabalho, pela amizade e oportunidades oferecidas. Ressalto o valor de sua dedicação à pesquisa e ao ensino dentro da comunidade acadêmica da Engenharia Mecânica.

Às funcionárias da secretaria de pós graduação da Engenharia Mecânica, Ana Paula e lara, pela amizade e esclarecimento de todas as dúvidas que tive.

Aos professores que me transmitiram o conhecimento necessário aos estudos e pesquisa do tema.

Ao CNPq, pela bolsa de mestrado concedida (processo № 135743/2013-3)

À Universidade de São Paulo e à Escola de Engenharia de São Carlos. 



\section{RESUMO}

Ribeiro, G. S. Análise do comportamento termoelástico de um freio a tambor, utilizando o método dos elementos finitos. 2015. 156 p. Dissertação de mestrado - Escola de Engenharia de São Carlos, Universidade de São Paulo, São Carlos, 2015.

O objetivo desse trabalho é apresentar o desenvolvimento de modelos numéricos baseados no método dos elementos finitos, para investigar o comportamento termoelástico, de um freio a tambor utilizado em veículos pesados. $O$ acoplamento de fenômenos físicos e mecânicos durante o processo de frenagem é uma etapa fundamental para o projeto com foco em confiabilidade. A identificação de falhas potenciais decorrentes dos diferentes processos de frenagens, ainda na fase do projeto preliminar, permite o desenvolvimento de projetos mais robustos, incluindo reduções de tempo e nos custos de ensaios experimentais. Este trabalho apresenta o desenvolvimento e implementação de um modelo computacional baseado no comportamento termoelástico dos principais elementos mecânicos de um freio a tambor envolvidos no processo de frenagem. Foram consideradas três condições principais de análise: estática de corpos rígidos, estática de corpos flexíveis e dinâmica em regime permanente com corpos flexíveis. O objetivo é investigar e estimar valores de pressão de contato, cargas resultantes nos apoios, bem como obter o gradiente de temperatura e tensão devido à carga térmica em regiões de interesse. Essa análise pode melhorar o entendimento dos fenômenos envolvidos nos diferentes processos de frenagens, auxiliando as tomadas de decisões técnicas, principalmente na antecipação de falhas prematuras relacionadas com fadiga térmica e desgaste adesivo.

Palavras-chave: análise termoelástica; projeto de freios automotivos; método dos elementos finitos; hot spots. 



\begin{abstract}
Ribeiro, G. S. Analysis of the thermoelastic behavior of a drum brake, using the finite element method. 2015. 156 p. Dissertação de mestrado - Escola de Engenharia de São Carlos, Universidade de São Paulo, São Carlos, 2015.

This work presents the development of a numerical model based on thermoelastic behavior of a drum brake applied to heavy vehicles. The coupling of physics and mechanical phenomena during the braking process represents an important phase in the design vehicle systems. The identification of potential failures during the braking processes, considering the preliminary design phase gives robustness to the design. This characteristic allows reducing the time and cost of experimental set-up. This work presents the development and preliminary results of a numerical model based on thermal-elastic behavior of an automotive drum brake. It was considered three main conditions for the analysis: rigid bodies statics, flexible bodies statics and flexible bodies steady state dynamic analysis. The main objective of this study is investigate and estimate the relationship between the design parameters, as strain, stress as well thermal loads and temperature gradient, in conditions of static and quasi-static steady state regime. The estimative of these parameters to support the technical decisions related to reliability design, mainly to anticipate failures arising to thermal fatigue and adhesive wear.
\end{abstract}

Key words: thermoelastic analysis; automotive brake design; finite element method; hot spots. 



\section{LISTA DE FIGURAS}

Figura 1.1 - Percentuais da matriz de transportes terrestres brasileira (CNT, 2015). 23

Figura 3.1 - Sistema de freio a tambor: (a) sistema de freio conforme montado na roda de um veículo (PUHN, 1985); (b) Ilustração das partes internas com indicação de nomenclatura (LIMPERT, 1999).

Figura 3.2 - Sistema de freio a disco: (a) sistema de freio conforme montado na roda de um veículo (PUHN, 1985); (b) ilustração com indicação de nomenclatura (LIMPERT, 1999). ...34 Figura 3.3 - Tipos básicos de atuação em freios a tambor hidráulicos: (a) Sistema de sapatas primária e secundária; (b) Sistemas de duas sapatas primárias; (c) Sistema duo-servo (adaptado de LIMPERT, 1999).

Figura 3.4 - Sistema de freio a tambor do tipo S Camo (MPI, 2015). 36

Figura 3.5 - Comparação entre os diversos sistemas de freio automotivos com base no fator de freio em função da variação no coeficiente de atrito (LIMPERT, 1999). 37

Figura 3.6 - Ampliação de amostra de pastilha de freio empregando microscópio eletrônico de varredura (CHAN; STACHOWIAK, 2004).

Figura 3.7 - Imagem esquemática de dois corpos sob a ação de carga fretting (AMIRI; KHONSARI, 2010).

Figura 3.8 - Topografia de superfícies representando picos de asperezas de cinco amostras de aço inox, com diferentes níveis de polimento (KALIN; POGAčNIK, 2013).

Figura 3.9 - Esquema de contato mostrando seis tipos de hot spots e instabilidades termoelásticas (ANDERSON; KNAPP, 1990).

Figura 3.10 - Classificação de hot spots auxiliada por imagens termográficas em disco de freio de trens(PAINER; DUFRÉNOY; WEICHERT, 2004) .............................................. 50

Figura 3.11 - Modelo para formulação da TEl usado por Dow e Burton (1972). 45

Figura 3.12 - Coeficiente exponencial do tempo em função da velocidade de deslizamento da lâmina para diferentes pares de materiais (DOW; BURTON, 1972).

Figura 3.13 - Ângulo de cone em discos de freio devido aplicação de cargas térmicas. 47

Figura 3.14 - Comparação entre medições e simulação numérica da deformação Coning Angle em disco de freio após oito frenagens consecutivas (VALVANO; LEE, 2000).

Figura 3.15 - Mecanismo para uma distribuição de pressões e desgaste desigual, devido a distorções induzidas termicamente, em uma pastilha e sua placa de apoio traseira (Eriksson, Bergman, Jacobson, 2002).

Figura 3.16 - Formação em dinamômetro de bancada de hot bands para diferentes diâmetros de disco (a) 10" e (b) 12" (CHO; CHO, 2008). 
Figura 3.17 - Desenvolvimento do coeficiente de atrito e fração nominal de contato de área de um disco de freio durante uma sequênica de frenagens (Eriksson, Bergman, Jacobson, 2002).

Figura 3.18 - Demonstração da presença de modo antissimétrico de vibração em discos de freio sujeitos a esforços de atrito: (a) Imagem termográfica de dois lados simultâneos de um disco de freio, exibindo MHS (PAINER; DUFRÉNOY; WEICHERT, 2004); (b) Ilustração da configuração deformada a partir da teoria de instabilidades termoelásticas (TEI) (LEE; BARBER, 1993). 56

Figura 3.19 - Imagem termográfica demonstrando o surgimento de hot-spots em um disco de freio de 12" de diâmetro para duas pressões aplicadas: (a) 1,5 bar; (b) 2,0 bar ( $\mathrm{CHO}$; $\mathrm{CHO}$, 2008).

Figura 3.20 - Alteração do coeficiente de atrito, em situação de aumento de temperatura (aquecimento) e posterior diminuição da mesma (recuperação) (FRAS-LE, 2014). .59 Figura 3.21 - Efeito do aumento do coeficiente de atrito durante ensaios realizados em um novo freio a disco. Dados experimentais: variação automática da pressão de frenagem entre 3- 25 bar, frenagens repetidas no intervalo de 3 a 1 rps (Eriksson, Bergman, Jacobson, 2002).

Figura 3.22 - Aparência da superfície de uma pastilha de freio, exibindo planos de contato e a superfície rugosa circundante. A mesma área é vista com auxílio de duas técnicas diferentes: (a) micrografia perfilométrica 3-D; (b) Microscópio eletrônico de varredura (Eriksson, Bergman, Jacobson, 2002).

Figura 3.23 - Disco de freio usado em trens de passageiros exibindo a distribuição radial de trincas térmicas (KIM; KWON; YOON, 2009).

Figura 3.24 - Condições de desgaste encontradas em tambores de freio: (a) Desgaste uniforme; (b) Trincas devido à fadiga térmica; (c) Pontos negros indicando hot spots; (d) Vitrificação, ou Glazing, da superfície interna do tambor (MERITOR, 2006).

Figura 4.1 - Forças atuantes na sapata auto-energizante (primária) de um freio a tambor (BUDYNAS; NISBETT, 2011).

Figura 4.2 - Fração de energia absorvida pela lona para diferentes valores de condutividade térmica (do disco e da pastilha) na ITL (LOIZOU, 2012). 72

Figura 5.1 - Sistema de acionamento de freio a tambor do tipo S Camo (MERITOR, 2006) 81 Figura 5.2 - Dimensões do sistema de freio simplificado em $\mathrm{mm}$.

Figura 5.3 - Representação do elemento Solid226 utilizado para acoplamentos multifísicos

Figura 5.4 - Fluxograma da implementação do estudo.

Figura 5.5 - Dimensões e malha de elementos finitos condições aplicadas a um primeiro modelo considerando os efeitos termoelásticos. 
Figura 5.6 - Resultados obtidos para o modelo de barras sob influência de atrito de deslizamento: (a) Fluxo de calor em Y com máximo valor em 1283,7 W/m² para a barra; (b)

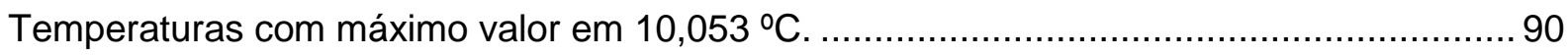
Figura 5.7 - Freio genérico com sapatas internas expansíveis; dimensões em milímetros (BUDYNAS; NISBETT, 2011).

Figura 5.8 - Equações de restrição ligadas aos nós pilotos, gerando comportamento de corpo rígido nas sapatas e no tambor. 92

Figura 5.9 - Elementos de superfície usados na transferência de esforços por contato escolhidos para a análise: (a) Elementos CONTA174 para as sapatas; (b) Elementos TARGE170 para o tambor. 93

Figura 5.10 - Malha, esforços e restrições aplicadas ao modelo, indicando a atribuição de primária e secundária às sapatas devido ao sentido de giro do tambor. 93 Figura 5.11 - Esforços aplicados e reações de apoio obtidas para um modelo preliminar...94 Figura 5.12 - Restrições e carregamentos a serem determinados e aplicados no modelo. . 95 Figura 5.13 - Ilustração da lógica de montagem dos eixos S Camo no sistema de freio estudado, para ambos os lados do veículo e duas possíveis posições do eixo acionador cada (MERITOR, 2005). 96

Figura 5.14 - Direção de aplicação das forças nas sapatas 96

Figura 5.15 - Braços de alavanca do acionamento das sapatas.

Figura 5.16 - Curva de comportamento mecânico sob compressão para 4 amostras de material de atrito usado em pastilhas de freio (VOICULESCU, 2010). 98 Figura 5.17 - Malha, esforços e restrições aplicadas ao modelo do caso 1 (convecção não mostrada atuante em todas as áreas com exceção das áreas de contato). 103 Figura 5.18 - Equações de restrição ligadas aos nós pilotos, gerando comportamento de corpo rígido nas sapatas e no tambor, mantendo apenas a lona como corpo flexível.. 103 Figura 5.19 - Malha, esforços e restrições aplicadas ao modelo dos casos 2 e 3 (convecção não mostrada atuante em todas as áreas com exceção das áreas de contato). 105 Figura 6.1 - Reações de apoio nas sapatas primária e secundária (acima) e no nó-piloto do tambor (centro), demonstradas sobre o espectro do modelo, considerando o modelo do caso 1. 107

Figura 6.2 - Gráfico da evolução no tempo das reações de apoio, em $X$ e $Y$, nos pinos das sapatas, considerando o modelo do caso 1. 108

Figura 6.3 - Configuração deformada (120x) para o modelo do caso 1, corpos rígidos com exceção da lona, apresentando deslocamento máximo em 0,231 mm. 108 Figura 6.4 - Campo de tensões equivalentes Von Mises sobre as lonas do modelo do caso 1. Valor máximo de $1,1 \mathrm{MPa}$. 109 
Figura 6.5 - Tensões de Von Mises ao longo do comprimento médio (sentido anti-horário) da sapata primária para o modelo do caso 1. 109

Figura 6.6 - Tensões de Von Mises ao longo do comprimento médio (sentido horário) da sapata secundária para o modelo do caso 1.

Figura 6.7 - Reações de apoio e momentos resultantes nos nós-piloto da sapatas e tambor, sem exibição do modelo, para o modelo do caso 2.

Figura 6.8 - Gráfico da evolução no tempo das reações de apoio, em $X, Y$ e $Z$, nos pinos das sapatas, considerando o modelo do caso 2 .

Figura 6.9 - Configuração deformada (60x) para o modelo do caso 2, apresentando deslocamento máximo em 0,804 mm no ponto de aplicação de força da sapata primária. 112 Figura 6.10 - Campo de tensões equivalentes de Von Mises do modelo do caso 2, apresentando tensão máxima de $247 \mathrm{MPa}$ no ponto de fixação da sapata primária. 112 Figura 6.11 - Campo de tensões equivalentes de Von Mises das lonas do modelo do caso 2 plotados em termos de solução individual dos elementos, exibindo continuidade imperfeita, mas adequada, dos valores. Máxima tensão de 2,57 MPa .

Figura 6.12 - Tensões de Von Mises ao longo do comprimento médio (sentido anti-horário) da sapata primária para o modelo do caso 2 . 114

Figura 6.13 - Tensões de Von Mises ao longo do comprimento médio (sentido horário) da sapata secundária para o modelo do caso 2 . 114

Figura 6.14 - Campo de deformações equivalentes de Von Mises do modelo do caso 2 plotados em termos de solução individual dos elementos, exibindo continuidade imperfeita, mas adequada, dos valores. Máximas deformações em 0,002571 nas extremidades das lonas.

Figura 6.15 - Condição do contato na interface de atrito entre as lonas e o tambor, após a aplicação do torque, para o modelo do caso 2 ...... 115

Figura 6.16 - Campo de temperaturas nas lonas e sapatas do freio do modelo do caso 2. Temperatura máxima de 21,07 ํㅡ. 116

Figura 6.17 - Campo de temperaturas no tambor do freio do modelo do caso 2. Temperatura máxima de $21,06{ }^{\circ} \mathrm{C}$ 116

Figura 6.18 - Reações de apoio e momentos resultantes nos nós-piloto da sapatas e tambor, sem exibição do modelo do caso 3.

Figura 6.19 - Gráfico da evolução no tempo das reações de apoio, em $X, Y$ e $Z$, nos pinos das sapatas, considerando o modelo do caso 3. 118

Figura 6.20 - Configuração deformada (80x) para o modelo do caso 3, apresentando deslocamento máximo em $0,611 \mathrm{~mm}$ nas bordas externas do tambor. 118 Figura 6.21 - Campo de tensões equivalentes de Von Mises do modelo do caso 3, apresentando valor máximo de 373 MPa no ponto aplicação de força da sapata primária.119 
Figura 6.22 - Campo de tensões equivalentes de Von Mises das lonas do modelo do caso 3 plotados em termos de solução individual dos elementos, exibindo continuidade imperfeita, mas adequada, dos valores. Máxima tensão de 1,5 $\mathrm{MPa}$ 120

Figura 6.23 - Tensões de Von Mises ao longo do comprimento médio (sentido anti-horário) da sapata primária para o modelo do caso 3.

Figura 6.24 - Tensões de Von Mises ao longo do comprimento médio (sentido horário) da sapata secundária para o modelo do caso 3 .

Figura 6.25 - Campo de deformações equivalentes de Von Mises do modelo do caso 3 plotados em termos de solução individual dos elementos, exibindo continuidade imperfeita, mas adequada, dos valores. Máximas deformações em 0,001866 no ponto de força e lona primária.

Figura 6.26 - Condição do contato na interface de atrito entre as lonas e o tambor, após a aplicação da velocidade de deslizamento, para o modelo do caso 3. 122

Figura 6.27 - Campo de temperaturas nas lonas e sapatas do freio do modelo do caso 3. Temperatura máxima de $383,3 \stackrel{\circ}{ } \mathrm{C}$.

Figura 6.28 - Campo de temperaturas no tambor do freio do modelo do caso 3. Temperatura máxima de $366,0 \stackrel{\circ}{ } \mathrm{C}$. 123

Figura 6.29 - Fluxo de calor direcionado ao tambor e à lona primária, no ponto de contato de máxima temperatura para o modelo do caso 3 . 124

Figura 6.30 - Estimativa das áreas sujeitas à convecção de cada subconjunto: (a) Áreas externas do tambor; (b) Áreas externas (desconsiderando a região de contato) das sapatas. 125

Figura 6.31 - Temperaturas máximas para as superfícies de contato do tambor e lona primária para o modelo do caso 3 . 126

Figura 6.32 - Plotagem da temperatura máxima no tambor calculada em função do tempo, com base na equação (4.29) empregando valores físicos do modelo estudado. 128 Figura 6.33 - Termografia de ensaios de frenagem de um sistema de freio a tambor para

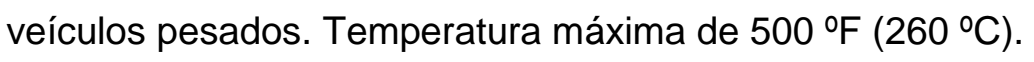
129 Figura 6.34 - Evolução da temperatura da lona de um freio a tambor em ensaio de frenagens sucessivas (LEE; SON; YANG, 2006). 


\section{LISTA DE TABELAS}

Tabela 3.1 - Velocidades críticas para alguns pares de deslizamento usando o mesmo

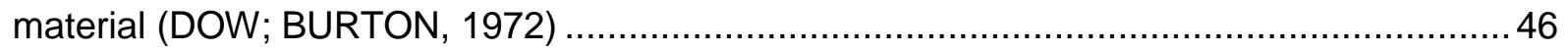

Tabela 3.2 - Comparação entre os tipos de hot spots (ANDERSON; KNAPP, 1990).......... 48 Tabela 3.3 - Classificação de hot spots em freios de trens (PAINER; DUFRÉNOY;

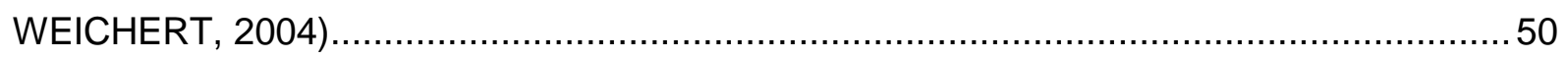

Tabela 5.1 - Propriedades físicas de uma classe geral de Ferro Fundido Cinzento (ASM, 1990).

Tabela 5.2 - Propriedades físicas de uma categoria genérica de aço-carbono, empregado na fabricação de sapatas e pastilhas de freio (ASM, 1990).

Tabela 5.3 - Propriedades físicas do material de atrito usado em lonas de freio a tambor para veículos pesados (Fonte: Fras-Le ${ }^{\circledR}$ ). 83

Tabela 5.4 - Parâmetros adotados para os elementos de contato de atrito. 86

Tabela 5.5 - Valores empregados na simulação de barras em atrito dinâmico. 88 Tabela 5.6 - Dados da malha de elementos finitos usada para o modelo de comparação. .94 Tabela 5.7 - Comparação entre as reações obtidas analiticamente e por elementos finitos.

Tabela 5.8 - Dados da malha de elementos finitos usada para o modelo rígido com lonas flexíveis. 104

Tabela 5.9 - Dados da malha de elementos finitos usada para os modelos dos casos 2 e 3. 104

Tabela 6.1 - Componentes e resultante das reações nos pinos ao final da análise do caso 1.

Tabela 6.2 - Componentes e resultante das reações nos pinos ao final da análise do modelo do caso 2 .

Tabela 6.3 - Componentes e resultante das reações nos pinos ao final da análise do caso 3. 


\section{Lista de AbREVIaturas e Siglas}

TEI Instabilidade termoelástica (Thermoelastic Instability)

MEF Método dos elementos finitos

PWD Distorção por ondulação progressiva (Progressive waviness distortion)

MHS Microscopic Hot Spots

NVH Noise, vibration and harshness

TCC Condutividade térmica (Thermal conductivity)

FGHT Fração de energia disspada por calor

FWGT Fator de distribuição do calor. 


\section{Lista de Símbolos}

\section{Alfabeto Latino}

$a \quad$ Distância entre o pino e o centro de giro do tambor $(m)$

$A_{s}, A_{\text {var }} \quad$ Área de superfície; e área varrida $\left(\mathrm{m}^{2}\right)$

$b \quad$ Largura da lona de freio $(m)$

Bi Número de Biot (-)

$c$ Distância entre o pino e o ponto de aplicação da força $(m)$

$C_{p} \quad$ Calor específico $(\mathrm{J} / \mathrm{kgK})$

$D^{-1} \quad$ Matriz de flexibilidade

$e \quad$ Proporção de eixos em elipse; Número de euler

$\dot{E}_{s t}, \dot{E}_{g} \quad$ Taxa de energia armazenada e gerada $(W)$

$E_{f} \quad$ Energia de frenagem $(J)$

$F \quad$ Força $(N)$

$f(Z, S) \quad$ Função de redução da temperatura flash

$G_{a b s} \quad$ Energia absorvida por radiação $(W)$

$h \quad$ Coeficiente de transferência de calor por convecção $\left(W / m^{2} K\right)$

$k \quad$ Condutividade térmica $(\mathrm{W} / \mathrm{mK})$

$L_{c} \quad$ Comprimento característico $(m)$

$\dot{m}_{a} \quad$ Fluxo mássico de $\operatorname{ar}\left(\mathrm{m}^{3} / \mathrm{s}\right)$

$M_{\mu} \quad$ Momento das forças de atrito (N.m)

$M_{N} \quad$ Momento das forças normais (N.m)

$p, p_{a} \quad$ Pressão e pressão máxima na sapata $\left(N / m^{2}\right)$

$q^{\prime \prime} \quad$ Fluxo de calor $W / m^{2}$

$q_{c}{ }^{\prime \prime} \quad$ Transferência de calor por convecção por unidade de área $\left(W / m^{2}\right)$

$q^{\prime \prime}{ }_{t} \quad$ Fluxo de calor para o tambor $W / m^{2}$

$q "{ }_{l} \quad$ Fluxo de calor para a lona $W / m^{2}$

$q^{\prime \prime}$ rad $\quad$ Fluxo de calor por radiação $W / m^{2}$

$q_{0} \quad$ Energia de frenagem $(W)$

$r \quad$ Raio $(m)$

Re Número de Reynolds (-). 


$\begin{array}{ll}S\left(e, V_{r 1}\right) & \text { Função de forma e velocidade (TEl) } \\ S & \text { Entropia } \\ T & \text { Torque }(N . m) ; \text { Temperatura }\left(K \text { ou }{ }^{\circ} \mathrm{C}\right) \\ T_{r e f}, T_{\infty} & \text { Temperatura de referência }\left(K o u{ }^{\circ} \mathrm{C}\right) \\ T_{u n i f}, T_{s} & \text { Temperatura uniforme e de superfície }\left(K o u{ }^{\circ} \mathrm{C}\right) \\ U & \text { Energia interna }(W) \\ V, V_{r} & \text { Velocidade e velocidade relativa }(m / s) \\ v_{t} & \text { Volume do tambor }\left(m^{3}\right) \\ W & \text { Trabalho }(W) \\ Z\left(V_{r}\right) & \text { Função de velocidade }\end{array}$

\section{Alfabeto Grego}

$\alpha \quad$ Coeficiente de expansão térmica (1/K); absortividade $(0 \leq \alpha \leq 1)$

$\beta \quad$ Coeficiente adimensional: 0,7 para freios frontais e 0,3 para traseiros

$\delta_{l} \quad$ Espessura da lona $(m)$

$\boldsymbol{\nabla} \quad$ Operador gradiente

$\varepsilon \quad$ emissividade $(0 \leq \varepsilon \leq 1)$; deformação $(-)$

$\mu \quad$ Coeficiente de atrito dinâmico (-); viscosidade dinâmica (Pa.s)

$\omega \quad$ Velocidade angular $(1 / s)$.

$\rho \quad$ Massa específica $\left(\mathrm{kg} / \mathrm{m}^{3}\right)$

$\sigma \quad$ Constante de Stefan-Boltzmann $\left(\sigma=5.67 \times 10^{-8} \frac{W}{m^{2} K^{4}}\right)$; Tensão (MPa)

$\varphi_{t}, \varphi_{l} \quad$ Fração de energia absorvida pelo tambor e lona (-)

$\emptyset_{i} \quad$ Razão entre força de frenagem do freio e a total do veículo (-) 



\section{SUMÁRIO}

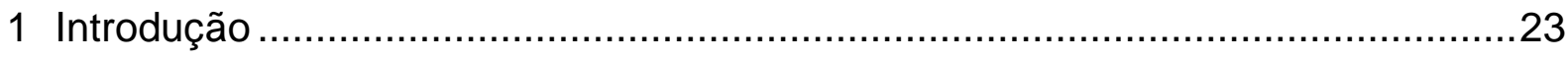

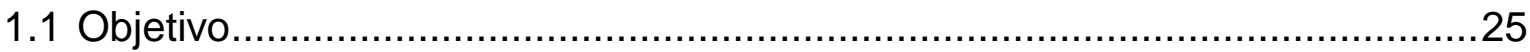

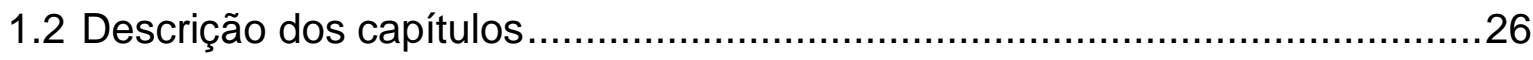

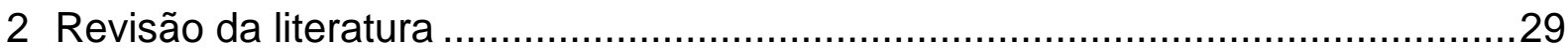

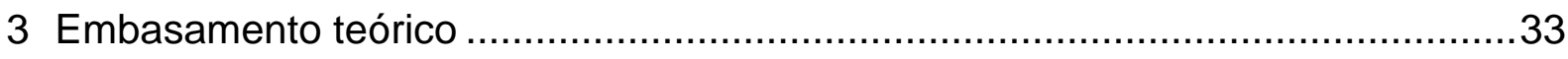

3.1 Sistemas de freio para uso automotivo............................................... 33

3.1.1 Sistemas de freio a tambor...................................................... 34

3.1.2 Materiais para a fabricação de tambores de freios............................38

3.1.3 Materiais para fabricação de pastilhas e lonas de freio........................39

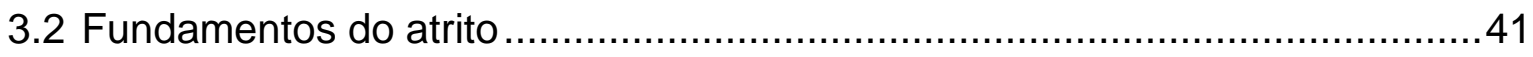

3.3 Fenômenos térmicos relacionados ao atrito .......................................44

3.3.1 instabilidade termoelástica (TEl) e hot spots..................................44

3.3.2 Efeitos de vibração e hot judder...............................................58

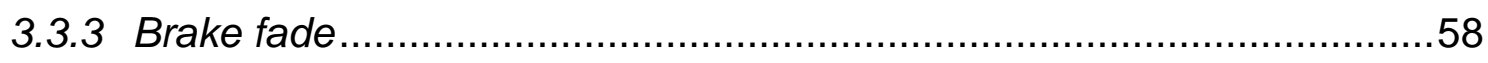

3.3.4 Mecanismos do desgaste e falhas ..........................................59

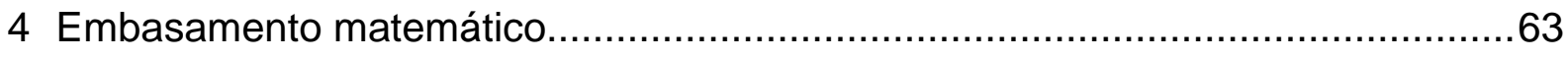

4.1 Conceitos de estática aplicada a freios a tambor ....................................63

4.2 Transferência de calor aplicada a sistemas de freio .................................65

4.2.1 Conceitos iniciais da transferência de calor ...................................65

4.2.2 Energia de frenagem, máxima temperatura e fracionamento de energia

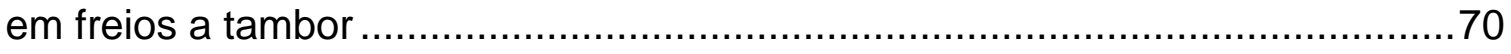

4.2.3 Calor gerado por atrito de deslizamento ..................................... 75

4.3 Conceitos de termoelasticidade ....................................................... 76

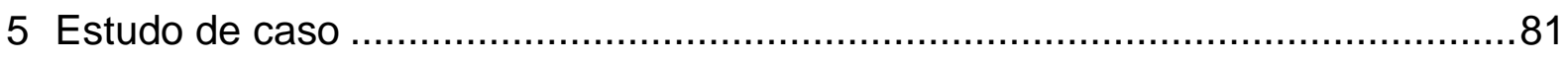

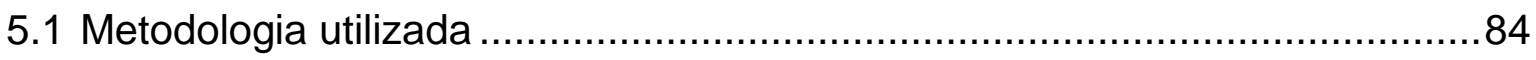

5.1.1 Sequênciamento das etapas do estudo ..................................... 87

5.2 Estudo preliminar do deslizamento entre um bloco e uma barra ....................88

5.3 Estudo preliminar aplicado a freios: validação de um modelo simples ...........91 
5.4 Estudo aplicado ao modelo do freio a tambor S Camo ……......................... 95

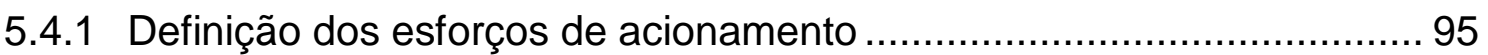

5.4.2 Descrição dos modelos de elementos finitos do sistema estudado ..... 102

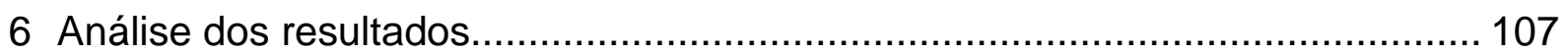

6.1 Caso 1: estático - Modelo rígido com lonas flexíveis ................................. 107

6.2 Caso 2: estático - Modelo flexível.............................................................. 110

6.3 Caso 3: rotação em regime permanente (Modelo flexível) ............................ 117

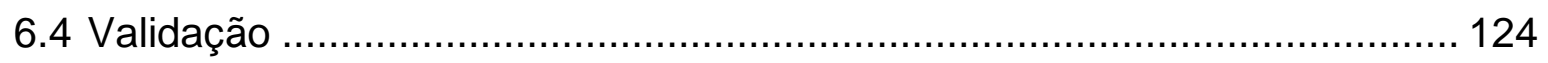

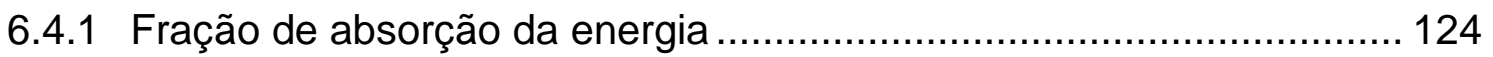

6.4.2 Temperatura máxima de frenagem................................................ 126

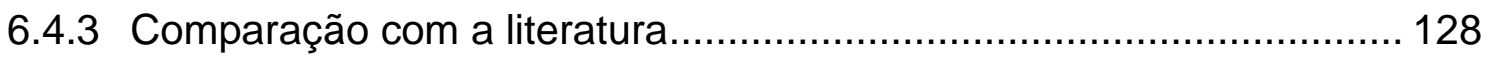

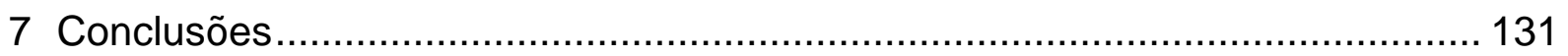

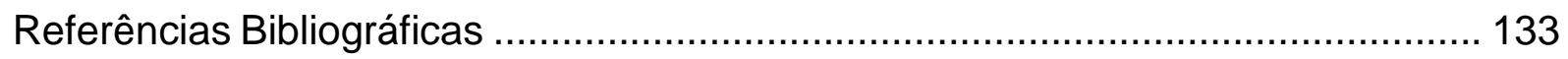

Apêndice A - Macro Da Análise do caso 1 em ambiente ANSYS V15.0 ............... 141

Apêndice B - Macro Da Análise do caso 2 em ambiente ANSYS V15.0 ............... 145

Apêndice C - Macro Da Análise do caso 3 em ambiente ANSYS V15.0 ............... 151 


\section{INTRODUÇÃO}

O sistema de freios presentes em veículos leves e pesados representa um item fundamental de segurança, regido por normas técnicas e supervisionado pelo CONTRAN-Brasil (Conselho Nacional de Trânsito). Em Hodel (2010) são discutidos alguns dados sobre o mercado de transporte de carga brasileiro e os veículos comerciais. Entre esses dados, segundo Cavenaghi et al. (1997) apud Hodel (2010): "Dentre as modalidades existentes de transportes, o transporte rodoviário de cargas é o mais utilizado no Brasil, somando cerca de 1,1 milhões de caminhões, 12 mil empresas e outras 50 mil de carga própria, além de 350 mil autônomos". Neste sentido, A Figura 1.1 apresenta o percentual atualizado empregado na matriz de transportes terrestres brasileira, segundo a Confederação Nacional dos Transportes - CNT (2015) .

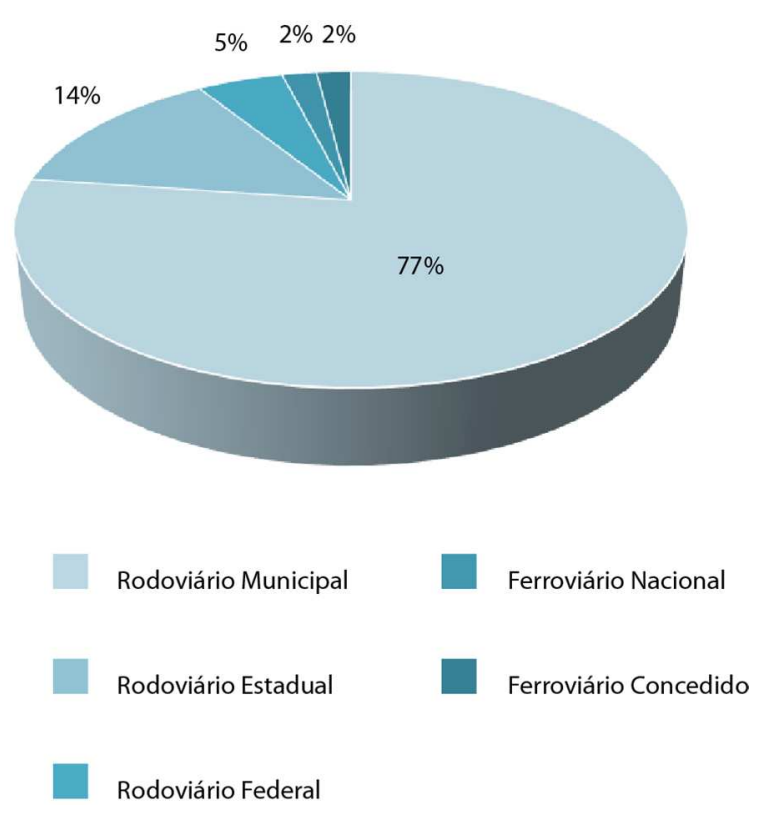

Figura 1.1 - Percentuais da matriz de transportes terrestres brasileira (CNT, 2015).

A maioria dos países com grande área territorial utiliza grandemente do modal de transporte ferroviário, com pequeno uso comparativo com o modal rodoviário. Porém, o Brasil de destaca no sentido oposto à esta tendência, priorizando sua malha rodoviária em detrimento dos custos e gargalos de infraestrutura. 
A melhoria de projeto de sistemas de freios contribui para maximizar sua disponibilidade, promovendo maior competitividade nacional. A contextualização apresentada reforça a importância de se antecipar possíveis falhas em sistemas de freios, bem como explorar condições de melhor desempenho, de forma a se obter projetos cada vez mais robustos, frente aos complexos acoplamentos de fenômenos obervados em diversas situações de frenagem, assegurando uma maior segurança veicular.

Grande parte dos sistemas de freios utiliza o princípio mecânico-hidráulico para o acionamento por meio de contato de superfícies, promovendo contato por atrito entre sapatas e lonas ou discos e pastilhas, para execução dos diferentes regimes de frenagens. A energia mecânica gerada durante o processo de frenagem, por meio contato mecânico, é convertida em energia térmica. A elevação da temperatura em períodos críticos de frenagem, especificamente temperaturas próximas ao ponto de fusão dos elementos metálicos ou de atrito, gera uma taxa de desgaste, que podem alterar as propriedades físicas e mecânicas do material, que pode levar ainda em período de vida útil, à perda de desempenho e até mesmo a falhas catastróficas. Se as superfícies de contato entre estes elementos, principalmente no par de contato lona/tambor, operarem por um tempo acima do previsto em temperaturas máximas ou repetidamente nessas temperaturas, podem surgir efeitos que contribuem desde falhas potenciais até possíveis falhas catastróficas. Esses efeitos incluem: fading, vibrações de baixa frequência, fadiga térmica (vitrificação), e desgaste prematuro das superfícies de contato. $\mathrm{O}$ aumento do torque de atrito é limitado pelo diâmetro da superfície de contato, coeficiente de atrito estático e dinâmico, pressão por unidade de área, além de outros fatores. Entretanto, os valores máximos da temperatura de contato descritos em literatura e por fabricantes, indicam que a determinação desta faixa de temperaturas é um parâmetro fundamental de projeto durante o processo de frenagem.

Dessa forma, durante o processo de frenagem, parâmetros de projeto como: velocidade, pressão de contato, coeficiente de atrito e propriedades físicas e mecânicas dos materiais, principalmente entre os elementos mecânicos de contato, tambor, sapata e lona, no caso de freios de tambor devem ser investigadas em condições quasi-estáticas, para comparação e ajuste experimental em experimentos mais simplificados, e em condições transientes em dinamômetros, que podem 
representar com maior aproximação as condições reais de funcionamento do sistema de freios.

Segundo Yevtushenko e Grezes (2010), o aquecimento promovido pelo atrito entre superfícies é responsável pelo aumento da temperatura na interface de acoplamento dos elementos mecânicos do subconjunto de acionamento, o que influencia significativamente as características tribológicas do sistema de freio, e, portanto, nos requisitos de confiabilidade do veículo.

A estimativa do perfil e da área de distribuição da temperatura máxima durante o processo de frenagem pode ser obtida por meio de experimentos físicos ou modelos analíticos, muitas vezes simplificados devido à complexidade de acoplamento de fenômenos físicos e mecânicos. Segundo Yeutushenko e Grzes (2010) a formulação de modelos analíticos envolvendo transferência de calor por condução por atrito requer formulações matemáticas baseadas em semi-espaços e/ou faixas planas paralelas.

O trabalho gerado durante o processo de frenagem é quase todo dissipado em forma de energia térmica, em função da velocidade de deslizamento no contato de atrito. A estimativa da distribuição de temperatura durante a operação operação pode fornecer parâmetros de projeto relacionando atrito, esforços mecânicos, gradientes de temperatura com vistas à prevenção de propagação e nucleação de trincas, desgaste e demais fenômenos relacionados à instabilidade termodinâmica comum nestes.

\subsection{OBjetivo}

O objetivo desse trabalho é apresentar e comparar o desenvolvimento de modelos numéricos que representam um sistema de freio a tambor amplamente utilizado em veículos pesados, em especial do tipo Camo $S$, tamanho 16,5", dado os altos esforços e altas taxas de desgaste ao longo do uso, além da escassa presença nos meios acadêmicos de trabalhos que investiguem novos métodos de predição de fenômenos correlatos, dando continuidade ao estudo feito por Chiaroni e Silveira (2014).

Empregando o método dos elementos finitos, foram analisados três modelos com diferentes tipos de carregamento e condições aplicadas, com intenção de avaliar a proximidade de modelos rígidos aos cálculos analíticos, a influência da consideração 
de corpos elásticos sobre os resultados e, por fim, a resposta de um modelo completo que considera a influência de uma velocidade de deslizamento entre o par de contato lona-tambor.

Costuma-se investigar a influência dos fenômenos térmicos e elásticos separadamente, o que traz simplificações que acabam por distanciar os resultados da realidade. Além disso, o problema do atrito é por diversas vezes ignorado, dado sua grande dificuldade de implementação. Com o uso adequado de matrizes de acoplamento termoelástico, pretende-se avaliar sistemas que considerem não apenas as respostas estruturais típicas, mas também a influência destas na geração de calor e vice versa.

\subsection{DESCRIÇÃo dOS CAPÍTULOS}

A estrutura deste trabalho é composta de: revisão da literatura, embasamento teórico e matemático, descrição técnica do problema estudado e da metodologia empregada, análise e validação dos resultados e conclusões.

O capítulo 2 (Revisão da literatura) provê uma revisão bibliográfica dos trabalhos mais importantes e recentes de interesse para este texto, descrevendo metodologias e abordagens empregadas no estudo de fenômenos de atrito em sistemas de freio.

O capítulo 3 (Embasamento teórico) apresenta o conteúdo mínimo para que se possa entender os fenômenos por trás de falhas em sistemas de freio de um modo geral. Inicia com a apresentação mecânica dos tipos fundamentais de freio, passando à avaliação dos materiais empregados. Em seguida, são revisados os fundamentos que regem o mecanismo de atrito entre dois sólidos em contato e uma descrição dos fenômenos térmicos baseados em atrito e suas respostas indesejáveis.

O capítulo 4 (Embasamento matemático) fornece o mínimo necessário para que se compreenda o equacionamento por trás dos efeitos do acoplamento mutlifísico de termoelasticidade aplicada a freios a tambor. Inicia-se com uma revisão de estática aplicada a freios a tambor, passando para os equacionamentos fundamentais de transferência de calor, equacionamentos voltados exclusivamente para sistemas em atrito e finaliza com uma visão geral da modelagem matemática por trás da termoelasticidade. 
O capítulo 5 (Estudo de caso) deve explicar com clareza as várias etapas necessárias até o alcance de modelos confiáveis. Avalia-se o uso de um sistema fundamentalmente básico de estudo de geração de calor por atrito, representado por um conjunto bloco sobre barra, para verificar o entendimento do fenômeno e a validade do método matricial empregado pelo software. Segue-se um estudo preliminar de um freio a tambor genérico de equacionamento analítico previamente realizado e atestado, a fim de se comprovar a eficácia das escolhas de condições e ajustes que devem reger os modelos principais. Então, o capítulo finaliza com um estudo direcionado às peculiaridades do modelo de freio estudado, com uma descrição das condições finais para os três modelos de elementos finitos gerados.

O capítulo 6 (Análise dos resultados) separa e discute os resultados obtidos para cada uma das três simulações principais realizadas. Começa com um modelo de corpo rígido, que esteja próximo dos cálculos analíticos, seguindo a um modelo de corpos flexíveis e finalizando com outro modelo de corpos flexíveis, mas desta vez com aplicação direta dos efeitos de um carregamento dinâmico em regime permanente. Após os resultados, o capítulo finaliza com várias abordagens de validação dos resultados.

Por fim, no capítulo 7 (Conclusões), são apresentadas as conclusões obtidas e sugestões de trabalhos futuros. 



\section{REVISÃo dA LITERATURA}

Segundo Yevtushenko e Grzes (2010), o fenômeno de instabilidade termoelástica pode ser estudado como um processo iterativo, no qual a obtenção dos parâmetros de pressão e área de contato são obtidas pela estimativa da geração de calor devido ao atrito, obtida pela solução do problema de condução de calor assumindo-se uma distribuição teórica sem restrição. Assim, nos freios a tambor, o estudo do acoplamento termoelástico auxilia no entendimento da deformação dos elementos causada pelas elevadas cargas térmicas. A distribuição não uniforme da pressão, sendo numa primeira hipótese um material com constituição perfeitamente elástico, o estudo do perfil incluirá a direção radial e circunferencial dessas superfícies.

Matysiak e Yevtushenko (2001) classificam os problemas desenvolvidos em condições de geração de calor, especificamente por meio do atrito, como: estacionários, quasi-estacionários e não estacionários. Em um problema estacionário, se a velocidade de deslizamento for suficientemente pequena, de forma que a convecção causada pelo movimento não altere a temperatura e o fluxo de calor, e ainda, se a condução para uma dada condição externa tiver um comprimento longo o suficiente, a influência de suas condições iniciais pode ser desconsiderada. Problemas térmicos de contato quasi-estacionários, por sua vez, são definidos como aqueles onde $o$ atrito entre os corpos ocorre em um período longo o suficiente de duração, tais como problemas em regime permanente típicos de transferência de calor. Por fim, um problema de contato do tipo não estacionário é condicionado a uma distribuição de pressão de contato ou por uma velocidade não estacionária de deslizamento, além de que o processe de aquecimento por atrito é considerado a partir de um tempo inicial. Os autores ressaltam que a maioria dos problemas de frenagem são de curta duração e não estacionários, enquadrando-os no terceiro caso.

Nos problemas de análise de contato, considerando a geração de calor, Jaeger (1942) e Blok (1963), apud Matysiak e Yevtushenko (2001), propuseram formulações matemáticas, nas quais os problemas de geração de calor por atrito são estudados por meio da obtenção do campo de variação de temperatura causados pelo fluxo de calor conhecido, assumindo-se, como hipótese preliminar, que o fluxo de calor é proporcional às distorções causadas pelas tensões de cisalhamento, sendo por sua vez proporcional à força de atrito. A distribuição das tensões normais foi determinada 
a partir de condições isotérmicas. Nos problemas estacionários são consideradas distribuições uniformes e elípticas, obtidas com soluções baseadas no problema de contato.

Barber (1969) propôs a teoria das instabilidades termoelásticas (TEI do inglês Thermoelastic Instabilities) para explicar o crescimento de perturbações que levam ao aparecimento de altas termperaturas localizadas conhecidas por hot spots. Por sua vez, Dow e Burton (1972) modelaram matematicamente o surgimento das instabilidades previstas pela teoria das TEl.

Chinchinadze et al. (1979) propuseram um critério para avaliação da taxa de geração de desgaste por atrito das superfícies em contato, com base na temperatura. O trabalho permitiu a obtenção das tensões térmicas de atrito dos materiais e a capacidade de contato, de acordo com valores específicos de coeficientes de atrito e intensidade de desgaste. Os métodos experimentais para investigação dos materiais, considerando as tensões de cisalhamento e normais surgidas a partir das taxas de geração de calor durante o processo de frenagem, podem ser utilizados para se estimar a temperatura média da superfície de atrito, temperatura no volume estudado, distribuição do fluxo de calor e a profundidade efetiva de sobreaquecimento.

Com enfoque aos problemas mais práticos, Anderson e Knapp (1990) são os primeiros pesquisadores a propor uma classificação detalhada para os hot spots observados em sistemas de freio automotivos.

Mais recentemente, novos trabalhos contribuíram para o avanço da pesquisa no campo da análise de instabilidade termoelástica. Choi e Lee (2004) empregaram, em um modelo axissimétrico, o método dos elementos finitos para uma análise termoelástica transiente do processo de frenagem com repetição, com vistas a investigação da influência das propriedades dos materiais na geração de fenômenos de instabilidade termoelástica. Os autores concluiram que o coeficiente de expansão térmica e o módulo de elasticidade são os maiores responsáveis. Ainda demonstram a superioridade do emprego de materiais compósitos de carbono na confecção de discos de freio, como os usados em freios de aviões e pontas de reentrada de foguetes na atmosfera.

Painer et al. (2004) propuseram uma teoria alternativa às TEI, conhecida como PWD (do inglês Progressive Waviness Distortion), que baseia-se na fixação, em regime plástico, de deformações criadas pela pressão do material de atrito contra o rotor. 
Cho e Cho (2008) ressaltam que a teoria das TEl requer que sejam assumidas muitas condições de simplificação, o que acaba desviando os resultados analíticos dos experimentais. Os autores propuseram a predição do surgimento de pontos de concentração de calor (hot spots) em discos de freio interpolando dados sobre a velocidade crítica de giro obtida numericamente através do software Hotspotter ${ }^{\circledR}$, criado por Yi et al. (1999), captura de imagens termográficas em dinamômetro e distribuição da pressão estimada por modelo de elementos finitos.

Jung et al. (2011) publicaram o primeiro trabalho onde se obteve o surgimento de hot spots via simulação por elementos finitos ao investigarem o fenômeno da vibração resultante de deformações termoelásticas (hot judder) em discos de freio ventilados. Apesar da grande complexidade computacional envolvida, o modelo foi testado e validado por medição de temperatura em ensaios de dinamômetro.

Abbasi et al. (2014) estudaram o os resultados de uma série de experimentos do tipo pin-on-disc, ou pino sobre disco, para investigarem detalhadamente o comportamento termomecânico de atrito sobre um bloco de ferro fundido cinzento, empregado em freios ferroviários. Em seguida, um modelo transiente de elementos finitos foi gerado afim de estudar a partição do calor destinado a cada corpo via modelo de resistência térmica de contato, calibrado a partir do ensaio anterior. Dentre os parâmetros estudados, os autores tabelaram valores para a fração de energia absorvida no pino que, em média, ficam próximos de $17 \%$ do calor gerado, e de $83 \%$ para o disco.

De maneira geral, o uso do Método dos Elementos Finitos (MEF) tem contribuído importantemente para se estimar a dissipação de calor nos componentes de contato de sistemas de freios automotivos, seja considerando análises estruturais ou térmicas, como visto nos trabalhos de Choi e Lee (2004), Cho e Cho (2008), Adamowicz e Grzes (2012), Jung et al. (2011), Belhocine e Bouchetara (2013), Hamid, Teoh e Ripin (2013), Chiaroni e Silveira (2014), e outros. 



\section{EmbasAmEnTo TEÓRICO}

\subsection{SISTEMAS DE FREIO PARA USO AUTOMOTIVO}

Juvinall e Marshek (2006) indicam que a maioria dos componentes de máquinas opera por meio de superfícies deslizantes, como engrenagens, rolamentos e camo. Nesses mecanismos ou máquinas, que têm o objetivo de transmitir o movimento, os esforços da engenharia se concentram no intuito de diminuir o atrito entre as superfícies, a fim de reduzir ao máximo as perdas de energia por atrito. Em contrapartida, os freios são componentes que dependem desta perda de energia por atrito para desempenharem sua função. Nesse caso, o projeto desses componentes visa maximizar o coeficiente de atrito entre estas superfícies, ao mesmo tempo em que se deseja o menor desgaste possível.

De acordo com Limpert (1999), freios de atrito automotivos são agrupados, a partir de seu projeto, em duas categorias básicas: Freios a tambor e a disco. Freios a tambor utilizam um sistema de sapatas empurradas em uma direção radial contra um tambor, que consiste basicamente de um cilindro metálico externo ao sistema, com movimento de rotação solidário ao giro da roda do veículo, ilustrado na Figura 3.1.

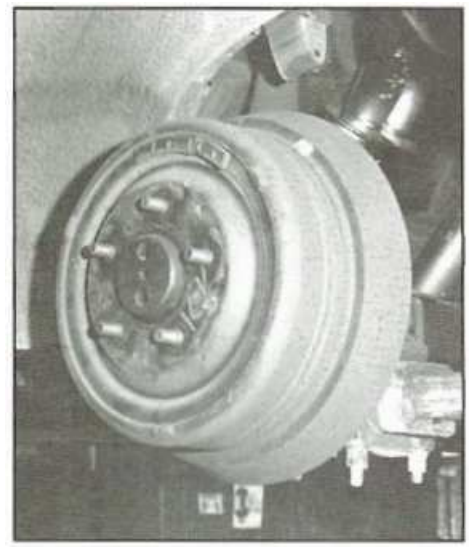

(a)

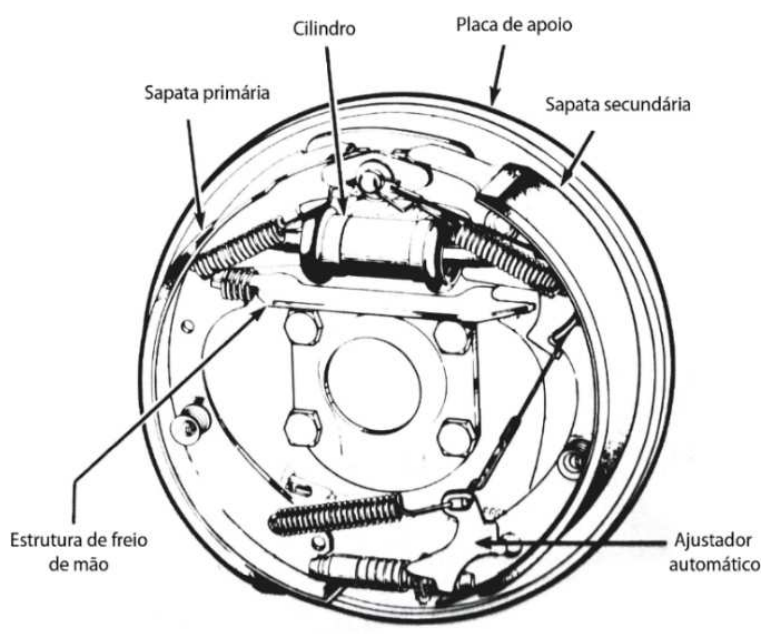

(b)

Figura 3.1 - Sistema de freio a tambor: (a) sistema de freio conforme montado na roda de um veículo (PUHN, 1985); (b) llustração das partes internas com indicação de nomenclatura (LIMPERT, 1999). 
Por sua vez, freios a disco empregam pastilhas ao invés de sapatas, que são pressionadas axialmente contra um rotor ou disco, que assim como o tambor também é solidário ao movimento de giro de rotação da roda do veículo, conforme ilustra a Figura 3.2.

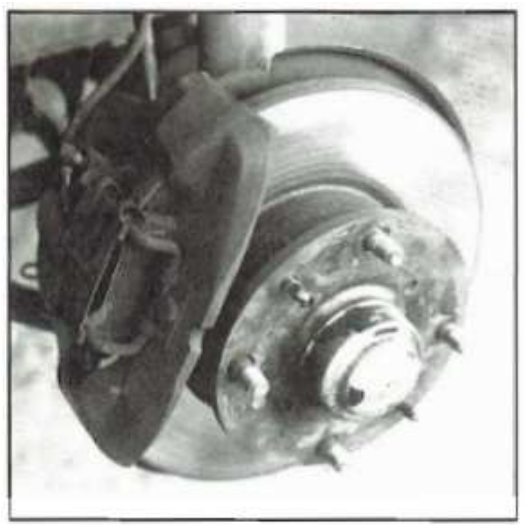

(a)

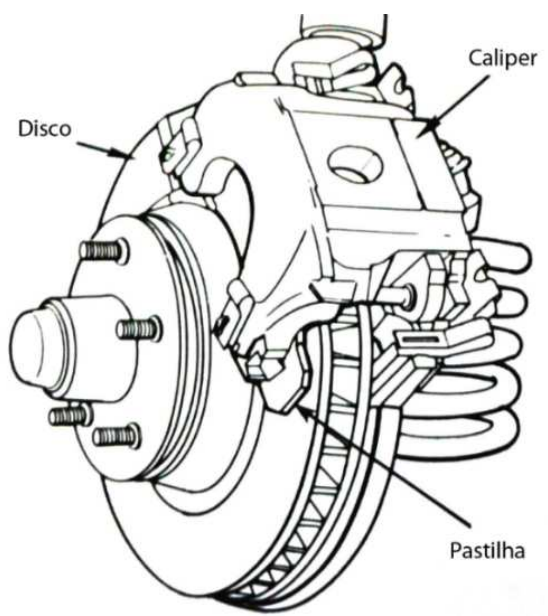

(b)

Figura 3.2 - Sistema de freio a disco: (a) sistema de freio conforme montado na roda de um veículo (PUHN, 1985); (b) ilustração com indicação de nomenclatura (LIMPERT, 1999).

\subsubsection{SISTEMAS DE FREIO A TAMBOR}

Freios a tambor são usados desde o início do surgimento dos automóveis, dada a sua facilidade de fabricação. Por muitos anos, foram utilizados nas quatro rodas de carros e caminhões, o que vem sendo mudado devido aos avanços de projeto dos carros e pequenas caminhonetes, que requisitaram a implementação de freios a disco em seus eixos frontais (SCHARFF, 1989). Porém, freios a tambor ainda são utilizados na parte traseira da maioria dos veículos atuais, já que estes são responsáveis por dissipar entre 20 a $40 \%$ da energia de frenagem apenas, além da facilidade de integração de freios de estacionamento, conhecidos no Brasil como "freio de mão". O baixo custo de fabricação faz com que este tipo de sistema de freios seja muito utilizado em ônibus e caminhões, especialmente nos eixos de tração e reboque. (LIMPERT, 1999; HAMID; TEOH; RIPIN, 2013).

Freios a tambor por expansão interna das sapatas são subdivididos de acordo com a atuação das sapatas em primária e secundária, duas sapatas primárias ou 
como o sistema duo-servo, como mostrado na Figura 3.3. A forma de fixação das sapatas também difere em cada sistema, sendo possível ser do tipo deslizantes ou fixas em um ponto. Por fim, pode-se agrupar o acionamento de freios a tambor em hidráulico, pneumático e por sistema de alavancas mecânicas (LIMPERT,1999).

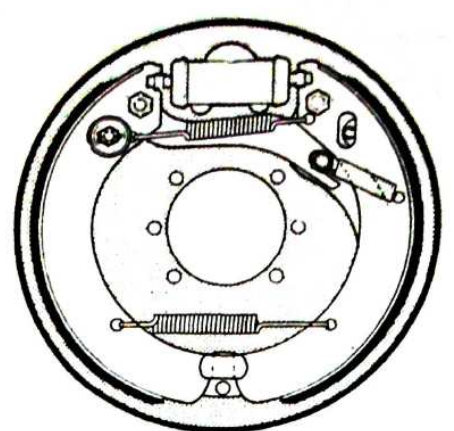

a)

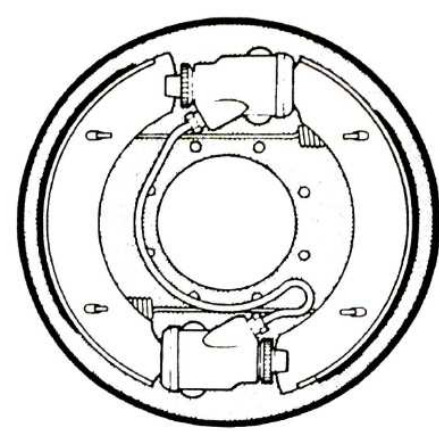

b)

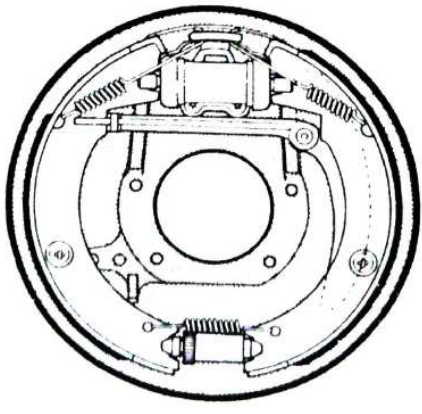

c)

Figura 3.3 - Tipos básicos de atuação em freios a tambor hidráulicos: (a) Sistema de sapatas primária e secundária; (b) Sistemas de duas sapatas primárias; (c) Sistema duo-servo (adaptado de LIMPERT, 1999).

O sistema (a), da Figura 3.3, representa o tipo de arranjo de sapatas primáriasecundária, onde cada sapata possui sua extremidade ancorada na placa traseira de fixação. Scharff (1989) define a sapata primária como sendo aquela orientada para a parte frontal do veículo. $O$ atrito entre ela e o tambor força-a a se deslocar levemente em uma direção que siga o giro do tambor. De acordo com Budynas e Nisbett (2011), esta tendência ao deslocamento é responsável pelo efeito de auto-travamento, ou auto-energizante, efeito em que, segundo Limpert (1999), se observa um aumento na força normal aplicada à sapata primária devido ao arrasto do tambor. Por isso, uma das desvantagens deste arranjo é justamente o fato de que os esforços não são distribuídos igualmente entre os componentes.

Por sua vez, o sistema (b) da Figura 3.3 representa o sistema com duas primárias, sendo ambas ancoradas, cada uma em sua extremidade, na placa de fixação traseira. Com esta disposição, busca-se gerar o efeito auto-energizante em ambas as sapatas, em uma tentativa de ampliar o fator de freio, razão entre o torque de frenagem e a força aplicada.

Por fim, o sistema (c) mostrado na Figura 3.3 representa o sistema de arranjo duo-servo, nome derivado do fato de que a força auto-energizante gerada na sapata primária ser transferida à secundária, independente do sentido de rotação, através de 
um mecanismo ajustável que liga a parte inferior delas (SCHARFF, 1989). A maior vantagem do sistema de freio duo-servo é um alto fator de freio, mas o que o torna muito sensível à variação do coeficiente de atrito. Este pode, por exemplo, variar devido à umidade do ar, o que pode aumentar de maneira não desejada o fator de freio do sistema, resultando em travamentos (LIMPERT, 1999).

Uma configuração importante para este trabalho é a exibida na Figura 3.4, e diz respeito ao modelo Camo $S$, equipado em mais de $90 \%$ dos veículos pesados de acionamento pneumático. Baseado no sistema de sapatas primária e secundária, o acionamento mecânico é dado pela rotação de um camo, em forma de "S", que pressiona e distancia os roletes das sapatas entre si. Devido à geometria fixa do camo, o sistema compensa um pouco da diferença entre as parcelas do esforço suportado pelas sapatas do freio, resultando em um comportamento próximo ao esperado de um desgaste uniforme, que atribui uma maior durabilidade às lonas (Limpert, 1999).

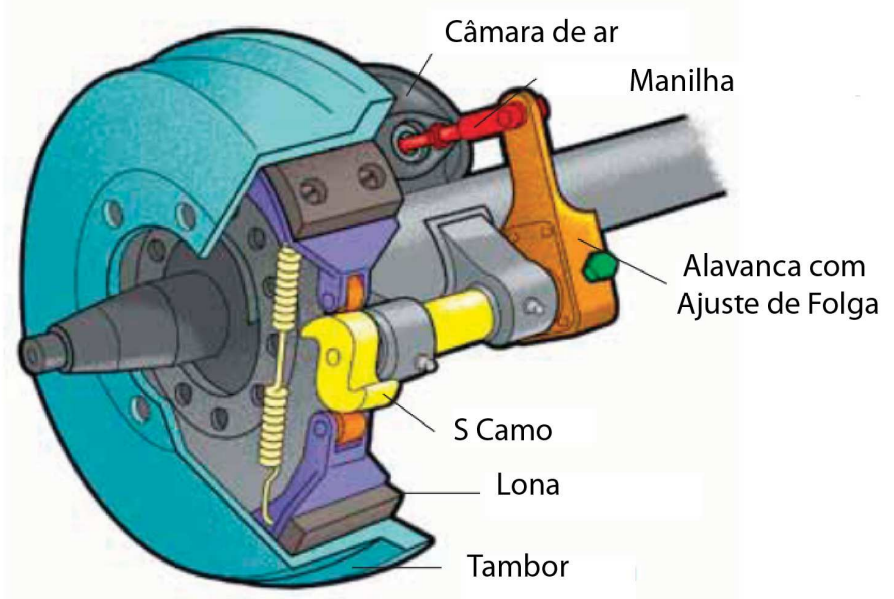

Figura 3.4 - Sistema de freio a tambor do tipo Camo S (MPI, 2015).

Quando comparados aos freios a disco, os freios a tambor possuem grande desvantagem em relação ao seu aquecimento durante sua operação. Day e Newcomb (1984) indicam que freios a tambor frequentemente indicam variações no torque de frenagem, tendo como principal causa a expansão térmica sofrida pelo tambor. Recomenda-se que uma temperatura máxima de $430 \stackrel{\circ}{\circ}$ (aproximadamente $700 \mathrm{~K}$ ) não seja ultrapassada, tanto pela variação no coeficiente de atrito, quanto pela dilatação excessiva do tambor. Limpert (1999) indica que, a $375^{\circ} \mathrm{C}$, o diâmetro de um tambor de freio de carro de passeio típico pode aumentar de 1 a 1,5 mm, suficiente 
para aumentar entre 30 a $40 \%$ a distância do pedal. Já freios a tambor do tipo Camo $S$ indicam um aumento de $12 \mathrm{~mm}$ na abertura dos roletes das sapatas para um aumento de, aproximadamente, $320^{\circ} \mathrm{C}$ na temperatura do tambor.

$O$ fator de freio é um indicador interessante para a capacidade de frenagem de um freio para um dado valor de coeficiente de atrito. A Figura 3.5 emprega este parâmetro como comparação entre os tipos de freio discutidos anteriormente e mostra que alguns tipos, como o duo-servo e duas sapatas primárias, possuem uma variação muito alta do torque de frenagem com o aumento do coeficiente de atrito, algo que não é desejável para frenagem em serviço, mas apenas para freio de estacionamento. Nota-se, porém, que o modelo de duas sapatas secundárias possui curva próxima à curva do freio a disco, o que pode ser pensado como um ponto de partida para o projeto de um modelo cada vez mais estável.

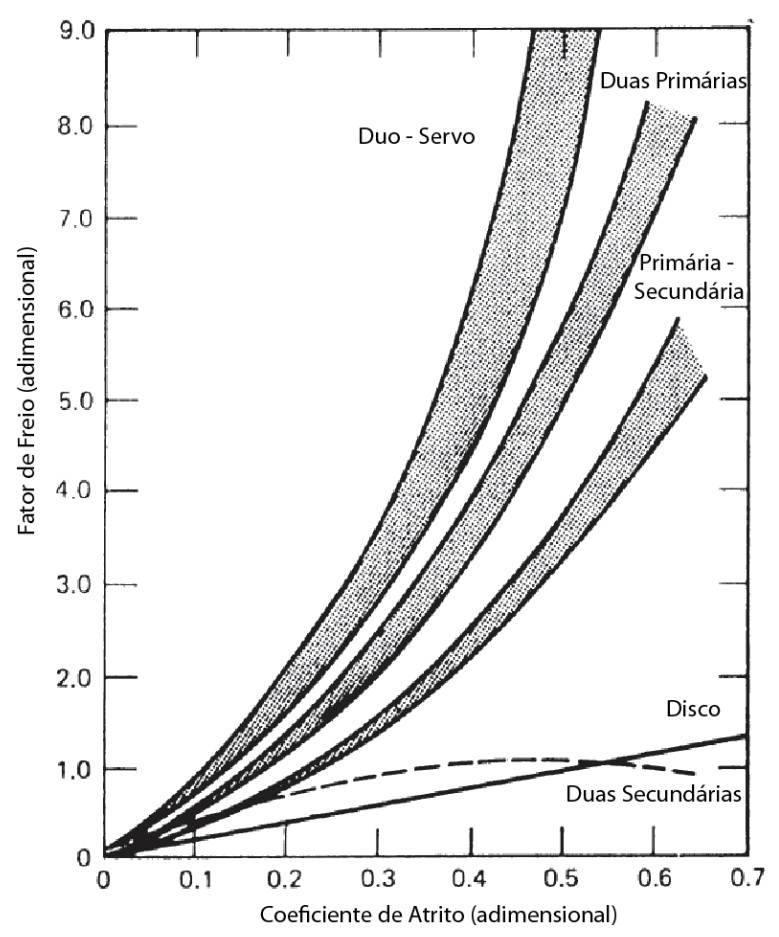

Figura 3.5 - Comparação entre os diversos sistemas de freio automotivos com base no fator de freio em função da variação no coeficiente de atrito (LIMPERT, 1999).

Em freios a tambor, o elemento de atrito é denominado lona e está fixado através de rebites, parafusos ou união adesiva à sapata de freio, a qual corresponde ao componente estrutural do mesmo. A força de frenagem, oriunda do sistema hidráulico, em se tratando de veículos de passeio populares, é aplicada na sapata, a qual é responsável por forçar o elemento de atrito contra o tambor, gerando o torque 
de frenagem. O tambor é o componente cilíndrico que fica acoplado à roda, portanto tem a mesma velocidade angular desta (LIMPERT, 1999).

\subsubsection{MATERIAIS PARA A FABRICAÇÃo DE TAMBORES DE FREIOS}

Com relação ao material empregado nos tambores, deve-se levar em conta que os principais fatores de risco ao projeto são os que dizem respeito ao desgaste e condutividade térmica. Além destes, outros fatores devem ser levados em conta quando em serviço, tais como capacidade de amortecimento de vibrações e ruído, resistência mecânica e resistência à fadiga, módulo de elasticidade e resistência à fadiga térmica. Algumas destas propriedades seriam influenciadas principalmente pela grafita (capacidade de amortecimento de vibrações, condutividade térmica), o que mostra o potencial de otimização destas propriedades; entretanto, a maioria das propriedades é afetada tanto pela grafita quanto pela matriz, de modo que sua otimização envolve sempre um compromisso de propriedades (GUESSER et al., 2003).

Dentre as variadas possibilidades, consta-se que o ferro fundido cinzento de alto carbono é o que melhor atende às expectativas, além do fato de serem os ferros fundidos uma classe de materiais altamente empregada na indústria automobilística para a fabricação de discos de freio, desde o início do século XX. Ainda assim, visando otimizar o desempenho de discos e tambores de freio, foi desenvolvida uma classe de ferro fundido cinzento de alta condutividade térmica, associada ainda a bons valores de resistência mecânica e de resistência ao desgaste. A microestrutura destes materiais apresenta grande quantidade de grafita e matriz perlítica, a grafita conferindo alta condutividade térmica e a matriz perlítica fornecendo resistência mecânica e ao desgaste. Este material é obtido com o uso de teores relativamente elevados de carbono (3,7 a 3,9\%) e de elementos de liga perlitizantes, como o cobre, cromo e estanho (GUESSER et al., 2003; GUESSER; GUEDES, 1997). 


\subsubsection{MATERIAIS PARA FABRICAÇÃo DE PASTILHAS E LONAS DE FREIO}

Segundo Limpert (1999), os materiais comumente usados na confecção de pastilhas e lonas de freio podem ser separados em duas categorias básicas: as que se utilizam de asbeto, ou amianto, e as que não se utilizam, uma vez que maiores detalhes da constituição destes materiais é mantido sob sigilo por boa parte das indústrias. Nas pastilhas/lonas com amianto, tem-se a presença de certa quantidade deste composto em uma matriz aglutinante orgânico. Já as pastilhas/lonas livres de amianto possuem uma matriz de material fenólico, fibras de reforço que podem ser de aço ou outros metais e modificadores para o controle de condução de calor, normalmente cobre ou materiais similares. Esta composição torna esta constituição conhecida como revestimento semi-metálico.

A composição básica de um revestimento de pastilha e lonas de freio recai nos quatro grupos seguintes (LIMPERT, 1999; ERIKSSON; BERGMAN; JACOBSON, 2002; CHAN; STACHOWIAK, 2004):

- Fibras: fornecem a rigidez e resistência para o material e, também, para materiais submetidos a altas temperaturas, fornecem estabilidade térmica. Materiais fibrosos incluem asbetos, aço ou fibras de aramida.

- Preenchedores: materiais de baixo custo que aumentam a vida útil das pastilhas, preenchem espaços e minimizam custos. São compostos de baritas, argila, carbonato de cálcio, ou, em caso de lonas metálicas, de pó metálico.

- Filtros: usados principalmente para redução dos custos de fabricação facilitando sua manufatura. São utilizados materiais minerais como Mica e Vermiculit, como também sulfato de bário pode ser utilizado como um filtro.

- Aglutinantes: são materiais responsáveis pela união dos demais. Os mais comumente usados são os fenol-formaldeídos. A cura do aglutinante ocorre a temperaturas superiores a $230^{\circ} \mathrm{C}$ por muitas horas, e caso não seja feita adequadamente, a pastilha terá sua resistência à temperatura reduzida. 
- Aditivos para ativo: geralmente elastômeros, que melhoram propriedades mecânicas e diminuem o desgaste, tanto nas pastilhas/lonas quanto nos discos/tambores. Bronze, zinco, ou outros metais são adicionados para o controle de propriedades abrasivas e também "limpar" a superfície do rotor.

Uma amostra da microestrutura de uma pastilha de freio analisada sob microscopia eletrônica é mostrada na Figura 3.6.

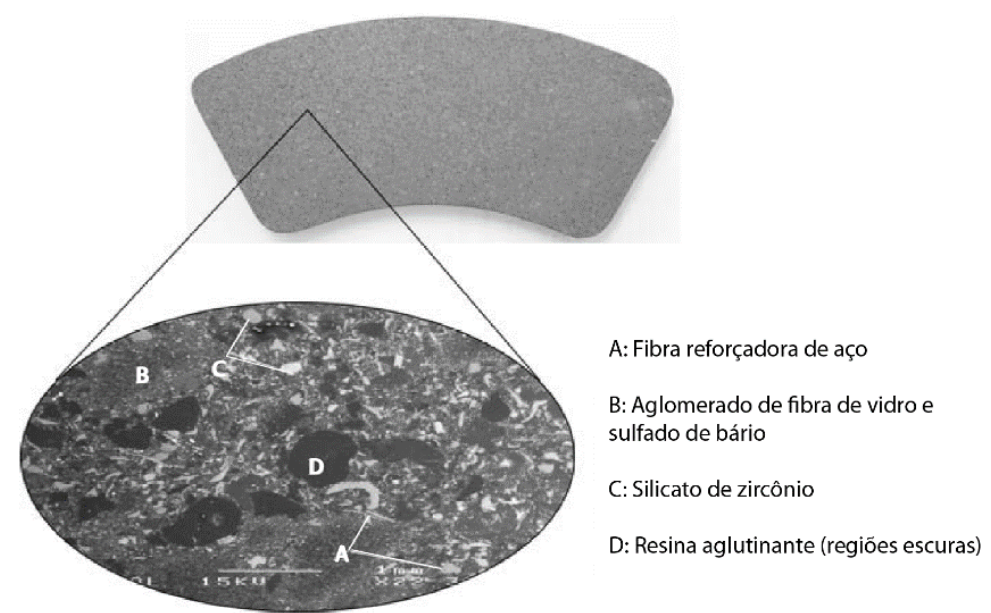

Figura 3.6 - Ampliação de amostra de pastilha de freio empregando microscópio eletrônico de varredura (CHAN; STACHOWIAK, 2004).

Eriksson, Bergman e Jacobson (2002) explicam que o coeficiente de atrito deve ser relativamente alto, mas é de maior importância que seja estável. O ideal é que seja mantido um nível de estabilidade independente da temperatura de trabalho, além de umidade, envelhecimento, desgaste e corrosão, presença de sujeita e água das estradas e que não produzam desconforto durante o uso, como vibração e ruído. Contudo, Limpert (1999) ressalta que devido a não uniformidade na distribuição de pressão entre a pastilha e o disco, ou lona e tambor, além de suas irregularidades superficiais, a temperatura na superfície de atrito não será uniforme. Áreas com altas temperaturas terão menores coeficiente de atrito do que outras áreas de baixa temperatura, levando a uma dificuldade muito alta em se definirem expressões analíticas do fenômeno, deixando a tarefa a cargo de ensaios experimentais e simulações numéricas.

O projeto básico de um sistema de freio é baseado na performance de torque alcançado com freios "frios". Um freio é considerado frio quando sua temperatura de operação está abaixo de $93^{\circ} \mathrm{C}$. A maioria dos materiais de atrito de pastilhas e lonas 
de freio terá seu coeficiente de atrito aumentado em temperaturas de aproximadamente 150 a $200 \stackrel{\circ}{\circ}$. Em elevadas temperaturas, próximas de 250 a 315 ${ }^{\circ} \mathrm{C}$, seu coeficiente de atrito tende a diminuir para níveis abaixo aos valores frios (LIMPERT, 1999). O relatório de práticas SAE j661 é uma referência para se determinar os níveis de atrito de diversos tipos de materiais empregados para este fim.

Lonas de freio são fixadas às sapatas por meio de compactação de pó, rebitagem, colagem e outros. O material que predomina na fabricação de sapatas de freio é o aço, através do processo de fabricação por fundição, forjamento ou soldagem.

\subsection{FUndAMENTOS DO ATRITO}

A força de atrito é classicamente definida como sendo a resistência ao movimento experimentada por um corpo deslizando sobre outro, tangencial à interface de contato entre os corpos e de igual direção mas sentido contrário ao deslizamento. Todavia, considerar apenas este caráter tangencial da força leva ao desprezo de outras componentes produzidas por este processo, tal como uma componente normal do atrito oriunda dos picos e vales microscópicos presentes em qualquer superfície (ARANGO, 2010).

Dois corpos quando pressionados um contra o outro e em movimento relativo sempre será acompanhado de dissipação de energia, tendo o atrito interfacial como o fator de maior importância a definir o comportamento desta nova forma de energia gerada. De uma forma geral, a energia de atrito gerada entre dois corpos em contato será governada pela carga e velocidade aplicadas. Por outro lado, é possível também considerarmos o atrito e energia gerados na forma de contato não-deslizante, genericamente referido como fretting wear na língua inglesa. Nesta forma de dissipação de energia, considera-se a fricção de duas superfícies com baixa amplitude de deslocamento relativo, geralmente da ordem de micra, em movimento oscilatório periódico, conforme ilustra a Figura 3.7. Este tipo de movimento oscilatório repetitivo de pequenas amplitudes degrada as superfícies em contato devido à força de cisalhamento gerada (AMIRI; KHONSARI, 2010). 


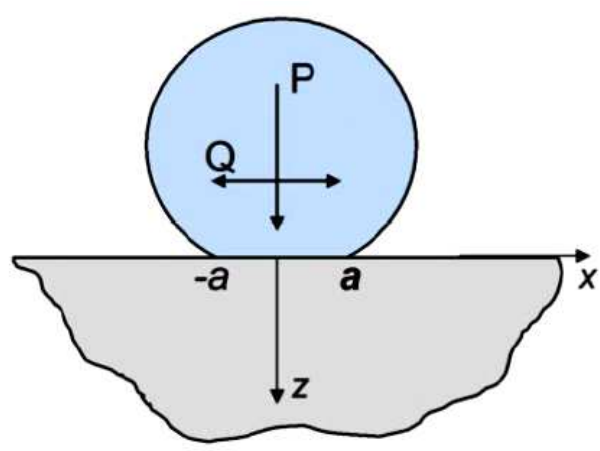

Figura 3.7 - Imagem esquemática de dois corpos sob a ação de carga fretting (AMIRI; KHONSARI, 2010).

Em corpos sob deslizamento, a força de atrito possui caráter não-conservativo (i.e. força dissipativa). Em um estudo mais aprofundado sobre o tema, há que se analisar como se distribui a energia associada ao trabalho necessário à manutenção do movimento relativo entre os corpos. Uma parte da energia é dissipada na forma de calor, outra na criação de superfícies (desgaste) e outra na deformação nas superfícies e em suas camadas posteriores. Além disso, caso haja a presença de lubrificantes ou partículas de desgaste, outras distribuições de energia deverão ser consideradas (ARANGO, 2010).

Zhu et al. (2015) realizaram experimentos de mensuração tridimensional, de alta resolução, de volume de rugosidade (volume roughness) e asperezas de contato (asperity contact), em vistas de estabelecerem um modelo híbrido de técnicas matemáticas, representativo para o atrito baseado em fluência do material. Por sua vez, Kalin e Pogačnik (2013) propõe o emprego de uma abordagem determinística, em detrimento de técnicas estatísticas convencionais, para a mensuração de valores mais realistas para áreas de contato superficiais tridimensionais, visando aplicações em engenharia e tribologia. Empregando um interferômetro óptico 3D, obtiveram 5 imagens representando os níveis de rugosidade superficial usados em seu estudo a partir de amostras de aço inoxidável esmerilhadas e polidas. As asperezas, presentes em qualquer região de contato entre sólidos, tornam-se facilmente identificáveis a partir destas imagens, exibidas na Figura 3.8. 
a

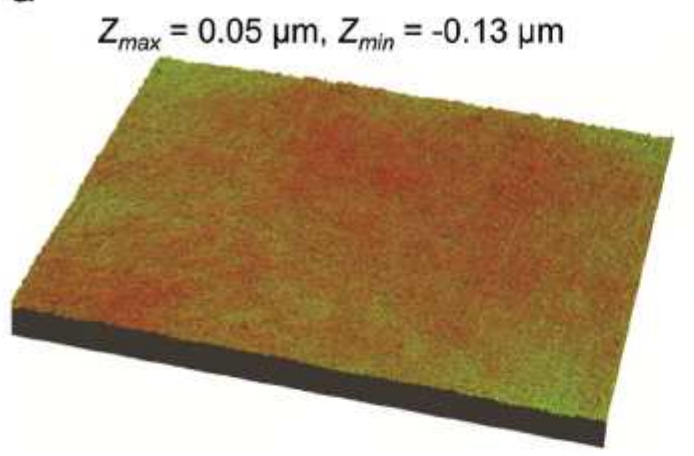

C

$$
Z_{\text {max }}=1.47 \mu \mathrm{m}, Z_{\text {min }}=-1.48 \mu \mathrm{m}
$$

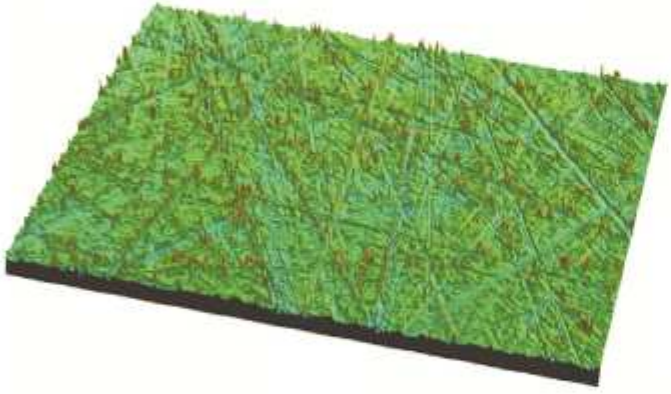

b $Z_{\max }=1.20 \mu \mathrm{m}, Z_{\min }=-0.85 \mu \mathrm{m}$

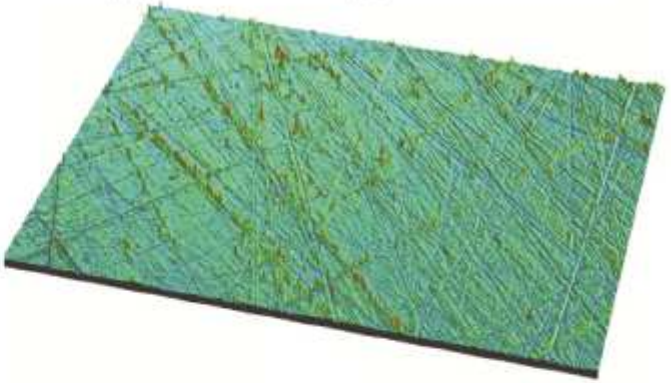

d

$$
Z_{\text {max }}=2.04 \mu \mathrm{m}, Z_{\text {min }}=-2.38 \mu \mathrm{m}
$$

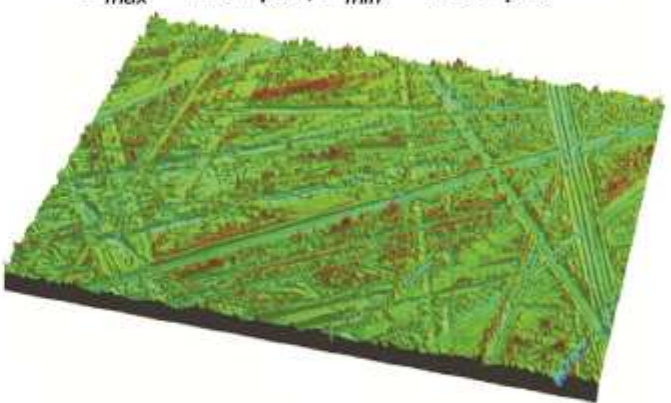

e

$$
Z_{\text {max }}=2.98 \mu \mathrm{m}, Z_{\text {min }}=-2.49 \mu \mathrm{m}
$$

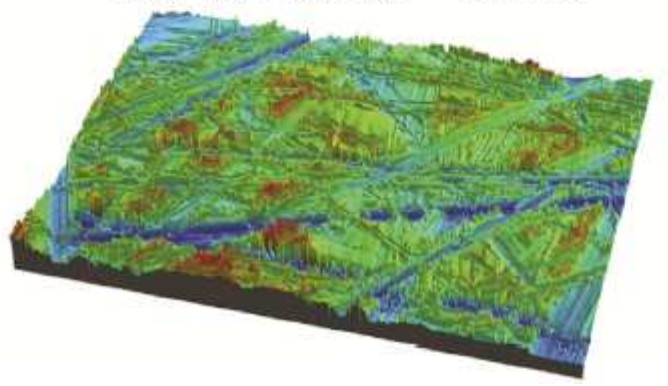

Figura 3.8 - Topografia de superfícies representando picos de asperezas de cinco amostras de aço inox, com diferentes níveis de polimento (KALIN; POGAčNIK, 2013).

É importante frisar que a parcela de energia de atrito que é transformada em energia térmica pode resultar em altas temperaturas superficiais na interface do par deslizante. Tais temperaturas influenciam as propriedades dos materiais em contato, bem como características das camadas superficiais, causando problemas que vão desde a oxidação acelerada e degradação de material, até problemas mais sérios como falhas termomecânicas. Logo, o mapeamento dos campos de temperatura na interface de qualquer sistema de atrito é de fundamental importância. 


\subsection{FenÔMEnOS tÉRMICOS RELACIONADOS AO ATRITO}

\subsubsection{INSTABILIDADE TERMOELÁSTICA (TEI) E HOT SPOTS}

O calor gerado em elementos de máquinas de atrito, tais como freios e embreagens, induz distorções térmicas que podem levar a áreas de contato localizadas e desenvolvimento de hot spots, que são pontos de localizados de altos gradientes térmicos na superfície de contato e estão entre os mais perigosos fenômenos que podem ocorrer em sistemas mecânicos de atrito. Tem sido demostrado que solicitações termomecânicas devido aos hot spots podem induzir a ciclos de tensões de tração e compressão com presença de variações plásticas. Consequentemente, ciclos térmicos de fadiga podem ocorrer, levando ao surgimento de trincas na superfície do disco de freio. Além disso, podem levar inclusive a níveis inaceitáveis de desempenho de frenagem, tais como a diminuição do coeficiente de atrito, conhecida como fade e problemas relacionados à vibração (hot judder) (PAINER; DUFRÉNOY; WEICHERT, 2004). Ao longo dos últimos anos, observações experimentais do surgimento de hot spots têm sido reportadas em várias aplicações, como automotivas, ferroviárias e aeroviárias. Todavia, a ocorrência de hot spots não é bem entendida até o momento, sendo motivo recente de estudo e desenvolvimento de novas teorias.

Até o momento, a teoria que melhor explica o fenômeno dos hot spots em sistemas mecânicos baseados em atrito é a teoria das instabilidades termoelásticas, ou TEI do inglês Thermoelastic Instabilities, proposta inicialmente por Barber (1969), e baseia-se nas variações de contato por atrito causadas pela interação entre expansão térmica, aquecimento, condução do calor para fora da zona de contato e desgaste. Esta teoria afirma que hot spots surgem a partir de velocidades críticas de deslizamento (PAINER; DUFRÉNOY; WEICHERT, 2004).

Uma alternativa à teoria TEI proposta por Painer et al. (2004) é chamada de distorção por ondulação progressiva (ou PWD do inglês Progressive Waviness Distortion). Baseando-se na assimetria dos esforços existente principalmente em discos de freio ferroviários, os autores propõem que a deformação inicial da superfície do disco tome uma forma de ondas e vales, principalmente devido aos momentos fletores causados pelas pastilhas de freios. Com um alto fluxo térmico, tais deformações entrariam em regime plástico e dariam forma a uma nova configuração 
de deformações, com a formação de novas ondas estacionárias. Assim, os vales seriam responsáveis pelos contatos pontuais responsáveis pelo número e posição fixos dos hot spots.

Em um destes trabalhos, Dow e Burton (1972) desenvolveram um equacionamento analítico, baseado em conceitos de termoelasticidade, com o propósito de estudar o surgimento das instabilidades termoelásticas. Para o mesmo, considera-se uma lâmina, de comprimento $L$ e espessura $z$, pressionada contra um espaço semi-infinito, conforme mostra a Figura 3.9.

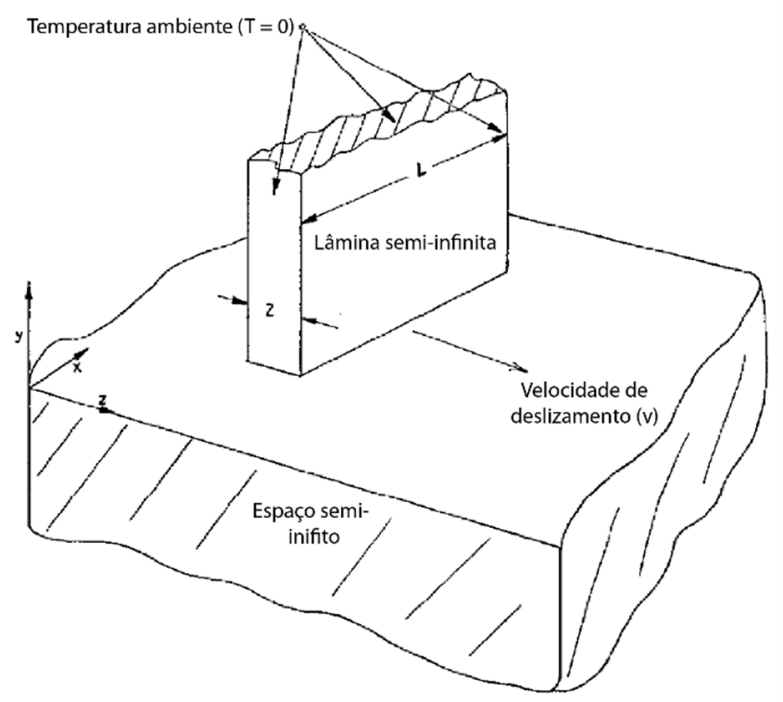

Figura 3.9 - Modelo para formulação da TEl usado por Dow e Burton (1972).

Aplicando uma perturbação senoidal na pressão externa, ou na temperatura da superfície da lâmina, Dow e Burton (1972) modelaram condições onde esta perturbação seja amortecida ou amplificada, referindo-se à transição entre elas como um ponto de instabilidade. Foi demonstrado que instabilidade é atingida se a velocidade exceder certo valor crítico, que dependerá do comprimento de onda da perturbação aplicada.

Os resultados do estudo foram obtidos considerando pares de contato de mesmo material e desprezando o efeito do desgaste. Uma vez que a função final é periódica, deve-se considerar o período de onda do distúrbio aplicado. A Tabela 3.1 apresenta resultados obtidos para a velocidade crítica, onde $V_{1}$ refere-se à velocidade correspondente ao primeiro modo, enquanto $V_{10}$ refere-se ao décimo modo de onda. 
Tabela 3.1 - Velocidades críticas para alguns pares de deslizamento usando o mesmo material (DOW; BURTON, 1972)

\begin{tabular}{llll}
\hline Material & Coeficiente de atrito & $\boldsymbol{V}_{\mathbf{1}}$ (in/s) & $\boldsymbol{V}_{\mathbf{1 0}}$ (in/s) \\
\hline Carbeto de Silício & 1.0 & 20.4 & 33.3 \\
Alumínio & 0.5 & 125 & 225 \\
Ferro fundido & 0.23 & 155 & 203 \\
\hline
\end{tabular}

Por sua vez, a Figura 3.10 exibe um gráfico para os três materiais listados na Tabela 3.1, considerando apenas o primeiro modo. Os autores definem a função coeficiente exponencial do tempo, função da velocidade de deslizamento, que tornase zero nas velocidades possivelmente causadoras de instabilidade.

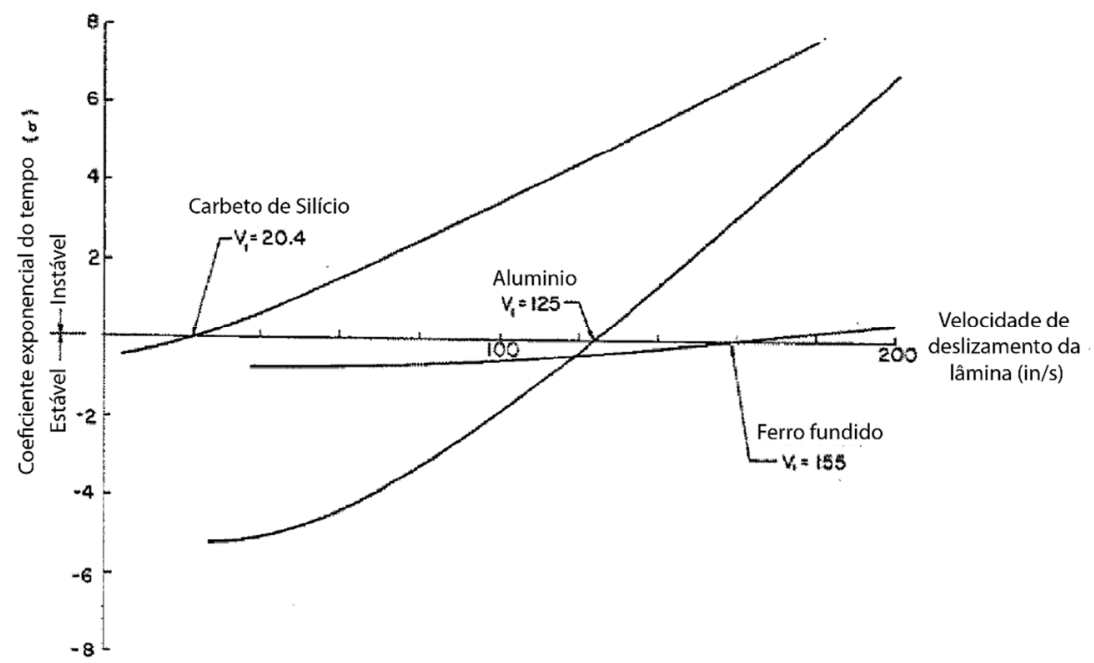

Figura 3.10 - Coeficiente exponencial do tempo em função da velocidade de deslizamento da lâmina para diferentes pares de materiais (DOW; BURTON, 1972).

Esta instabilidade acaba por levar, geralmente, ao estabelecimento de regiões de altas temperaturas localizadas (hot spots), observáveis em várias aplicações práticas (LEE; BARBER, 1993).

Por outro lado, Cho e Cho (2008) afirmam que, apesar de se estimar o projeto de freios visando a diminuição de vibrações com base nas velocidades críticas induzidas por TEI, na prática muito se perde devido às simplificações adotadas. Eles ressaltam que três fatores são fundamentais na obtenção de resultados mais precisos, a saber: 
- A teoria TEI considera as propriedades dos materiais como constantes; porém, durante experimentos, as propriedades materiais são alteradas devido à temperatura;

- Não há modelo matemático na teoria TEl que considere a variação de pressão de contato entre o rotor e o material de atrito considerando diferentes formas de aplicação das forças de frenagem;

- A deformação associada à formação do ângulo de cone (Coning Angle) no disco/tambor não é levada em conta.

Quando submetidos a altos gradientes térmicos, discos e tambores de freio sofrem um fenômeno de deformação cônica, conhecido por rotor coning. Este fenômeno causa uma mudança no paralelismo das superfícies do rotor, gerando a formação de um ângulo de cone, ou coning angle, e é atribuído à sua expansão térmica considerando suas restrições na face de montagem com o cubo (VALVANO; LEE, 2000; CHO; CHO, 2008).

A Figura 3.11 ilustra uma simulação simples realizada em um disco de freio para este trabalho, apenas com a intenção de se demonstrar este efeito.

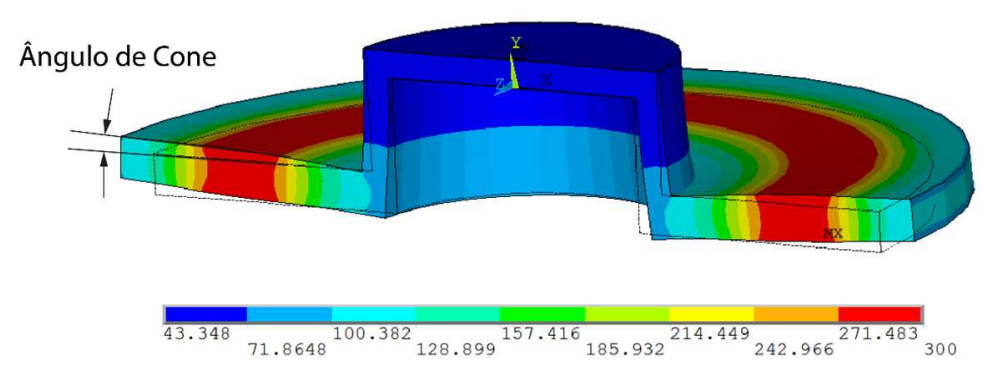

Figura 3.11 - Simulação realizada por elementos finitos usando ANSYS v15.0 para demonstrar o ângulo de cone em discos de freio devido aplicação de cargas térmicas (Fonte: Autor).

Assim como outros fenômenos, a deformação cônica do rotor é cumulativa ao longo de frenagens sequenciais, o que pode ser visto no gráfico obtido experimentalmente e por simulação numérica exibido na Figura 3.12. 


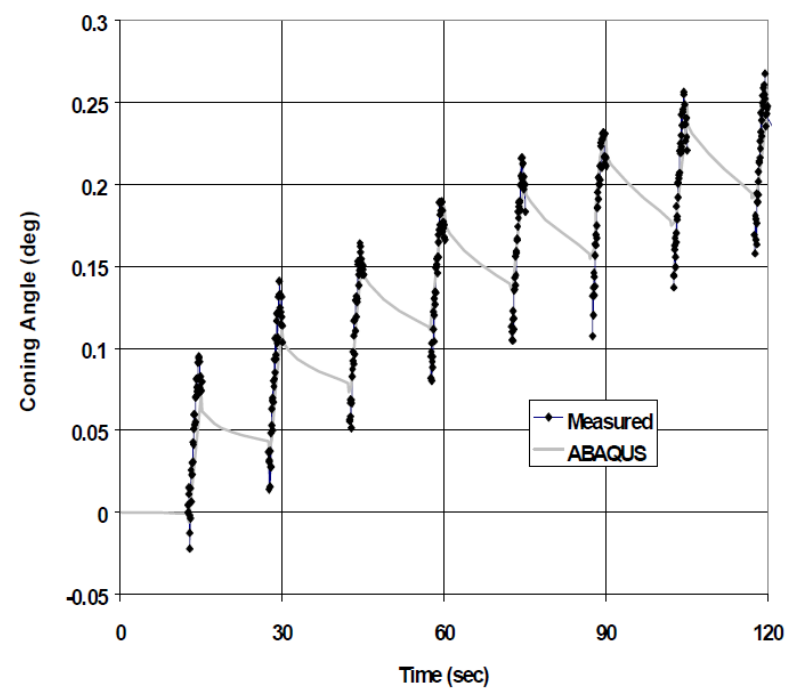

Figura 3.12 - Comparação entre medições e simulação numérica da deformação coning angle em disco de freio após oito frenagens consecutivas (VALVANO; LEE, 2000).

Anderson e Knapp (1990) foram os primeiros a propor uma classificação para hot spots observados em sistemas de freio automotivos. Coletando dados ao longo de vinte anos de estudo, quatro tipos de hot spots foram classificados conforme a Tabela 3.2.

Tabela 3.2 - Comparação entre os tipos de hot spots (ANDERSON; KNAPP, 1990).

\begin{tabular}{cccc}
\hline Tipo & $\begin{array}{c}\text { Espessura } \\
(\mathbf{m m})\end{array}$ & $\begin{array}{c}\text { Temperatura } \\
\left({ }^{\circ} \mathbf{C}\right)\end{array}$ & $\begin{array}{c}\text { Duração } \\
(\mathbf{s e g} .)\end{array}$ \\
\hline Aspereza & $<1$ & Até 1200 no pico & $<1$ \\
Focal & $5-20$ & $750-1200$ no pico & $0,5-20$ \\
Distorcional & $20-100$ & $100-700$ & 10 \\
Regional & $50-200$ & $10-100$ & 10 \\
\hline
\end{tabular}

Por sua vez, a Figura 3.13, elaborada por Anderson e Knapp (1990), ilustra estes tipos de hot spots, com os padrões encontráveis no disco/tambor de ferro fundido exibidos na parte superior e os padrões encontráveis nas pastilhas/lonas de freio na parte inferior da imagem. 


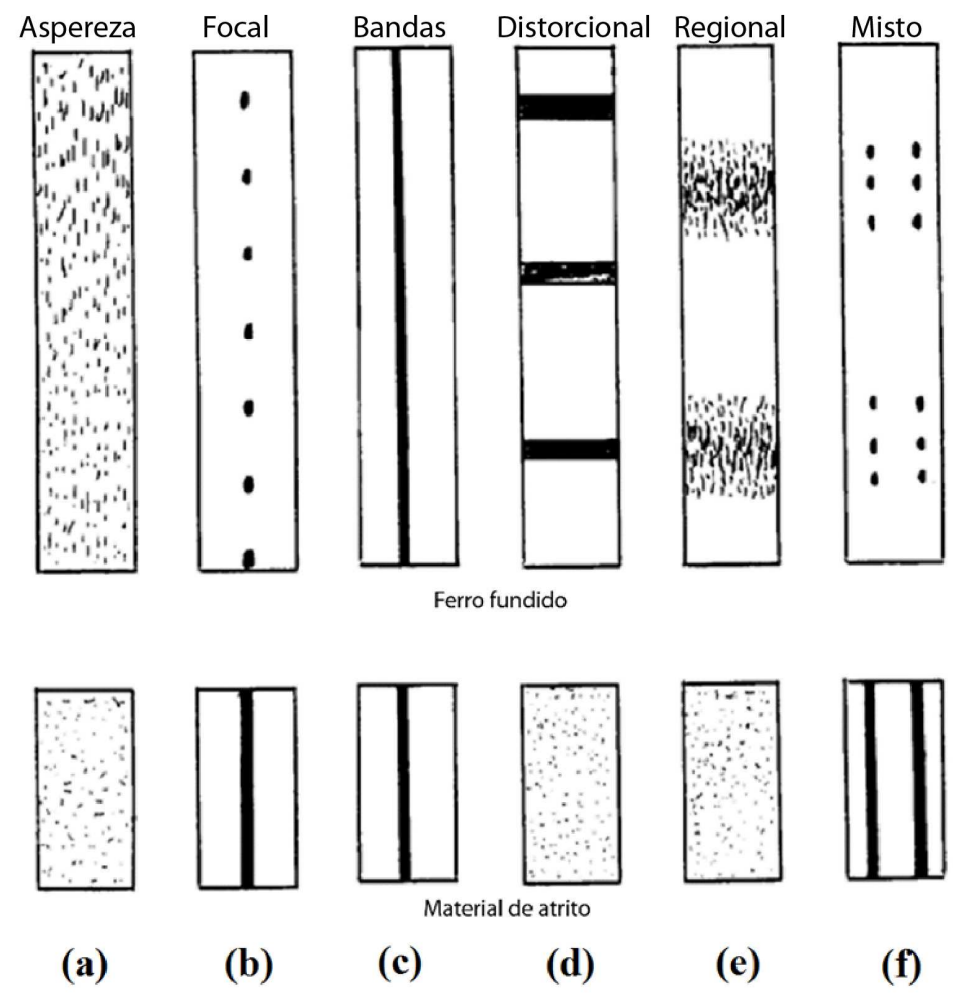

Figura 3.13 - Esquema de contato mostrando seis tipos de hot spots e instabilidades termo-elásticas (ANDERSON; KNAPP, 1990).

A Figura 3.13 separa seis tipos de padrões, listados abaixo:

(a) Hot spots devido à aspereza do material são os que surgem em maior quantidade, portanto o contato com o ferro fundido forma pequenas linhas na direção do deslizamento;

(b) Hot spots focais no disco ou tambor de ferro fundido estão relacionados à formação de uma banda termoelasticamente induzida na pastilha de freio;

(c) A forma de banda no disco ou tambor é precursora da forma focal, sendo estável em frenagens leves em baixas velocidades de deslizamento;

(d) A forma distorcional é grande e difusa quando comparada com o tipo focal;

(e) um padrão regional que pode ser formado em discos ou tambores de freio em frenagens leves, do tipo que produz hot spots focais dentro de fronteiras delimitadas.

(f) Padrão misto, onde encontra-se a presença de hot spots focais distribuídos em duas ou mais bandas.

Painer, Dufrénoy e Weichert (2004) fornecem uma classificação similar, mas um pouco mais próxima dos problemas cotidianos, definida com base em discos de freios de trens, mostrada na Tabela 3.3 e na Figura 3.14. 
Tabela 3.3 - Classificação de hot spots em freios de trens (PAINER; DUFRÉNOY; WEICHERT, 2004)

\begin{tabular}{llll}
\hline & $\begin{array}{l}\text { Largura } \\
(\mathrm{mm})\end{array}$ & $\begin{array}{l}\text { Temperatura } \\
(\stackrel{0}{ })\end{array}$ & Duração \\
\hline Aspereza (tipo 1) & $<1$ & 1200 (pico) & $<1 \mathrm{~ms}$ \\
Gradientes em hot bands (tipo 2) & $5-20$ & $650-1000$ & $0.5-10 \mathrm{~s}$ \\
Hot bands (tipo 3) & $5-50$ & 800 & $>10 \mathrm{~s}$ \\
MHS (tipo 4) & $40-110$ & 1100 (pico) & $>10 \mathrm{~s}$ \\
Hot spots regionais (tipo 5) & $80-200$ & $20-300$ & $>10 \mathrm{~s}$ \\
\hline
\end{tabular}

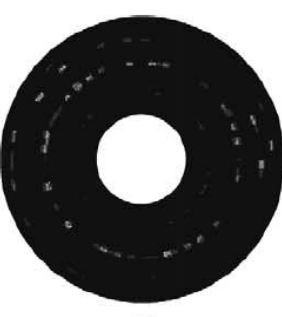

(1)

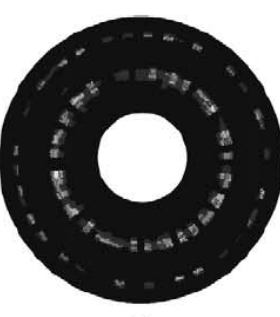

(2)

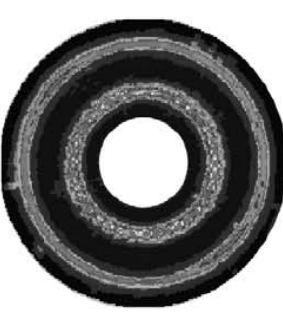

(3)

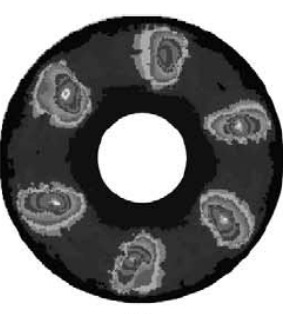

(4)

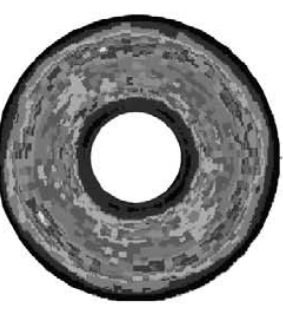

(5)

Figura 3.14 - Classificação de hot spots auxiliada por imagens termográficas em disco de freio de trens(PAINER; DUFRÉNOY; WEICHERT, 2004).

A lista a seguir propõe uma breve descrição dos cinco tipos de hot spots classificados. Ressalta-se aqui uma importante observação, feita por Painer, Dufrénoy e Weichert (2004), de que os tipos mais perigosos de gradientes térmicos correspondem aos tipos 2,3 , e 4 .

\section{Aspereza (tipo 1)}

A partir do momento em que as asperezas superficiais entram em contato, surgem pontos discretos de aumento de temperatura de curta duração, conhecida por temperatura flash, igualmente distribuídos ao longo da superfície em contato que, conforme discutido anteriormente, podem ultrapassar os $1000{ }^{\circ} \mathrm{C}$ (ANDERSON; KNAPP, 1990).

Blok (1937), apud Amiri e Khonsari (2010), é tido como pioneiro no campo da análise de temperatura de superfícies em contato. Ele considera o aumento de temperatura devido a uma fonte de calor de pequena dimensão, em analogia a um único contato entre asperezas superficiais (ABDEL-AAL, 1997). Em seguida, propôs 
o conceito de temperatura flash - que são as maiores temperaturas de curta duração em áreas de contato - e formula a estimativa de sua magnitude.

Outros autores seguiram desdobrando os trabalhos de Blok (1937), porém uma forma mais global para o equacionamento do problema foi proposta por Kuhlmannwilsdorf (1987). O autor propôs uma série de equações que podem ser utilizadas na estimativa da máxima temperatura flash em micro contatos de materiais dissimilares. As equações são aplicáveis à velocidades arbitrárias e regiões de contato elípticas, com eixos $A$ e $B$, onde $B=A / e$. A temperatura flash média para uma região de contato, onde considera-se o movimento relativo de ambos os lados, pode ser representada pela equação (3.1):

$$
\Delta T\left(e, V_{r 1}, V_{r 2}\right)=f(Z, S) \cdot \Delta T_{0}
$$

onde $f(Z, S) \leq 1$ é uma função que representa a redução na temperatura flash devido ao movimento (a partir de uma função de velocidade $Z\left(V_{r}\right)$ ), devido à forma elíptica do contato (a partir da função de forma $S\left(e, V_{r 1}\right)$ ) e devido à condutividade térmica do substrato (a partir da condutividade térmica relativa, $k_{r}=k_{2} / k_{1}$ ). Sua forma desenvolvida é dada pela equação (3.2):

$$
f(Z, S)=\frac{1}{\frac{1}{Z\left(V_{r 1}\right) \cdot S\left(e, V_{r 1}\right)}+\frac{k_{r}}{Z\left(V_{r 2}\right) \cdot S\left(e, V_{r 2}\right)}}
$$

Para esta função tem-se as relações mostradas nas equações (3.3) e (3.4):

$$
Z\left(V_{r}\right)<2=\frac{1}{1+V_{r} / 3}
$$

ou:

$$
Z\left(V_{r}\right) \geq 2=\frac{9 / 8}{\sqrt{V_{r}}+\sqrt{1 / 8}}
$$

E também, equação (3.5): 


$$
S\left(e, V_{r} \leq 1\right)=S_{0}(e)=\frac{4 / 3}{\sqrt{\left(1+\frac{e^{3 / 4}}{3}\right) \cdot\left(1+\frac{1}{3 e^{3 / 4}}\right)}}
$$

que pode ser reescrita de outra forma:

$$
S\left(e, V_{r}>1\right)=\frac{e^{1 / 4}+\frac{e^{1 / 4}}{\sqrt{\left(8 V_{r}\right)}}}{1+\frac{e^{3 / 4}}{\sqrt{\left(8 V_{r}\right)}}}
$$

$\mathrm{Na}$ equação (3.1), $\Delta T_{0}$ representa o valor de $\Delta T$ para um contato circular, em repouso, enquanto o material do segundo corpo é considerado isolante. Seu valor é dado considerando a condutividade térmica do corpo principal, $k_{1}$, o fluxo de calor (taxa de calor por unidade de área) que é considerada na interface, $q$ ", e uma dimensão geométrica característica, $r=\sqrt{A B} / 2$, dado pela equação (3.7):

$$
\Delta T_{0}=\frac{\left(\frac{\pi}{4}\right) \cdot q^{\prime \prime} \cdot r}{k_{1}}
$$

O autor destaca que o máximo valor da temperatura flash na interface do contato é aproximadamente um terço maior do que $\Delta T$, i.e. $\Delta T_{\max }=(4 / \pi) \Delta T$ para baixas velocidades, e $\Delta T_{\max }=1.42 \Delta T$ para velocidades relativas mais altas.

De acordo com Anderson e Knapp (1990), este aumento de temperatura localizado é influenciado por todos os processos mecânicos, plásticos, elásticos e térmicos que envolvem uma frenagem, mas são primordialmente afetados pela velocidade de deslizamento. Uma vez que sistemas de atrito automotivos operam em altas velocidades, comumente acima de $3 \mathrm{~m} / \mathrm{s}$, tais temperaturas podem ter um pico superior à $1000^{\circ} \mathrm{C}$, mas de duração da ordem de milissegundos. 


\section{Gradientes em hot bands (tipo 2)}

Correspondem a pequenas regiões de contato que surgem ao longo de uma única trilha de atrito, devido a deformações localizadas. Segundo Anderson e Knapp (1990), estas deformações são explicadas através da teoria de instabilidades termoelásticas excitadas por atrito (TEI).

\section{Hot bands (tipo 3)}

O fenômeno das hot bands é visto no disco como anéis estreitos de alta temperatura seguindo a direção do deslizamento que surgem durante a frenagem. Hot bands são causadas a partir da redução da área de contato da pastilha. Segundo Eriksson, Bergman e Jacobson (2002), durante momentos de superaquecimento, a superfície de pastilhas e lonas de freio em contato com o rotor se aquecerão e atingirão maior temperatura com relação às faces destes componentes expostas ao ar, levando a uma flexão convexa da pastilha/lona que gera uma distribuição desigual de pressões, conforme mostra a Figura 3.15.
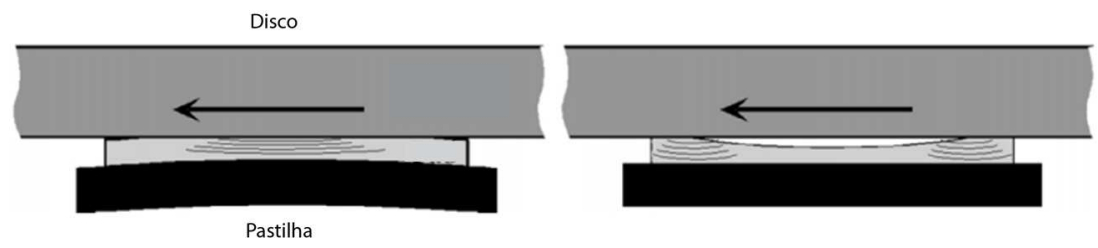

Figura 3.15 - Mecanismo para uma distribuição de pressões e desgaste desigual, devido a distorções induzidas termicamente, em uma pastilha e sua placa de apoio traseira (ERIKSSON; BERGMAN; JACOBSON, 2002).

A distribuição de temperaturas característica do fenômeno das hot bands foi captada experimentalmente usando câmera termográfica com auxílio de um dinamômetro de bancada por Cho e Cho (2008), sendo ilustradas para dois diâmetros de disco de freio na Figura 3.16. 


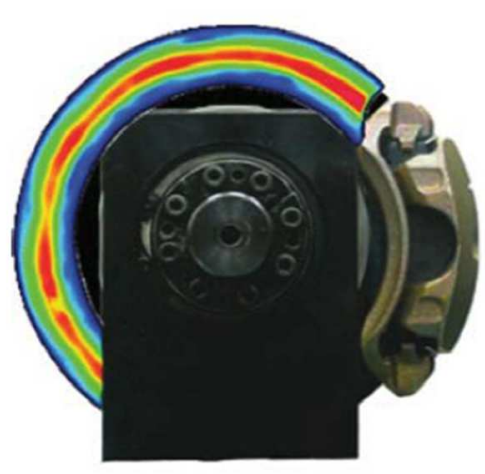

(a)

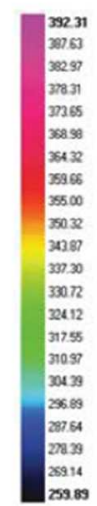

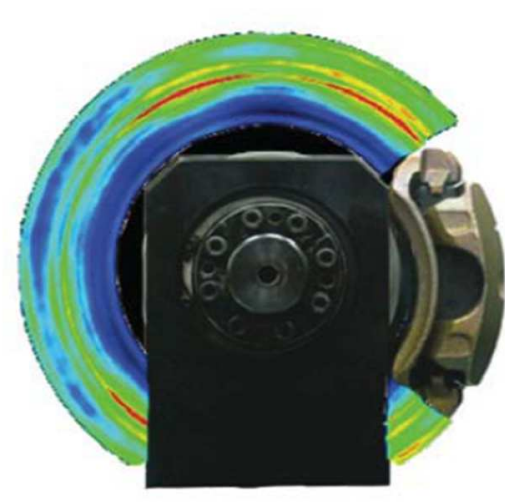

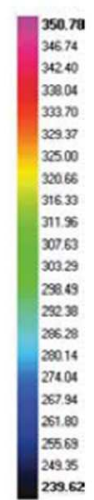

(b)

Figura 3.16 - Formação em dinamômetro de bancada de hot bands para diferentes diâmetros de disco (a) 10" e (b) 12" (CHO; CHO, 2008).

Um modelo termomecânico foi desenvolvido levando-se em conta o cálculo da pressão de contato entre a pastilha e o disco, as distorções térmicas dos componentes, o desgaste da pastilha e o comportamento termomecânico dos materiais. Este modelo previu a formação e evolução de "anéis de calor", com excelente concordância com resultados experimentais (KAO; RICHMOND; MOORE, 1994 apud PAINER; DUFRÉNOY; WEICHERT, 2004).

Distorções termomecânicas também podem ser causadas pelo superaquecimento do rotor de freio. Usualmente, o superaquecimento é o resultado de um dimensionamento térmico inadequado do componente de frenagem. Como resultado desse fenômeno, o metal pode perder propriedades mecânicas adquiridas em tratamentos térmicos, ou seja, podem acarretar numa diminuição de sua dureza, diminuição da resistência mecânica e modificação de sua forma de projeto.

Outra forma de exemplificar a importância do enfoque em área de contato se refere ao trabalho de Bergman, Eriksson e Jacobson (1999), onde se demonstrou que o jateamento da superfície de discos de freio reduz o coeficiente de atrito, uma vez que a área de contato acaba por diminuir. Após certo período de uso, mostrou-se que a área de contato tende a aumentar à medida que o disco e a pastilha realizam uma troca de polimento, contudo sem haver restauração do coeficiente de atrito inicial. Antes do jateamento, o coeficiente de atrito era mensurado em torno de 0,6. Após o jateamento baixou para 0,3, estabilizando após 1200 ensaios de frenagem em 0,4, conforme mostra a Figura 3.17. 


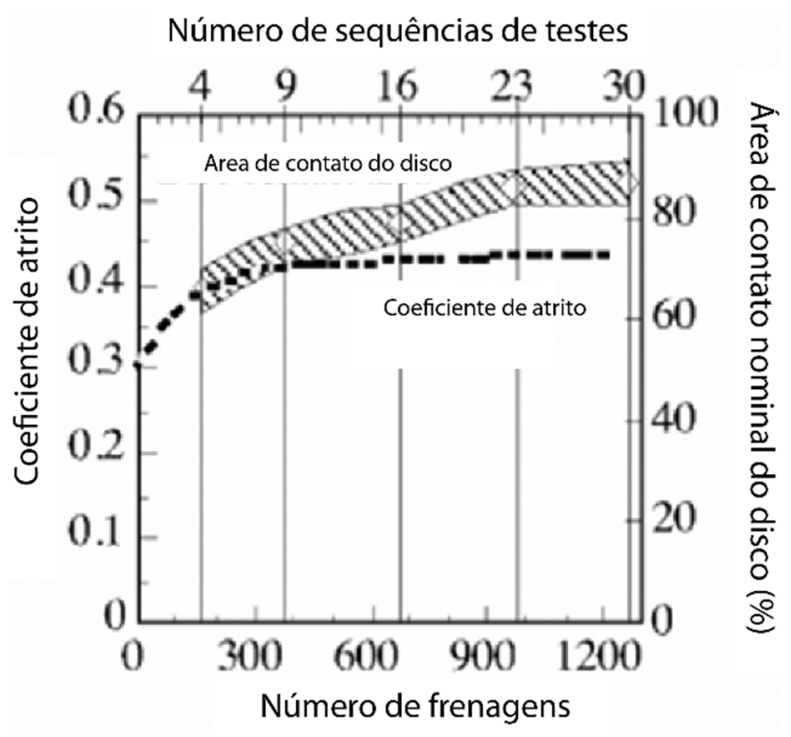

Figura 3.17 - Coeficiente de atrito e fração nominal de contato de área de um disco de freio durante uma sequência de frenagens (ERIKSON; BERGMAN; JACOBSON, 2002).

\section{Macroscopic hot spots (tipo 4)}

São áreas de grande gradiente térmico regularmente distribuídas ao longo da superfície do disco. Sua posição é fixa no disco, como um padrão de curvatura do mesmo. Este fenômeno reduz drasticamente a área de contato gerando altas temperaturas locais.

O tipo 4 refere-se aos MHS, que apresenta os maiores gradientes térmicos e comumente é considerado como o maior mecanismo de falha em discos de freio. Lee e Barber (1993) demonstram haver configuração de vibração simétrica e antissimétrica em função da velocidade crítica mostrando, inclusive, que os modos antissimétricos tornam-se instáveis em velocidades mais baixas. A Figura 3.19 ilustra um resultado experimental demonstrando a presença de MHS nesta condição. 


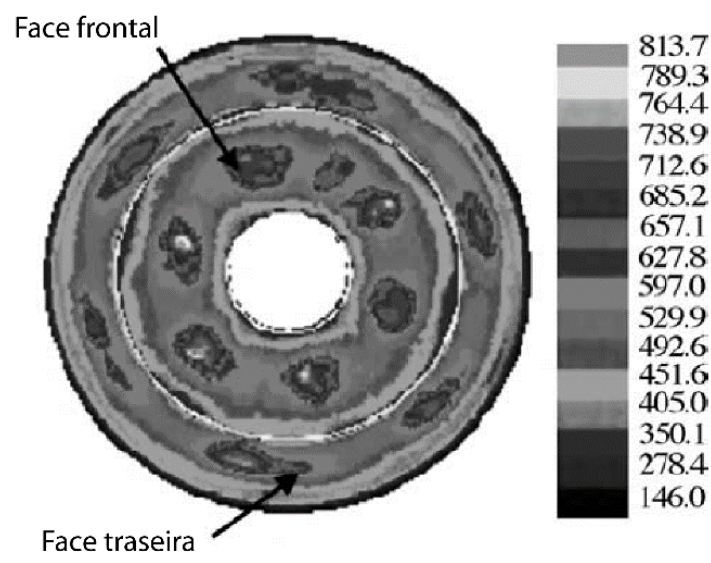

(a)

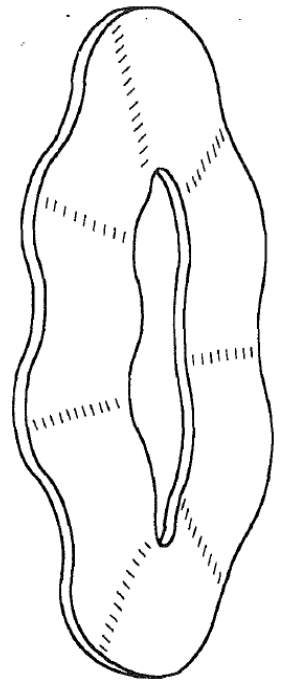

(b)

Figura 3.18 - Demonstração da presença de modo antissimétrico de vibração em discos de freio sujeitos a esforços de atrito: (a) Imagem termográfica de dois lados simultâneos de um disco de freio, exibindo MHS (PAINER; DUFRÉNOY; WEICHERT, 2004); (b) Ilustração da configuração deformada a partir da teoria de instabilidades termoelásticas (TEI) (LEE; BARBER, 1993).

Geralmente, MHS ocorrem em situações de grande energia de frenagem e grande velocidade, mas também podem ocorrer em frenagens mais leves. Normalmente observam-se cinco ou seis MHS por lado de um disco de freios. Segundo Lee e Barber (1993) o número de hot spots pode ser previsto pela teoria de instabilidade termoelástica (TEI), e depende do comprimento de contato entre a pastilha e o disco e aparenta corresponder à razão entre o perímetro médio do disco e o comprimento de contato. Experimentos e simulações conduzidas por Cho e Cho (2008) demonstram esta relação, com um exemplo ilustrado pela Figura 3.19, onde nota-se hot spots com intensidades e concentração de calor diferentes para duas pressões aplicadas (1,5 e 2,0 bar), porém mantendo o mesmo número de 6 hot spots em ambas. Os experimentos mostram haver uma relação mais forte com a geometria do disco, da pastilha e mesmo do caliper do que outros parâmetros. 


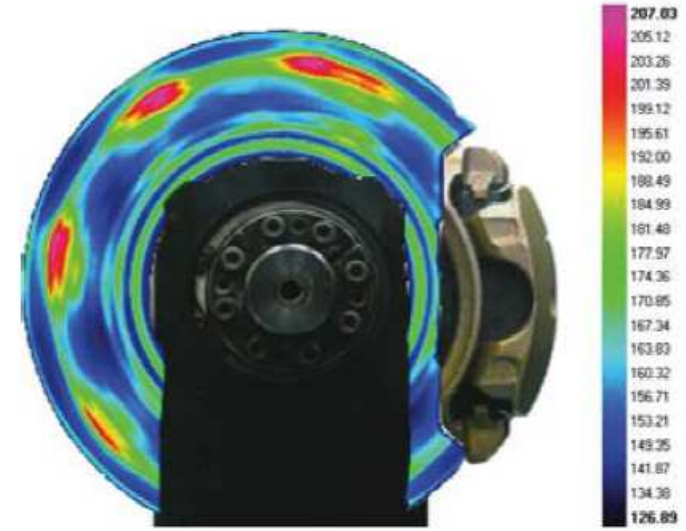

(a)

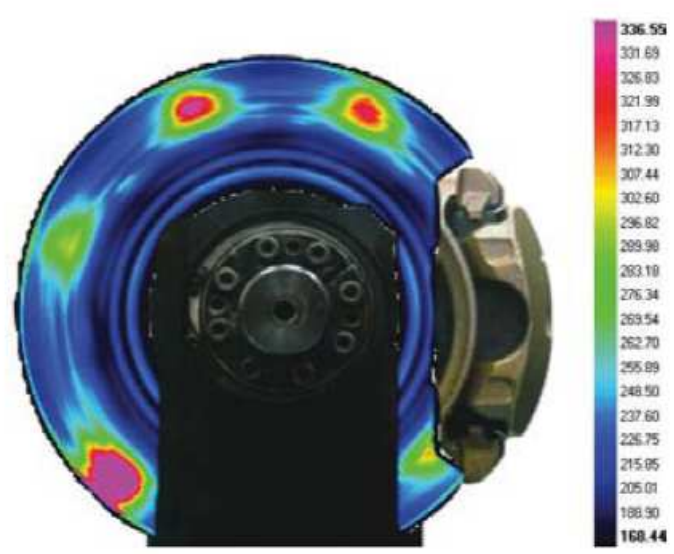

(b)

Figura 3.19 - Imagem termográfica demonstrando o surgimento de hot-spots em um disco de freio de 12" de diâmetro para duas pressões aplicadas: (a) 1,5 bar; (b) 2,0 bar (CHO; $\mathrm{CHO}, 2008$ ).

Análises metalúrgicas em discos de freios ferroviários mostram mudanças na estrutura cristalina, com formação de martensita, nos locais de MHS (PAINER; DUFRÉNOY; WEICHERT, 2004). Isto leva ao surgimento de trincas e deformações uma vez que a fase martensita, que basicamente surge de um processo de têmpera, resulta na redução da ductilidade, tenacidade, aparecimento de tensões internas e possui maior volume específico (CHIAVERINI, 2005).

\section{$\underline{\text { Hot spots regionais (tipo 5) }}$}

São regiões de baixo gradiente térmico distribuídas ao longo de toda a superfície do disco, devido ao resfriamento não homogêneo. Tais distribuições surgem no final da frenagem após a estabilização da difusão térmica. 


\subsubsection{EFEITOS DE VIBRAÇÃO E HOT JUDDER}

Hot judderé o termo empregado para definir o fenômeno de vibrações de baixa frequência, geralmente na ordem de $10 \mathrm{a} 30 \mathrm{~Hz}$, produzidas em sistemas de freio a partir da formação de regiões de alta concentração de calor, formadas, por sua vez, a partir de distorções termoelásticas (hot spots). Esta vibração gera, além de ruído, a propagação de energia do disco ou tambor para o condutor, através do pedal de freio (CHO; $\mathrm{CHO}, 2008$ ).

A redução de ruídos induzidos por atrito, especialmente nas condições de regime transiente, é um dos problemas mais complexos enfrentados pela indústria automotiva. Este tópico chega a consumir mais de $50 \%$ do orçamento destinado à pesquisa em empresas que lidam com materiais de atrito e sistemas de freio, em uma categoria conhecida por engenharia de NVH, do inglês noise, vibration and harshness. Existem muitas ferramentas para se investigar, analisar e validar estudos sobre este fenômeno, como ensaios em dinamômetro, martelo de impacto e análise por elementos finitos. A solução costuma estar relacionada ao aumento das frequências naturais dos componentes considerando-se a presença de altas temperaturas (MIHA et al., 2012).

Particularmente interessante para este trabalho, Hamid, Teoh e Ripin (2013) ressaltam que mesmos os trabalhos mais recentes possuem pouca referência ao fenômeno relacionado a sistemas de freio a tambor, prevalecendo freios a disco. Ruídos em tambores de freio compartilham dos mesmos mecanismos de vibração excitada por atrito que discos, mas a escassa quantidade de dados experimentais dificulta a validação dos modelos.

\subsubsection{BRAKE FADE}

A redução da capacidade de frenagem em um sistema de freio, sem que seja alterada a força aplicada ao sistema, é conhecida como fade, ou ainda brake fade, sendo referida como uma redução no coeficiente de atrito durante a frenagem. Herring (1967) estabeleceu a teoria de que o fenômeno de brake fade ocorre devido ao acúmulo dos gases gerados na frenagem em pequenos vazios presentes nos materiais da interface em atrito devido sua decomposição. A expansão destes gases 
seria capaz de gerar esforços na direção oposta à aplicada pelo condutor e teria a consequência de diminuir a força de atrito.

Por sua vez, Cho et al. (2009) acrescentam que o fenômeno não depende apenas da decomposição e vaporização dos componentes orgânicos, como havia sido proposto, mas também é fortemente afetado pelos demais ingredientes que compõe o material de atrito, principalmente devido às mudanças tribológicas sofridas em altas temperaturas pelos ingredientes unidos por resinas.

Experimentalmente, mostra-se uma clara relação entre o aumento da temperatura e a diminuição do coeficiente de atrito, ao passo que com o decréscimo da temperatura o coeficiente volta a recuperar seu valor original, conforme ilustra o gráfico de ensaios em dinamômetro da Figura 3.20.

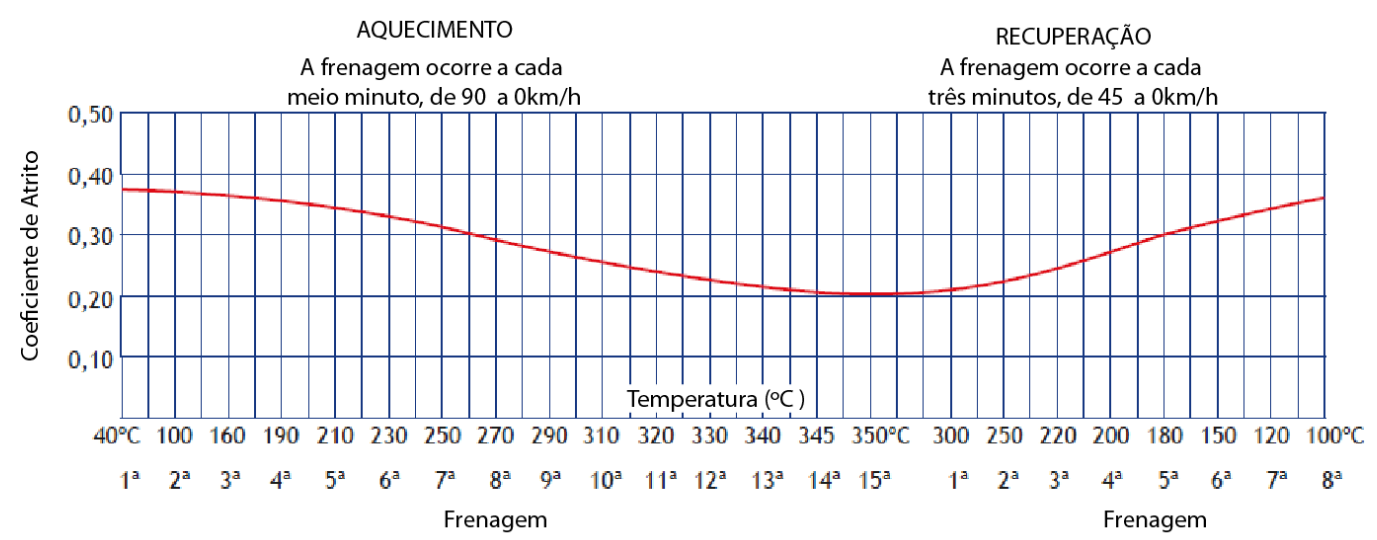

Figura 3.20 - Alteração do coeficiente de atrito, em situação de aumento de temperatura (aquecimento) e posterior diminuição da mesma (recuperação) (FRAS-LE, 2014).

\subsubsection{Mecanismos do desGaste e falhas}

O exame cuidadoso da dinâmica de contatos confirma que o desgaste possui efeito no processo gerador de instabilidades termodinâmicas, mas quando a taxa de desgaste é baixa, ou mesmo quando o período analisado é pequeno, ele poderá ser desprezado (DOW; BURTON, 1972). Porém, conforme pode ser visto na Figura 3.21, ensaios realizados em discos de freio mostram claramente o aumento do coeficiente de atrito após as primeiras 50 frenagens, resultado do aumento da área de contato devido ao desgaste da pastilha e disco de freio (Eriksson, Bergman, Jacobson, 2002). 


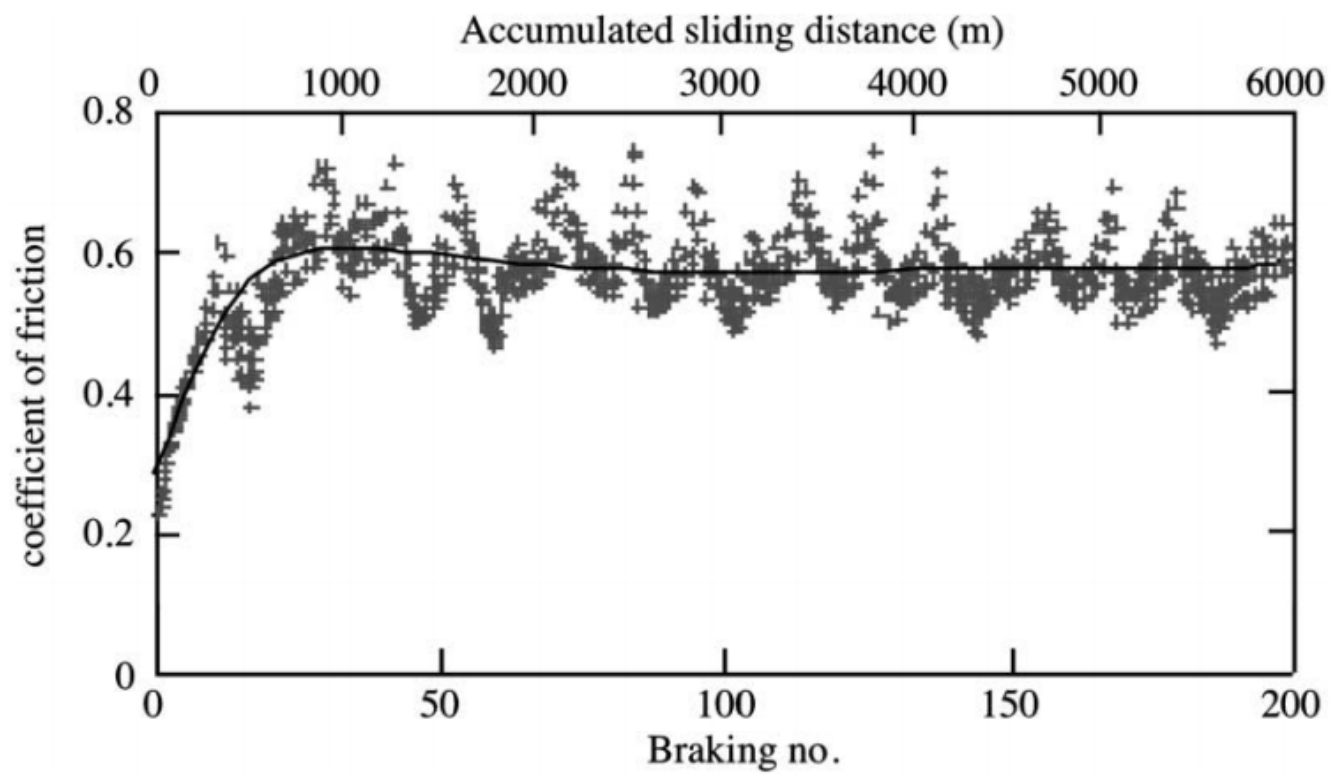

Figura 3.21 - Efeito do aumento do coeficiente de atrito durante ensaios realizados em um novo freio a disco. Dados experimentais: variação automática da pressão de frenagem entre 3- 25 bar, frenagens repetidas no intervalo de 3 a 1 rps (Eriksson, Bergman, Jacobson, 2002).

Eriksson, Bergman e Jacobson (2002) explicam que muitos fenômenos complexos observados em atrito devem ser investigados sabendo-se que apenas uma fração da área real de pastilhas e lonas entram em contato com o rotor. $O$ contato real fica delimitado a um número de elevações do relevo, que por meio de microscopia mostram sinais de serem planos, desgaste acentuado e marcas paralelas na direção do deslizamento, como ilustrado pela Figura 3.22.

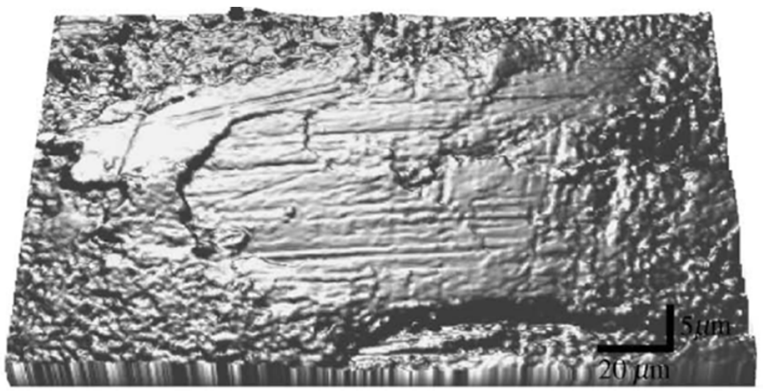

(a)

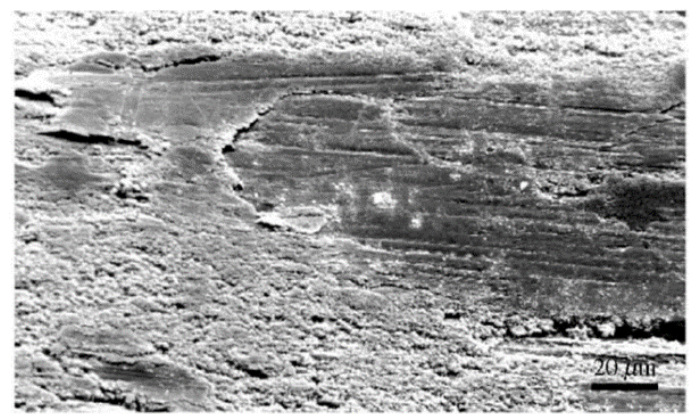

(b)

Figura 3.22 - Aparência da superfície de uma pastilha de freio, exibindo planos de contato e a superfície rugosa circundante. A mesma área é vista com auxílio de duas técnicas diferentes: (a) micrografia perfilométrica 3-D; (b) Microscópio eletrônico de varredura (Eriksson, Bergman, Jacobson, 2002). 
Tschiptschin et al., (2000) mostram resultados de experimentos feitos com algumas ligas de ferro fundido possivelmente empregadas na fabricação de discos e tambores de freio. Os resultados obtidos pelos autores constatam uma maior resistência ao desgaste e aumento de temperatura dos ferros fundidos cinzentos de alto carbono, em comparação com outras formas ferro fundido.

Por fim, trincas térmicas, em tambores e discos de freio, são comumente encontradas em veículos de alto desempenho, aparecendo, usualmente, na pista de atrito dos discos ou tambores, situando no lado externo do mesmo. Isto se deve a maior capacidade de resfriamento desta região pela presença de uma maior concentração de área em temperatura ambiente. Uma vez iniciadas estas trincas, a vida útil de um tambor ou disco de freio passa a ser governada pela velocidade de propagação das mesmas. A Figura 3.23 exemplifica o surgimento de trincas térmicas em um disco de freio ventilado, fabricado em ferro fundido cinzento, de trens de passageiros atualmente utilizado na Coréia do Sul.
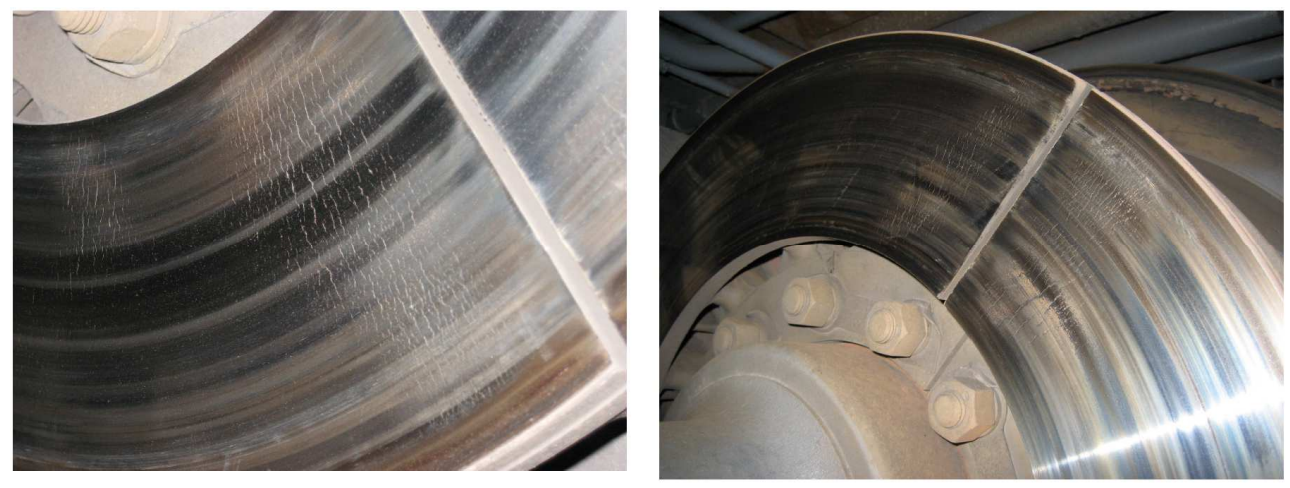

Figura 3.23 - Disco de freio usado em trens de passageiros exibindo a distribuição radial de trincas térmicas (KIM; KWON; YOON, 2009).

Por sua vez, a Figura 3.24 exibe, além de trincas térmicas, as formas mais comuns de desgaste em tambores de freio: (a) desgaste uniformemente distribuído, previsto pela vida útil dos componentes; (b) indicação de trincas formadas pela fadiga térmica dos materiais, tais como explicadas no parágrafo anterior; (c) regiões com presença de formação de maternsita, indicando pontos onde de hot spots e (d) indica a vitrificação (do inglês glazing) da superfície interna do tambor, o que acaba por diminuir o coeficiente de atrito projetado para o contato com a lona de freio. 


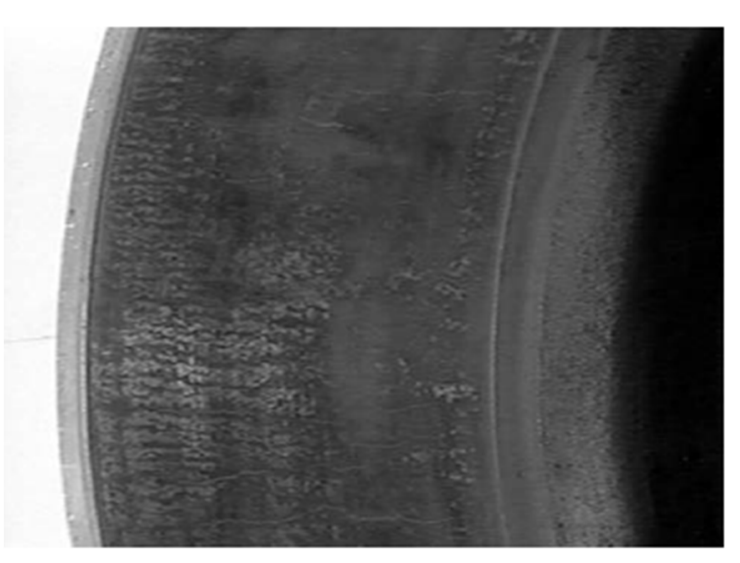

(a)

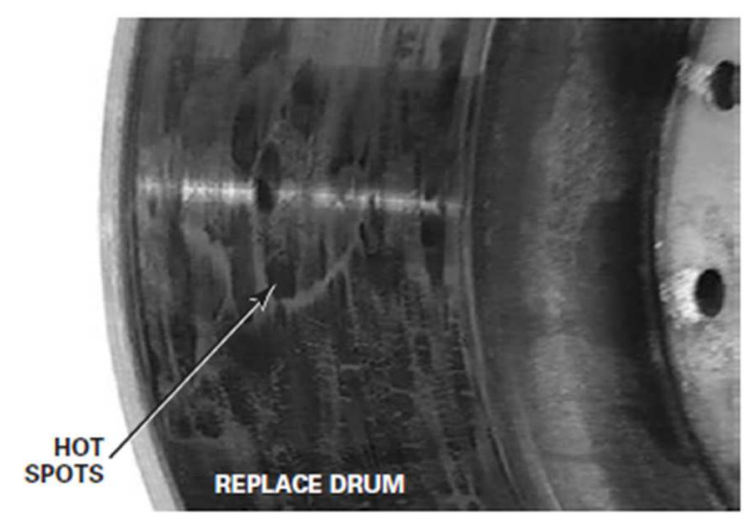

(c)

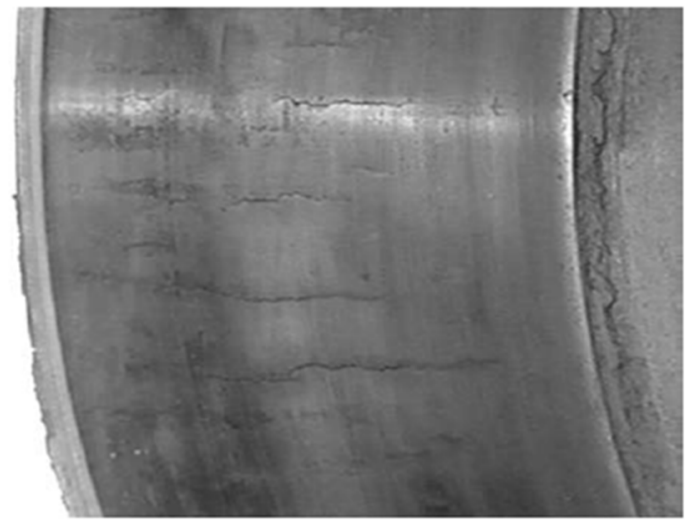

(b)

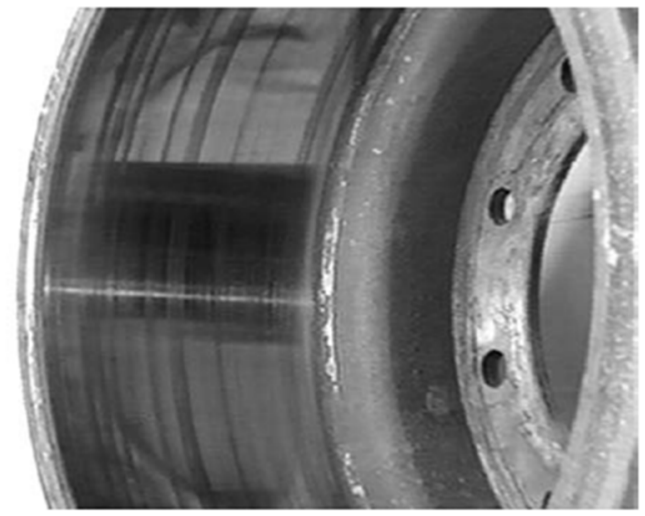

(d)

Figura 3.24 - Condições de desgaste encontradas em tambores de freio: (a) Desgaste uniforme; (b) Trincas devido à fadiga térmica; (c) Pontos negros indicando hot spots; (d) Vitrificação, ou Glazing, da superfície interna do tambor (MERITOR, 2006). 


\section{Embasamento matemático}

$\mathrm{Na}$ operação de freios automotivos, a geração das forças de arrasto sempre é combinada pela geração e dissipação de calor, e a maior limitação nas técnicas convencionais de análise de freios têm sido o tratamento separado destes dois itens (DAY; NEWCOMB, 1984). Todavia, Evtushenko, Ivanik e Horbachova (2000) discutem que os processos devido ao atrito presentes em sistemas de freio são de fato muito complicados. Eles são tão interconectados que o próprio problema da temperatura gerada por atrito não pode ser considerado puramente em sua forma clássica de difusão térmica. Por esta razão, o cálculo das tensões e dos modos térmicos em freios será confiável desde que seu equacionamento seja bem estudado.

Com isso em mente, os equacionamentos a seguir propõem embasar uma primeira abordagem quanto aos fenômenos de acoplamento termoelástico discutidos até o momento.

\subsection{ConCEITOS DE ESTÁtICA APLICADA A FREIOS A TAMBOR}

As hipóteses iniciais para o estudo dos esforços suportados por freios a tambor iniciam-se a partir do estudo de seu comportamento estático e a hipótese de corpos rígidos, não considerando a rotação (movimento), mas somente a aplicação da carga por meio de um torque no tambor, que deve ser resistido pelas sapatas. Segundo este princípio, Budynas e Nisbett (2011) propõe um modelo de cálculo baseado na geometria do sistema de freios (Figura 4.1), que servirá de base para um estudo preliminar dos esforços. 


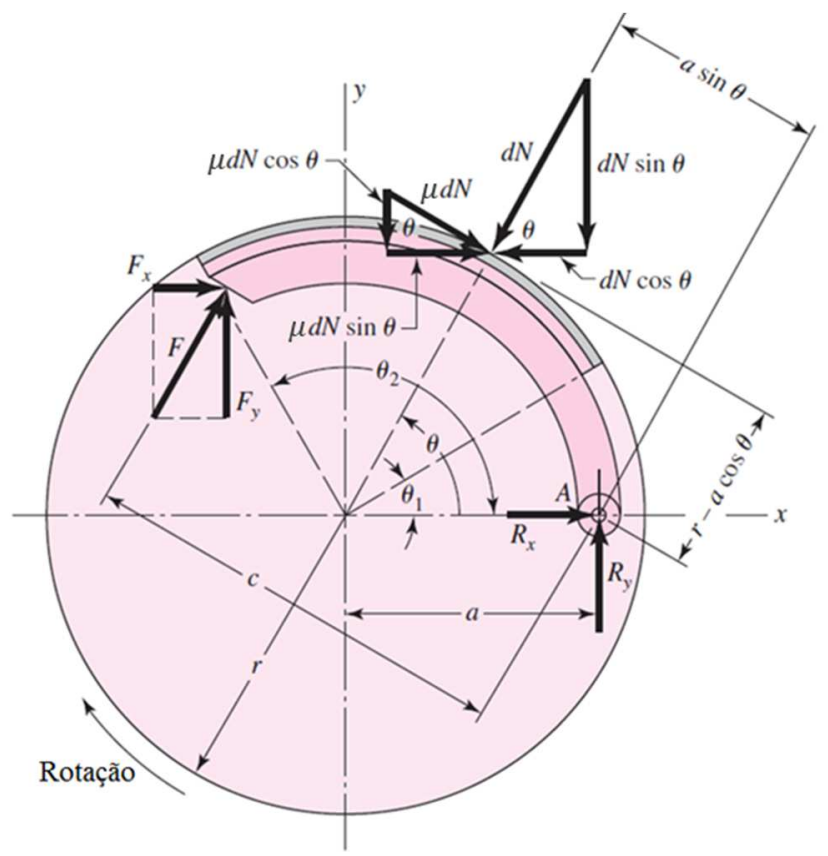

Figura 4.1 - Forças atuantes na sapata auto-energizante (primária) de um freio a tambor (BUDYNAS; NISBETT, 2011).

De acordo com o diagrama de corpo livre ilustrado na Figura 4.1, o torque $T$ aplicado ao tambor pelas sapatas do freio pode ser obtida pela Eq. (4.1):

$T=\int \mu r d N=\frac{\mu p_{a} \delta_{l} r^{2}}{\operatorname{sen} \theta_{a}} \int_{\theta_{1}}^{\theta_{2}} \operatorname{sen} \theta d \theta=\frac{\mu p_{a} \delta_{l} r^{2}}{\operatorname{sen} \theta_{a}}\left(\cos \theta_{1}-\cos \theta_{2}\right)$

onde:

$$
\begin{aligned}
\mu & =\text { Coeficiente de atrito entre a lona e o tambor; } \\
r & =\text { Raio da região de contato entre a lona e o tambor }(\mathrm{m}) ; \\
p_{a} & =\text { Pressão máxima na sapata }\left(\mathrm{N} / \mathrm{m}^{2}\right) ; \\
\delta_{l} & =\text { Espessura da lona }(\mathrm{m}) ;
\end{aligned}
$$

A diferença entre os esforços dissipados na sapata primária e secundária deve considerar a rotação do tambor. Tais esforços acabam por serem maiores na sapata primária, devido ao efeito auto-energizante. Com esse efeito, se observa um aumento na força normal aplicada à sapata primária devido ao arrasto do tambor. Segundo Budynas e Nisbett (2011), para estimar esta diferença, pode-se calcular a força atuante na sapata baseando-se nos momentos causados pela integração dos 
diferenciais de força normal $d N$ e, de atrito $\mu d N$, em torno do pino de articulação de uma sapata, conforme as equações (4.2) e (4.3):

$$
\begin{aligned}
& M_{\mu}=\int \mu d N(r-a \cos \theta)=\frac{\mu p_{a} b r}{\operatorname{sen} \theta_{a}} \int_{\theta_{1}}^{\theta_{2}} \operatorname{sen} \theta(r-a \cos \theta) d \theta \\
& M_{N}=\int d N(a \operatorname{sen} \theta)=\frac{p_{a} b r a}{\operatorname{sen} \theta_{a}} \int_{\theta_{1}}^{\theta_{2}} \operatorname{sen}^{2} \theta d \theta
\end{aligned}
$$

O balanço de momentos para a sapata primária retorna, então, a força a ser aplicada pela equação (4.4):

$$
F=\frac{M_{N}-M_{\mu}}{c}
$$

$a=$ Distância entre o pino e o centro de giro do tambor $(m)$;

$c=$ Distância entre o pino e o ponto de aplicação da força $(m)$.

Para o caso da sapata secundária, a direção relativa da rotação será invertida, o que altera o balanço de momentos em torno do pino de articulação: Para este segundo caso, a força atuante será dada pela equação (4.5):

$$
F=\frac{M_{N}+M_{\mu}}{c}
$$

\subsection{TransferênCIA DE CALOR APLICADA A SISTEMAS DE FREIO}

\subsubsection{ConCEITOS INICIAIS DA TRANSFERÊNCIA DE CALOR}

Os processos de transferência de calor são geralmente quantificados através de equações de taxas, relativas a cada processo, e que podem ser usadas para calcular a quantidade de energia que é transferida por unidade de tempo. O fluxo de condução de calor por unidade de área $\boldsymbol{q u}^{\prime \prime}\left(\mathrm{W} / \mathrm{m}^{2}\right)$ é uma quantidade vetorial, 
representada pela equação (4.6), conhecida como Lei de Fourier (BERGMAN et al., 2011):

$$
\boldsymbol{q}^{\prime \prime}=-k \boldsymbol{\nabla} T=-k\left(\boldsymbol{i} \frac{\partial T}{\partial x}+\boldsymbol{j} \frac{\partial T}{\partial y}+\boldsymbol{k} \frac{\partial T}{\partial z}\right)
$$

onde:

$$
\begin{aligned}
k & =\text { Condutividade térmica isotrópica do material }(\mathrm{W} / \mathrm{mK}) \\
\boldsymbol{\nabla} & =\text { Operador gradiente; } \\
T(x, y, z) & =\text { Campo escalar de temperaturas }(K) .
\end{aligned}
$$

Com o objetivo de se determinarem a distribuição do calor, através da variação do campo de temperaturas em uma dada região sobre o tempo, deriva-se a equação da difusão de calor para um volume de controle diferencial, $d x d y d z$. Para isso, partese da equação (4.7), que representa a primeira lei da termodinâmica para volume de controles (em termos de taxas):

$$
\dot{E}_{s t}=\dot{E}_{e}-\dot{E}_{s}+\dot{E}_{g}
$$

Nesta equação, cada termo representa uma quantidade de energia transferida no tempo. Assim, as equações (4.8) e (4.9) representam a taxa de energia gerada e armazenada, respectivamente,

$$
\begin{aligned}
& \dot{E}_{g}=\dot{q} d x d y d z \\
& \dot{E}_{s t}=\rho C_{p} \frac{\partial T}{\partial t} d x d y d z
\end{aligned}
$$

enquanto $\dot{E}_{e}$ e $\dot{E}_{s}$ simbolizam a taxa de energia que entra e sai do volume de controle por condução. Determinados os termos da equação da conservação da energia, temos a forma básica da equação da equação da difusão do calor (4.10):

$$
\frac{\partial}{\partial x}\left(k \frac{\partial T}{\partial x}\right)+\frac{\partial}{\partial y}\left(k \frac{\partial T}{\partial y}\right)+\frac{\partial}{\partial z}\left(k \frac{\partial T}{\partial z}\right)+\dot{q}=\rho C_{p} \frac{\partial T}{\partial t}
$$


As condições de contorno associadas ao corpo, e uma condição inicial, devem ser consideradas quanto ao cálculo da distribuição de temperaturas aplicando a equação (4.10). Neste caso, duas condições de contorno principais aplicadas a problemas de transferência de calor são as formas de transferência por convecção e radiação.

Enquanto o modo de transferência de calor por condução ocorre por meio da difusão da energia em um meio devido a um gradiente de temperatura, através do mecanismo físico de atividade molecular randômica, representado pela Lei de Fourier, a transferência de calor por convecção é composta de dois mecanismos. Em adição a energia transferida por difusão, ela também é transferida devido ao movimento macroscópico de um fluido sobre uma superfície com temperatura diferente deste (BERGMAN et al., 2011).

Independente da natureza da transferência de calor por convecção, a forma apropriada para descrevê-la é dada pela equação (4.11), que representa a Lei de Newton do Resfriamento:

$$
q_{c}{ }^{\prime}=h\left(T_{s}-T_{\infty}\right)
$$

onde:

$$
\begin{aligned}
q_{c}{ }^{\prime} & =\text { Transferência de calor por convecção por unidade de área }\left(\mathrm{W} / \mathrm{m}^{2}\right) \\
h & =\text { Coeficiente de transferência de calor por convecção }\left(\mathrm{W} / \mathrm{m}^{2} \mathrm{~K}\right) \\
T_{S} & =\text { Temperatura da superfície }(K) \\
T_{\infty} & =\text { Temperatura do fluido }(K) .
\end{aligned}
$$

O coeficiente $h$ possui importância fundamental na determinação da transferência de calor por convecção, tendo sido exaustivamente investigadas equações empíricas para diversas geometrias e condições de ensaio. Quando estudada sobre a ótica generalista da camada limite térmica sobre uma superfície, o coeficiente de convecção local pode ser expressado através da equação (4.12), que relaciona o termo $k_{f}$, ou condutividade térmica do fluido, com o fluxo de calor por condução que ocorre logo na superfície do fluido $(y=0)$. 


$$
h^{\prime}=\frac{-k_{f}\left(\frac{\partial T}{\partial y}\right)_{y=0}}{T_{s}-T_{\infty}}
$$

Uma vez que este coeficiente depende da localização onde é estudado, devese lembrar que costuma-se adotar valores médios para ele. Matematicamente, o coeficiente de transferência de calor por convecção médio, para toda uma superfície, é definido pela integração mostrada na equação (4.13):

$$
h=\frac{1}{A_{s}} \int_{A_{S}} h^{\prime} d A_{S}
$$

Por outro lado, de interesse prático para este trabalho, duas importantes formulações empíricas são mostradas. Em um primeiro caso, Mitschke (1972) propôs que o coeficiente de transferência de calor por convecção, para tambores de freio totalmente expostos ao fluxo de ar, é dado pela equação (4.14):

$$
h=0,1\left(\frac{k_{a}}{D}\right) R e^{2 / 3}
$$

onde:

$$
\begin{aligned}
k_{a} & =\text { Condutividade térmica do } \operatorname{ar}(\mathrm{W} / \mathrm{mK}) \\
D & =\text { Diâmetro externo do tambor }(m) ; \\
R e & =\text { Número de Reynolds (adimensional). }
\end{aligned}
$$

Neste caso, o número de Reynolds é definido pela equação (4.15):

$$
\begin{aligned}
R e=\frac{V \rho_{a} L_{c}}{\mu} & \\
V & =\text { Velocidade do veículo }(\mathrm{m} / \mathrm{s}) \\
\rho_{a} & =\text { Massa específica do } \operatorname{ar}\left(\mathrm{kg} / \mathrm{m}^{3}\right) \\
L_{c} & =\text { Comprimento característico }(\mathrm{m}) ; \\
\mu & =\text { Viscosidade dinâmica do ar }(\mathrm{Pa} . \mathrm{s}) .
\end{aligned}
$$


Uma segunda avaliação para o cálculo deste coeficiente foi proposta por Limpert (1976), baseando em testes in loco de veículos pesados equipados com freios a tambor e mostrada na equação (4.16):

$$
h=18808+67073 \beta V e^{-0,01 V} \quad\left(N m / h K m^{2}\right)
$$

onde:

$\beta=$ Coeficiente adimensional: 0,7 para freios frontais e 0,3 para traseiros;

Dado a natureza dos ensaios realizados, optou-se neste trabalho pelo emprego desta última formulação. Como referência, nota-se que para o veículo parado, $V=0$, obtemos $18808 \mathrm{Nm} / \mathrm{hKm}^{2}$, o que equivale a $5,3 \mathrm{~W} / \mathrm{m}^{2} \mathrm{~K}$.

Radiação térmica é a energia emitida em forma de ondas eletromagnéticas pela matéria que se encontra em uma temperatura não-nula (BERGMAN et al., 2011). A taxa na qual a energia é liberada por uma superfície por unidade de área é conhecida como poder emissivo $E$, que pode ser calculado pela equação (4.17):

$$
E=\varepsilon \sigma T_{s}^{4}
$$

onde $\varepsilon$ é uma propriedade da superfície conhecida como emissividade $(0 \leq \varepsilon \leq 1)$ e $\sigma$ é a constante de Stefan-Boltzmann $\left(\sigma=5.67 \times 10^{-8} \mathrm{~W} / \mathrm{m}^{2} \mathrm{~K}^{4}\right)$. Porém, uma superfície não apenas emite radiação, ela também absorve uma parte da radiação que incide sobre ela, e é proveniente da radiação emitida por outras superfícies. A taxa na qual energia radiante é absorvida por uma superfície é dada pela equação (4.18):

$$
G_{a b s}=\alpha G
$$

sendo $\alpha$ a absortividade da superfície $(0 \leq \alpha \leq 1)$ e $G$ a taxa de energia radiante total que incide sobre a superfície. Para uma superfície cuja vizinhança pode ser considerada uma superfície isotérmica, o valor de $G$ é dado pela radiação emitida pela vizinhança que pode ser aproximada pela equação (4.19), que representa a emissão de um corpo negro: 


$$
G=\sigma T_{v i z}^{4}
$$

Por fim, para tais casos mais simples, a taxa líquida de transferência de calor por radiação saindo da superfície por unidade de área pode ser expressa pela equação (4.20):

$$
q_{r a d}{ }^{\prime}=\varepsilon E-\alpha G
$$

Neste trabalho optou-se por não se considerar a transferência de calor por radiação. Ao serem analisadas as equações fundamentais do fenômeno, vê-se que é preciso considerar outros corpos/superfícies que estejam ao redor do sistema de freio, o que traria desvios ao estudo. Além disso, sua contribuição seria muito menor do que as demais, mas exigindo maior consumo computacional dado que tratam-se de equações de quarta ordem na variável principal (temperatura).

\subsubsection{ENERGIA DE FRENAGEM, MÁXIMA TEMPERATURA E FRACIONAMENTO DE ENERGIA EM FREIOS A TAMBOR}

Durante a frenagem, a energia cinética e potencial de um veículo em movimento são convertidas, principalmente, em energia térmica através do atrito dos freios. Assim, em termos da variação de energia cinética, considerando que toda a energia seja dissipada nos freios, a energia de frenagem $E_{f}(J)$ é dada pela equação (4.21):

$$
E_{f}=\frac{m}{2}\left(V_{1}^{2}-V_{2}^{2}\right)+\frac{I}{2}\left(\omega_{1}^{2}-\omega_{2}^{2}\right)
$$

onde:

$$
\begin{aligned}
m & =\text { Massa do veículo }(\mathrm{m}) \\
V_{1}, V_{2} & =\text { Velocidades inicial e final }\left(\mathrm{m} / \mathrm{s}^{2}\right) ; \\
I & =\text { Momento de inércia de massa das partes girantes }\left(\mathrm{kgm}^{2}\right) ; \\
\omega_{1}, \omega_{2} & =\text { Velocidade angular inicial e final das partes girantes }(1 / \mathrm{s}) .
\end{aligned}
$$


Por sua vez, a potência de frenagem $q_{0}(W)$ é definida pela taxa de variação no tempo da energia absorvida na frenagem, conforme mostra a equação (4.22):

$$
q_{0}=\frac{d E_{f}}{d t}
$$

A potência de frenagem será distribuída entre a lona e o tambor, seguindo a relação entre as resistências térmicas associadas a ambos os lados da interface de contato. Assim, podemos expressar a fração de energia absorvida pelo tambor $\varphi_{t}$ como a razão entre fluxo de calor recebido pelo tambor $\left(q_{t} "\right)$ e o fluxo de calor total produzido, que será recebido pelo tambor e pela lona $\left(q_{t} "+q_{l} "\right)$. Esta razão, por sua vez, pode ser expressa em função das propriedades dos materiais envolvidos. Para o caso de frenagens curtas, esta relação é mostrada na equação (4.23), enquanto que para o caso de frenagens contínuas, é mostrada na equação (4.24):

$$
\begin{aligned}
& \varphi_{t}=\frac{q_{t}{ }^{\prime \prime}}{q_{t}{ }^{\prime \prime} q_{l}}=\frac{1}{1+\left(\frac{\rho_{l} C_{p l} k_{l} \rho_{t} C_{p t} k_{t}}{{ }^{\frac{1}{2}}}\right.} \\
& \varphi_{t}=\frac{q_{t}{ }^{\prime \prime}}{q_{t}{ }^{\prime \prime}+q_{l}^{\prime \prime}}=\left(1+\frac{h_{l} k_{l} k_{s} A_{l}}{h_{t} A_{t}\left(k_{l} k_{s}+\delta_{l} h_{l} k_{s}+\delta_{s} h_{l} k_{l}\right)}\right)^{-1}
\end{aligned}
$$

onde:

$$
\begin{aligned}
A_{t} & =\text { Área do tambor exposta à convecção }\left(\mathrm{m}^{2}\right) \\
A_{l} & =\text { Área da lona exposta à convecção }\left(\mathrm{m}^{2}\right) \\
\rho_{t} & =\text { Massa específica do material do tambor }\left(\mathrm{kg} / \mathrm{m}^{3}\right) \\
\rho_{l} & =\text { Massa específica do material da lona }\left(\mathrm{kg} / \mathrm{m}^{3}\right) \\
C_{p t} & =\text { Calor específico do material do tambor }(\mathrm{J} / \mathrm{kgK}) \\
C_{p l} & =\text { Calor específico do material da lona }(\mathrm{J} / \mathrm{kgK}) \\
k_{t} & =\text { Condutividade térmica do tambor }(\mathrm{W} / \mathrm{mK}) \\
k_{l} & =\text { Condutividade térmica da lona }(\mathrm{W} / \mathrm{mK})
\end{aligned}
$$


$h_{t}=$ Coeficiente de convecção atuante no tambor $\left(W / m^{2} K\right)$;

$h_{l}=$ Coeficiente de convecção atuante na lona $\left(W / m^{2} K\right)$;

$\delta_{l}=$ Espessura da lona $(m)$

$\delta_{l}=$ Espessura do tambor $(m)$.

Para casos mais generalistas, de superfícies planas em contado de deslizamento, como em freios a disco, Belhocine e Bouchetara (2013) mostram que é possível calcular a fração de energia absorvida por uma superfície $A_{1}$ em contato com uma superfície $A_{2}$ através da relações (4.25) a (4.27):

$$
\begin{aligned}
& R=\frac{\sqrt{\rho_{1} C_{1} k_{1}}}{\sqrt{\rho_{2} C_{2} k_{3}}} \cdot \frac{A_{1}}{A_{2}} \\
& \varphi_{1}=q_{0} \frac{R}{1+R} \\
& \varphi_{2}=q_{0} \frac{1}{1+R}
\end{aligned}
$$

Loizou (2012) investigou a fração de energia absorvida por pastilhas e lonas de freio, gerada na Interface Tribo-Layer (ITL), que corresponde a uma nova composição de material gerada por processos físicos e químicos na interface entre discos e pastilhas de freio. Alguns valores de referência são mostrados no gráfico da Figura 4.2 .

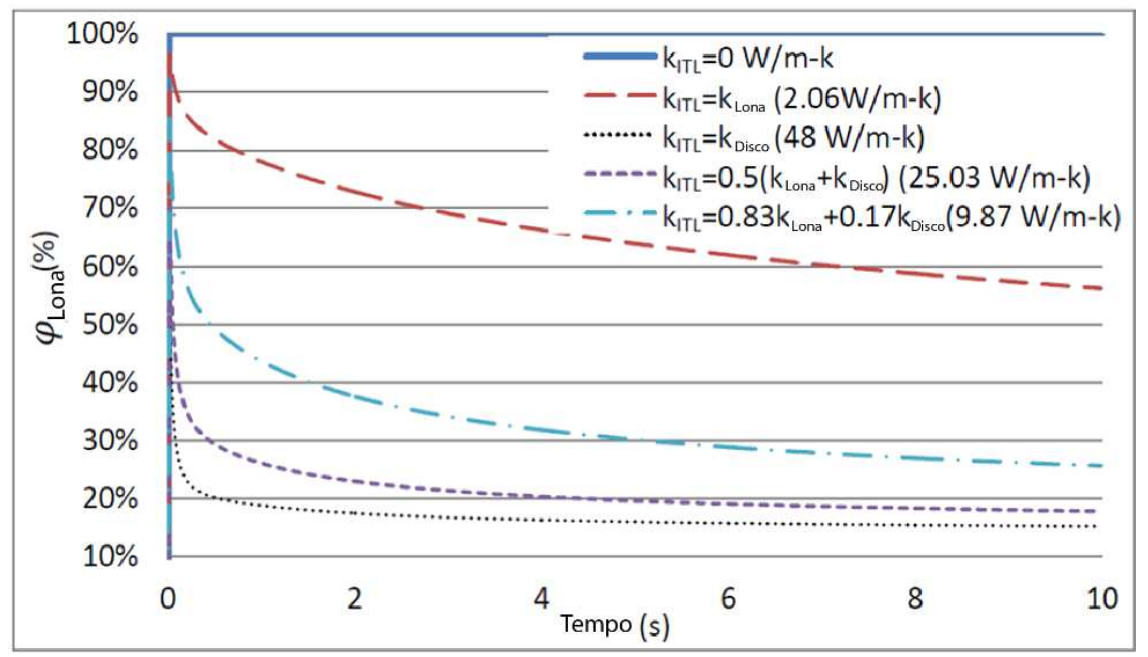

Figura 4.2 - Fração de energia absorvida pela lona para diferentes valores de condutividade térmica (do disco e da pastilha) na ITL (LOIZOU, 2012). 
Para frenagens contínuas, como no caso onde o freio seja acionado em declives, o resfriamento por convecção causa maior influência do que nos demais equacionamentos existentes para o cálculo da temperatura dos componentes (LIMPERT, 1999). Assim, a temperatura final atingida por um tambor de freio, em uma situação de frenagem contínua, pode ser estimada através do estudo da condução de calor transiente em sólidos empregando o método da capacitância global, sendo aplicável ao problema de freios através da equação (4.28):

$$
T=\left(T_{i}-T_{\infty}-\frac{q_{t}}{h A_{t}}\right) e^{-\left(\frac{h A_{t} t}{\rho_{t} c_{p t} v_{t}}\right)}+T_{\infty}+\frac{q_{t}}{h A_{t}}
$$

onde:

$$
\begin{aligned}
T_{i} & =\text { Temperatura inicial }(K) ; \\
q_{t} & =\text { Potência de frenagem absorvida pelo tambor }(W) ; \\
v_{t} & =\text { Volume do tambor }\left(m^{3}\right) ; \\
t & =\operatorname{Tempo}(s) .
\end{aligned}
$$

Em essência, o método baseia-se na premissa de que o sólido possui temperatura uniformemente distribuída no espaço, o que exige a condição de que a resistência à transferência de calor no interior do sólido for muito menor do que a resistência à transferência de calor entre o sólido e sua vizinhança (BERGMAN et al., 2011). O parâmetro adimensional que relaciona a resistência à condução no interior do sólido com a resistência à convecção através da camada limite no fluido é o número de Biot, exposto na equação (4.29) em função do comprimento característico do corpo $\left(L_{c}\right)$, do coeficiente de convecção do meio $(h)$ e do coeficiente de condução do corpo $(k)$ :

$$
B i=\frac{h L_{c}}{k}
$$

De acordo com Bergman et al. (2011), se o número de Biot for menor do que 0,1, então o erro relacionado ao uso do método da capacitância global é pequeno o suficiente. Outro ponto importante relacionado na premissa de temperatura uniforme 
assumida por este método é a de que esta equação será aproximada apenas para o estudo de transferência de calor em pontos localizados no sistema de freio, especificamente nas regiões de maior temperatura.

Outros autores propõem novas abordagens para equacionar a temperatura atingida por diversos tipos de sistema de freio. Olesiak, Pyryev e Yevtushenko (1997) propuseram um equacionamento baseado no emprego de constantes adimensionais para o cálculo da temperatura em semi-espaços deslizantes, considerando-se o desgaste. Já Evtushenko, Ivanik e Horbachova (2000) listaram em seu artigo de revisão outras abordagens empregadas nos 20 anos anteriores, como por exemplo o emprego da dependência empírica entre a dureza dos materiais para freio e seu coeficiente de atrito, ou mesmo o equacionamento de frenagens sobre altas cargas térmicas sendo resfriadas por longo período. Porém, a maior parte dos trabalhos possui enfoque em contextos que dificilmente são aplicáveis a um estudo que não seja aquele em que foram aplicados.

Segundo Limpert (1999), observa-se que poderá haver o surgimento de trincas térmicas na superfície de atrito de tambores de freios no momento em que o fluxo de calor destinado a eles for superior a certo valor, conforme demonstrado na equação (4.30):

$$
q_{\text {perm }}^{\prime \prime}=\frac{q_{0} \emptyset_{i}}{3600 A_{\text {var }}}<170
$$

onde:

$$
\begin{aligned}
q_{\text {perm }} & =\text { Fluxo de calor permissível para o tambor }\left(\mathrm{W} / \mathrm{cm}^{2}\right) \\
q_{0} & =\text { Potência de frenagem dada em } \mathrm{J} / \mathrm{h} \\
\emptyset_{i} & =\text { Razão entre força de frenagem do freio e a total do veículo; } \\
A_{\text {var }} & =\text { Área de varrida no tambor }\left(\mathrm{cm}^{2}\right)
\end{aligned}
$$

Como as unidades adotadas pelo autor referem-se à $W / \mathrm{cm}^{2}$ e $J / h$, podemos facilmente simplificar a equação (4.30) se considerarmos que a razão $q_{0} / A_{\text {var }}$ se refere ao fluxo de calor total gerado na frenagem. Assim, a equação (4.30) é mais claramente representada pela equação (4.31): 


$$
q^{\prime \prime}{ }_{\text {erm }}=q_{0}{ }_{0} \emptyset_{i}<1,70 \frac{M W}{m^{2}}
$$

\subsubsection{Calor gerado por atrito de deslizamento}

Segundo Talati e Jalalifar (2009), as parcelas do fluxo de calor gerado pelo atrito de frenagem podem ser estimadas fazendo-se uso da fração de energia absorvida pelo tambor, definida anteriormente, aplicado à conversão do trabalho dissipativo da força de atrito em calor, por meio das equações (4.32) e (4.33):

$$
\begin{aligned}
& q^{\prime \prime}{ }_{l}=\left(1-\varphi_{t}\right) \mu p r \omega \\
& q^{\prime \prime}{ }_{t}=\varphi_{t} \mu p r \omega
\end{aligned}
$$

onde:

$$
\begin{aligned}
q{ }_{l} & =\text { Fluxo de calor recebido pelo tambor }\left(\mathrm{W} / \mathrm{m}^{2}\right) \\
q^{{ }^{2}}{ }_{t} & =\text { Fluxo de calor recebido pela lona }\left(\mathrm{W} / \mathrm{m}^{2}\right) \\
r & =\text { Raio da superfície de contato }(\mathrm{m}) \\
\omega & =\text { Velocidade angular do tambor }(\mathrm{rad} / \mathrm{s}) . \\
p & =\text { Pressão sobre a lona }\left(\mathrm{N} / \mathrm{m}^{2}\right)
\end{aligned}
$$

Analisando as equações (4.32) e (4.33), vemos que o produto $\mu p$ refere-se à tensão de cisalhamento superficial por atrito $\tau$, enquanto que $r \omega$ refere-se à velocidade escalar de deslizamento entre os corpos em contato, $V$. Desta forma, uma maneira mais prática é mostrada nas equações (4.34) e (4.35):

$$
\begin{aligned}
q^{\prime \prime}{ }_{l} & =\left(1-\varphi_{t}\right) \tau V \\
q^{\prime \prime}{ }_{t} & =\varphi_{t} \tau V
\end{aligned}
$$




\subsection{Conceitos DE TERMOELASTICIDADE}

A termoelasticidade é um campo que trata do equilíbrio dos corpos no regime elástico tratando-os como sistemas termodinâmicos. Estuda-se a interação de corpos com o ambiente através do acoplamento dos efeitos forças externas e condutividade térmica.

A teoria, que hoje é considerada uma ciência fundamentada, iniciou-se com a introdução do termo das dilatações na equação da condutividade térmica por Duhamel (1837), mas apenas foi plenamente justificada por Biot (1956), que considerou a equação da condutividade térmica baseada na termodinâmica de fenômenos irreversíveis. Suas equações diferenciais governantes foram sendo formuladas, enquanto cada vez mais métodos para solucioná-las, e associá-las a teoremas variacionais, vêm sendo derivados (NOWACKI, 1970).

A dedução matemática explicada por Nye (1957) inicia-se considerando os nove componentes do tensor de tensões $\sigma_{i j}$ e a temperatura $T$ como variáveis independentes que representem o estado de um sólido, podemos dizer que o tensor de deformações $\varepsilon_{i j}$ e a entropia $S$ podem então serem determinadas.

Considerando um volume diferencial, as equações (4.36) e (4.37) indicam a base para o acoplamento das duas disciplinas:

$$
\begin{gathered}
d \varepsilon_{i j}=\left(\frac{\partial \varepsilon_{i j}}{\partial \sigma_{k l}}\right)_{T} d \sigma_{k l}+\left(\frac{\partial \varepsilon_{i j}}{\partial T}\right)_{\sigma} d T \\
d S=\left(\frac{\partial S}{\partial \sigma_{k l}}\right)_{T} d \sigma_{k l}+\left(\frac{\partial S}{\partial T}\right)_{\sigma} d T
\end{gathered}
$$

Quanto ao lado direito da equação (4.36), o primeiro termo se refere à elasticidade do material, enquanto o segundo à sua expansão térmica. Já para o lado direito da equação (4.37), o primeiro termo se refere ao efeito piezocalorífico e o segundo à capacidade térmica do sólido. Em ambos os casos, o índice inferior se refere a derivação considerando temperatura ou tensão constantes.

Para definir a relação de dependência entre os quatro efeitos descritos acima deve-se considerar a energia do sistema. Da primeira lei da termodinâmica para um volume diferencial, tem-se que um aumento da energia interna $d U$ é resultado de uma 
entrada de calor $d Q$ e uma quantidade de trabalho realizado sobre a fronteira do corpo $d W$, relação representada pela equação (4.38):

$$
d U=d W+d Q
$$

Nye (1957) demonstra que o trabalho realizado por uma componente do tensor de tensões agindo sobre uma face de um cubo elementar é dada pela equação (4.39):

$$
d W=\sigma_{i j} d \varepsilon_{i j}
$$

Por sua vez, da segunda lei da termodinâmica para uma transformação reversível, tem-se a equação (4.40):

$$
d Q=T d S
$$

Assim, pode-se reescrever a equação (4.38) como a equação (4.41):

$$
d U=\sigma_{i j} d \varepsilon_{i j}+T d S
$$

Neste ponto, pode-se definir uma nova função $\Phi$, através da equação (4.42):

$$
\Phi=U-\sigma_{i j} \varepsilon_{i j}-T S
$$

que, quando diferenciada, torna a forma da equação (4.43):

$$
d \Phi=d U-\sigma_{i j} d \varepsilon_{i j}-d \sigma_{i j} \varepsilon_{i j}-T d S-S d T
$$

Combinando a equação (4.43) com a equação (4.41) obtêm-se a equação (4.44):

$$
d \Phi=-\sigma_{i j} d \varepsilon_{i j}-S d T
$$


Na definição de $\Phi$ pela equação (4.42), os seus termos são função de $\left(\sigma_{i j}, T\right)$. Assim, a própria função $\Phi$ é função de $\left(\sigma_{i j}, T\right)$ e, assim, da equação (4.41), tem-se as equações (4.45) e (4.46):

$$
\begin{aligned}
& \left(\frac{\partial \Phi}{\partial \sigma_{i j}}\right)_{T}=-\varepsilon_{i j} \\
& \left(\frac{\partial \Phi}{\partial T}\right)_{\sigma}=-S
\end{aligned}
$$

que podem ser novamente diferenciadas em $T$ e $\sigma_{i j}$ (primeira e segunda, respectivamente), provendo uma terceira relação entre termodinâmica e elasticidade (equação (4.47)):

$$
-\frac{\partial^{2} \Phi}{\partial \sigma_{i j} \partial T}=\left(\frac{\partial \varepsilon_{i j}}{\partial T}\right)_{\sigma}=\left(\frac{\partial S}{\partial \sigma_{i j}}\right)_{T}
$$

Com respeito às equações (4.36) e (4.37), observa-se a relação entre coeficientes de expansão térmica e coeficientes que fornecem o efeito piezocalorífico, que formam matrizes simétricas dos lados direitos destas equações.

Considerando-se que as propriedades do material serão sempre aproximadamente lineares sobre pequenas variações, e então, para pequenas variações de tensão e temperatura, as equações podem ser integradas e expostas matricialmente usando um artifício de simplificação de notação tensorial em matricial demonstrado por Nye (1956), expondo melhor o acoplamento termoelástico sob a forma das equações (4.48) e (4.49):

$$
\begin{aligned}
& \boldsymbol{\varepsilon}=\boldsymbol{D}^{-1} \boldsymbol{\sigma}+\boldsymbol{\alpha}\left(T-T_{\text {ref }}\right) \\
& \Delta S=\boldsymbol{\alpha}^{\boldsymbol{T}} \boldsymbol{\sigma}+\left(\frac{\rho C^{\sigma}}{T}\right)\left(T-T_{r e f}\right)
\end{aligned}
$$

Nesta equação, $\rho C^{\sigma}$ refere-se à capacidade térmica à uma tensão constante, semelhante ao caso tradicional de pressão constante. Quanto aos termos vetoriais, $\boldsymbol{\varepsilon}$ simboliza o vetor de deformações, $\boldsymbol{\sigma}$ o vetor de tensões, $\boldsymbol{\alpha}$ o vetor dos coeficientes de 
expansão térmica e $\boldsymbol{D}^{-1}$ a matriz de flexibilidade (inversa da matriz de rigidez), dados pelas equações $(4.50)$ a (4.53):

$$
\begin{aligned}
\boldsymbol{\varepsilon} & =\left\{\varepsilon_{x} \varepsilon_{y} \varepsilon_{z} \gamma_{x y} \gamma_{y z} \gamma_{x z}\right\}^{T} \\
\boldsymbol{\sigma} & =\left\{\sigma_{x} \sigma_{y} \sigma_{z} \sigma_{x y} \sigma_{y z} \sigma_{x z}\right\}^{T} \\
\boldsymbol{\alpha} & =\left\{\alpha_{x} \alpha_{y} \alpha_{z} 000\right\}^{T} \\
\boldsymbol{D}^{-1} & =\left[\begin{array}{ccccccc}
\frac{1}{E_{x}} & -\frac{v_{x y}}{E_{x}} & -\frac{v_{x z}}{E_{x}} & 0 & 0 & 0 \\
-\frac{v_{y x}}{E_{y}} & \frac{1}{E_{y}} & -\frac{v_{y z}}{E_{y}} & 0 & 0 & 0 \\
-\frac{v_{z x}}{E_{z}} & -\frac{v_{z y}}{E_{z}} & \frac{1}{E_{z}} & 0 & 0 & 0 \\
0 & 0 & 0 & \frac{1}{G_{x y}} & 0 & 0 \\
0 & 0 & 0 & 0 & \frac{1}{G_{y z}} & 0 \\
0 & 0 & 0 & 0 & 0 & \frac{1}{G_{x z}}
\end{array}\right]
\end{aligned}
$$

As tensões e deformações equivalentes totais podem ser representadas aplicando as equações (4.48) e (4.49) a partir da equação de Von Mises para tensões (4.54) e deformações (4.55):

$$
\begin{aligned}
& \sigma_{e}=\left(\frac{1}{2}\left[\left(\sigma_{x}-\sigma_{y}\right)^{2}+\left(\sigma_{y}-\sigma_{z}\right)^{2}+\left(\sigma_{x}-\sigma_{z}\right)^{2}+6\left(\sigma_{x y}^{2}+\sigma_{y z}^{2}+\sigma_{x z}^{2}\right)\right]\right)^{\frac{1}{2}} \\
& \varepsilon_{e}=\frac{1}{\sqrt{2}(1+v)}\left[\left(\varepsilon_{x}-\varepsilon_{y}\right)^{2}+\left(\varepsilon_{y}-\varepsilon_{z}\right)^{2}+\left(\varepsilon_{x}-\varepsilon_{z}\right)^{2}+\frac{3}{2}\left(\gamma_{x y}^{2}+\gamma_{y z}^{2}+\gamma_{x z}^{2}\right)\right]^{\frac{1}{2}}
\end{aligned}
$$





\section{ESTUDO DE CASO}

O trabalho proposto teve como motivação inicial estudar a geração de energia em processos de frenagens para freios a tambor utilizados em veículos pesados de transporte de cargas, como caminhões, ônibus, chassi plataforma, reboque ou semireboque, e semelhantes.

Em especial, o trabalho foca no funcionamento do modelo Camo $S$, tamanho 16,5 " x 8", baseado no modelo Q-Plus da fabricante de componentes automotivos Meritor ${ }^{\circledR}$ exemplificado pela Figura 5.1. Este modelo de freio está presente hoje em mais de $95 \%$ dos implementos rodoviários que circulam no Brasil, além de ser utilizado em veículos extra pesados, em que a capacidade superior de torque é exigida (MASTER, 2015).

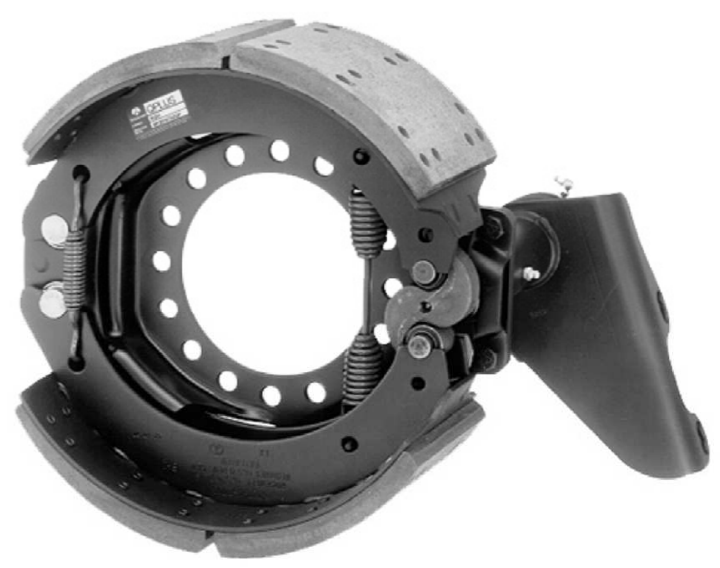

Q Plus ${ }^{\mathrm{TM}}$

Figura 5.1 - Sistema de acionamento de freio a tambor do tipo Camo S (MERITOR, 2006)

Em certas condições de operação, as temperaturas e esforços neste modelo de freio a tambor podem chegar a valores muito altos. Com relação às temperaturas, ensaios de dinamômetro com captação por câmera termográfica mostram que, com facilidade, os valores máximos obtidos para o freio do tipo Camo $S$ ultrapassam os $260^{\circ} \mathrm{C}$ (WEBB, 2015). Com relação à elasticidade, o sistema apresenta um perfil de distribuição de pressão obtido experimentalmente ao longo da região de contato, com valores máximos em operação que superam $360 \mathrm{MPa}$, e deformações acima de 0,0014 (SUH; JEE, 2009). 
Conforme discutido nos capítulos anteriores, convencionalmente o tambor de freio é fabricado em ferro fundido cinzento. Para fins práticos deste trabalho, a Tabela 5.1 lista as principais propriedades físicas de uma classe geral deste material segundo o Handbook da ASM (1990).

Tabela 5.1 - Propriedades físicas de uma classe geral de Ferro Fundido Cinzento (ASM, 1990).

\begin{tabular}{cc}
\hline Propriedade & Valor \\
\hline Módulo de Elasticidade $(E)$ & $160 \mathrm{GPa}$ \\
Coeficiente de Poisson $(v)$ & 0,28 \\
Massa específica $(\rho)$ & $7150 \mathrm{~kg} / \mathrm{m}^{3}$ \\
Condutividade térmica $(K)$ & $46,861 \mathrm{~W} / \mathrm{m}^{2} \mathrm{~K}$ \\
Coeficiente de expansão térmica $(\alpha)$ & $1,05 \times 10^{-5} 1 / \mathrm{K}$ \\
Calor específico $(c)$ & $603 \mathrm{~J} / \mathrm{kgK}(20$ a $700 \stackrel{\circ}{ } \mathrm{C})$ \\
\hline
\end{tabular}

Por sua vez, as sapatas são fabricadas em aço-carbono forjado ou soldado. A Tabela 5.2 lista as propriedades físicas de uma categoria comum de aço-carbono, dado a grande variedade de composições utilizadas na indústria de freios.

Tabela 5.2 - Propriedades físicas de uma categoria genérica de aço-carbono, empregado na fabricação de sapatas e pastilhas de freio (ASM, 1990).

\begin{tabular}{cc}
\hline Propriedade & Valor \\
\hline Módulo de Elasticidade $(E)$ & $200 \mathrm{GPa}$ \\
Coeficiente de Poisson $(v)$ & 0,3 \\
Massa específica $(\rho)$ & $7850 \mathrm{~kg} / \mathrm{m}^{3}$ \\
Condutividade térmica $(K)$ & $60 \mathrm{~W} / \mathrm{m}^{2} \mathrm{~K}$ \\
Coeficiente de expansão térmica $(\alpha)$ & $1,2 \times 10^{-5} 1 / \mathrm{K}$ \\
Calor específico $(c)$ & $434 \mathrm{~J} / \mathrm{kgK}$ \\
\hline
\end{tabular}

Por fim, as propriedades físicas do material de atrito empregadas neste trabalho são listadas na Tabela 5.3. Estes dados foram gentilmente cedidos pela empresa nacional do ramo de fabricação de equipamentos de segurança automotiva Fras-Le ${ }^{\circledR}$. 
Tabela 5.3 - Propriedades físicas do material de atrito usado em lonas de freio a tambor para veículos pesados (Fonte: Fras-Le ${ }^{\circledR}$ ).

\begin{tabular}{cc}
\hline Propriedade & Valor \\
\hline Coeficiente de atrito com Fofo $(\mu)$ & 0,4 \\
Módulo de Elasticidade $(E)$ & $1 \mathrm{GPa}$ \\
Coeficiente de Poisson $(v)$ & 0,2 \\
Massa específica $(\rho)$ & $2000 \mathrm{~kg} / \mathrm{m}^{3}$ \\
Condutividade térmica $(K)$ & $1,4 \mathrm{~W} / \mathrm{m}^{2} \mathrm{~K}$ \\
Coeficiente de expansão térmica $(\alpha)$ & $1 \times 10^{-5} 1 / \mathrm{K}$ \\
Calor específico $(c)$ & $900 \mathrm{~J} / \mathrm{kgK}$ \\
\hline
\end{tabular}

As dimensões básicas do freio a tambor do tipo Camo $S$ foram baseadas em informações obtidas junto à fabricante nacional Fras-Le ${ }^{\circledR}$, além dos catálogos do fabricante de componentes automotivos Meritor ${ }^{\circledR}$. As dimensões finais foram simplificadas e convertidas para milímetros e são ilustradas na Figura 5.2.
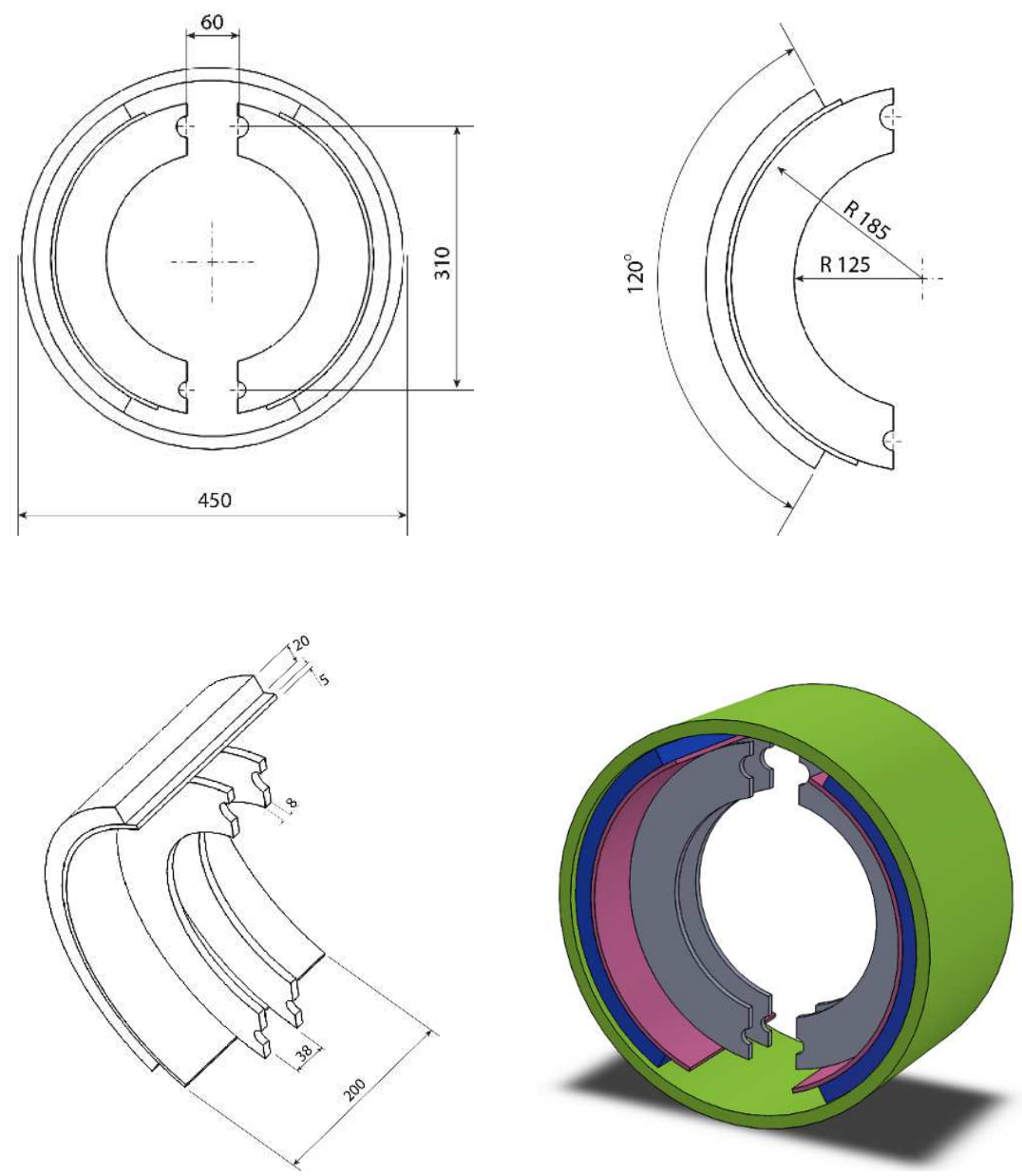

Figura 5.2 - Dimensões do sistema de freio simplificado em $\mathrm{mm}$. 


\subsection{Metodologia utilizada}

Uma análise acoplada é uma combinação de análises de diferentes áreas da física, que interagem para solucionar um problema global de engenharia, o que explica a referência ao uso do nome "análise multifísica". Nestes casos, a entrada de dados de um campo depende dos resultados do outro.

Algumas análises possuem apenas um caminho único. Por exemplo, em uma análise de tensões térmicas, o campo de temperaturas introduz deformações na estrutura, mas as deformações não são capazes de afetar a distribuição de temperaturas. Casos mais complicados exigem a transferência de resultados em ambos os caminhos, o que acaba por requerer cálculos iterativos que necessitem convergirem para cada etapa da solução. Alguns exemplos de aplicação de análises com acoplamento multifísico são vasos de pressão e sistemas de freio (termoelasticidade), constritores de fluxo de fluidos (interação fluido-estrutura), calor por indução (análise termomagnética), transdutores ultrassônicos (análise piezoelétrica), etc.

A forma mais prática de se aplicar acoplamentos de diferentes campos das ciências físicas em elementos finitos é por meio da inserção das equações representativas de cada campo nas matrizes do sistema numérico, o que configura o chamado "método direto". Nesta forma, a análise acoplada é realizada em uma única etapa usando elementos de acoplamento multifísico. Tais elementos possuem todos os graus de liberdade necessários, e lidam com 0 problema incluindo 0 equacionamento de cada caso em suas matrizes.

Para o caso do acoplamento termoelástico, deve-se selecionar os elementos apropriados para análises multifísicas e, então, indicar através de suas keyoptions que devem ser acoplados. Assim, é apresentado na Figura 5.3 o elemento Solid226, sólido tridimensional, inicialmente hexaédrico de segunda ordem (20 nós por elemento), com opção de ser usado em forma prismática e tetraédrica. 

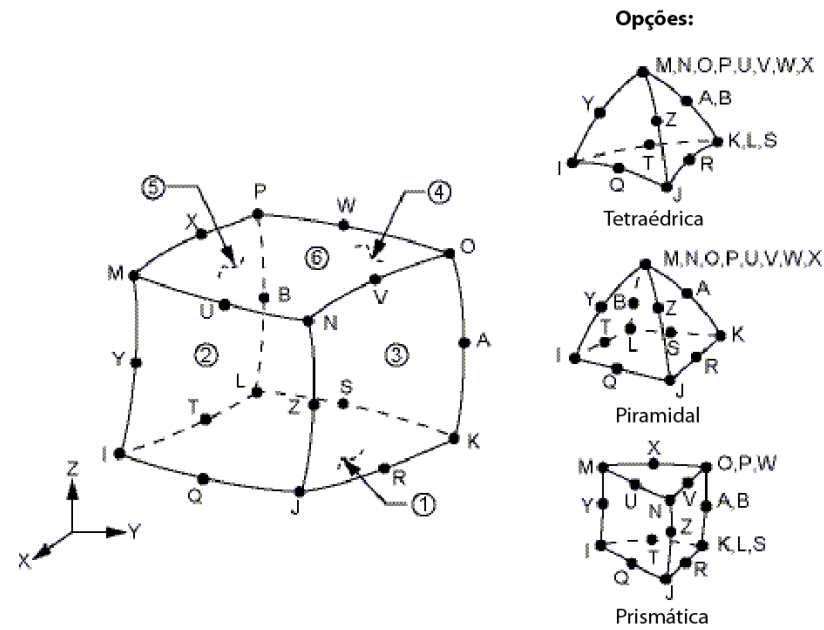

Figura 5.3 - Representação do elemento Solid226 utilizado para acoplamentos multifísicos

Quando utilizado em análises termoelásticas, o elemento, então com quatro graus de liberdade (UX, UY, UZ e Temperatura), gera um novo sistema de matrizes, empregando princípios variacionais na equação do movimento e conservação do fluxo de calor, acoplados pelas equações constitutivas da termoelasticidade (4.48) e (4.49) resultando na equação (4.56):

$$
\left[\begin{array}{cc}
{[M]} & 0 \\
0 & 0
\end{array}\right]\left\{\begin{array}{l}
\{\ddot{\ddot{u}}\} \\
\{\ddot{T}\}
\end{array}\right\}+\left[\begin{array}{cc}
{[C]} & 0 \\
{\left[C^{t u}\right]} & {\left[C^{t}\right]}
\end{array}\right]\left\{\begin{array}{l}
\{\dot{u}\} \\
\{\dot{T}\}
\end{array}\right\}+\left[\begin{array}{cc}
{[K]} & {\left[K^{t u}\right]} \\
0 & {\left[K^{t}\right]}
\end{array}\right]\left\{\begin{array}{l}
\{\ddot{u}\} \\
\{T\}
\end{array}\right\}=\left\{\begin{array}{c}
\{F\} \\
\{Q\}
\end{array}\right\}
$$

onde:

$[M]=$ Matriz de massa do elemento;

$[C]=$ Matriz de amortecimento estrutural do elemento;

$[K]=$ Matriz de rigidez do elemento;

$\{u\}=$ Vetor deslocamento;

$\{F\}=$ Soma das forças nodais sobre $o$ elemento;

$\left[C^{t}\right]=$ Matriz de calor específico do elemento;

$\left[K^{t}\right]=$ Matriz de condutividade térmica do elemento;

$\{T\}=$ Vetor temperatura;

$\{Q\}=$ Soma das cargas de geração de calor no elemento;

$\left[C^{t u}\right]=$ Matriz de amortecimento termoelástico do elemento. 
O principal requisito para uma simulação de transferência de esforços por atrito é de que o contato entre as partes que possuem movimento relativo entre si seja modelado de acordo com as formulações numéricas de contato por atrito disponíveis, independentemente de possíveis dificuldades em sua implementação. Assim, o contato entre as lonas e a superfície interna do tambor foi realizado por meio da sobreposição de elementos de superfície sobre os nós destas superfícies. Os nós da superfície interna do tambor foram recobertos por elementos TARGET170, indicados para superfícies 3-D, enquanto os nós das superfícies externas das sapatas foram recobertos por elementos CONTA174, elementos de segunda ordem, com possibilidade de emprego de graus de liberdade de deslocamento e temperatura e boa resposta em deslizamento e atrito. A união interna entre os dois tipos de elementos citados acima é feita empregando uma única tabela de constantes reais (Real Constants) para ambos, que são valores de propriedades específicas para cada elemento a serem empregadas nos cálculos internos do programa. O conceito de par "Contact - Target" vêm sendo amplamente empregado simulações de elementos finitos. Os principais atributos dos pares de contato formulados neste trabalho são o coeficiente de atrito, a condutividade térmica de contato (TCC), e os fatores que definem a quantidade de energia mecânica dissipada na forma de calor (FGHT) e a parcela de calor inicialmente direcionada a cada superfície (FWGT), cada um escolhido pensando em se manter a transferência de calor no contato intacta. A escolha destes e outros parâmetros são exibidos na Tabela 5.4.

Tabela 5.4 - Parâmetros adotados para os elementos de contato de atrito

\begin{tabular}{ccccccc}
\hline TCC & FGHT & FWGT & $\boldsymbol{\mu}$ & Formulação & Detecção & $\begin{array}{c}\text { Rigidez } \\
\text { Normal }\end{array}$ \\
\hline $1 \times 10^{5}$ & 1 & 0,5 & $\begin{array}{c}\text { Cada } \\
\text { caso }\end{array}$ & $\begin{array}{c}\text { Lagrangeana } \\
\text { aumentada }\end{array}$ & $\begin{array}{c}\text { Projeção de } \\
\text { superfícies }\end{array}$ & 0,1 \\
\hline
\end{tabular}

A subdivisão das cargas foi feita com aplicação de diferentes passos de carregamento, ou Load Steps. Em todos os casos, o primeiro Load Step foi responsável pela acomodação dos modelos sobre efeito de compressão, no caso forças aplicadas às sapatas. Já o segundo Load Step é responsável pela aplicação do esforço de giro, 
seja um torque equilibrado estaticamente pelas lonas, seja uma rotação aplicada através de velocidade de deslizamento relativa.

\subsubsection{SEQUÊnCIAMENTO dAS ETAPAS do ESTUdo}

A Figura 5.4 mostra o fluxograma da implementação dos modelos em estudo.

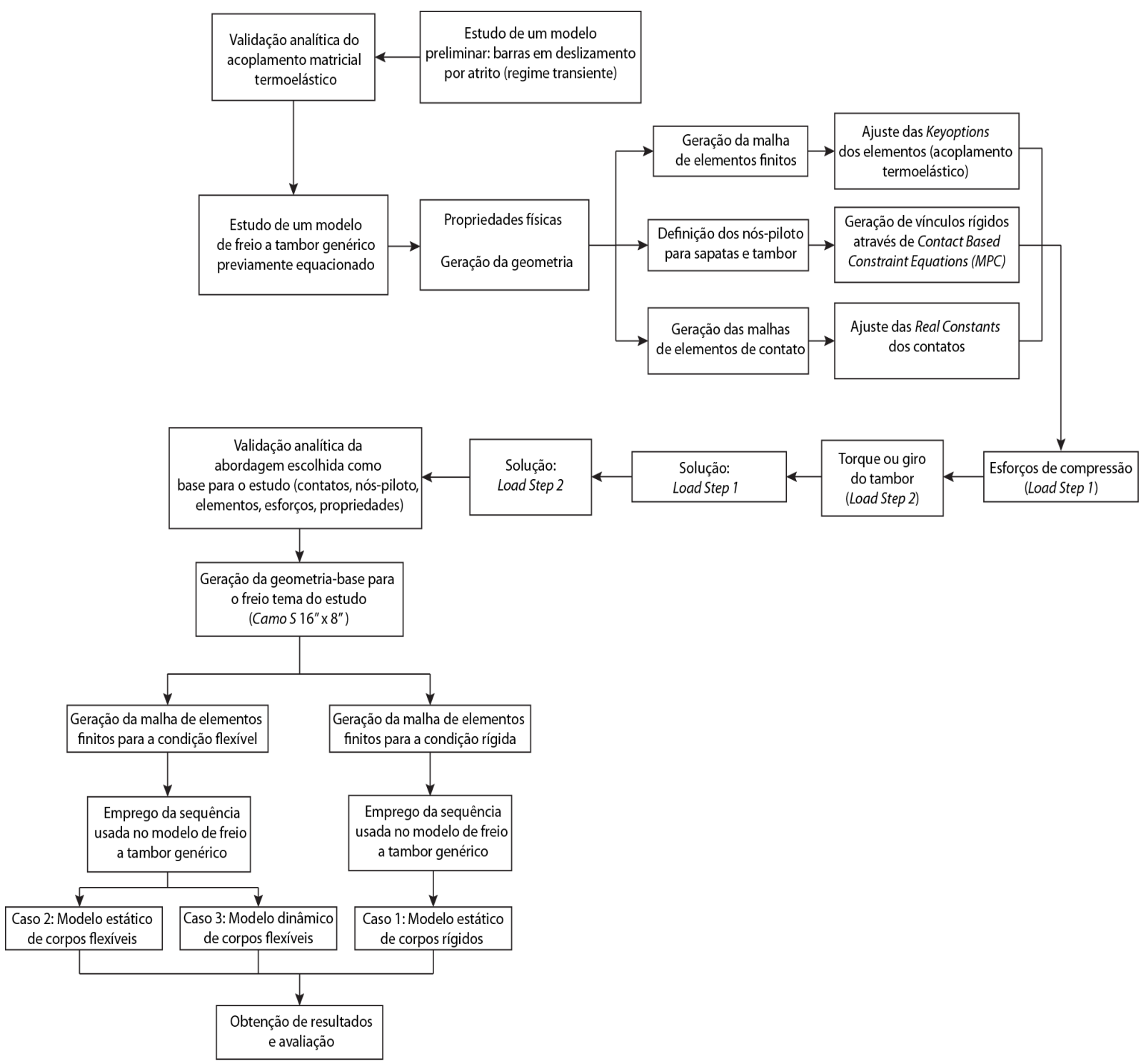

Figura 5.4 - Fluxograma da implementação do estudo. 


\subsection{ESTUDO PRELIMINAR DO DESLIZAMENTO ENTRE UM BLOCO E UMA BARRA}

Em uma primeira etapa, foram realizados ensaios em modelos bi e tridimensionais representando um sistema simples de bloco e barra em atrito, a fim de verificar a validade da aplicação numérica do conceito de termoelasticidade feito pelo software. Optou-se pela realização de um estudo em regime transiente, afim de forçar o sistema a calcular os resultados com maior detalhamento, considerando as variações no tempo. A Figura 5.5 (a) apresenta o modelo tridimensional e (b) sua malha.

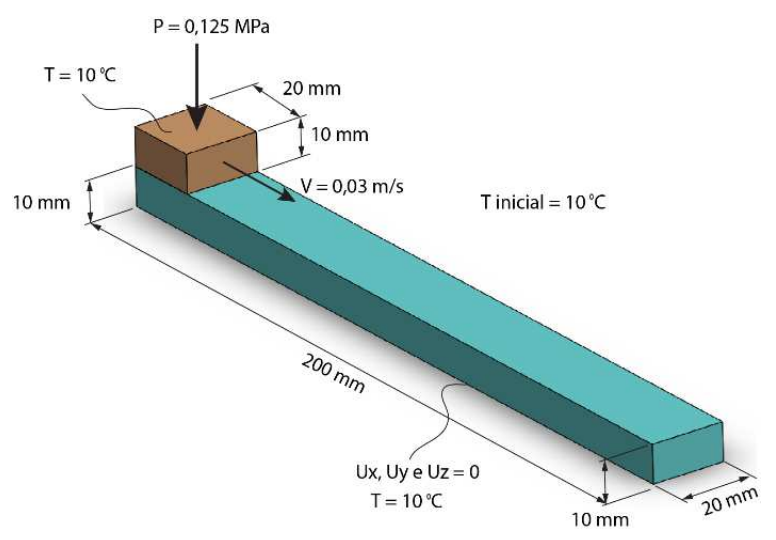

(a)

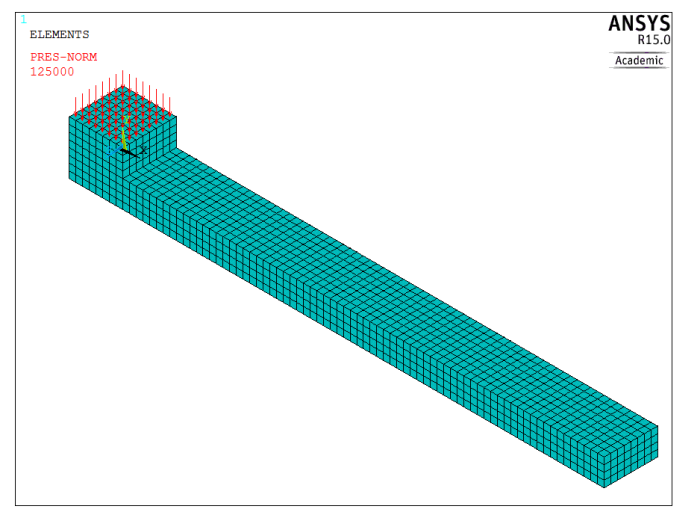

(b)

Figura 5.5 - Dimensões e malha de elementos finitos condições aplicadas a um primeiro modelo considerando os efeitos termoelásticos.

As condições escolhidas são ilustradas na imagem e seus valores mostrados na Tabela 5.5, onde os valores de $T_{\text {ref }}$ e $T_{\text {unif }}$ referem-se à temperatura de referência para cálculos de dilatação térmica e à temperatura inicial do modelo, respectivamente.

Tabela 5.5 - Valores empregados na simulação de barras em atrito dinâmico.

\begin{tabular}{|c|c|c|c|c|c|}
\hline$T_{r e f}$ & $T_{\text {unif }}$ & Restrições & $\boldsymbol{V}$ & $P$ & $\mu$ (aço-aço) \\
\hline $10 \stackrel{\circ}{\circ}$ & $10^{\circ} \mathrm{C}$ & $\begin{array}{c}\text { Ux, Uy, Uz =0 } \\
T=10^{\circ} \mathrm{C}\end{array}$ & $0,03 \mathrm{~m} / \mathrm{s}$ & $0,125 \mathrm{MPa}$ & 0,3 \\
\hline
\end{tabular}

Neste caso, a equações (4.26) a (4.28) são as que melhor descrevem a fração de energia direcionada a cada superfície,e por se tratar de um modelo simples de contato aço/aço a razão entre as raízes da equação (4.26) torna-se igual a 1. Logo: 


$$
\begin{gathered}
R=\frac{A_{1}}{A_{2}}=\frac{A_{\text {barra }}}{A_{\text {bloco }}}=\frac{4 \times 10^{-3}}{4 \times 10^{-4}}=10 \\
\varphi_{1}=\frac{R}{1+R}=90,9 \%(\text { barra }) \\
\left.\varphi_{2}=\frac{1}{1+R}=9,1 \% \text { (bloco }\right)
\end{gathered}
$$

A partir das equações (4.34) e (4.35), pode-se estimar o fluxo de calor total e direcionado para cada face em contato nesta simulação:

$$
\begin{gathered}
q^{\prime \prime}{ }_{\text {total }}=\tau V= \\
q_{1}=0,909 q^{\prime \prime}{ }_{\text {total }}=1022,6 \frac{\mathrm{W}}{\mathrm{m}^{2}} \\
q_{2}=0,091 q^{\prime \prime}{ }_{\text {total }}=102,4 \frac{\mathrm{W}}{\mathrm{m}^{2}}
\end{gathered}
$$

De posse do fluxo de calor direcionado para cada corpo, podemos estimar o gradiente de temperatura a ser atingida em regime permanente através da Lei de Fourier, equação (4.6):

$$
q^{\prime \prime}=-k \frac{d T}{d x} \rightarrow 1022,6=-60 \times \frac{\Delta T}{0,01} \rightarrow \Delta T=-0,17 \rightarrow T_{2}=10,17^{\circ} \mathrm{C}
$$

Ambos os resultados, fluxo de calor em cada área e temperatura máxima na interface de contato por atrito puderam ser verificados no pós-processamento do modelo, com resultados exibidos na Figura 5.6.

Do lado esquerdo está plotado o contorno de cores para o fluxo de calor na direção $\mathrm{Y}$, em uma seção em corte que expõe o interior de ambos os corpos. Nota-se que o fluxo de calor direcionado para o bloco é de $390,7 \mathrm{~W} / \mathrm{m}^{2}$, e para a barra é de $1283,8 \mathrm{~W} / \mathrm{m}^{2}$, totalizando $1674,5 \mathrm{~W} / \mathrm{m}^{2}$. Assim, $\varphi_{1}=76,7 \%$ e $\varphi_{2}=23,3 \%$. Por sua vez, a temperatura sofre uma elevação máxima de $0,05^{\circ} \mathrm{C}$. Nota-se que foram obtidos valores próximos dos calculados, mas não idênticos devido à consideração de uma geometria tridimensional, do pouco tempo de análise que distancia o modelo de um possível regime permanente e, principalmente, de possíveis erros numéricos de contato, o que pode ser deduzido pela concentração excessiva de fluxo de calor 
direcionado à barra em um ponto, indicado como valor mínimo na Figura 5.6 (a) por se tratar de uma grandeza vetorial, onde o sistema cartesiano global orienta o eixo y para cima.

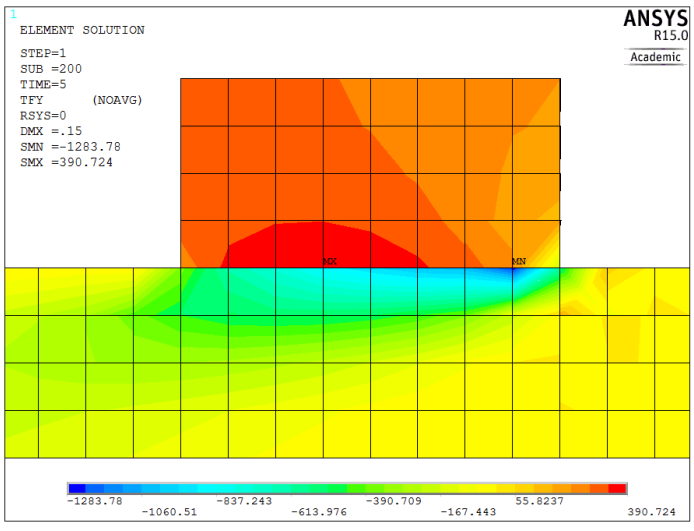

(a)

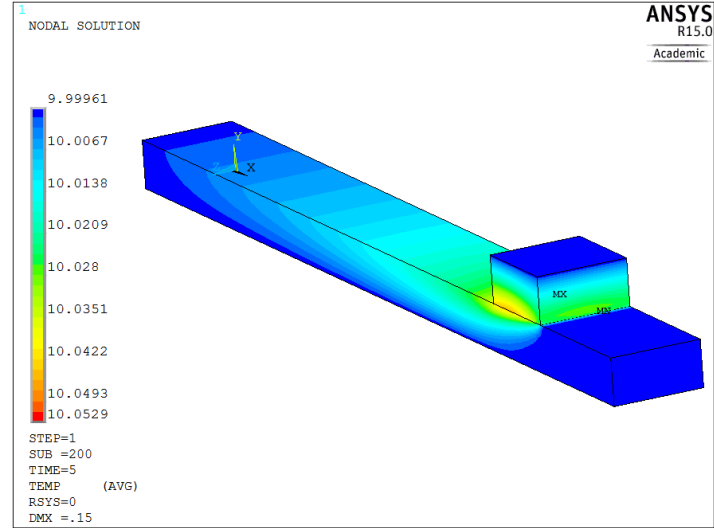

(b)

Figura 5.6 - Resultados obtidos para o modelo de barras sob influência de atrito de deslizamento: (a) Fluxo de calor em Y com máximo valor em 1283,7 W/m² para a barra; (b) Temperaturas com máximo valor em $10,053 \stackrel{\circ}{\circ}$.

Assim, pode-se concluir que as condições de contato e elemento escolhido inicialmente satisfazem os princípios básicos da termoelasticidade. Entretanto, devese ressaltar que, uma vez que modelos em regime transiente exigem o emprego das forças de inércia $[M]\{\ddot{u}\}$ e amortecimento $[C]\{\dot{u}\}$, além da necessidade de integração dos resultados no tempo, o que acaba por exigir um maior número de soluções, mesmo em casos tão simples quanto este o gasto computacional é elevado. Em um computador equipado com processador Intel i7 com 3.40 Ghz de frequência e 12 GB de memória RAM, o modelo necessitou em torno de 40 minutos para atingir os resultados finais. Além disso, notou-se uma grande dificuldade na adaptação dos elementos em contato deslizante, o que trouxe problemas de convergência para situações onde a solicitação fosse aumentada, como por exemplo um aumento da velocidade de deslizamento. Portanto, deve-se ter em mente que simulações dinâmicas em regime transiente são, por natureza, muito custosas, e a inclusão de não linearidades, tais como esforços de atrito por deslizamento, acabam por exigir tempo de computação muito alto para computadores de baixo custo. 


\subsection{ESTUDO PRELIMINAR APLICADO A FREIOS: VALIDAÇÃO DE UM MODELO SIMPLES}

Dado a complexidade deste tipo de análise, é necessário que se realize um primeiro estudo a fim de se verificar a confiabilidade dos parâmetros usados na modelagem, tais como: adequação do elemento escolhido; adequação da formulação de contato para as regiões em atrito; da forma de fixação do tipo "nó-piloto" adotada para o tambor; da resposta dos deslocamentos e reações de apoio nos nós-piloto das sapatas.

Para isso, optou-se por reproduzir um modelo calculado analiticamente por Budynas e Nisbett (2011) e comparar os resultados. Neste modelo, apresentado na Figura 5.7, os autores calcularam os esforços admissíveis e as reações de apoio nos pinos para o material da lona de freio com emprego das equações (4.1) a (4.5). Como trata-se, basicamente, de um problema geométrico, os autores não precisaram de outros dados que não fossem a tensão de compressão admissível nas lonas, em 1 $\mathrm{MPa}$, e o coeficiente de atrito entre o par lona-tambor, em 0,32.

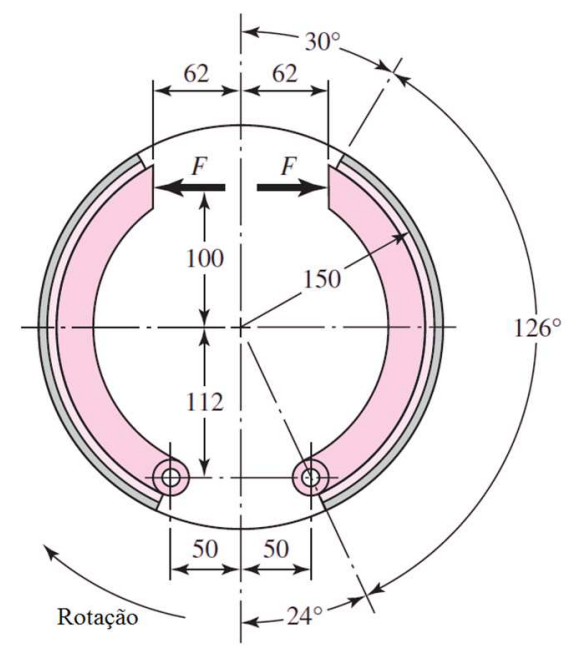

Figura 5.7 - Freio genérico com sapatas internas expansíveis; dimensões em milímetros (BUDYNAS; NISBETT, 2011).

Para adequar o modelo de elementos finitos à hipótese de sapatas e tambores rígidos, fez-se uso de 5 nós-piloto:

- No tambor, um nó-piloto foi responsável por reger sua superfície externa, com a opção de manter esta superfície rígida, mantendo apenas o GDL 
de rotação em z livre. Assim, mesmo que os elementos do tambor possam ser comprimidos por serem flexíveis, seu comportamento final é de corpo rígido, i.e. não há permissão de expansão de seu raio externo. A vantagem, observada pelo autor, nesta técnica é de que mantemos os benefícios da formulação Augmented Lagrange para contatos de atrito, que exige o uso de corpos flexíveis.

- Nas sapatas, optou-se por empregar 2 nós pilotos em cada uma, e em cada caso, ambos são vinculados à mesma superfície interna. Os nós superiores representam o ponto de aplicação das forças horizontais, enquanto os nós inferiores representam o vínculo cilíndrico da sapata rígida, mantendo apenas o GDL de rotação em z livre.

A Figura 5.8 mostra as ligações que vinculam equações de restrição rígidas entre os nós-pilotos e os nós das superfícies do tambor e das sapatas. O software ANSYS ${ }^{\circledR}$ V.15 fornece várias maneiras de realizar este tipo de ligação. Dado a simplicidade de implementação, optou-se por empregar o método de formar um contato entre os nós-piloto e suas superfícies, empregando a formulação MPC com opção de geração de restrições rígidas baseadas em superfícies (Surface-Based Constraint). Esta formulação gera o efeito de corpos rígidos através do acoplamento de nós por meio de equações de restrição de movimento, tornando um grupo de nós submisso ao movimento direcionado pelos nós-piloto.

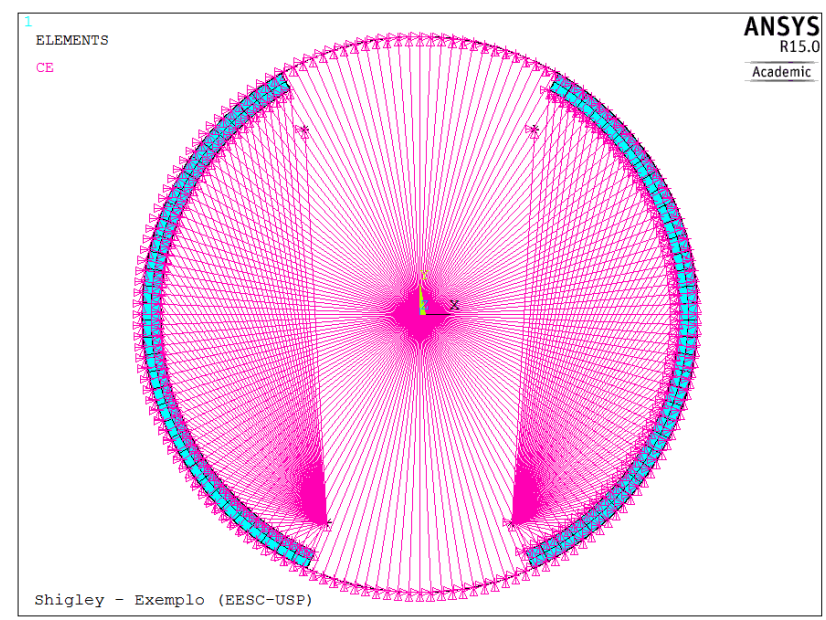

Figura 5.8 - Equações de restrição ligadas aos nós pilotos, gerando comportamento de corpo rígido nas sapatas e no tambor. 
Conforme o problema analítico o qual este modelo foi gerado, o coeficiente de atrito para o par de contato da Figura 5.9 foi atribuído em 0,32, como uma propriedade material dos próprios elementos.

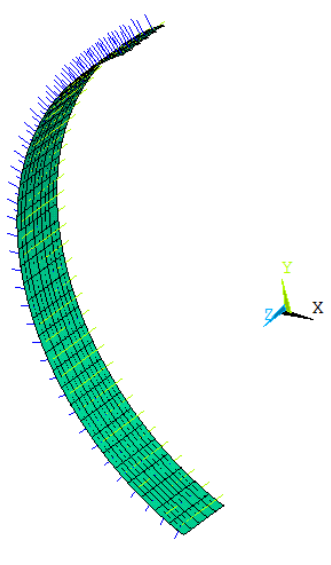

(a)

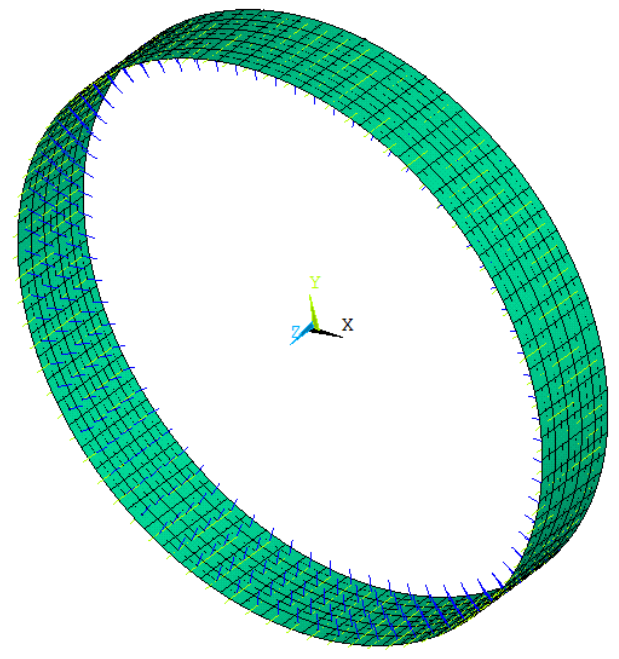

(b)

Figura 5.9 - Elementos de superfície usados na transferência de esforços por contato escolhidos para a análise: (a) Elementos CONTA174 para as sapatas; (b) Elementos TARGE170 para o tambor.

A Figura 5.10 exibe o modelo com a ilustração dos esforços aplicados, com destaque para a classificação das sapatas em primária e secundária, dado o sentido de giro do tambor, enquanto a Tabela 5.6 fornece os dados quantitativos desta malha.

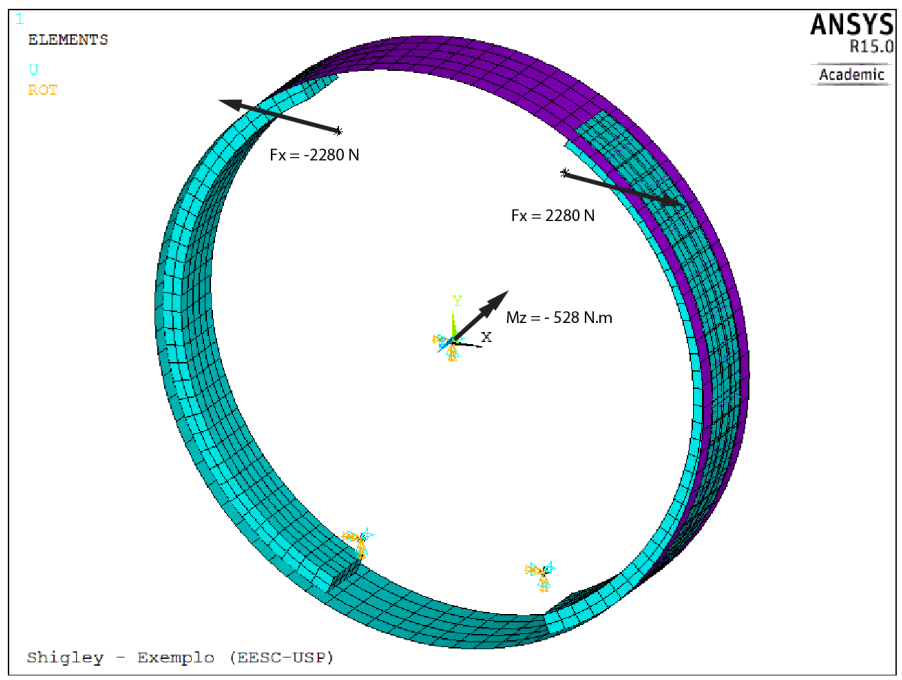

Figura 5.10 - Malha, esforços e restrições aplicadas ao modelo, indicando a atribuição de primária e secundária às sapatas devido ao sentido de giro do tambor. 
Tabela 5.6 - Dados da malha de elementos finitos usada para o modelo de comparação.

\begin{tabular}{ccccc}
\hline Tipo de elemento & № de elementos & № de nós & GDL & Materiais \\
\hline \multirow{2}{*}{ Solid 226 } & \multirow{2}{*}{2955} & & & Fofo Cinzendo \\
& & 7705 & Ux, Uy, Uz e & (tambor); \\
& & & Temperatura & material de \\
& & & atrito (lona) \\
\hline
\end{tabular}

A Figura 5.11 exibe os resultados, em forma de vetores, obtidos com satisfação para as reações de apoio a partir dos esforços aplicados. A flexibilidade dos elementos presentes não afetou significativamente os resultados esperados, que foram comparados aos obtidos analiticamente e descritos na Tabela 5.7.

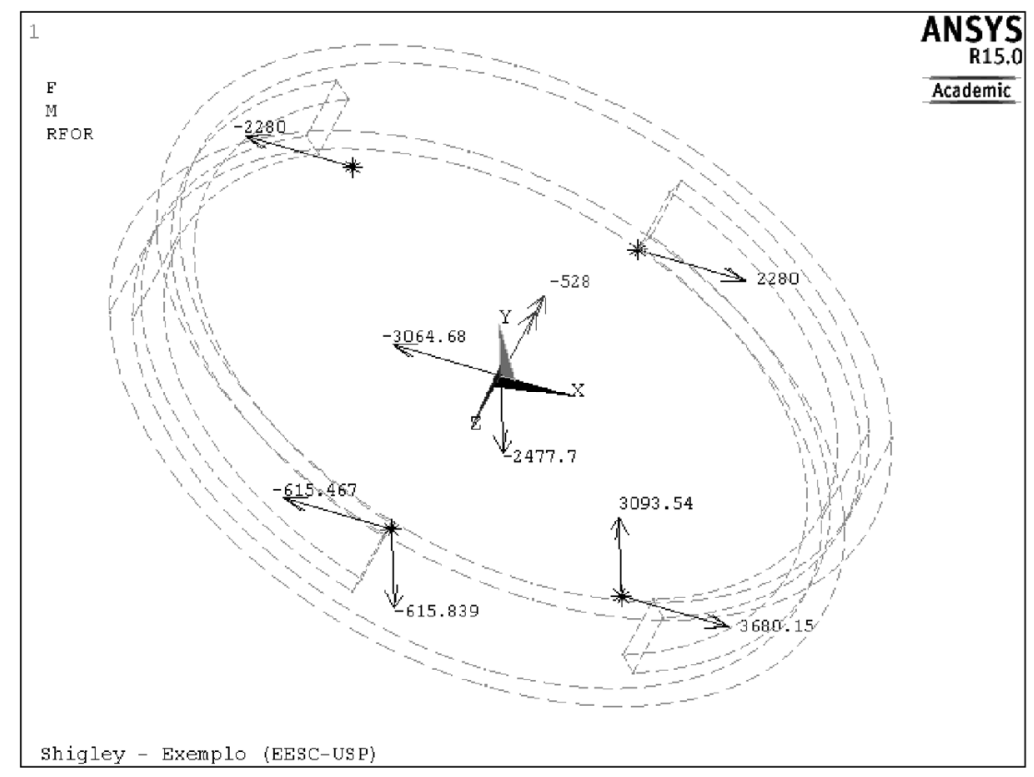

Figura 5.11 - Esforços aplicados e reações de apoio obtidas para um modelo preliminar.

Tabela 5.7 - Comparação entre as reações obtidas analiticamente e por elementos finitos.

\begin{tabular}{lcc}
\hline Força de reação & Sapata primária & Sapata secundária \\
\hline Modelo analítico & $5,04 \mathrm{kN}$ & $0,866 \mathrm{kN}$ \\
Modelo de elementos finitos & $4,807 \mathrm{kN}$ & $0,870 \mathrm{kN}$ \\
\hline
\end{tabular}

Uma vez que o principal propósito deste modelo é o de demonstrar a viabilidade das escolhas feitas, não é de interesse neste trabalho de exibir mais resultados que 
não tenham interesse prático. Porém, pode-se constatar que o modelo apresentou uma boa aproximação com os valores analíticos, demonstrando que o conjunto de escolhas é adequado em uma primeira abordagem.

\subsection{ESTUDO APLICADO AO MODELO DO FREIO A TAMBOR S CAMO}

\subsubsection{DEFINIÇÃo dos ESFORÇOS DE ACIONAMENTO}

Com auxílio da Figura 5.12, exibe-se uma representação inicial, qualitativa, da configuração dos esforços atuantes em um modelo simplificado deste tipo de freio.

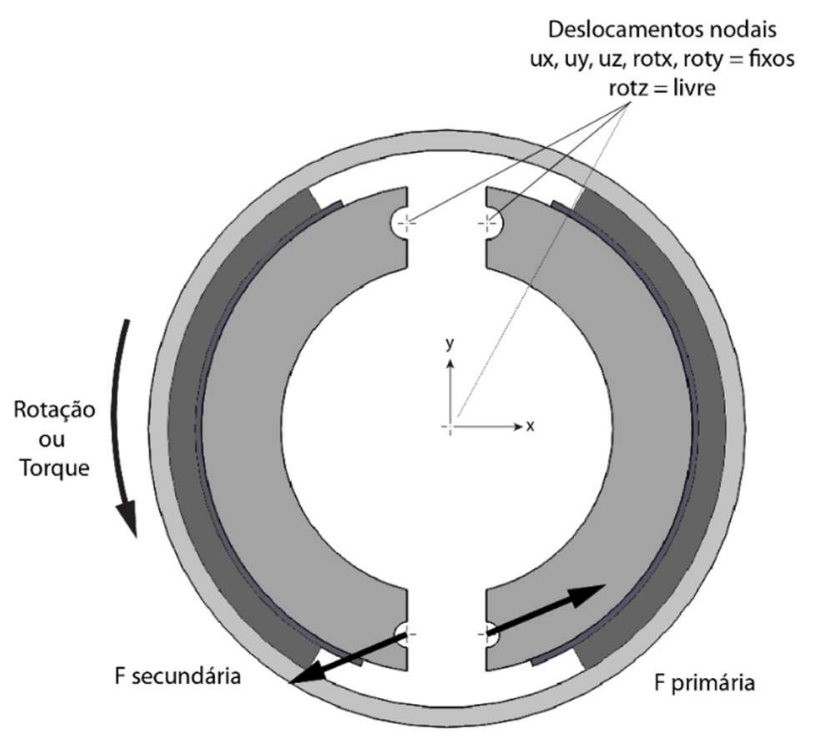

Figura 5.12 - Restrições e carregamentos a serem determinados e aplicados no modelo.

Ressalta-se a importância em se adequar o sentido de giro (ou aplicação de torque) no tambor e o sentido da inclinação das forças nas sapatas, uma vez que o eixo $S$ de acionamento deste freio é instalado simetricamente, tanto no lado esquerdo quanto no direito do veículo, para que se tenha esta orientação de esforços nas sapatas primária e secundária. Esta regra para o acionamento dos eixos Camo $S$ é ilustrada nas imagens da Figura 5.13. 


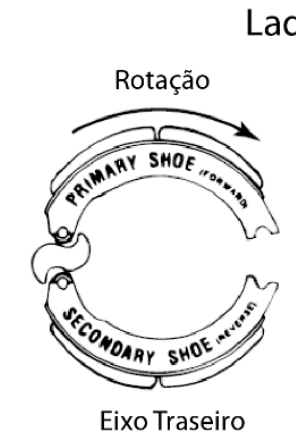

Lado Direito
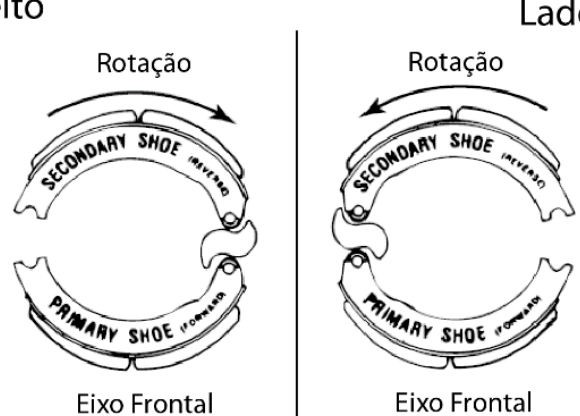

Lado Esquerdo

Eixo Frontal

Eixo Fronta

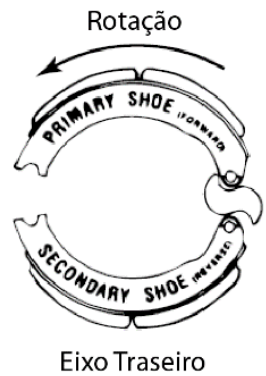

Figura 5.13 - llustração da lógica de montagem dos eixos $S$ Camo no sistema de freio estudado, para ambos os lados do veículo e duas possíveis posições do eixo acionador cada (MERITOR, 2005).

A forma do Camo S, responsável pelo acionamento do freio estudado, empurra os roletes na medida que seu eixo rotacional pelo movimento do pedal do motorista. Como trata-se de uma região de contato entre superfícies cilíndricas, foi preciso estimar o ângulo em que este contato ocorre, uma vez que nestas situações a força terá direção orientada para o centro dos roletes, para destes ser transferida às sapatas. Com auxílio de um material cedido pela empresa nacional Fras-Le ${ }^{\circledR}$, foi possível estimar um ângulo de $22^{\circ}$ com a horizontal para ambas as forças oriundas da rotação deste camo, conforme ilustra a Figura 5.14. Deve-se ressaltar que, além desta orientação ser variável na medida em que os roletes se afastam, ela também varia de acordo com os diversos modelos e tamanhos disponíveis no mercado. Optouse, então, por se manterem os ângulos fixos, dado que o deslocamento é pequeno e esta medida condiz com o modelo estudado.

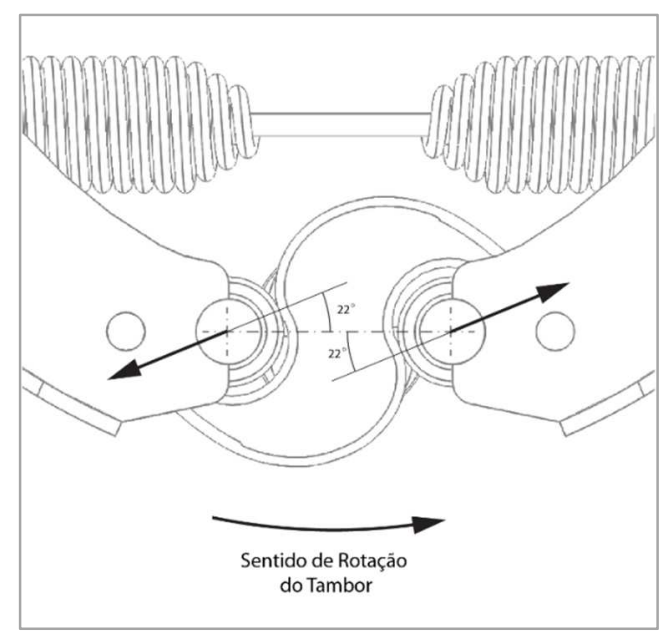

Figura 5.14 - Direção de aplicação das forças nas sapatas 
Outro parâmetro geométrico necessário para o primeiro equacionamento dos esforços é o braço de alavanca que se forma entre a direção das forças e o ponto de giro das sapatas. Conforme ilustrado na Figura 5.15, o valor encontrado com auxílio de software CAD SolidWorks ${ }^{\circledR}$ foi de $287,43 \mathrm{~mm}$, aproximado para 0,287 m.

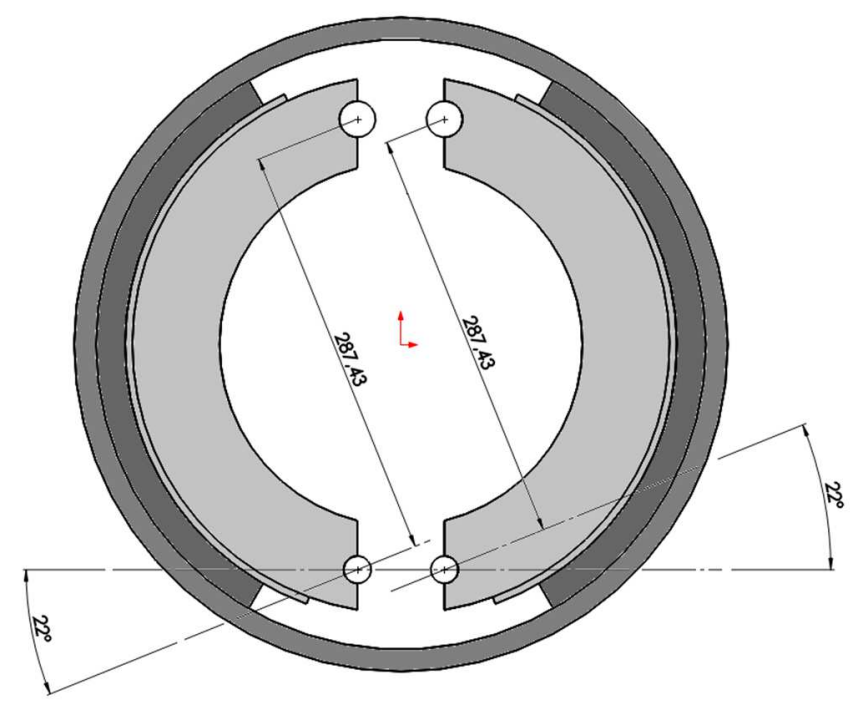

Figura 5.15 - Braços de alavanca do acionamento das sapatas.

\subsubsection{PRIMEIRA CONDIÇÃO: ESFORÇOS MÁXIMOS - MOdELO ESTÁTICO}

Nesta etapa, foram estudados dois modelos de elementos finitos diferentes para uma mesma configuração de carregamento estático:

- Um modelo próximo à condição de modelo rígido, semelhante ao estudo realizado no ítem 4.1, com o propósito de se terem valores iniciais de referência;

- Um modelo inteiramente composto de corpos elásticos, onde entrarão os efeitos da geometria das sapatas e tambor, buscando levar a condição descrita anteriormente para mais próximo de um ensaio real.

Budynas e Nisbett (2011) apresentam uma estimativa da força máxima a ser aplicada em uma sapata de freio a tambor, considerando o caso estático sem 
deslizamento relativo entre os componentes. Essa estimativa consiste em se avaliar a máxima compressão admissível para o material de atrito da lona. Voiculescu (2010) demonstrou experimentalmente que, para uma classe geral de pastilhas de freio automotivas, o módulo de compressibilidade mantém comportamento linear elástico entre $50 \mathrm{~N} / \mathrm{mm}^{2}$ e $200 \mathrm{~N} / \mathrm{mm}^{2}$, conforme mostra a Figura 5.16. Após este limite superior, o sistema apresenta deformação não linear, culminando na ruptura lateral da amostra estudada.

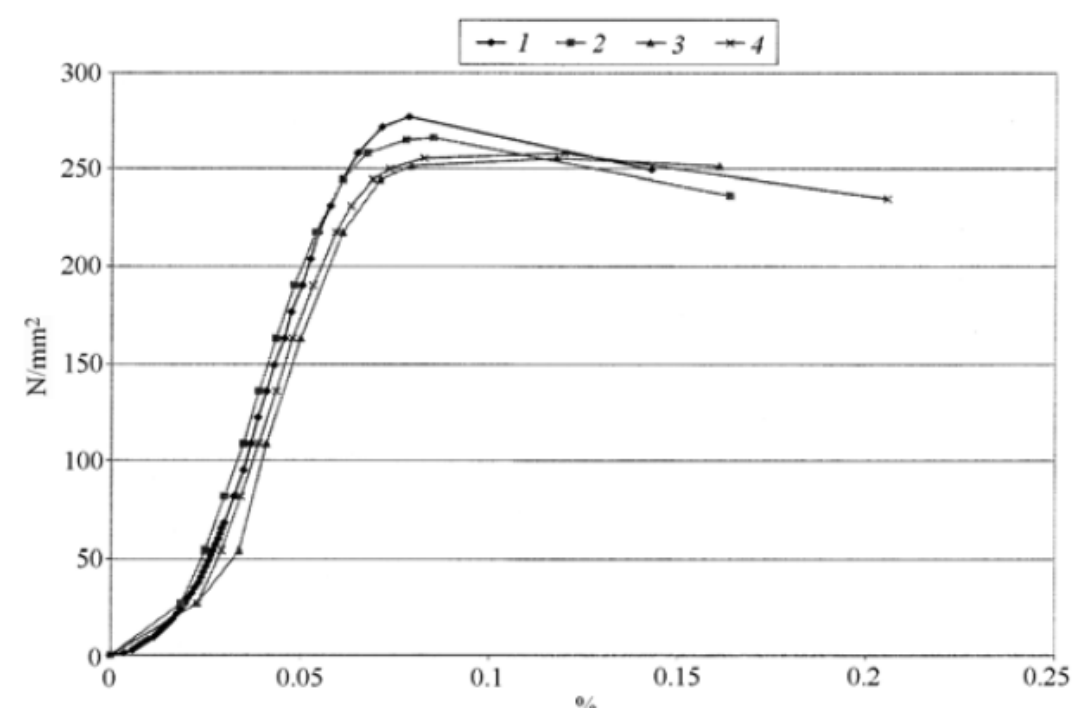

Figura 5.16 - Curva de comportamento mecânico sob compressão para 4 amostras de material de atrito usado em pastilhas de freio (VOICULESCU, 2010).

Porém, o ensaio não considerou o expressivo aumento da temperatura e presença de vibrações devido ao atrito durante a frenagem, dentre outras várias hipóteses. Optou-se, então, na falta de dados mais confiáveis, por seguir as tabelas citadas por Budynas e Nisbett (2011) e adotar uma resistência à compressão de 1 $\mathrm{N} / \mathrm{mm}^{2}$, ou $1 \mathrm{MPa}$, para o material de atrito das lonas de freio, considerando-as como asbeto moldado em chapa de aço.

As forças aplicadas às sapatas primária e secundária foram estimadas com base em uma possível máxima compressão admissível para a lona de freio. Portanto, como limite inferior adotou-se de $1 \mathrm{Mpa}$, conforme discutido. Assim, com base nas dimensões mostradas nas Figuras 5.2 e 5.15, junto ao o coeficiente de atrito lona/tambor de 0,4, conforme a Tabela 5.3 e considerando as equações (4.2), (4.3) e (4.4), obteve-se, os seguintes esforços para a sapata primária do modelo: 


$$
\begin{gathered}
p_{a_{\text {primária }}}=1 \mathrm{MPa} \\
M_{f}=0,43 \mathrm{kN} . \mathrm{m} \\
M_{N}=8,38 \mathrm{kN} . \mathrm{m} \\
|\boldsymbol{F}|=14,25 \mathrm{kN}
\end{gathered}
$$

onde

$$
\begin{gathered}
\boldsymbol{F}_{\text {primária }}=13,21 \boldsymbol{i}+5,34 \boldsymbol{j} k N \\
\boldsymbol{F}_{\text {secundária }}=-13,21 \boldsymbol{i}-5,34 \boldsymbol{j} k N
\end{gathered}
$$

Aplicando estes valores na equação (4.1), o torque máximo gerado pela sapata primária será de:

$$
T_{\text {primária }}=5,29 \mathrm{kN} . \mathrm{m}
$$

A pressão máxima suportada pela sapata secundária está limitada ao esforço que a primária recebe. As equações (4.2) e (4.3) indicam que os momentos devido à força de atrito e força normal são proporcionais à máxima pressão atuante sobre a lona. Logo, lançando o valor da força aplicada $F$ na equação (4.5), obtém-se:

$$
p_{a_{\text {secundária }}}=0,322 \mathrm{MPa}
$$

que resulta em um torque, através novamente da equação (4.1), de:

$$
T_{\text {secundária }}=1,71 \mathrm{kN} . \mathrm{m}
$$

Por fim, o torque total suportável é dado pela soma dos torques suportados por ambas as lonas:

$$
T_{\text {primária }}+T_{\text {secundária }}=7,0 \mathrm{kN} . \mathrm{m}
$$

Os valores encontrados mostram-se realistas quando comparados a outros trabalhos do mesmo gênero. Como exemplo, Kim, Kwon e Yoon (2010) realizaram ensaios em dinamômetro com auxílio de câmeras termográficas para análise de hot spots em discos de freio de trens. Seguindo as recomendações das Normas SulCoreanas Ferroviárias KRS BR 0007, aplicaram, em cada pastilha, forças de 25 kN. 
É de se esperar que este esforço seja um limite de esforço não-alcançável em um freio de caminhões, devido a discrepante diferença na energia dissipada em cada sistema. Em outro caso, Jung et al. (2011) realizaram estudo termo-mecânico por elementos finitos de um sistema de freio a disco automotivo, buscando a simulação de fenômenos de hot judder, aplicando uma pressão de 30 bar, equivalente a $3 \mathrm{MPa}$, em cada pastilha de freio. No caso, como estamos lidando com freio a tambor, um limite de pressão de $1 \mathrm{MPa}$ mostra-se mais interessante, já que pastilhas de freio sofrem esforços mais uniformes e planos quando comparados aos sofridos por lonas, que dependem de momento fletor e curvatura. Por fim, Yoshioka et al. (2008) realizaram a simulação de um sistema de freio a tambor do tipo Camo $S$ aplicando esforços horizontais nas sapatas de $4 \mathrm{kN}$, valor este inferior ao aplicado no presente estudo.

Por fim, uma vez que se trata de um modelo termoelástico, não se pode deixar de considerar as condições de carregamento térmico. Neste caso, a única fonte de calor será aquela gerada pelo atrito entre o par lona/tambor, mesmo que estes não cheguem a desenvolver deslizamento relativo. Foram aplicados, para dois casos distintos, a condição de fronteira de transferência de calor por convecção livre do ar, conforme a equação (4.11) que representa a Lei de Newton do Resfriamento. Nos dois casos será considerado o coeficiente de transferência de calor por convecção calculado com base na equação (4.16) para o ar parado. Assim, para as lonas e tambor obtêm-se:

$$
h_{t}=5,3 \frac{W}{m^{2} K} ; h_{l}=5,3 \frac{W}{m^{2} K} \text { e } T_{\infty}=20 C(293 K)
$$

\subsubsection{SEGUNDA CONDIÇÃO: FRENAGEM SOB DESLIZAMENTO CONSTANTE - REGIME PERMANENTE}

Em um segundo momento, foi feita a análise do sistema considerando que 0 mesmo está sob efeito de uma frenagem constante e de não-travamento do tambor. A malha de elementos finitos, bem como as restrições, são a mesma utilizada no caso estático de corpos flexíveis, porém os esforços aplicados são outros.

Primeiramente, deve-se lembrar das conclusões feitas para o primeiro estudo de barras. As dificuldades encontradas somam-se ao fato de que os modelos de freio 
a tambor serão compostos de um maior número de elementos e que a região em contato possui curvatura de raio pequeno, vendo-se com clareza que a geometria deste problema acrescenta uma dificuldade muito alta quando comparada com freios a disco, que sofrem deslizamento no plano.

Pensando no gasto computacional necessário à convergência de um modelo altamente não-linear quanto este, dado a dificuldade dos contatos de atrito trabalharem com geometria curva, optou-se por aplicar uma estratégia de simulação em regime permanente, que inclua o deslizamento e seus efeitos mas sem considerar a movimentação do corpo. Para esta aplicação, existe uma ferramenta aplicável por linha de comando justamente para o caso de estudo da geração de calor por atrito em freios, considerando-os em regime permanente de rotação. Com o comando CMROTATE, indicamos valores de velocidade angular segundo eixos cartesianos para que sejam inseridas numericamente no equacionamento de calor por atrito. A vantagem deste método é a implementação de uma condição de esforço tipicamente dinâmica em ambiente estático de solução (solver), consumindo muito menos tempo computacional.

Pensando deste modo, foi considerado um caso hipotético onde o veículo seja mantido a $30 \mathrm{~km} / \mathrm{h}$ (velocidade constante), em uma situação de declive que exija que o condutor mantenha o freio acionado, porém não travado.

De acordo com Jung et al. (2011), a rotação do tambor pode ser calculada por meio da rotação de um pneu, considerando um dos tamanhos de pneu indicado pelo fabricante para este freio com diâmetro de 42,2" (pneu tamanho 385/65R22.5), equivalente a 1,07 m e 0,95 de razão de deslizamento. O valor obtido é dado pela Eq. (4.57):

$$
\operatorname{Rot}_{\text {tambor }}=\frac{\frac{30 \times 1000}{3600}}{2 \pi \frac{1,07}{2}} \cdot 60 \cdot 0,95=141,3 \mathrm{rpm} \cong 15 \mathrm{rad} / \mathrm{s}
$$

Os coeficientes de convecção devem considerar o movimento do veículo, que pode ser calculado conforme a equação (4.16), uma vez que este equacionamento foi o mais próximo do ideal a este problema encontrado (equação experimental obtida para veículos pesados). Assim, para uma velocidade de $30 \mathrm{~km} / \mathrm{h}$, obteve-se o valor de $378651,81 \mathrm{Nm} / \mathrm{hKm}^{2}$ ou $105,2 \mathrm{~W} / \mathrm{m}^{2} \mathrm{~K}$ para os freios frontais. Para as sapatas, 
optou-se por aplicar aproximadamente duas vezes o valor do coeficiente para o ar parado, uma vez que as mesmas não estão em rotação, como o tambor. Assim, os coeficientes de convecção para o tambor $\left(h_{t}\right)$ e para a lona $\left(h_{l}\right)$, são respectivamente:

$$
h_{t}=105,2 \frac{W}{m^{2} K} ; h_{l}=10,6 \frac{W}{m^{2} K} \text { e } T_{\infty}=20 C(293 K)
$$

Por fim, estima-se que a força de acionamento dos freios seja de aproximadamente $10 \%$ do valor máximo. Um cálculo mais detalhado deveria levar em conta a dinâmica veicular, o que traria trabalho extra fora do escopo deste estudo. Assim:

$$
\begin{aligned}
\boldsymbol{F}_{\text {primária }} & =1,321 \boldsymbol{i}+0,534 \boldsymbol{j} k N \\
\boldsymbol{F}_{\text {secundária }} & =-1,321 \boldsymbol{i}-0,534 \boldsymbol{j} k N
\end{aligned}
$$

Neste caso, não há torque aplicado ao tambor, uma vez que a rotação aplicada será responsável pelo arrasto e gerar esforço de torque.

\subsubsection{DescriçÃo dos MOdelos de Elementos finitos do Sistema ESTUDADO}

A seguir, será feita uma descrição detalhada da implementação dos modelos de elementos finitos empregados no estudo do freio a tambor Camo $S$.

\subsubsection{CASO 1: ESTÁTICO - MODELO DE CORPO RÍGIDO COM LONAS FLEXÍVEIS}

Conforme calculado no item 4.2.2.1, foram aplicados esforços de $|\boldsymbol{F}|=$ 14, $25 \mathrm{kN}$ nas duas sapatas, com direção e sentido discutidos anteriormente. No tambor, aplicou-se um torque total de $T=7,0 \mathrm{kN} . \mathrm{m}$ com sentido positivo ao eixo $\mathrm{z}$. Nas superfícies externas do modelo, foi aplicada a convecção para a condição de ar parado, com $h_{t}=5,3 \frac{\mathrm{W}}{\mathrm{m}^{2} \mathrm{~K}} ; h_{l}=5,3 \frac{\mathrm{W}}{\mathrm{m}^{2} \mathrm{~K}}$ e $T_{\infty}=20 \mathrm{C}(293 \mathrm{~K})$. A Figura 5.17 exibe a malha de elementos finitos. 


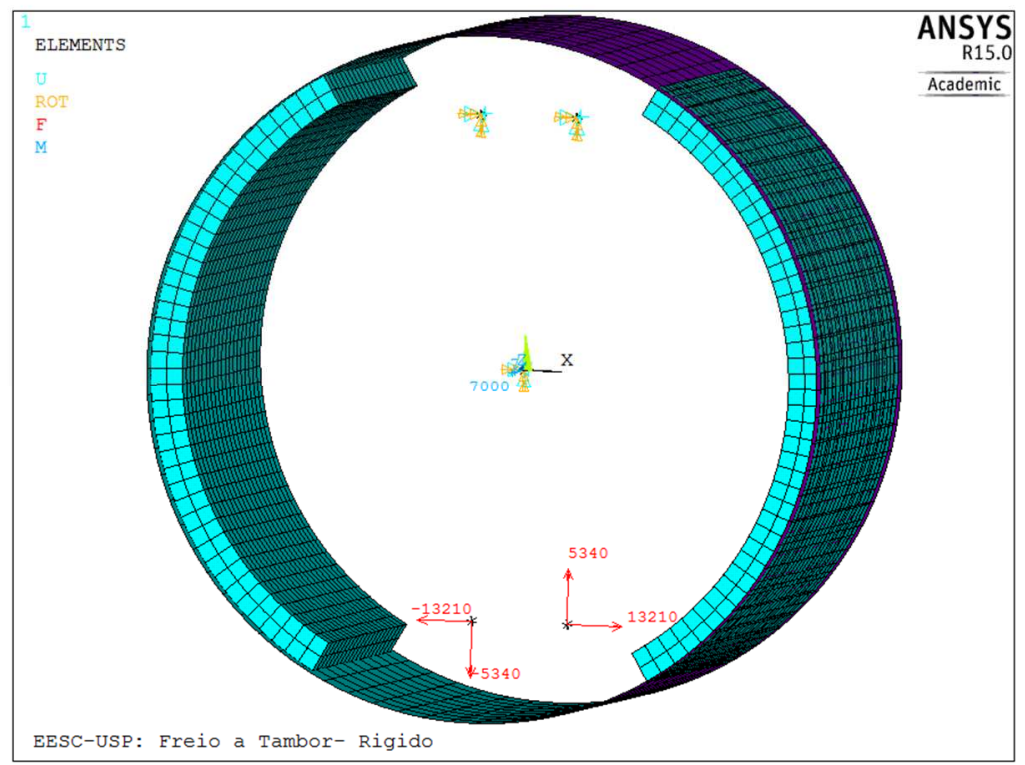

Figura 5.17 - Malha, esforços e restrições aplicadas ao modelo do caso 1 (convecção não mostrada atuante em todas as áreas com exceção das áreas de contato).

Da mesma maneira como feito para o modelo inicial de testes, a Figura 5.18 mostra as ligações que vinculam equações de restrição rígidas entre os nós-pilotos e os nós das superfícies do tambor e das sapatas, empregando a formulação MPC com opção de geração de restrições rígidas baseadas em superfícies (Surface-Based Constraint).

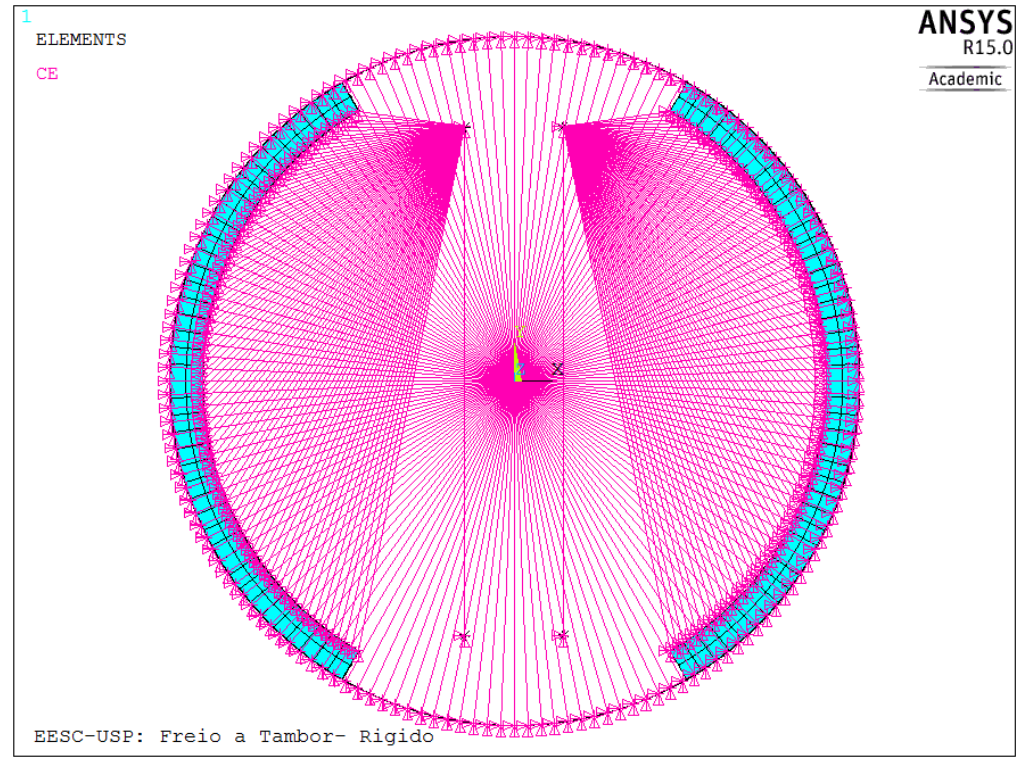

Figura 5.18 - Equações de restrição ligadas aos nós pilotos, gerando comportamento de corpo rígido nas sapatas e no tambor, mantendo apenas a lona como corpo flexível. 
Por fim, a Tabela 5.8 exibe dados quantitativos da malha de elementos finitos empregada para este modelo. Nota-se um alto número de elementos e nós, uma vez que a simplificação tornou possível uma simulação mais precisa.

Tabela 5.8 - Dados da malha de elementos finitos usada para o modelo rígido com lonas flexíveis.

\begin{tabular}{ccccc}
\hline Tipo de elemento & № de elementos & № de nós & GDL & Materiais \\
\hline \multirow{2}{*}{ Solid 226 } & 10805 & \multirow{2}{*}{25487} & Ux, Uy, Uz e & $\begin{array}{c}\text { Fofo Cinzendo } \\
\text { (tambor); } \\
\end{array}$ \\
& & & Temperatura & material de \\
& & & atrito (lona) \\
\hline
\end{tabular}

\subsubsection{CASO 2: ESTÁTICO - MOdELO FLEXÍvEL}

Os esforços aplicados a este modelo são exatamente os mesmos mostrados no item anterior, aplicados ao modelo rígido de sapatas flexíveis. A diferença entre os dois modelos está relacionada à presença de corpos flexíveis ao invés de equações de restrição que representem o comportamento de corpo rígido. A Figura 5.19 exibe a malha de elementos finitos deste modelo. Devido a difícil visualização dos esforços, um destaque foi feito para melhor ilustrá-la.

Por sua vez, a Tabela 5.9 exibe dados quantitativos da malha de elementos finitos empregada para este modelo. Desta vez, nota-se um número relativamente baixo de elementos e nós quando comparado ao modelo anterior. Tal condição foi necessária para reduzir o custo computacional de cálculo, dado que a flexibilidade trará maiores deslocamentos e, portanto, maior não-linearidade ao modelo.

Tabela 5.9 - Dados da malha de elementos finitos usada para os modelos dos casos 2 e 3.

\begin{tabular}{ccccc}
\hline Tipo de elemento & № de elementos & № de nós & GDL & Materiais \\
\hline & & & & Fofo Cinzendo \\
Solid 226 & 3419 & 13819 & Ux, Uy, Uz e & (tambor); \\
& & Temperatura & material de \\
& & & atrito (lona); \\
& & & Aço (sapatas)
\end{tabular}




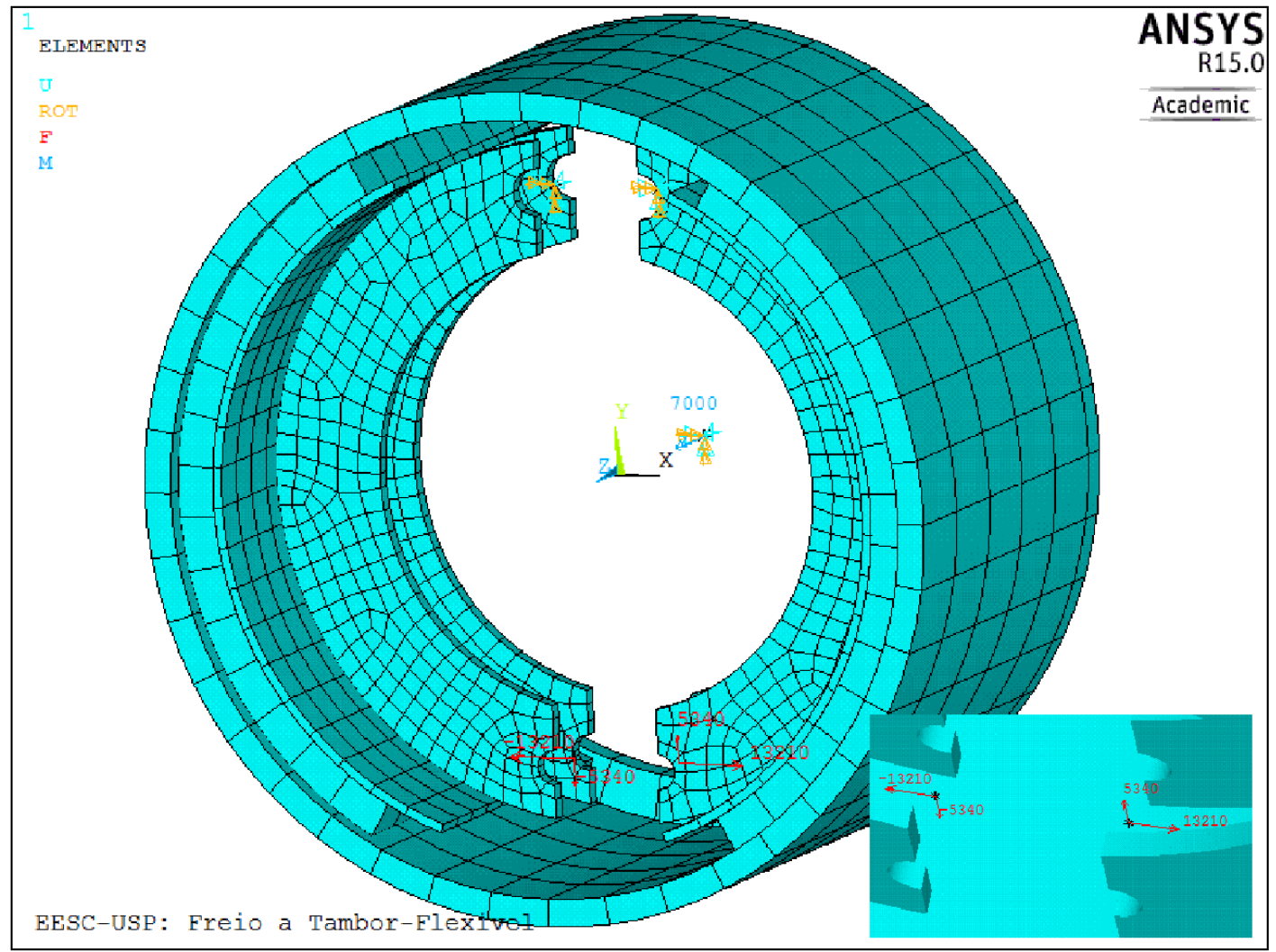

Figura 5.19 - Malha, esforços e restrições aplicadas ao modelo dos casos 2 e 3 (convecção não mostrada atuante em todas as áreas com exceção das áreas de contato).

\subsubsection{Caso 3: Deslizamento em regime permanente (Modelo FLEXÍVEL)}

O modelo empregado para esta análise é idêntico ao descrito no item 5.4.2.2. Todos os sólidos são considerados flexíveis, com o mesmo número de elementos, nós e condições de restrição. A diferença, porém, se fez nas condições de carregamento, explicadas no item 5.4.1.2. Assim, o modelo conta com esforços de $|\boldsymbol{F}|=\mathbf{1}, \mathbf{4 2 5} \mathrm{kN}$ nas duas sapatas, com direção e sentido discutidos anteriormente. No tambor,

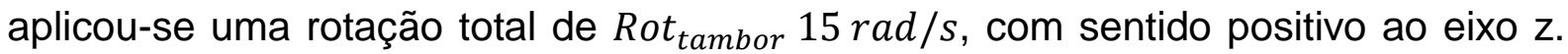
Nas superfícies externas do modelo, foi aplicada convecção para a condição de rotação do tambor e translação das sapatas e lonas, com $h_{t}=105,2 \frac{\mathrm{W}}{\mathrm{m}^{2} \mathrm{~K}} ; h_{l}=$ $10,6 \frac{W}{m^{2} K}$ e $T_{\infty}=20^{\circ} \mathrm{C}(293 K)$. 



\section{ANÁlise dos RESULTADOS}

\subsection{CASO 1: ESTÁTICO - MODELO RíGIDO COM LONAS FLEXÍVEIS}

A Figura 6.1 exibe uma imagem das reações de apoio nos pinos das sapatas primária e secundária, bem como as reações do nó-piloto do tambor.

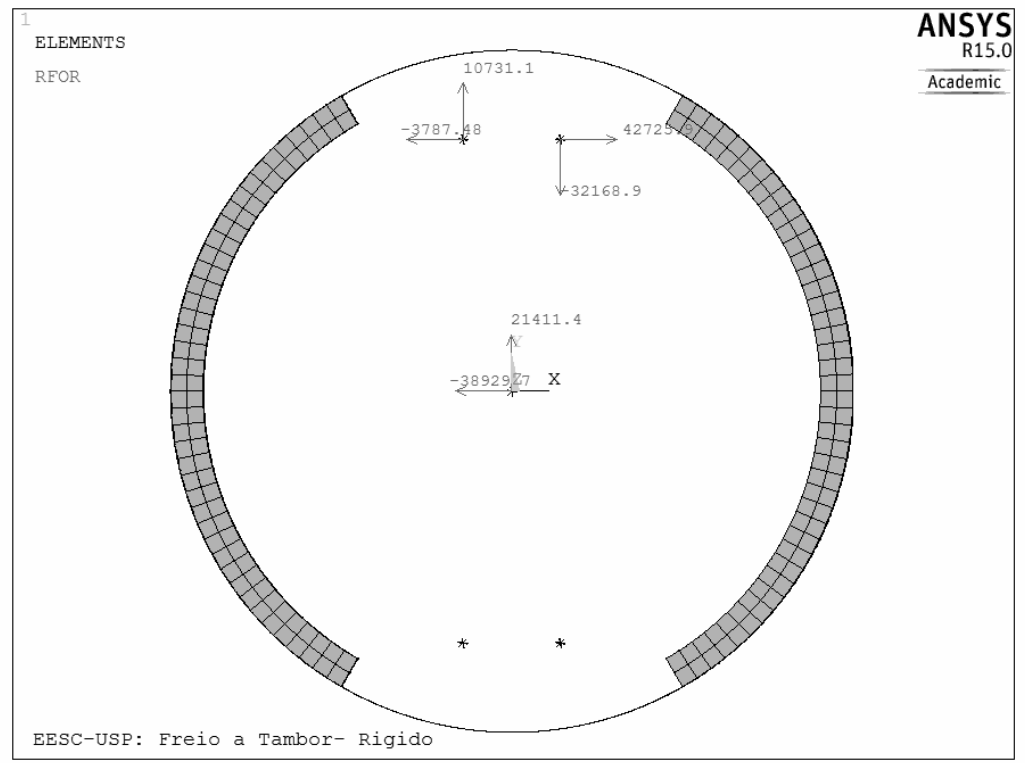

Figura 6.1 - Reações de apoio nas sapatas primária e secundária (acima) e no nó-piloto do tambor (centro), demonstradas sobre o espectro do modelo, considerando o modelo do caso 1.

Por sua vez, os valores das reações nos pinos das sapatas são expostos na Tabela 6.1, com indicação do valor resultante final de cada força.

Tabela 6.1 - Componentes e resultante das reações nos pinos ao final da análise do caso 1.

\begin{tabular}{cccc}
\hline Sapata & $\boldsymbol{F}_{\boldsymbol{x}}$ & $\boldsymbol{F}_{\boldsymbol{y}}$ & $\boldsymbol{R}$ \\
\hline Primária & $42725,9 \mathrm{~N}$ & $-32168,9 \mathrm{~N}$ & $\mathbf{5 3 4 8 2 , 1} \mathbf{N}$ \\
Secundária & $-3787,48 \mathrm{~N}$ & $10731,1 \mathrm{~N}$ & $\mathbf{1 1 3 7 9 , 9} \mathbf{~ N}$ \\
\hline
\end{tabular}

Já o gráfico da Figura 6.2 exibe os esforços de reação nas sapatas e sua evolução ao longo dos 2 load steps usados na análise. Após 1 segundo, as forças 
estão completamente estabelecidas, enquanto que após 2 segundos o torque está completamente aplicado, alterando os valores das reações.

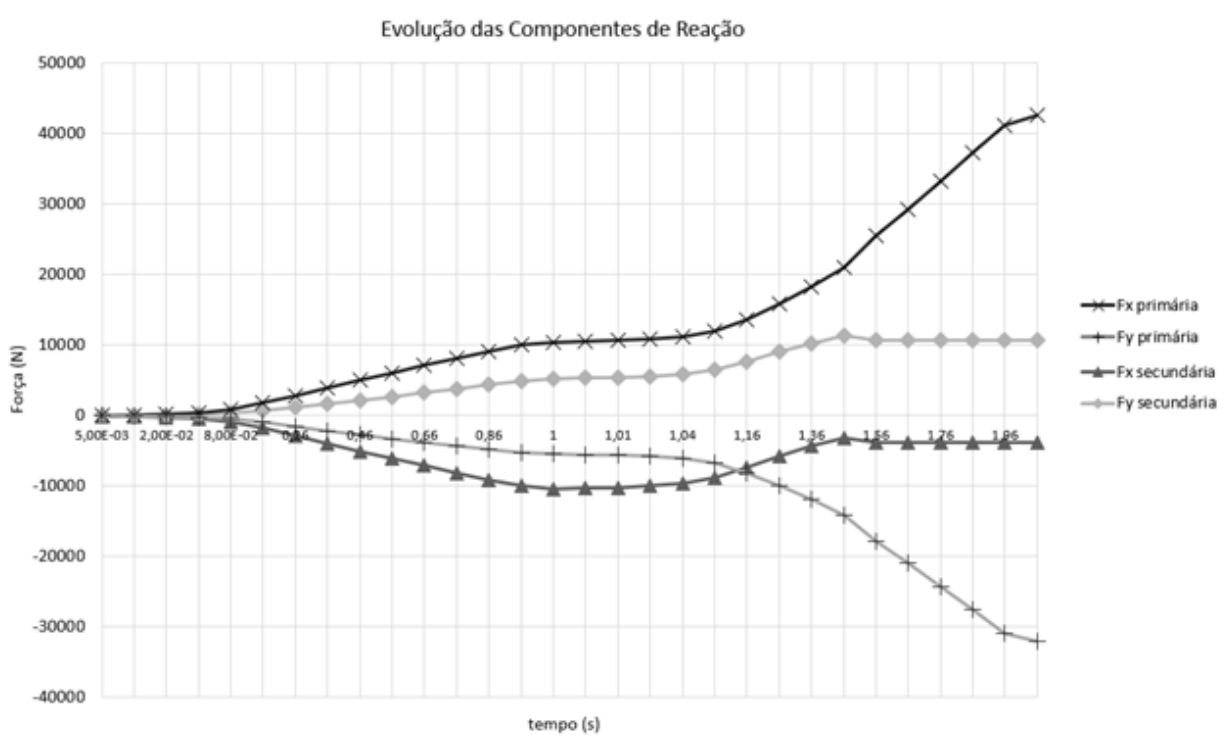

Figura 6.2 - Gráfico da evolução no tempo das reações de apoio, em $X$ e $Y$, nos pinos das sapatas, considerando o modelo do caso 1.

A Figura 6.3 exibe a configuração deformada para este modelo, com ampliação de 120x. Nota-se o acentuado deslocamento do ponto de aplicação da força na sapata primária, responsável pelo valor máximo de deslocamento em 0,231 mm.

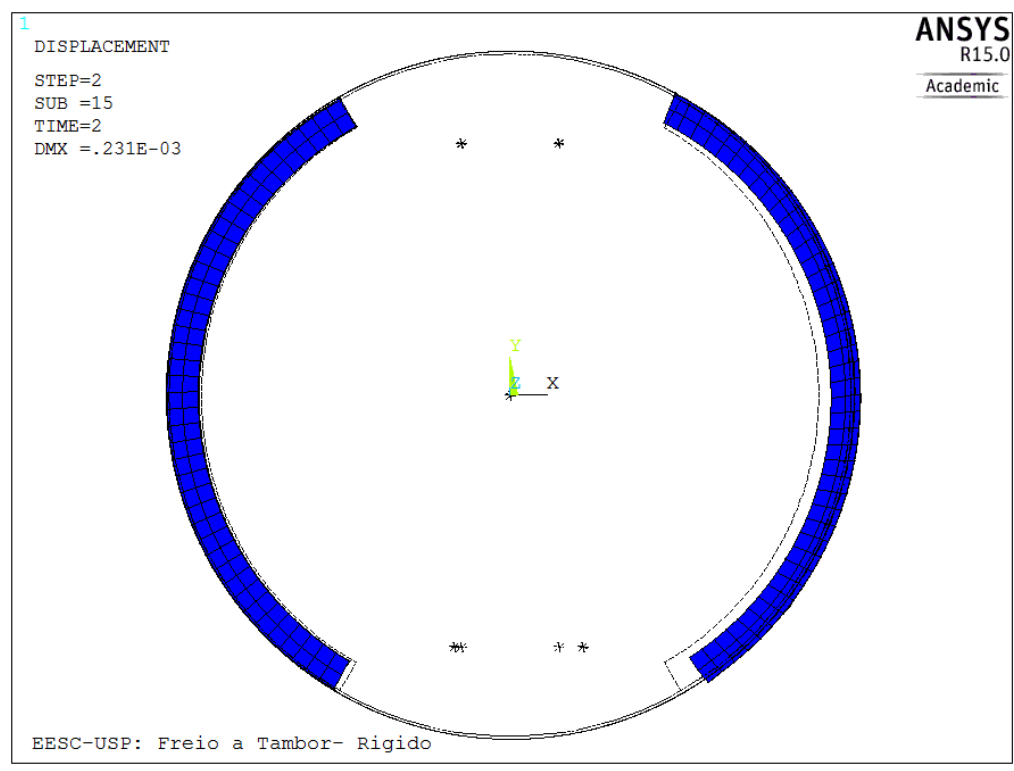

Figura 6.3 - Configuração deformada (120x) para o modelo do caso 1, corpos rígidos com exceção da lona, apresentando deslocamento máximo em $0,231 \mathrm{~mm}$. 
A Figura 6.4 exibe os valores de tensão equivalente de Von Mises apenas para as lonas, uma vez que estas são os corpos de interesse de tensões neste caso. Notase uma distribuição relativamente uniforme, com valores máximos próximos de 1,1 $\mathrm{MPa}$.

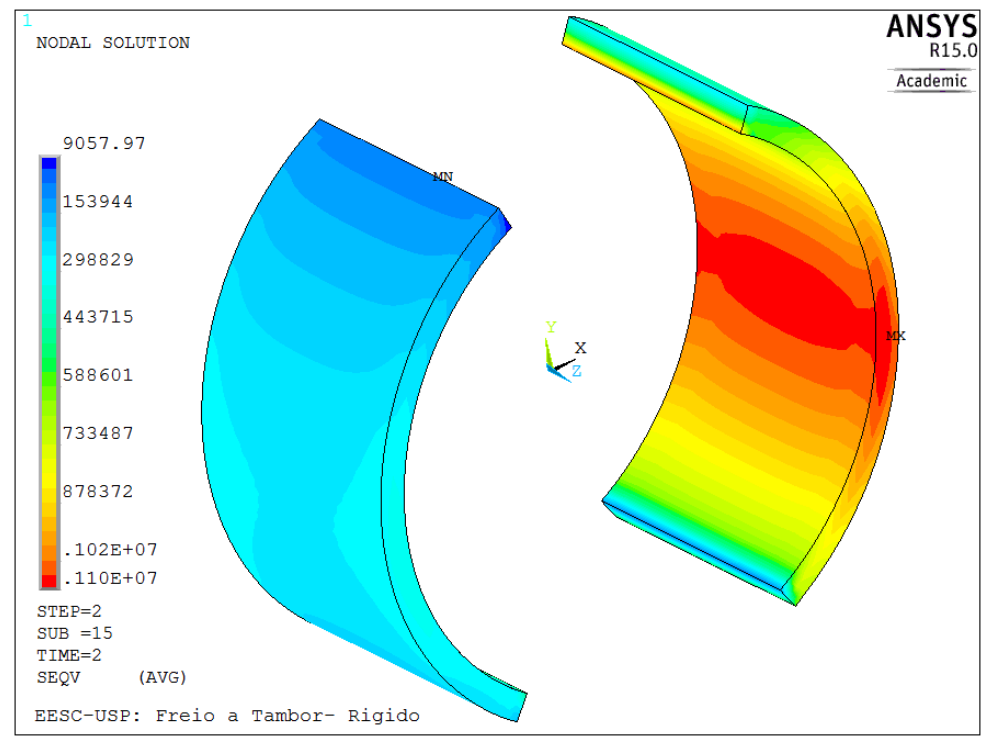

Figura 6.4 - Campo de tensões equivalentes Von Mises sobre as lonas do modelo do caso 1. Valor máximo de $1,1 \mathrm{MPa}$.

A Figura 6.5 e a Figura 6.6 plotam o gráfico de tensões de Von Mises ao longo do comprimento das sapatas. Nota-se a diferença de distribuição de tensões devido ao sentido de giro do tambor, porém mantendo o perfil de senóide comum para este tipo de freio.

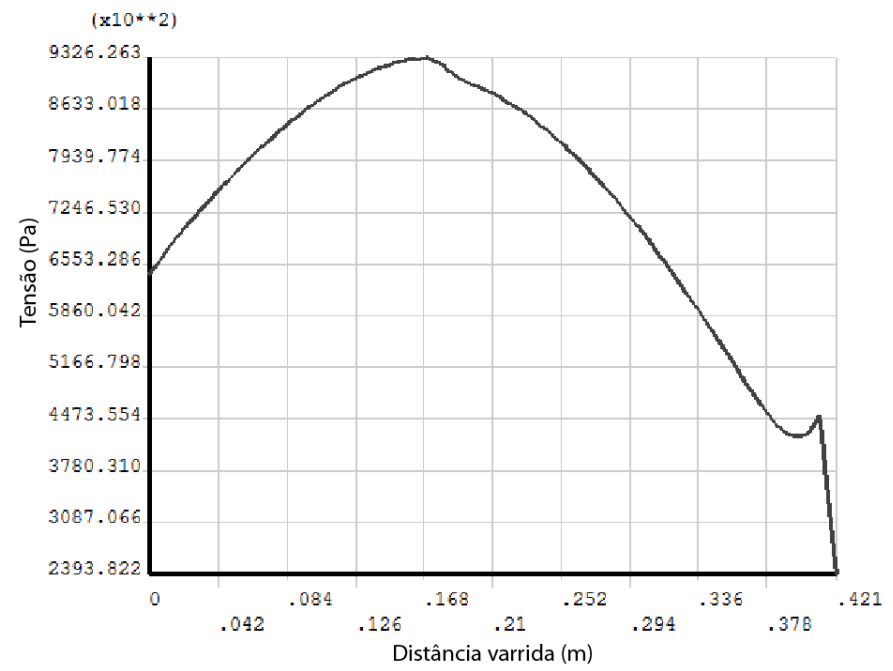

Figura 6.5 - Tensões de Von Mises ao longo do comprimento médio (sentido anti-horário) da sapata primária para o modelo do caso 1 . 


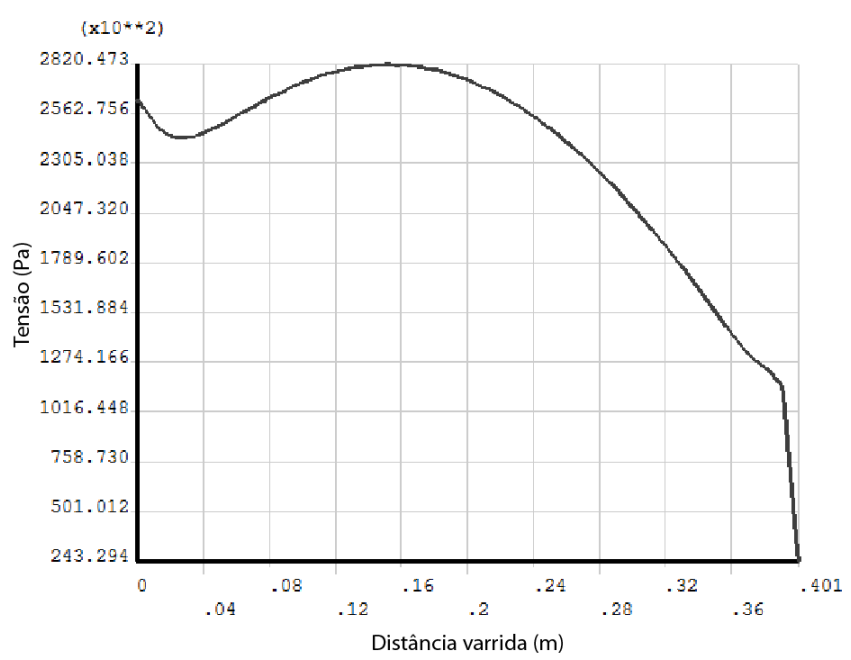

Figura 6.6 - Tensões de Von Mises ao longo do comprimento médio (sentido horário) da sapata secundária para o modelo do caso 1.

\subsection{CASO 2: ESTÁtICO - MOdELO FLEXível}

Para este caso, as reações são plotadas sem exibir o espectro do modelo, a fim de deixar a visualização mais clara. Nota-se que os momentos de reação possuem valores não nulos, além das forças de reação nos nós-piloto ser composta de vetores orientados nos 3 eixos cartesianos, conforme mostra a Figura 6.7.

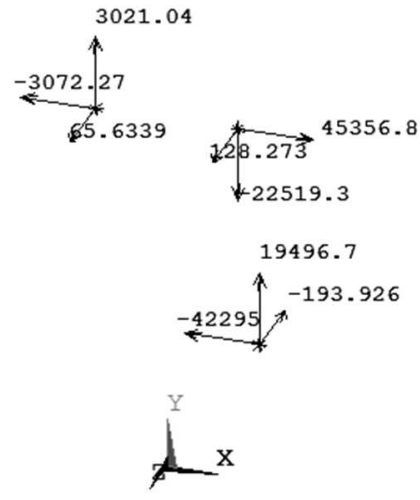

Reações
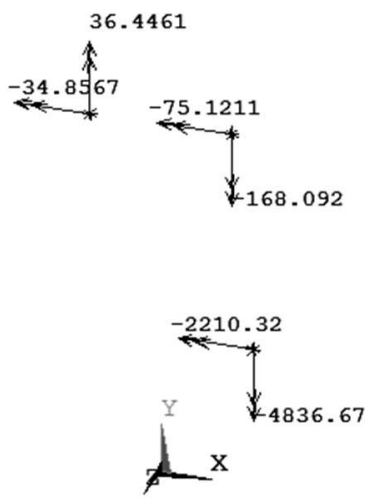

Momentos

Figura 6.7 - Reações de apoio e momentos resultantes nos nós-piloto da sapatas e tambor, sem exibição do modelo, para o modelo do caso 2. 
Os valores das reações nos pinos das sapatas são expostos na Tabela 6.2, com indicação do valor resultante final de cada força.

Tabela 6.2 - Componentes e resultante das reações nos pinos ao final da análise do modelo do caso 2.

\begin{tabular}{ccccc}
\hline Sapata & $\boldsymbol{F}_{\boldsymbol{x}}$ & $\boldsymbol{F}_{\boldsymbol{y}}$ & $\boldsymbol{F}_{\boldsymbol{z}}$ & $\boldsymbol{R}$ \\
\hline Primária & $45356,8 \mathrm{~N}$ & $-22519,3 \mathrm{~N}$ & $128,27 \mathrm{~N}$ & $\mathbf{5 0 6 3 9 , 6 5 \mathbf { N }}$ \\
Secundária & $-3072,27 \mathrm{~N}$ & $3021,04 \mathrm{~N}$ & $65,63 \mathrm{~N}$ & $\mathbf{4 3 0 9 , 2 7 \mathbf { N }}$ \\
\hline
\end{tabular}

Já o gráfico da Figura 6.8 exibe os esforços de reação nas sapatas ao longo dos 2 load steps usados na análise. Após 1 segundo, as forças estão completamente estabelecidas, enquanto que após 2 segundos o torque está completamente aplicado, alterando os valores das reações. Neste gráfico apenas os valores de força de reação foram plotados, uma vez que os momentos são de baixa intensidade.

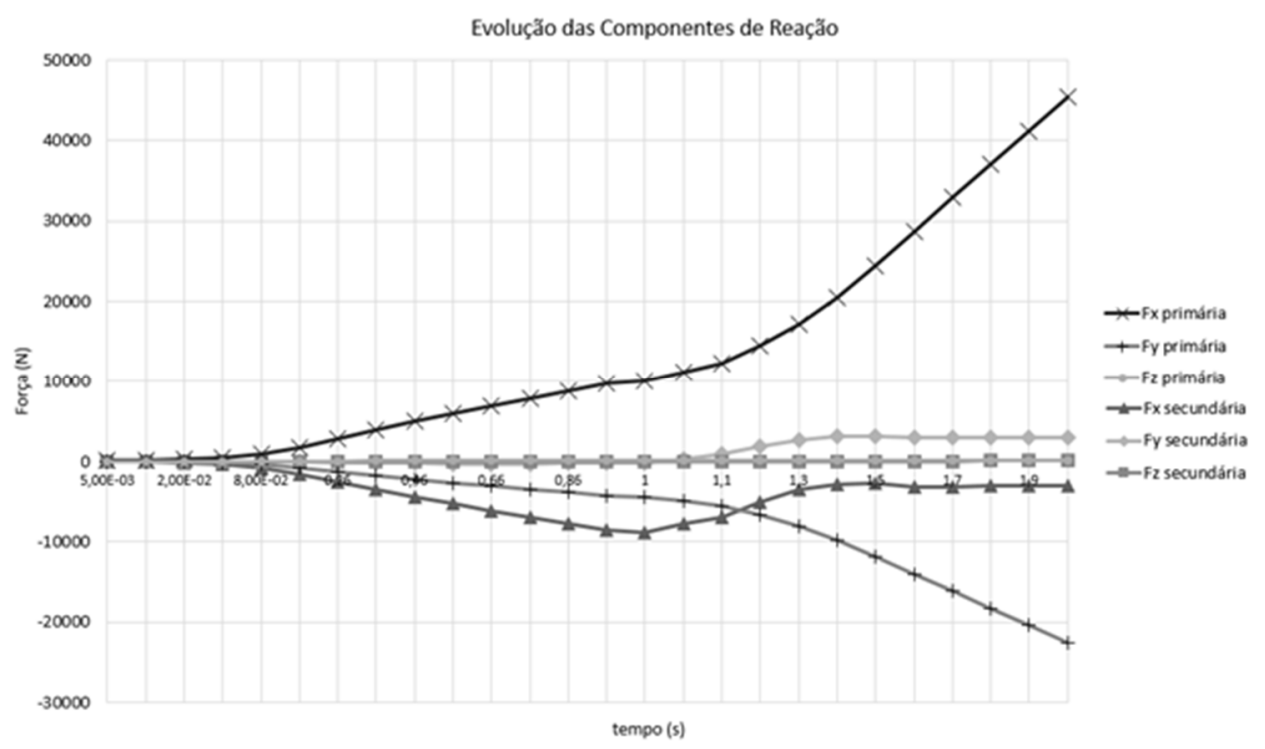

Figura 6.8 - Gráfico da evolução no tempo das reações de apoio, em $X, Y$ e $Z$, nos pinos das sapatas, considerando o modelo do caso 2.

A Figura 6.9 exibe a configuração deformada para este modelo, com ampliação de 120x. Nota-se o acentuado deslocamento do ponto de aplicação da força na sapata primária, responsável pelo valor máximo de deslocamento em 0,804 mm. 


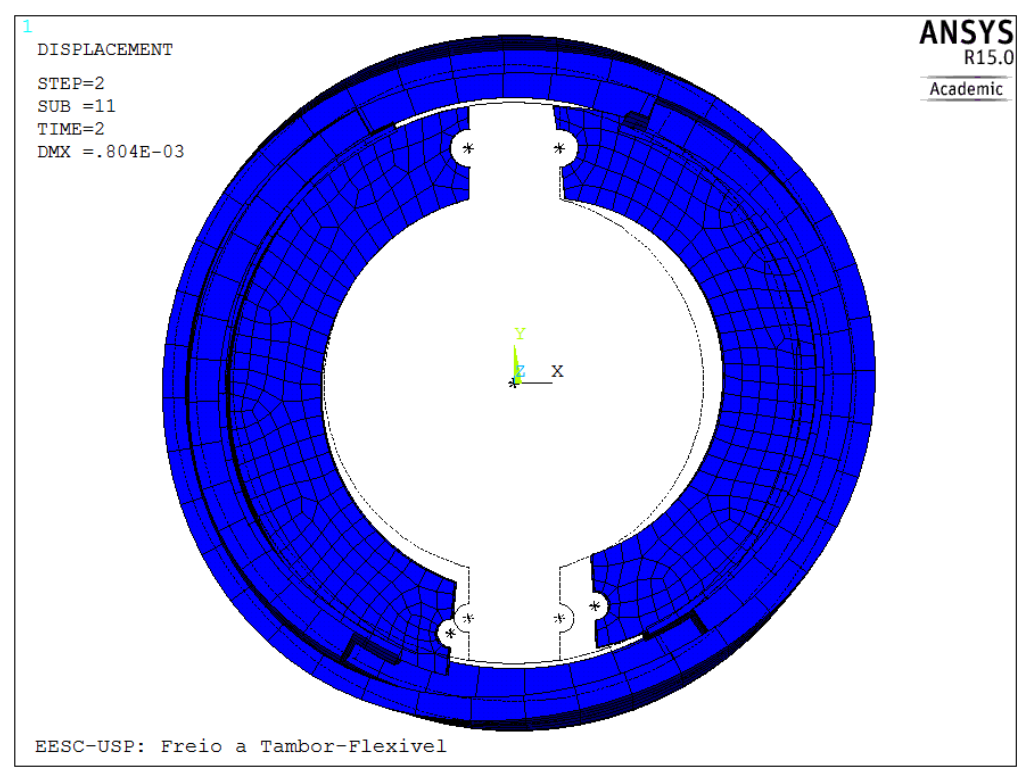

Figura 6.9 - Configuração deformada (60x) para o modelo do caso 2, apresentando deslocamento máximo em $0,804 \mathrm{~mm}$ no ponto de aplicação de força da sapata primária.

A Figura 6.10 exibe os valores de tensão equivalente de Von Mises para 0 conjunto todo. Nota-se uma alta concentração de tensões no ponto de apoio das sapatas, com valores máximos em $247 \mathrm{MPa}$, resultado do efeito auto-energizante e da deformação do conjunto.

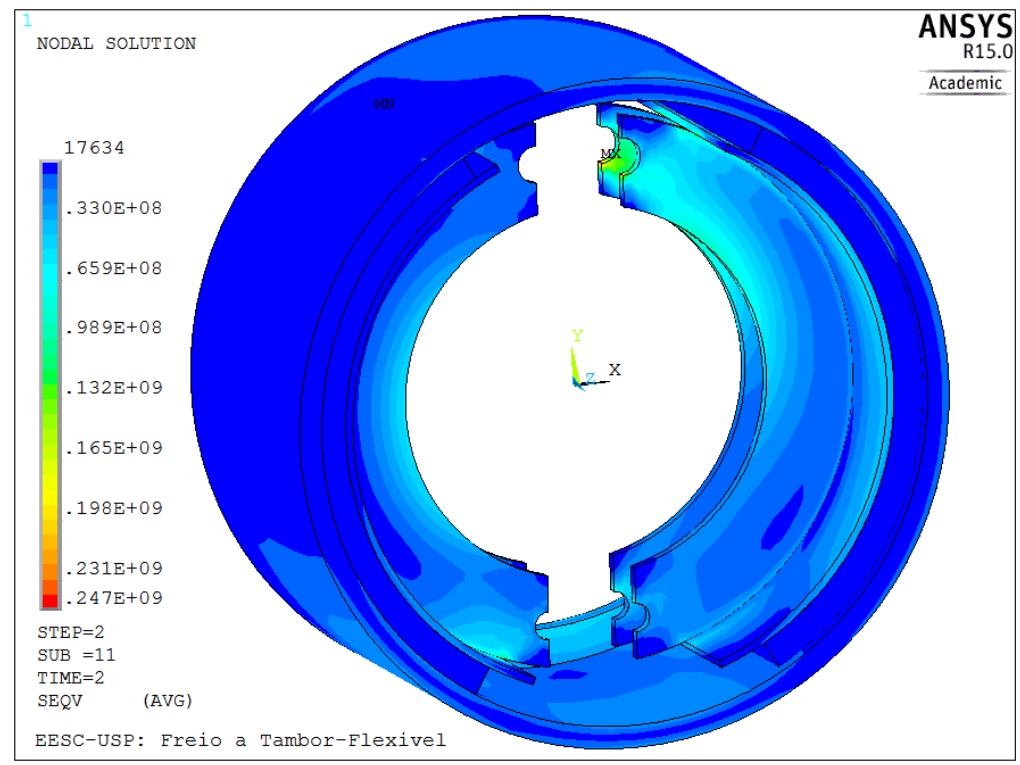

Figura 6.10 - Campo de tensões equivalentes de Von Mises do modelo do caso 2, apresentando tensão máxima de 247 MPa no ponto de fixação da sapata primária. 
Já Figura 6.11 exibe os valores de tensão equivalente de Von Mises apenas para as lonas a fim de compará-las com as obtidas no caso 1. Nota-se diferença com relação ao modelo anterior, com concentração de tensões próximas de 2,57 $\mathrm{MPa}$ devido à pressão concentrada pelas almas das sapatas. A alternância entre estarem próximos do ponto de apoio na primária e ponto de força na secundária deve-se ao efeito auto-energizante causado pelo giro do tambor.

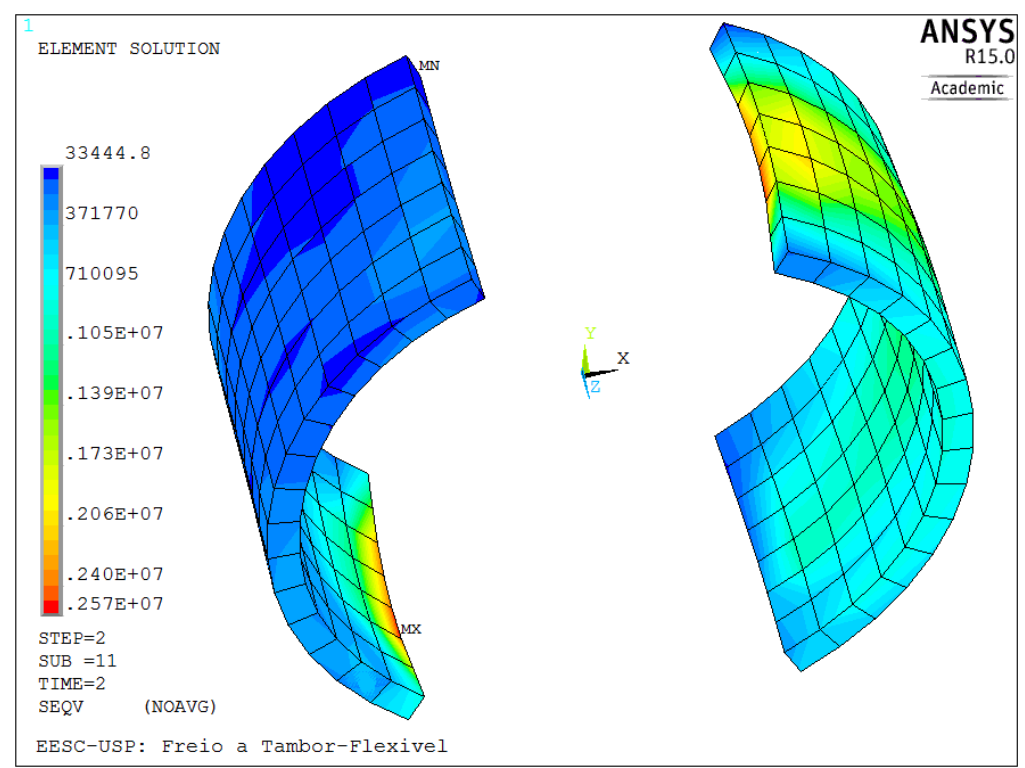

Figura 6.11 - Campo de tensões equivalentes de Von Mises das lonas do modelo do caso 2 plotados em termos de solução individual dos elementos, exibindo continuidade imperfeita, mas adequada, dos valores. Máxima tensão de $2,57 \mathrm{MPa}$

A Figura 6.12 e a Figura 6.13 plotam o gráfico de tensões de Von Mises ao longo do comprimento das sapatas. Nota-se que este caso diverge fortemente do caso 1, demonstrando a importância na consideração de corpos flexíveis e sua influência nos resultados previstos pelos modelos analíticos. 


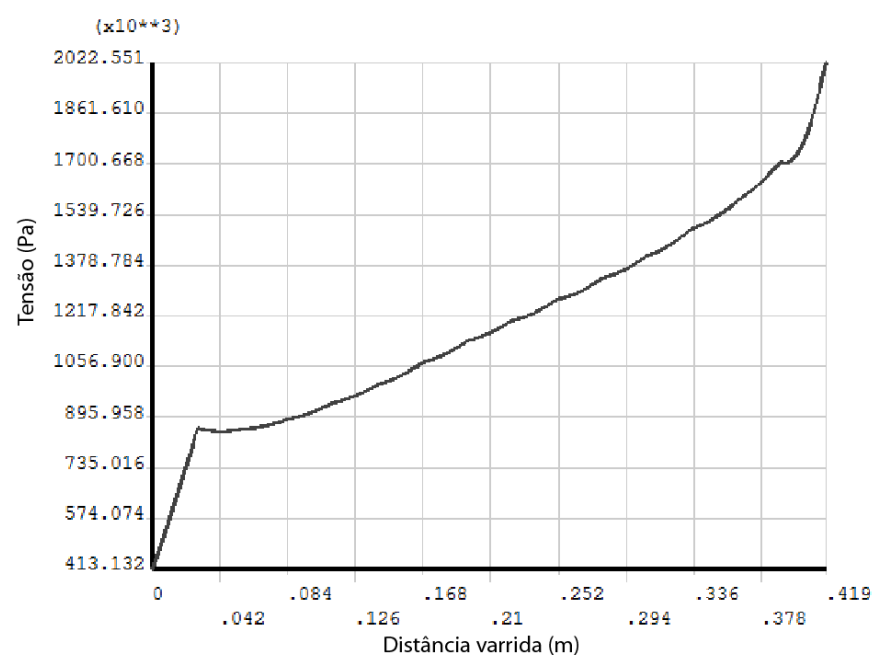

Figura 6.12 - Tensões de Von Mises ao longo do comprimento médio (sentido anti-horário) da sapata primária para o modelo do caso 2.

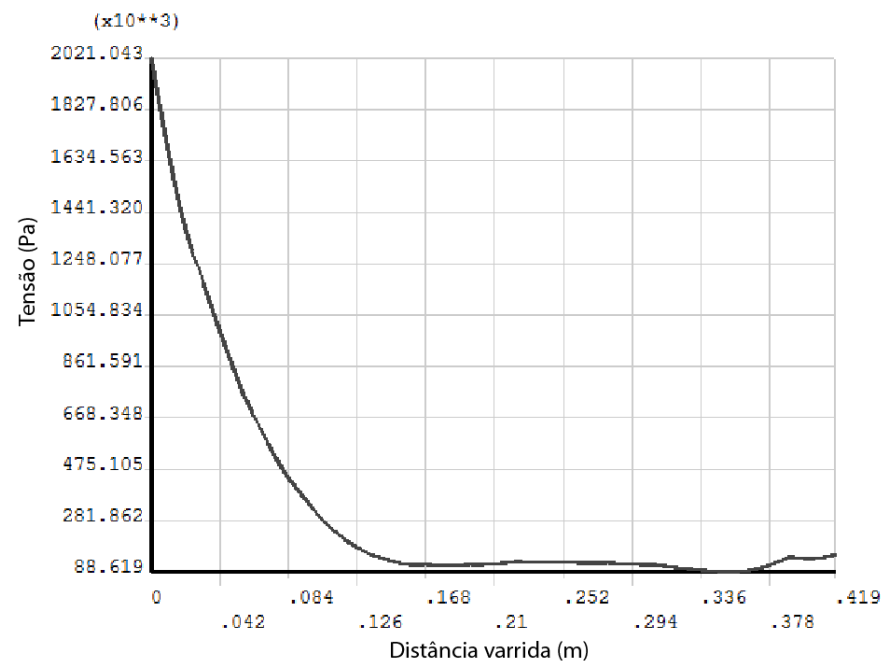

Figura 6.13 - Tensões de Von Mises ao longo do comprimento médio (sentido horário) da sapata secundária para o modelo do caso 2.

O campo de deformações equivalentes de Von Mises é mostrado na Figura 6.14. Conforme esperava-se, as deformações são maiores nas regiões de alta concentração de tensões, com valores máximos próximos de 0,0026.

Por sua vez, a Figura 6.15 exibe as condições de contato de deslizamento ao final da simulação do caso 2. Sua importância está no fato de que, com a aplicação de um torque, o sistema tende a se equilibrar e manter o contato nas faces da lona primária (sticking), mas tende a deslizar na lona secundária (sliding). Isso é esperado uma vez que a sapata primária sofre aumento da carga devido ao efeito autoenergizante, o que a comprime fortemente contra as paredes do tambor. 


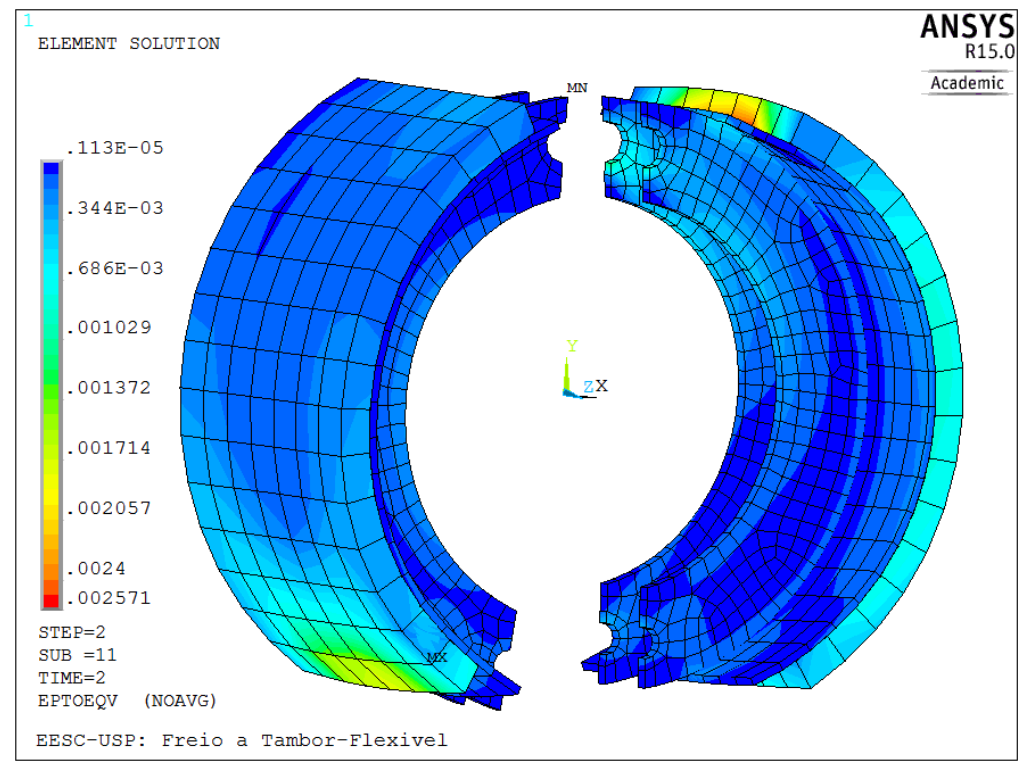

Figura 6.14 - Campo de deformações equivalentes de Von Mises do modelo do caso 2 plotados em termos de solução individual dos elementos, exibindo continuidade imperfeita, mas adequada, dos valores. Máximas deformações em 0,002571 nas extremidades das lonas.

Deve-se notar que há um ponto de nucleação de espaço vazio entre os contatos (indicado na figura como near contact), devido às deformações do modelo.

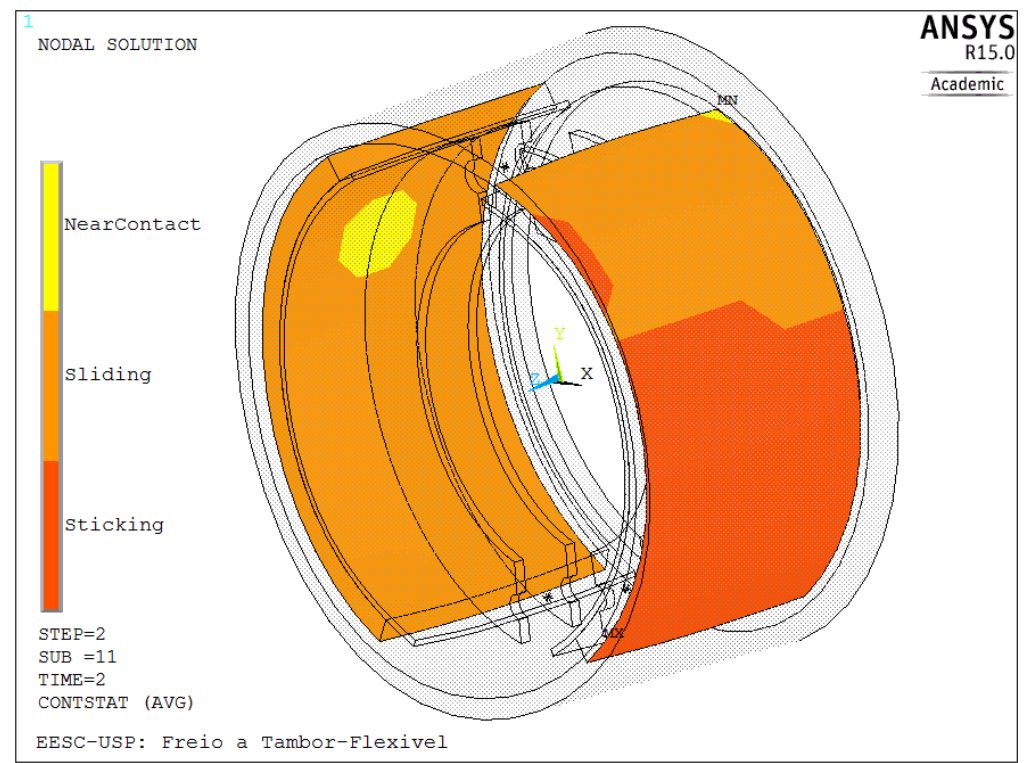

Figura 6.15 - Condição do contato na interface de atrito entre as lonas e o tambor, após a aplicação do torque, para o modelo do caso 2 .

Neste modelo, o calor toma maior importância devido ao deslizamento entre o tambor as lonas, o que é mostrado para as sapatas na Figura 6.16 e para o tambor 
na Figura 6.17. Nelas é possível ver que, nas regiões de atrito de deslizamento e altas cargas de compressão, temos a nucleação de pontos de maior temperatura. No caso, por quase não haver movimento relativo, as temperaturas máximas acabam superando os $21^{\circ} \mathrm{C}$.

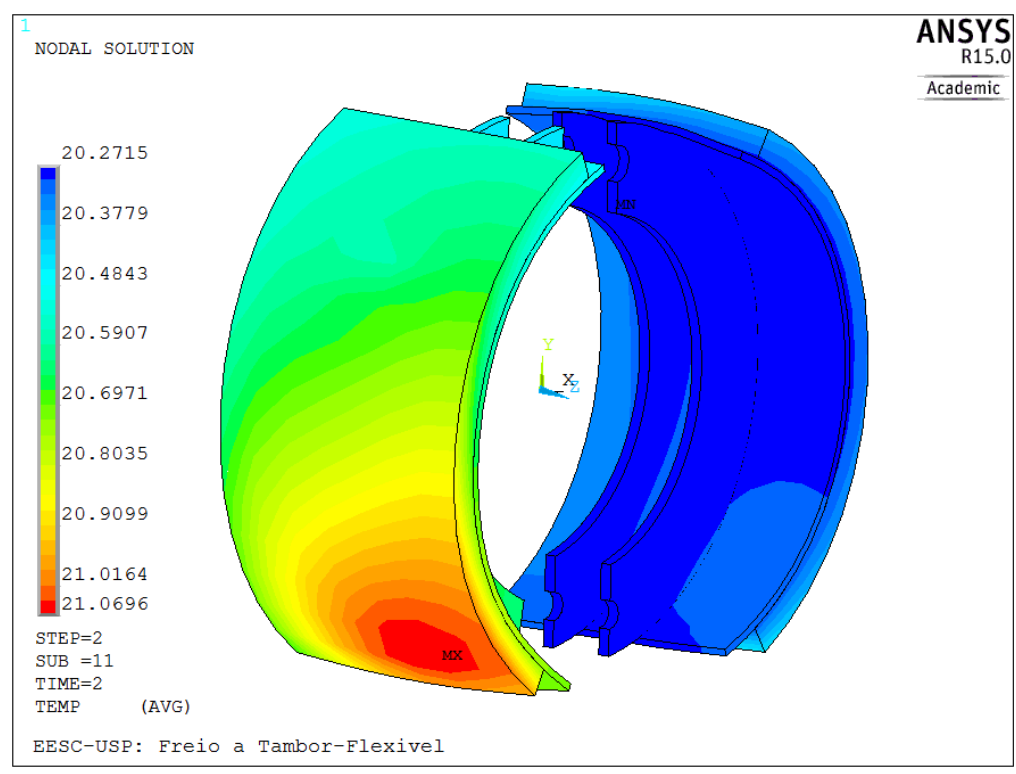

Figura 6.16 - Campo de temperaturas nas lonas e sapatas do freio do modelo do caso 2.

Temperatura máxima de $21,07^{\circ} \mathrm{C}$.

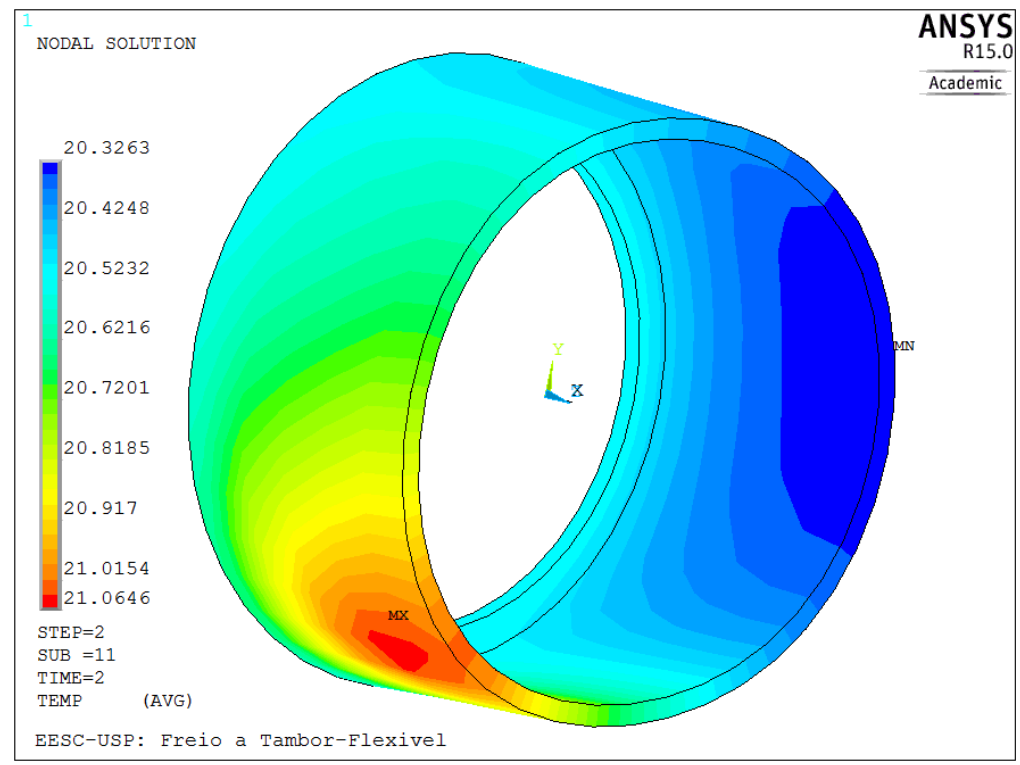

Figura 6.17 - Campo de temperaturas no tambor do freio do modelo do caso 2. Temperatura máxima de $21,06^{\circ} \mathrm{C}$. 


\subsection{CASO 3: ROTAÇÃo EM REgime PERMANENTE (MOdELo FLEXÍvEL)}

Novamente, as reações são plotadas sem exibir o espectro do modelo. Notase que os momentos de reação possuem valores não nulos, além das forças de reação nos nós-piloto ser composta de vetores orientados nos 3 eixos cartesianos, conforme mostra a Figura 6.18. A presença de reações das reações de apoio tridimensionais, além dos momentos de reação, indica o efeito da rotação aplicada ao tambor, mesmo que não haja, diretamente, um torque aplicado.
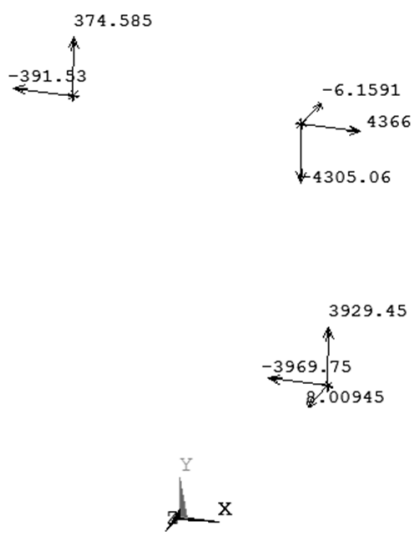

Reações

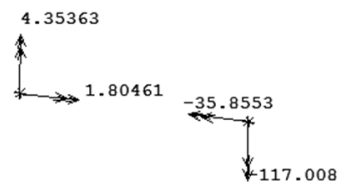

$$
\frac{-426.802}{22^{2} .104}
$$

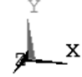

Momentos

Figura 6.18 - Reações de apoio e momentos resultantes nos nós-piloto da sapatas e tambor, sem exibição do modelo do caso 3.

Os valores das reações nos pinos das sapatas são expostos na Tabela 6.3, com indicação do valor resultante final de cada força.

Tabela 6.3 - Componentes e resultante das reações nos pinos ao final da análise do caso 3.

\begin{tabular}{ccccc}
\hline Sapata & $\boldsymbol{F}_{\boldsymbol{x}}$ & $\boldsymbol{F}_{\boldsymbol{y}}$ & $\boldsymbol{F}_{\boldsymbol{z}}$ & $\boldsymbol{R}$ \\
\hline Primária & $4366,0 \mathrm{~N}$ & $-4305,1 \mathrm{~N}$ & $-6,16 \mathrm{~N}$ & $\mathbf{6 1 3 1 , 5 5 \mathbf { N }}$ \\
Secundária & $-391,53 \mathrm{~N}$ & $374,59 \mathrm{~N}$ & $-0,04 \mathrm{~N}$ & $\mathbf{5 4 1 , 8 6 \mathbf { N }}$ \\
\hline
\end{tabular}

O gráfico da Figura 6.19 exibe os esforços de reação nas sapatas e sua evolução numérica ao longo dos 2 load steps usados na análise. Após 1 segundo, as forças estão completamente estabelecidas, enquanto que após 2 segundos a rotação, 
alterando os valores das reações. Neste gráfico apenas os valores de força de reação foram plotados, uma vez que os momentos são de baixa intensidade.

Nota-se uma elevação brusca dos valores das reações, o que é de se esperar no momento em que a rotação é aplicada.

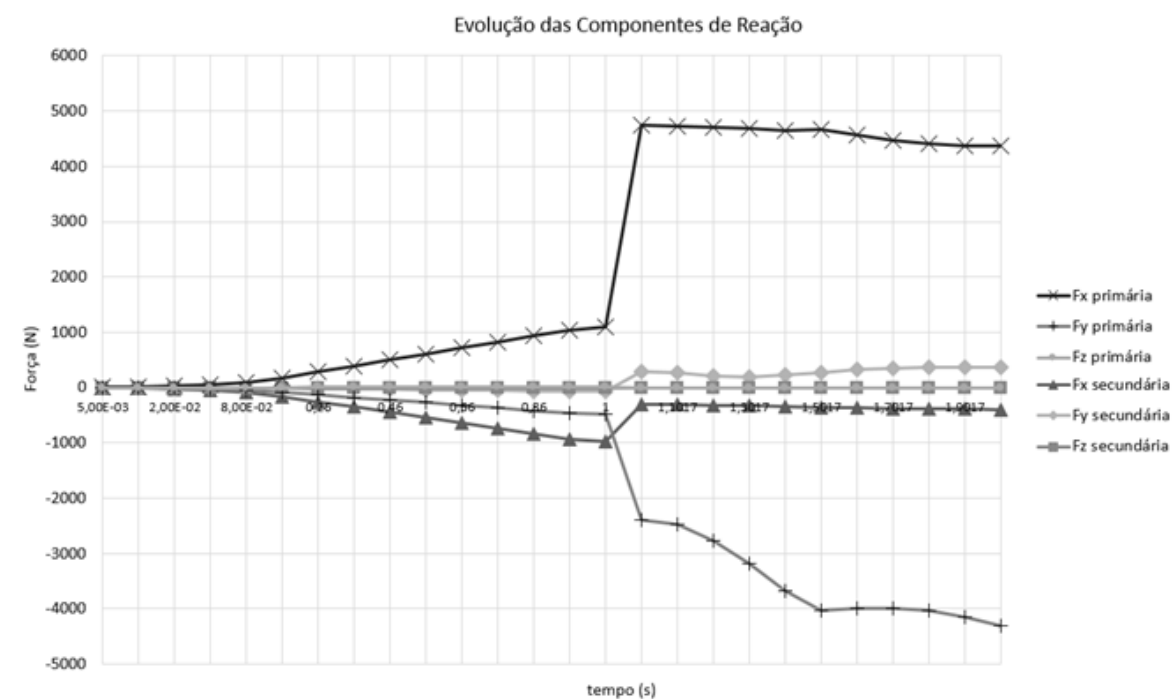

Figura 6.19 - Gráfico da evolução no tempo das reações de apoio, em $X, Y$ e $Z$, nos pinos das sapatas, considerando o modelo do caso 3.

A Figura 6.20 exibe a configuração deformada para este modelo, com ampliação de 80x. Nota-se o acentuado deslocamento do ponto de aplicação da força na sapata primária, porém o responsável pelo valor máximo de deslocamento em $0,611 \mathrm{~mm}$ é a borda direita do tambor, devido à expansão térmica sofrida.

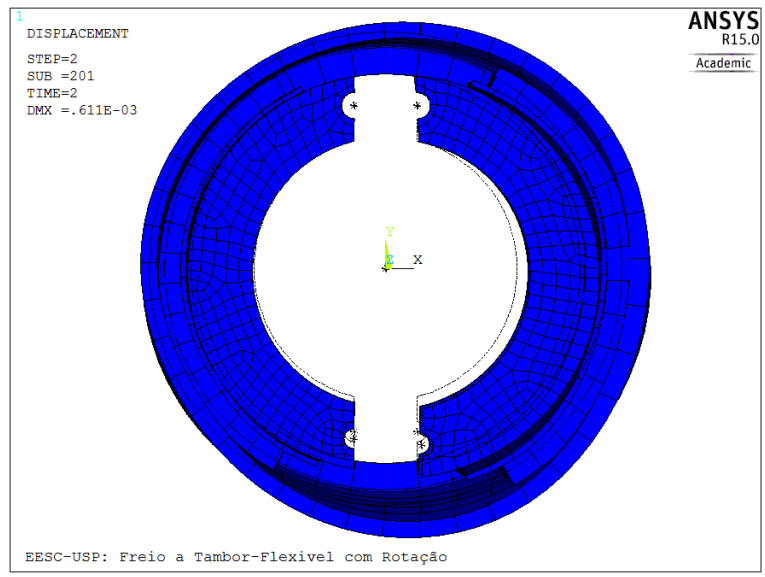

(a)

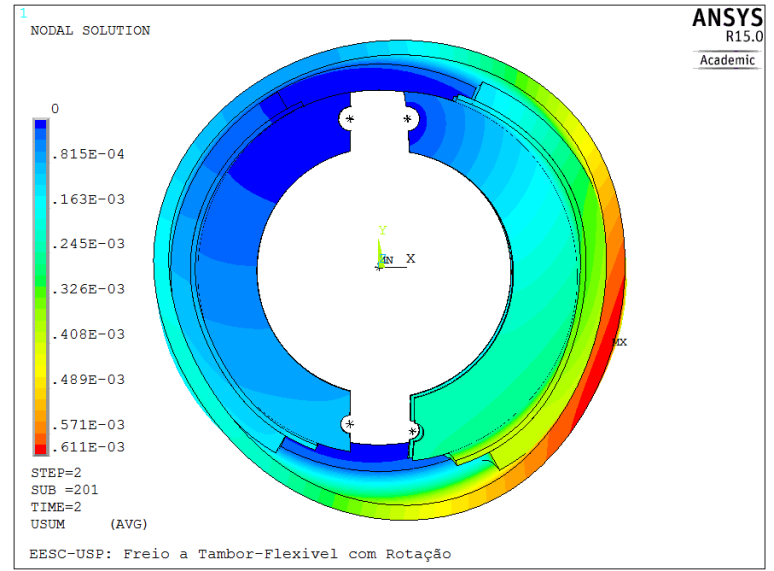

(b)

Figura 6.20 - Configuração deformada (80x) para o modelo do caso 3, apresentando deslocamento máximo em $0,611 \mathrm{~mm}$ nas bordas externas do tambor. 
A Figura 6.21 exibe os valores de tensão equivalente de Von Mises para o conjunto todo. Nota-se uma alta concentração de tensões no ponto de apoio e aplicação de esforços das sapatas, com valores máximos em $373 \mathrm{MPa}$, resultado do efeito auto-energizante e da deformação do conjunto.

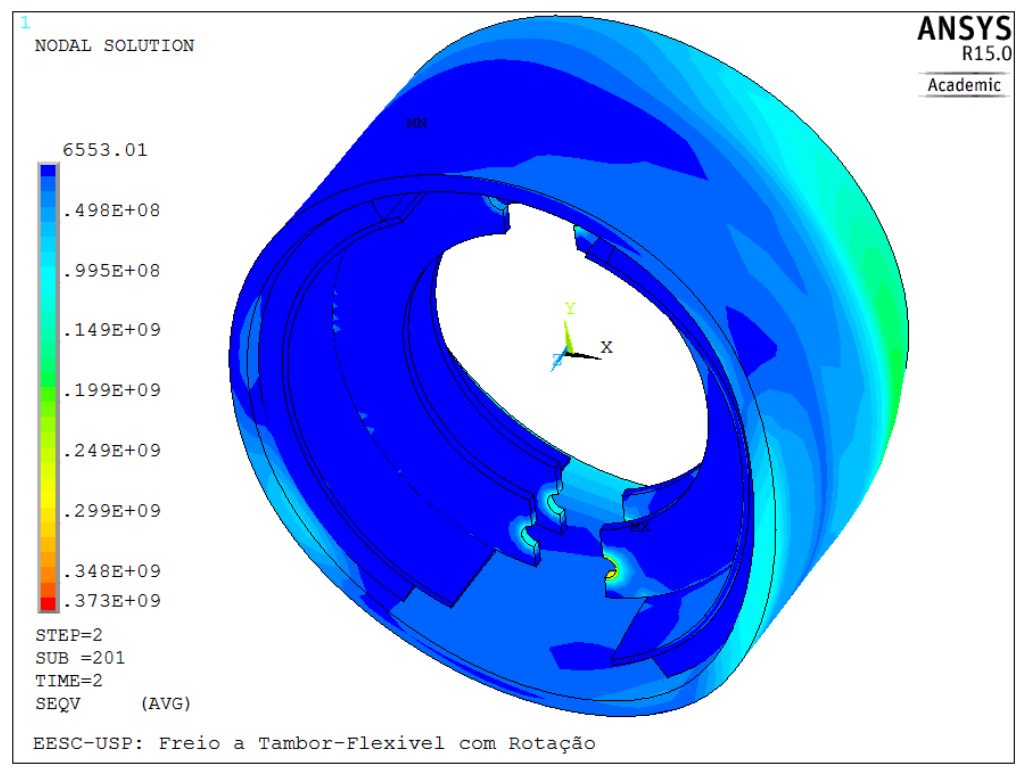

Figura 6.21 - Campo de tensões equivalentes de Von Mises do modelo do caso 3 , apresentando valor máximo de 373 MPa no ponto aplicação de força da sapata primária.

Por sua vez, a Figura 6.22 exibe os valores de tensão equivalente de Von Mises apenas para as lonas a fim de compará-las com as obtidas no casos 1 e 2 . Nota-se diferença com relação aos modelos anteriores, com concentração de tensões próximas de 1,5 MPa devido à presença de giro e deformações geradas por calor. Apesar dos esforços aplicados às sapatas terem sido estimados em $10 \%$ dos aplicados nos casos estáticos, nota-se que a lona atinge tensão equivalente acima do valor estipulado como limite de compressão, o que demonstra a forte influência do atrito de deslizamento. 


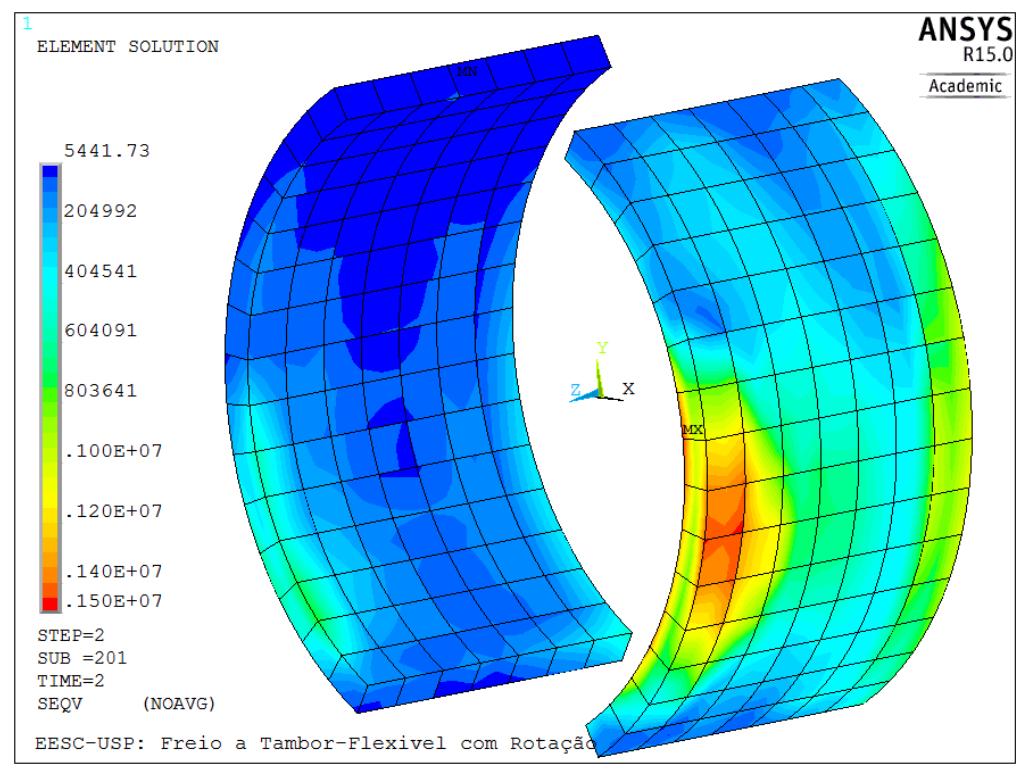

Figura 6.22 - Campo de tensões equivalentes de Von Mises das lonas do modelo do caso 3 plotados em termos de solução individual dos elementos, exibindo continuidade imperfeita, mas adequada, dos valores. Máxima tensão de 1,5 MPa

A Figura 6.23 e a Figura 6.24 plotam o gráfico de tensões de Von Mises ao longo do comprimento das sapatas. Nota-se que este caso diverge fortemente do caso 2, mas aproxima-se do caso 1, o que demonstra a importância na distinção entre um caso estático e outro dinâmico.

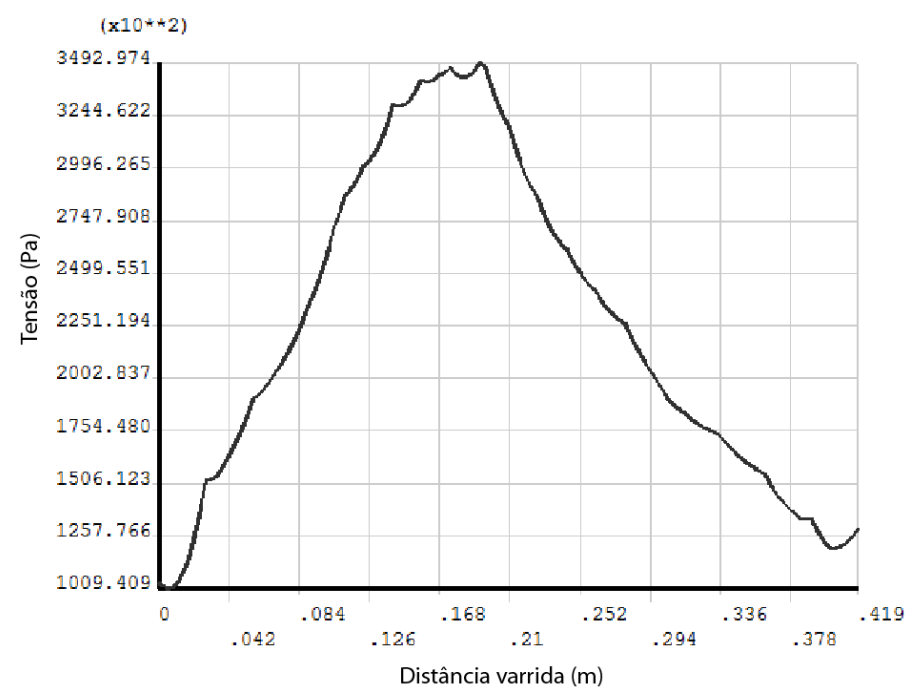

Figura 6.23 - Tensões de Von Mises ao longo do comprimento médio (sentido anti-horário) da sapata primária para o modelo do caso 3. 


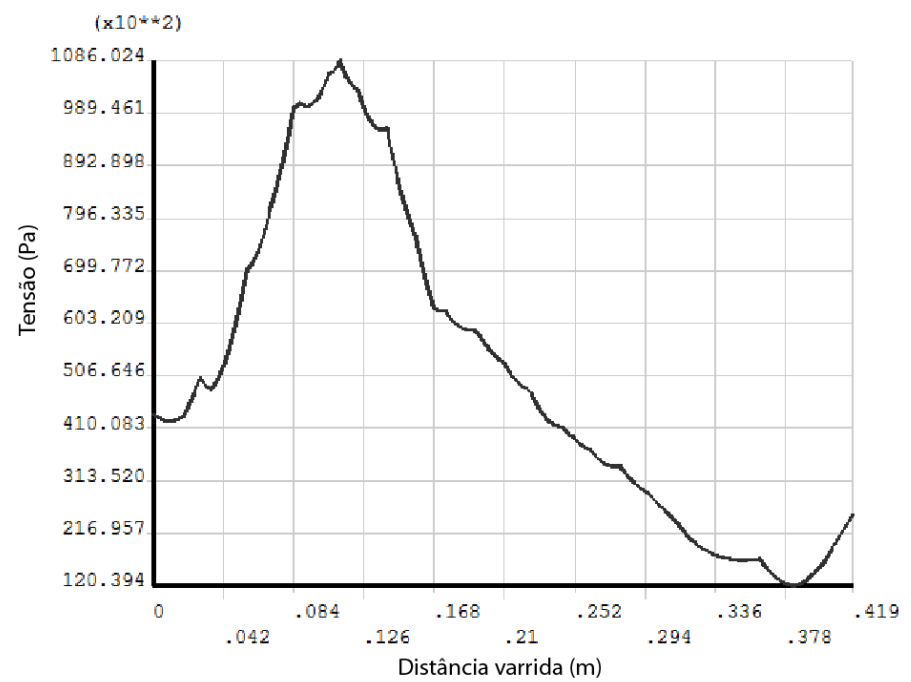

Figura 6.24 - Tensões de Von Mises ao longo do comprimento médio (sentido horário) da sapata secundária para o modelo do caso 3 .

O campo de deformações equivalentes de Von Mises é mostrado na Figura 6.25. Conforme esperava-se, as deformações são maiores nas regiões de alta concentração de tensões, mas neste caso presentes no ponto de aplicação da força e região de maior contato da lona com o tambor, com valores máximos próximos de 0,0019 .

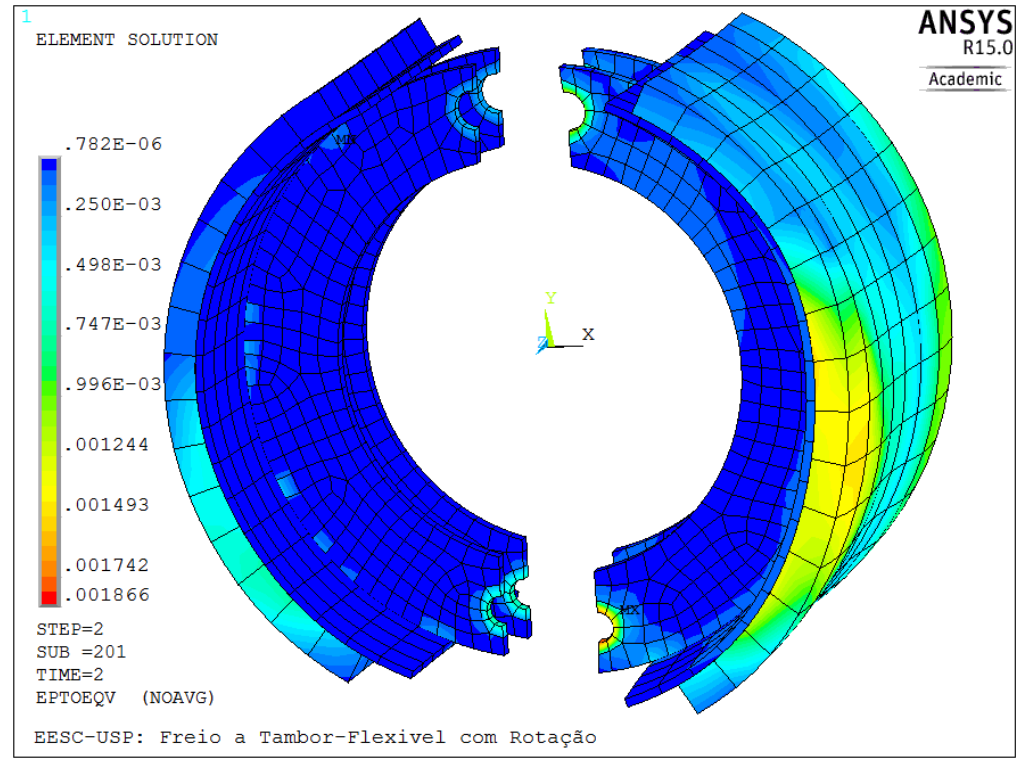

Figura 6.25 - Campo de deformações equivalentes de Von Mises do modelo do caso 3 plotados em termos de solução individual dos elementos, exibindo continuidade imperfeita, mas adequada, dos valores. Máximas deformações em 0,001866 no ponto de força e lona primária. 
Já a Figura 6.26 exibe as condições de contato de deslizamento ao final da simulação do caso 3. É possível notar que a velocidade de deslizamento possui importância crítica na condição do contato ao longo do tempo, uma vez que é evidente a separação dos corpos devido as deformações termoelásticas. Como era esperado, não há região de contato estático, mas apenas regiões com deslizamento (sliding) e distanciadas (near contact).

Esta configuração confere com aquilo que se encontra experimentalmente em relação à presença de hot spots em tambores de freio, que tomam forma de anéis de calor ao longo de seu diâmetro. Seu formato surge da acentuação da diferença de deformação termoelástica entre as almas da sapata e a lona.

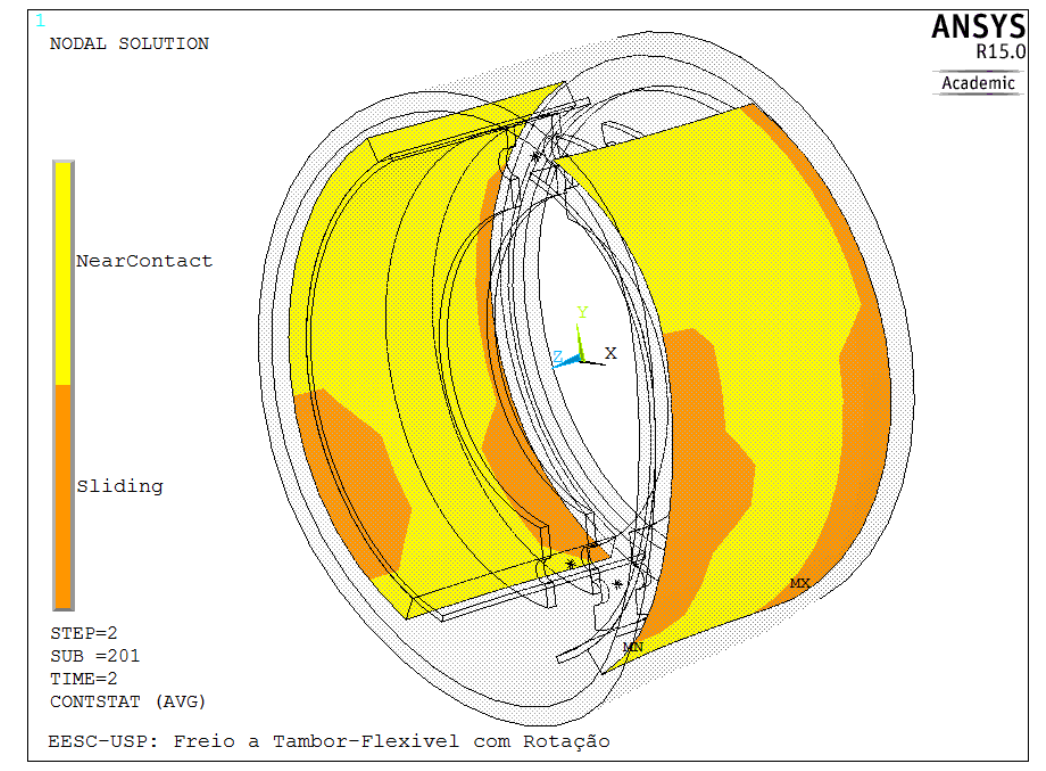

Figura 6.26 - Condição do contato na interface de atrito entre as lonas e o tambor, após a aplicação da velocidade de deslizamento, para o modelo do caso 3.

O calor e a temperatura tornam-se indispensáveis para uma análise mais correta de um modelo de frenagem em regime permanente. Conforme mostra a Figura 6.27 e Figura 6.28 , as temperaturas chegam $383^{\circ} \mathrm{C}$ na lona primária e $366^{\circ} \mathrm{C}$ na região de contato desta com o tambor, além dos valores distribuídos ao longo dos corpos estarem quase sempre acima dos $100^{\circ} \mathrm{C}$.

Um dos problemas em se utilizar a ferramenta CMROTATE é que o modelo não plota a distribuição da temperatura em regiões que a lona deve entrar em contato com o tambor ao longo do movimento relativo. Assim, tem-se a falsa impressão de que 
existem regiões a $27^{\circ} \mathrm{C}$, quando de fato estas estariam aquecendo e o campo de temperaturas teria uma característica mais próxima à de uma condição axissimétrica.

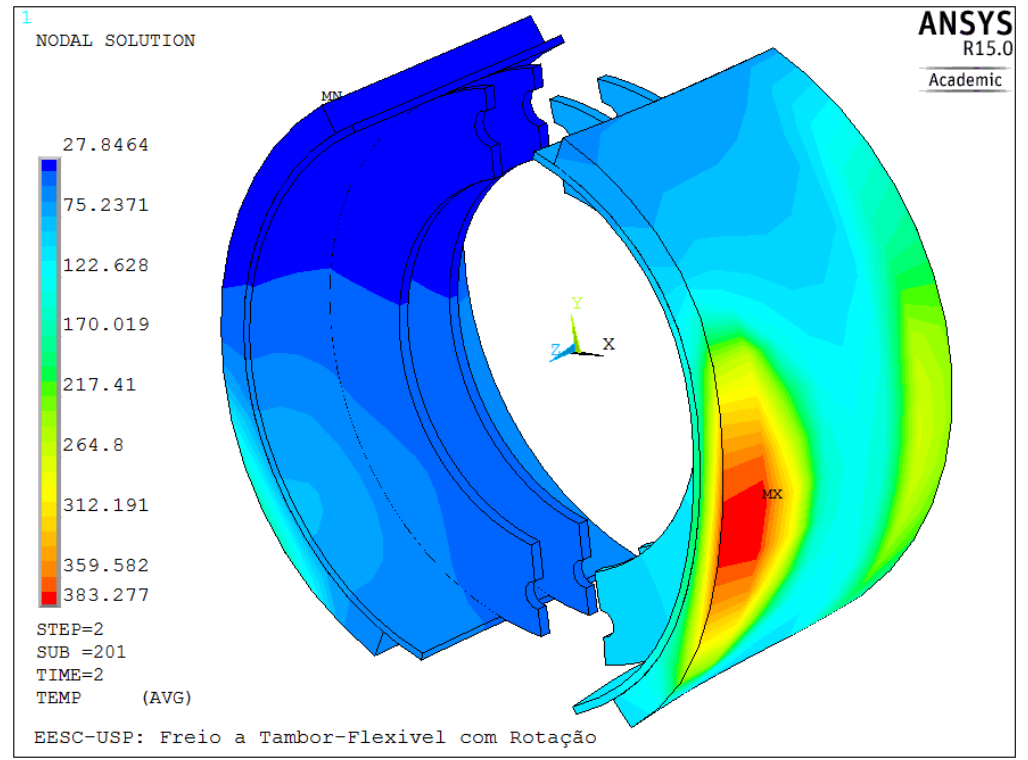

Figura 6.27 - Campo de temperaturas nas lonas e sapatas do freio do modelo do caso 3. Temperatura máxima de $383,3 \stackrel{\circ}{\circ}$.

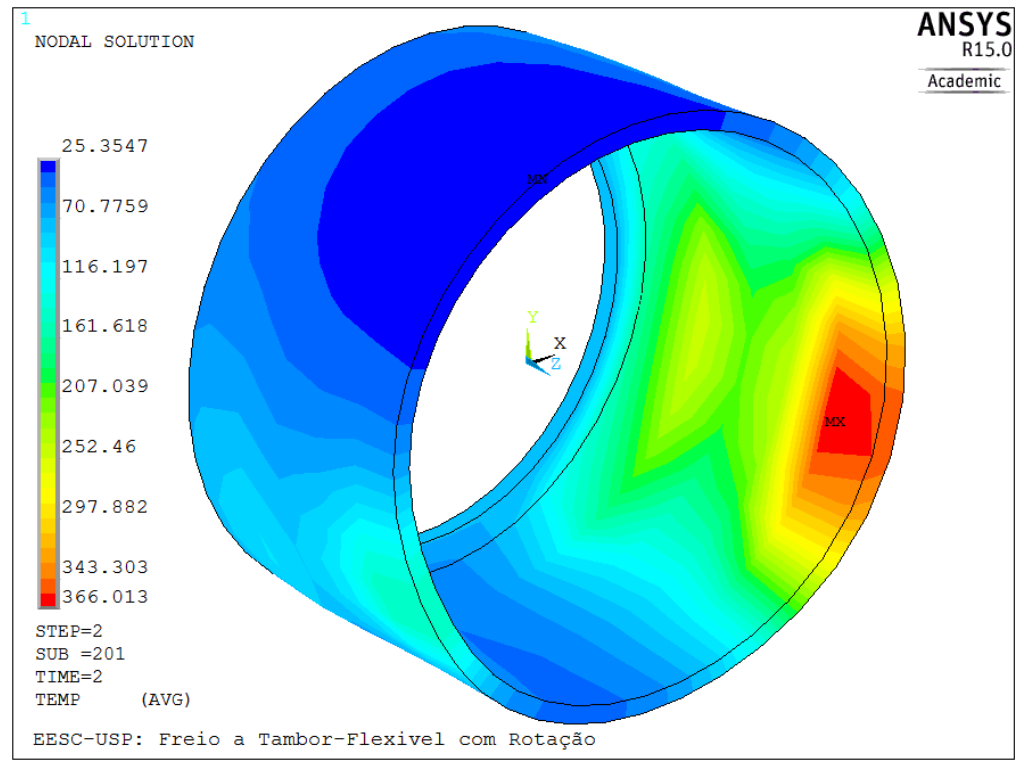

Figura 6.28 - Campo de temperaturas no tambor do freio do modelo do caso 3. Temperatura máxima de $366,0 \stackrel{\circ}{\circ}$. 


\subsection{VALIDAÇÃO}

\subsubsection{FrAÇÃO DE ABSORÇÃO DA ENERGIA}

Em uma primeira verificação, mediu-se os valores do fluxo na superfície do tambor e da lona, coletando dados nos nós de maior temperatura atingida para cada um. O resultado no tempo é mostrado na Figura 6.29.

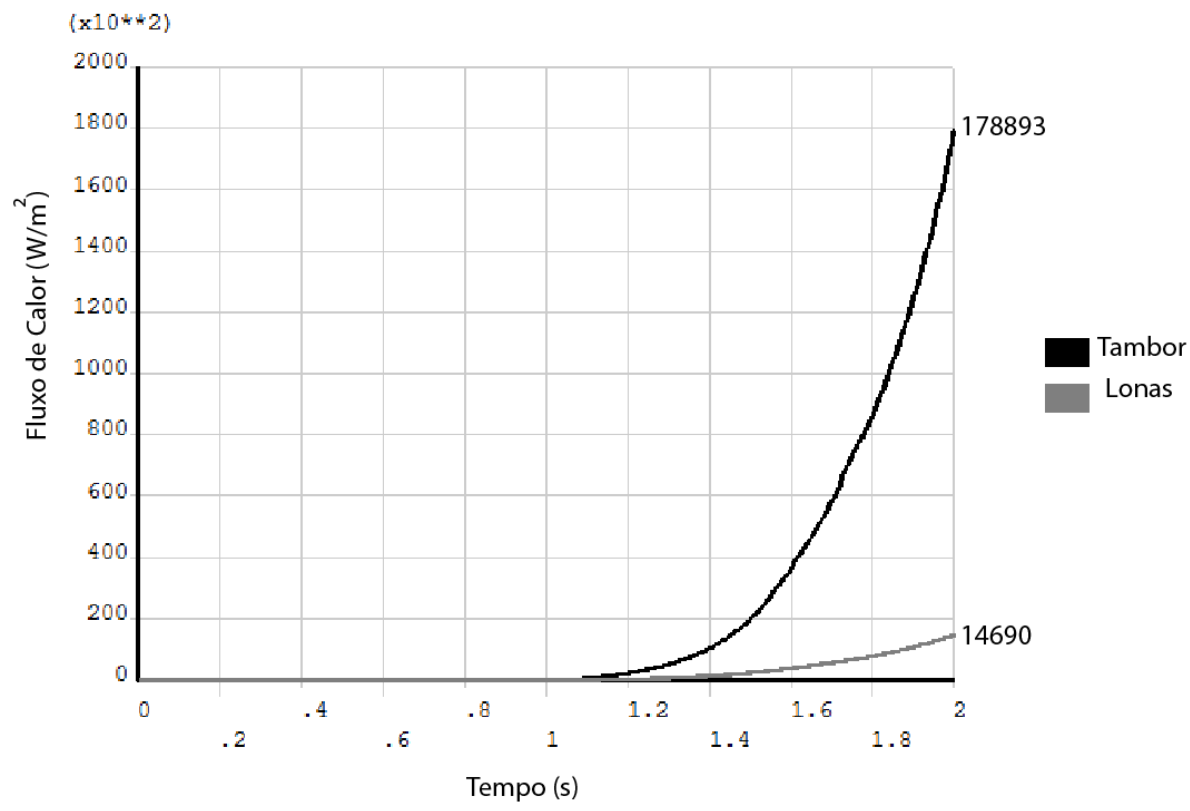

Figura 6.29 - Fluxo de calor direcionado ao tambor e à lona primária, no ponto de contato de máxima temperatura para o modelo do caso 3.

A partir do gráfico, podemos constatar os valores de fluxo máximo de calor para o tambor e lona primária após o regime permanente:

$$
q_{t}{ }^{\prime \prime}=178893 \mathrm{~W} / \mathrm{m}^{2} \text { e } q_{l}{ }^{\prime \prime}=14690 \mathrm{~W} / \mathrm{m}^{2}
$$

Assim, a fração de energia absorvida pelo tambor $\varphi_{t}$ definida anteriormente pôde ser calculada:

$$
\varphi_{t}=\frac{q_{t}{ }^{\prime \prime}}{q_{t}{ }^{\prime}+q_{l}{ }^{\prime \prime}}=0,924=92,4 \%
$$


o que indica que, aproximadamente, $92,4 \%$ do fluxo de calor gerado pelo atrito de frenagem neste modelo é direcionado ao tambor, e 7,6\% para as lonas $\left(\varphi_{l}\right)$.

A fim de se verificar este valor, foram aplicados os valores necessários à equação (4.24), que mostra-se a mais adequada para esta condição de frenagem. Com auxílio do software Solidworks ${ }^{\circledR}$ foi possível se obter o valor das áreas externas (i.e. sob efeito da convecção do ar), tanto do conjunto das sapatas e lonas quanto do tambor, conforme mostra a Figura 6.30. O valor aproximado foi de $0,45 \mathrm{~m}^{2}$ para ambos os casos.

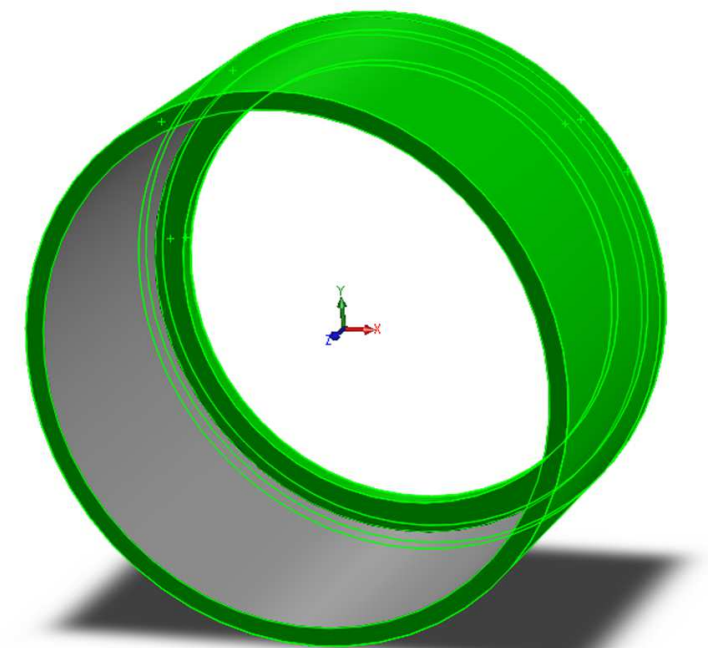

Área total: $0,45 \mathrm{~m}^{2}$

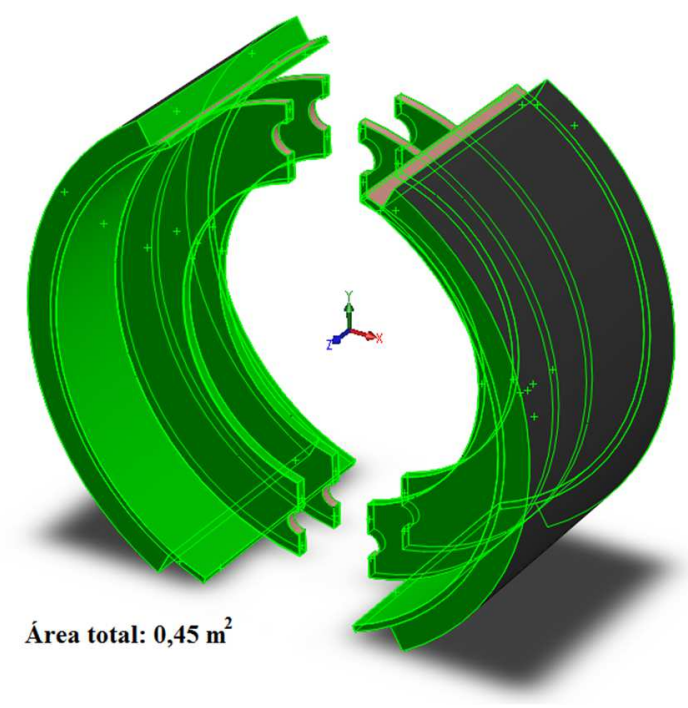

(b)

Figura 6.30 - Estimativa das áreas sujeitas à convecção de cada subconjunto: (a) Áreas externas do tambor; (b) Áreas externas (desconsiderando a região de contato) das sapatas.

Este e outros valores são expostos abaixo, baseados na geometria dos componentes e valores obtidos junto as Tabelas 5.1, 5.2 e 5.3, para que, enfim, a equação (4.24) seja verificada:

$$
\begin{aligned}
A_{t} & =0,45 \mathrm{~m}^{2} \\
A_{l} & =0,45 \mathrm{~m}^{2} \\
k_{t} & =46,86 \mathrm{~W} / \mathrm{mK} \\
k_{l} & =1,40 \mathrm{~W} / \mathrm{mK} \\
k_{s} & =60,00 \mathrm{~W} / \mathrm{mK}
\end{aligned}
$$

$$
\begin{aligned}
\delta_{l} & =0,02 \mathrm{~m} \\
\delta_{s} & =0,01 \mathrm{~m} \\
h_{l} & =10,60 \mathrm{~W} / \mathrm{m}^{2} \mathrm{~K} \\
h_{t} & =105,20 \mathrm{~W} / \mathrm{m}^{2} \mathrm{~K}
\end{aligned}
$$


Por sua vez, o resultado obtido é foi:

$$
\varphi_{t}=0,9196=91,96 \%
$$

o que indica que, teoricamente, aproximadamente $92 \%$ do fluxo de calor total gerado na frenagem estudada deveria ser direcionada ao tambor e $8 \%$ para as lonas $\left(\varphi_{l}\right)$. Este valor confere, com muita proximidade, com o obtido por leitura direta feita no modelo numérico $(92,4 \%)$.

Além da proximidade obtida através dos cálculos analíticos, o resultado pôde ser interpretado de acordo com o gráfico da Figura 4.2, do ítem 4.2.2, que mostra valores para diversos estudos da fração de energia absorvida pela lona, em relação à condutividade térmica da zona ITL. Segundo a imagem, o valor obtido se aproxima da condição para $k_{I T L}=k_{\text {Disco }}(48 \mathrm{~W} / \mathrm{mK})$, uma vez que seu valor converge para próximo de $\varphi_{l}=10 \%$.

\subsubsection{TEMPERATURA MÁXIMA DE FRENAGEM}

A Figura 6.31 mostra o gráfico no tempo da evolução das temperaturas máximas no tambor e na lona primária.

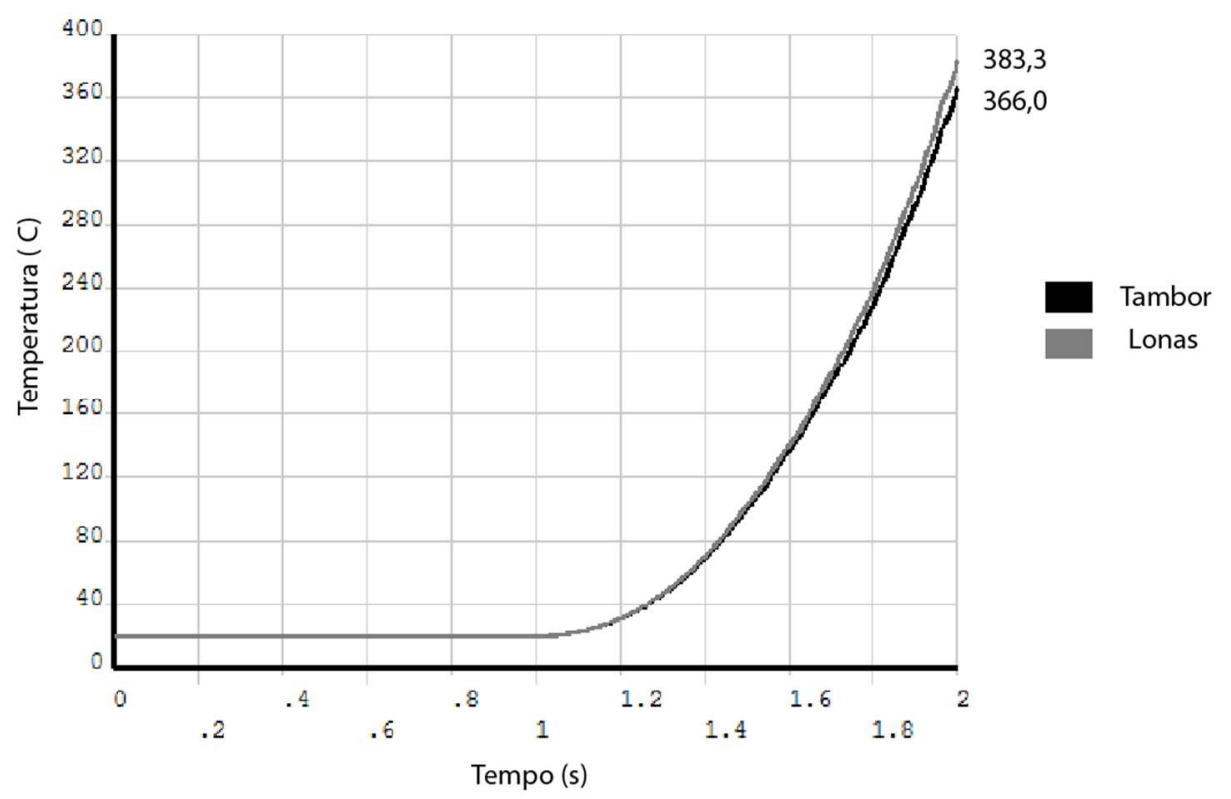

Figura 6.31 - Temperaturas máximas para as superfícies de contato do tambor e lona primária para o modelo do caso 3. 
Para se comparar a temperatura máxima obtida no tambor, durante a simulação feita para o caso de rotação em regime permanente, utilizou-se a equação (4.29), por ter sido definida para freios a tambor em condição de frenagem contínua. Novamente, o software SolidWorks ${ }^{\circledR}$ foi utilizado, desta vez para estimar o volume ocupado pelo tambor, resultando em $v_{t}=0,01 \mathrm{~m}^{3}$.

De posse dos demais valores necessários, os quais estão listados abaixo, foi possível comparar o resultado obtido com a solução da equação (4.28). Por simplicidade, optou-se pela conversão do tempo de segundos para horas:

$$
\begin{aligned}
T_{i} & =293 \mathrm{~K} & \rho_{t} & =7150 \mathrm{~kg} / \mathrm{m}^{3} \\
T_{\infty} & =293 \mathrm{~K} & C_{p t} & =603 \mathrm{~J} / \mathrm{kgK} \\
h & =378651,81 \mathrm{~J} / \mathrm{hKm}^{2} & v_{t} & =0,01 \mathrm{~m}^{3} \\
A_{t} & =0,45 \mathrm{~m}^{2} & q^{\prime \prime}{ }_{t} & =178893\left(\frac{\mathrm{J}}{\mathrm{m}^{2} s}\right) \times 3600\left(\frac{s}{h}\right)=644014800 \mathrm{~J} / \mathrm{hm}^{2}
\end{aligned}
$$

Com o fluxo de calor por unidade de área na região de máxima temperatura no tambor $\left(q^{\prime \prime}\right)$, podemos calcular a taxa de calor transferida nesta área para ser empregada na equação. Estimou-se esta área em $30 \%$ da área total da superfície interna do tambor, considerando o tambor girando para melhor aproximação com a formulação analítica. Assim, conforme visto na Figura 5.2, o raio interno do tambor é $0,21 m$ e sua largura $0,22 m$, o que fornecendo a fração da área interna a ser aplicada no cálculo da taxa de calor na região de máxima, conforme segue:

$$
q_{t}=644014800 \times 0,3(2 \pi \times 0,21 \times 0,22)=57961332 J / h
$$

Dessa forma, a equação (4.29) pode, então, ser dada em função do tempo:

$$
T(t)=-340,16 e^{-(3,95 t)}+633,16 \quad \text { (t em horas; T em Kelvin) }
$$

O gráfico da Figura 6.32 exibe o comportamento da curva formada pela equação (4.28) quando colocada sob a forma de função do tempo em horas. Nota-se que em regime permanente, as condições adotadas convergem para uma temperatura de, aproximadamente, $360^{\circ} \mathrm{C}$ nas regiões onde o fluxo de calor no tambor é máximo. Segundo o mesmo gráfico, o regime é atingido em 1 hora e 20 minutos ( $\cong 1,3$ horas). 


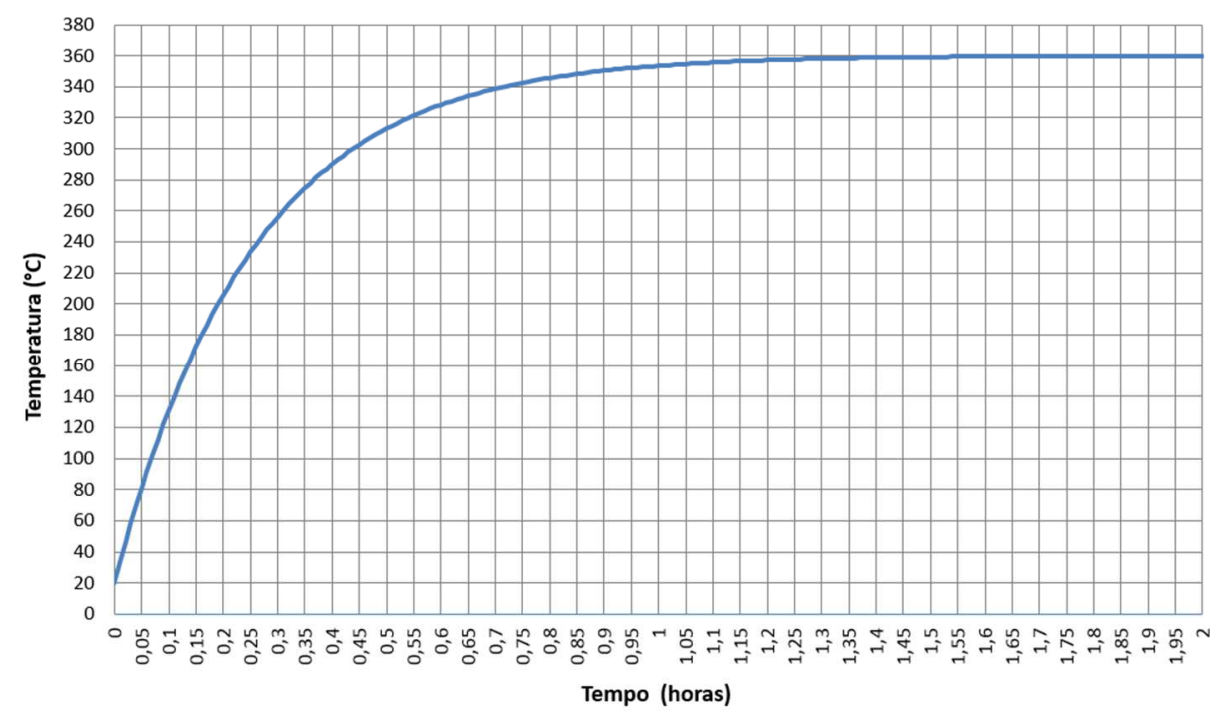

Figura 6.32 - Plotagem da temperatura máxima no tambor calculada em função do tempo, com base na equação (4.29) empregando valores físicos do modelo estudado.

\subsubsection{ComparaçÃo COM A Literatura}

Os resultados deste trabalho, em especial o caso 3, podem ser comparados a outros semelhantes obtidos na literatura técnico-científica voltada para área.

Conforme mencionando na revisão da literatura (Capítulo 2), os experimentos em pino sobre disco realizados por Abbasi et al. (2014), seguidos de modelos transientes de elementos finitos, estimam uma média de fração da energia de atrito absorvida pelo pino em $17 \%$ e $83 \%$ para o disco. Alguns valores ensaiados chegam, inclusive, próximos da fração 10 e $90 \%$, o que confirma a possibilidade do modelo do caso 3 estar próximo da realidade, o que deve ser confirmado experimentalmente nas mesmas condições.

Em outro caso, a imagem mostrada na Figura 6.33 foi obtida a partir de um vídeo promocional disponibilizado pelo fabricante de sistemas automotivos Webb (2015), e mostra um ensaio em dinamômetro com captura de imagem termográfica do lado externo de um tambor semelhante ao estudado neste trabalho. $O$ ensaio realizado estuda condições durante frenagens sucessivas que demonstrem o tempo de aquecimento e recuperação do sistema. Apesar de não se tratar de um ensaio com giro baixo e constante, sua temperatura máxima, de $260{ }^{\circ} \mathrm{C}$ possui ordem de grandeza próxima a encontrada no estudo do caso 3. 


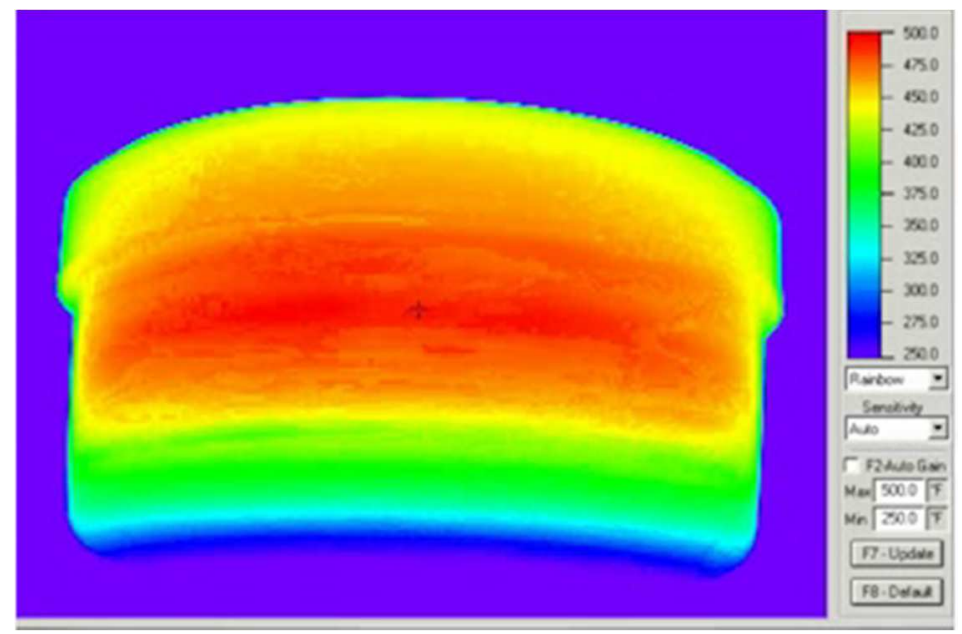

Figura 6.33 - Termografia de ensaios de frenagem de um sistema de freio a tambor para veículos pesados. Temperatura máxima de $500^{\circ} \mathrm{F}\left(260^{\circ} \mathrm{C}\right)(\mathrm{WBB}, 2015)$.

Nesta mesma linha de estudo de frenagens consecutivas, Valvano e Lee (2000) obtiveram um aumento de temperatura sobre um disco de freio que chega aos $419 \stackrel{\circ}{\mathrm{C}}$ ao atingir o regime permanente, por meio da aplicação de um fluxo de calor variável no tempo em um modelo de elementos finitos. De maneira mais elaborada, Lee, Son e Yang (2006) realizaram simulações transientes por elementos finitos, considerando acoplamento termoelástico, a fim de avaliar a distribuição de temperatura e tensões em freios automotivos a tambor. A simulação do aumento da temperatura na lona de freio foi comparada ao correspondente ensaio de bancada, gerando a plotagem gráfica mostrada na Figura 6.34. Após 30 frenagens, os autores obtiveram valores de temperatura máxima próximos dos $300{ }^{\circ} \mathrm{C}$, o que tende a se aproximar do valor de $383^{\circ} \mathrm{C}$ obtido para a lona primária do estudo do caso 3 .

Limpert (1999) indica que, a $375^{\circ} \mathrm{C}$, o diâmetro de um tambor de freio de carro de passeio típico pode aumentar de 1 a $1,5 \mathrm{~mm}$, suficiente para aumentar entre $30 \mathrm{a}$ $40 \%$ a distância do pedal. A Figura 6.28 , relativa ao caso 3, mostra valores máximos próximos de $370^{\circ} \mathrm{C}$ na interface lona/tambor. Quando comparada à Figura 6.20, que indica um deslocamento o campo de deslocamentos do conjunto, vê-se claramente que o diâmetro do tambor chega próximo de uma abertura de $1 \mathrm{~mm}$, de acordo com o previsto. 


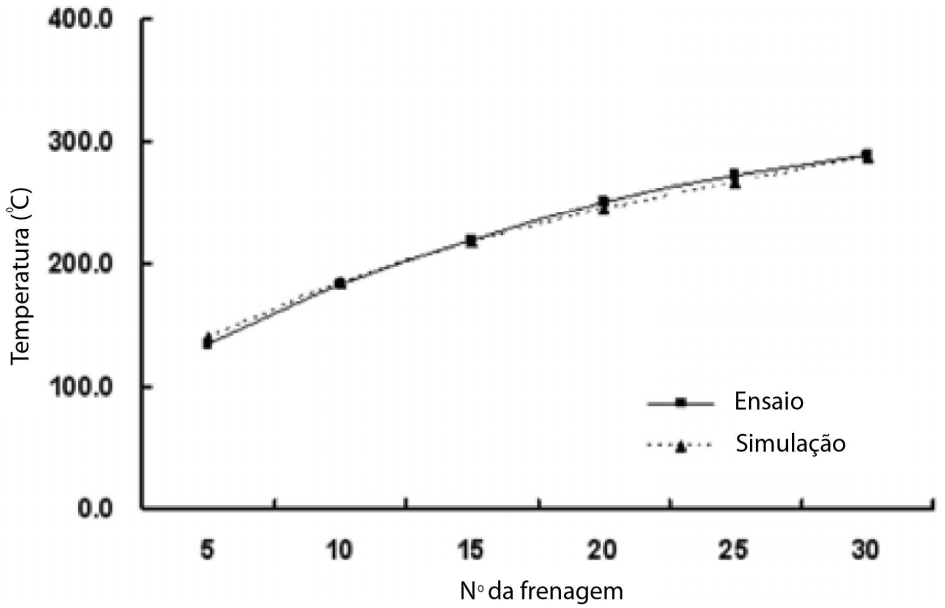

Figura 6.34 - Evolução da temperatura da lona de um freio a tambor em ensaio de frenagens sucessivas (LEE; SON; YANG, 2006). 


\section{CONCLUSÕES}

O projeto de freios envolve um estudo aprofundado das condições estáticas e dinâmicas ao qual será submetido. O emprego de modelos multifísicos que incorporem o comportamento da transferência de calor e de tribologia pode gerar modelos computacionais confiáveis, que além de reduzir o número de experimentos físicos, atribuem requisitos de confiabilidade e durabilidade ao projeto.

A análise estática, considerando em um primeiro estudo corpos rígidos, e posteriormente elementos flexíveis permitiu comparar como a simplificação altera os resultados de tensão e deformação, além das reações nos pontos de pivotamento das sapatas. $\mathrm{Na}$ análise estática, com modelo de elementos flexíveis, cada sapata foi modelada como estrutura esbelta metálica possuindo maior rigidez, enquanto que a lona, como material compósito, apresenta baixo módulo de elasticidade. Nos resultados pode-se perceber uma redução nas reações de apoio, bem como um aumento da deformação total do modelo. Essa condição ocorre, porque no modelo de corpos rígidos a lona se expande e fica restrita aos contatos rígidos que a circundam. No terceiro modelo, que incluiu a velocidade de deslizamento em regime transiente, pode-se observar a complexidade dos mecanismos envolvidos no processo de frenagem. As temperaturas atingem valores máximos de $366^{\circ} \mathrm{C}$ e $383^{\circ} \mathrm{C}$ obtidos para o tambor e lona da sapata primária, respectivamente, sem a necessidade da aplicação de grandes esforços. O contato de deslizamento não uniforme entre a lona e a sapata também pôde ser identificado, gerando uma condição de pressão não uniforme que pode conduzir à um conjunto de modos de falhas durante a vida útil do sistema de frenagem. Alguns desses modos de falha são o fade, surgimento de hot-spots, com posterior surgimento de vibrações ou hot judder e vitrificação do tambor.

O processo de frenagem é um fenômeno extremamente complexo, e a área de estudo relacionada requer $\mathrm{o}$ uso das melhores ferramentas computacionais disponíveis. Neste trabalho, a dificuldade de implementação de um modelo em regime transiente foi sentida logo em sua primeira tentativa, avaliando um sistema simples de contato de deslizamento entre uma barra e um bloco de aço. Por mais que se queira um modelo o mais próximo da realidade dos experimentos, deve-se sempre lembrar da disponibilidade de outras formas de testes e simulações, como foi o caso da escolha do emprego de rotação em regime permanente. 
A partir da verificação analítica, bem como a comparação feita com trabalhos semelhantes, concluiu-se que os modelos podem prover resultados confiáveis, contribuindo para a economia de custos com ensaios do gênero.

Em trabalhos futuros, será de grande importância a validação experimental destes modelos, a partir do emprego de termopares, strain-gauges e dinamômetros de bancada, principalmente aplicando as condições e simplificações de cada um e separar o máximo possível das influências entre os parâmetros, dado a forte presença da soma de efeitos térmicos e elásticos não-lineares.

Pretende-se aprofundar o estudo da termoelasticidade em sistemas de freio a partir da investigação de modelos constitutivos para materiais em contato de atrito. Conforme mencionado ao longo deste texto, vários métodos foram propostos, mas cada um se adequa às condições específicas as quais foram calibrados. Entretanto, sabendo aproveitar esta vasta literatura existente, pode-se realizar contribuições muito importantes para o equacionamento deste e outros fenômenos multifísicos presentes, como a condição elasto-plástica que governa a formação da região ITL na interface lona/tambor, a possibilidade de novos projetos visando melhorar o controle da rigidez nas sapatas e a aplicação de materiais com memória de forma que podem se beneficiar do calor excessivo. Porém, este estudo deve ser combinado com experimentos de alto rigor técnico e científico, como os realizados em ensaios de dinamômetros industriais.

Outros fenômenos tribológicos que envolvam acoplamentos multifísicos podem se beneficiar do andamento deste estudo, tal como a aplicação ao desgaste de mancais de rolamento e deslizamento, influência da termo-elasto-plasticidade nas velocidades críticas de giro de eixos, em processos de usinagem e conformação nãoconvencionais, e outros. 


\section{REFERÊNCIAS BIBLIOGRÁFICAS:}

ABBASI, S. et al. Temperature and termoelastic instability at tread braking using cast iron friction material. Wear, v. 314, n. 1-2, p.171-180, June 2014.

ABDEL-AAL, H. A. A remark on the flash temperature theory. Int. Comm. Heat Mass Transfer, v. 24, n. 2, p. 241-250, Apr. 1997.

ADAMOWICZ, A.; GRZES, P. Analysis of disc brake temperature distribution during single braking under non-axisymmetric load. Applied Thermal Engineering, v. 31, n. 6-7, p.1003-1012, May 2011.

AMIRI, M.; KHONSARI, M. M. On the thermodynamics of friction and wear - A review. Entropy, v. 12, n. 5, p.1021-1049, Apr. 2010.

ANDERSON, A. E.; KNAPP, R. A. Hot spotting in automotive friction systems. Wear, v. 135, n. 2, p.319-337, Jan. 1990.

ARANGO, C. C. Transição no regime de desgaste por deslizamento dos aços: uma abordagem termodinâmica. Tese (Doutorado em Engenharia Mecânica de Projeto de Fabricação) - Escola Politécnica, Universidade de São Paulo, São Paulo, 2010.

ASM Handbook Volume 1: Properties and selection: irons, steels and high performance alloys, 10. ed., 1990.

BARBER, J. R. Thermoelastic instabilities in the sliding of conforming solids. Proceedings of the royal society of London, série A, v. 312, p. 381-394, Sep. 1969.

BARBER, J. R. Solid mechanics and its applications - volume 172: Elasticity. 3. ed. Springer, 2010. 534 p. 
BELHOCINE, A.; BOUCHETARA, M. Thermo-mechanical analysis of a disc braking system.Transaction On Control And Mechanical Systems, v. 2, n. 6, p.302-309, Jun. 2013.

BERGMAN, T. L. et al. Fundamentals of heat and mass transfer. 7. ed. Jefferson City: John Wiley And Sons, 2011. 1048 p.

BERGMAN, F.; ERIKSSON, M.; JACOBSON, S. Influence of disc topography on generation of brake squeal, Wear, v. 225-229, n.1, p. 621-628, Apr. 1999.

BIOT, M. A. Thermoelasticity and irreversible thermodynamics, Journal of Applied Physics, v. 27, n.3, p. 240-253, Mar. 1956.

BLOK, $\mathrm{H}$. Theoretical study of temperature rise at surfaces of actual contact under oiliness lubricating condition, Proc. General Discussion on Lubrication and Lubricants, London, v. 2, p.222-235, 1937.

BUDYNAS, R.; NISBETT, J. Shigley's mechanical engineering design. 9. ed. New York: Macgraw Hill Companies, 2011.

CHAN, D.; STACHOWIAK, G. W. Review of automotive brake friction materials.Proceedings Of The Institution Of Mechanical Engineering, Part D: J Automobile Engineering, v. 218, n. 9, p.953-966, Sep. 2004.

CHIARONI, A.; SILVEIRA, Z. C. Thermal analysis o frear drum brake for lightweight passenger vehciles. Congresso SAE Brasil 2014, São Paulo, 2014.

CHIAVERINI, Vicente. Aços e ferros fundidos. 7. ed. São Paulo: Abm, 2005.

$\mathrm{CHO}, \mathrm{H}$.; $\mathrm{CHO}, \mathrm{C}$. Prediction of Hot Spots by Correlating Finite Element Analysis and Measurement for an Automotive Disk Brake. Tribology Transactions, v. 51, n. 5, p.609-620, Oct. 2008. 
$\mathrm{CHO}, \mathrm{K} . \mathrm{H}$. et al. The Roles of Ingredients in Fade Resistance of Brake Friction Materials. Jornal Of The Korean Society Of Tribologists And Lubrication Engineers, v. 25, n. 1, p.31-37, Feb. 2009.

$\mathrm{CHOI}$, J.; LEE, I. Finite element analysis of transient thermoelastic behaviors in disk brakes. Wear, v. 257, n. 1-2, p.47-58, July 2004.

CNT. Boletim Estatístico - Fevereiro 2015. Disponível em: < http://www.cnt.org.br/Paginas/Boletins_Detalhes.aspx?b=3 >. Acesso em: 13 mar. 2015.

DAY, A. J.; NEWCOMB, T. P. Combined thermal and mechanical analysis of drum brakes. Proceedings of the Institution of Mechanical Engineering, Part D: J Automobile Engineering, v. 198, n. 4, p.287-294, Oct. 1984.

DOW, T. A.; BURTON, R. A. Thermoelastic instability of sliding contact in the absence of wear. Wear, v. 19, n. 3, p. 315-328, Mar. 1972.

DUHAMEL, J. M. C., Second mémoire sur les phénomènes thermomécaniques, J. de l'Ecole Polytechn. V.15, p. 1-15, 1837.

ERIKSSON, M.; BERGMAN, F.; JACOBSON, S. On the nature of tribological contact in automotive brakes. Wear, v. 19, n. 1-2, p. 26-36, Jan. 2002.

EVTUSHENKO, O. O.; IVANIK, E. H.; HORBACHOVA, N. V. Analytic methods for thermal calculation of brakes (review). Materials Science, v. 36, n. 6, p.857-862, 2000.

FRAS-LE, Technical Manual Heavy Duty. Manual técnico de sistemas de freio de veículos pesados, 2014.

GUESSER, W. L.; GUEDES L.C., Desenvolvimentos recentes em ferros fundidos aplicados à indústria automobilística. IX Simpósio de Engenharia Automotiva, AEA. São Paulo,1997. 
GUESSER, W. et al. Ferros fundidos empregados para discos e tambores de freio, Brake Colloquium SAE Brazil, Gramado, 2003.

HAMID, M. N. A.; TEOH, C.; RIPIN, Z. M. The operational deflection shapes and transient analysis of the brake shoes in drum brake squeal. Proceedings of the Institution of Mechanical Engineering, Part D: J Automobile Engineering, v. 6, n. 227, p.866-884, Jun. 2013.

HERRING, J. Mechanism of Brake Fade in Organic Brake Linings. Sae Technical Paper 670146, Feb. 1967.

HODEL, M.N. Análise comparativa entre ensaios controlados e aplicações reais de pastilhas de freios de caminhões. Dissertação (Mestrado em Engenharia Mecânica) - Universidade Estadual de Campinas, Campinas, 2010.

JUNG, S. P. et al. Thermo-mechanical finite element analysis of hot judder phenomenon of a ventilated disc brake system. International Journal Of Precision Engineering And Manufacturing, v. 12, n. 5, p.821-828, Oct. 2011.

JUVINALL, R. C.; MARSHEK, K. M. Projeto de componentes de máquinas. 4. ed. Rio de Janeiro: LTC, 2006.

KALIN, M.; POGAčNIK, A. Criteria and properties of the asperity peaks on 3D engineering surfaces. Wear, v. 308, n. 1-2, p.95-104, Oct. 2013.

KAO, T. K.; RICHMOND, J. W.; MOORE, M. W. The application of predictive techniques to study thermo-elastic instability in braking. SAE Technical Paper 942087, Oct. 1994.

KIM, J.; KWON, S.; YOON, S. Analysis of hot spots evolution on brake disc using highspeed infrared camera. Key Engineering Materials, v. 417-418, n. 1, p.317-320, Oct. 2009. 
KUHLMANN-WILSDORF, D. Demystifying flash temperatures I: Analytical expressions based on a simple model. Materials Science and Engineering, v. 93, p.107-118, Sep. 1987.

LEE, K; BARBER, J. R. Frictionally excited thermoelastic instability in automotive disk brakes. Journal of Tribology, v. 115, n. 4, p.607-614, Oct. 1993.

LEE, K.; SON, S.; YANG, K. A study on the thermal behaviour characteristic of drum brake considering braking patterns. Transactions of Korean Society for Automotive Engineers, v. 14, n. 5, p. 145-154, 2006.

LIMPERT, R. Brake design and safety. 2. ed. Warrendale: SAE International, 1999. $525 \mathrm{p}$.

LIMPERT, R., Engineering design handbook: Analysis and design of automotive LOIZOU, A. An empirically based finite element model for the fundamental investigation of factors that influence the interface thermal resistance at the friction interface of a high energy sliding pair in a disc brake. Thesis (PhD in Mechanical Engineering), University of Bradford. 232p. 2012.

MATYSIAK, S. J.; YEVTUSHENKO, A. A. On heating problems of friction. Journal of Theoretical and Applied Mechanics, Warsaw, v. 39, n. 3, p.577-588, 2001.

MASTER, Freios pneumáticos. Freio S Came 16.5"Q e Q-Plus. Disponível em: <http://www.fmaster.com.br/pt/produto/7/28>. Acesso em: 15 jun. 2015.

MERITOR. Maintenance Manual 1 - Preventive Maintenance and Lubrication, Aug. 2006.

MERITOR. Maintenance Manual 4 - Cam Brakes and Automatic Slack Adjusters, Jan. 2005.

MIHA, P. et al. Modifying the brake drum geometry to avoid self-excited vibrations and noise.Journal Of Vibreengineering, v. 14, n. 2, p.751-758 June 2012. 
MITSCHKE, M. Dynamik der kraftfahrzeuge, Springer-Verlag, 1972, 529 p.

MPI, Manitoba Public Insurance. Air Brake Manual. Disponível em: https://www.mpi.mb.ca/en/PDFs/AirBrakeManual.pdf>. Acesso em: 15 jun. 2015.

NYE, J. F. Physical properties of crystals: their representation by tensors and matrices. Clarendon Press. Oxford. 1957.

NOWACKI, W. Problems of thermoelasticity. Progress in Aerospace Sciences, v. 10, p.1-63, 1970.

OLESIAK, Z.; PYRYEV, Y.; YEVTUSHENKO, A. Determination of temperature and wear during braking. Wear, v. 210, n. 1-2, p.120-126, Sep. 1997.

PAINER, S.; DUFRÉNOY, P.; WEICHERT, D. An experimental investigation of hot spots in railway disc brakes. Wear, v. 256, n. 7-8, p.764-773, April 2004.

PAINER, S. et al. Progressive waviness distortion: a new approach of hot spotting in disc brakes. Journal of Thermal Stresses, v. 28, n. 1, p.47-62, Aug. 2004.

PUHN, F. Brake handbook. Tucson: Hpbooks, 1985. 176 p.

SCHARFF, R. Complete brake systems. New York: Delmar Publishers Inc, 1989. $373 p$.

SUH, C. M.; JEE, H. C.. Structural Analysis of S-cam Brake Shoe for Commercial Vehicle by FEM. Journal Of Ocean Engineering And Technology, v. 23, n. 4, p.6971, Jan. 2009.

TALATI, F.; JALALIFAR, S. Analysis of heat conduction in a disk brake system, Heat and Mass Transfer, v. 45, p. 1047-1059, 2009. 
TSCHIPTSCHIN, A. P. et al. Desgaste de ferros fundidos usados em disco de freio de veículos automotores. IX Congresso e Exposição Internacional da Tecnologia da Mobilidade SAE BRASIL, São Paulo, 2000.

VALVANO, T.; LEE, K. An analytical method to predict thermal distortion of a brake rotor. Paper SAE 2000-01-0445, June 2000.

WEBB, Severe Duty Brakes. Brake heat management. Disponível em: <http://www.webbwheel.com/severeduty/about_video_vortex_thermal.html>. Acesso em: 20 abr. 2015.

YEVTUSHENKO, A. A.; GRZES, P. The fem-modeling of the frictional heating phenomenon in the pad/disc tribosystem (a review). Numerical Heat Transfer: Part A, v. 58, n. 3, p.207-226, Aug. 2010.

$\mathrm{YI}, \mathrm{Y}$. B. et al. Effect of geometry on thermoelastic instability in disk brakes and clutches. Journal of Tribology, v. 121, n. 4, p.661-666, Oct. 1999.

YOSHIOKA, O. et al. Análise dos efeitos das deformações elásticas das sapatas na distribuição de pressão de um freio a tambor. V Congresso Nacional de Engenharia Mecânica, Salvador, Ago. 2008.

ZHU, B. et al. Submicron volume roughness \& asperity contact friction model for principle slip surface in flash heating process. Journal of Earth Science, v. 26, n. 1, p.096-107, Feb. 2015. 



\title{
APÊNDICE A - MACRO DA ANÁLISE DO CASO 1 EM AMBIENTE ANSYS V15.0
}

\author{
finish \\ /clear \\ /prep7 \\ /title, EESC-USP: Freio a Tambor- Rigido \\ ! Criacao dos novos volumes \\ CYLIND, 0.225,0.210,-0.110,0.110,0,360, \\ wprota, -60 \\ CYLIND, $0.210,0.190,-0.100,0.100,0,120$, \\ WPCSYS, -1 \\ wprota, ,, 180 \\ wprota, -60 \\ CYLIND,0.210,0.190,-0.100,0.100,0,120, \\ wpcsys, -1 \\ ! Sapatas - P/ estudo flexível \\ CYLIND, $0.190,0.185,-0.100,0.100,0,135$, \\ WPCSYS, -1 \\ wprota, ,, 180 \\ wprota, -70 \\ CYLIND,0.190,0.185,-0.100,0.100,0,135, \\ WPCSYS, -1 \\ wpoffs, $0.030,-0.155,0.023$ \\ CYLIND, 0.0095, ,0.004,-0.004,0,360, \\ WPCSYS, -1 \\ wpoffs, $0.030,0.155,0.023$ \\ CYLIND, 0.0125, ,0.004,-0.004,0,360, \\ WPCSYS, -1 \\ wpoffs, $-0.030,-0.155,0.023$ \\ CYLIND, 0.0095, ,0.004,-0.004,0,360, \\ WPCSYS, -1 \\ wpoffs, $-0.030,0.155,0.023$ \\ CYLIND, $0.0125,0.004,-0.004,0,360$, \\ WPCSYS, -1 \\ wpoffs, $0.030,-0.155,-0.023$ \\ CYLIND, 0.0095, ,0.004,-0.004,0,360, \\ WPCSYS, -1 \\ wpoffs, $0.030,0.155,-0.023$ \\ CYLIND, 0.0125, , 0.004,-0.004,0,360, \\ WPCSYS, -1 \\ wpoffs, $-0.030,-0.155,-0.023$ \\ CYLIND, 0.0095, ,0.004,-0.004,0,360, \\ WPCSYS, -1 \\ wpoffs, $-0.030,0.155,-0.023$ \\ CYLIND, 0.0125, ,0.004,-0.004,0,360, \\ WPCSYS, -1 \\ wpoffs, ,.,0.023 \\ CYLIND, $0.125,0.185,0.004,-0.004,0,360$ \\ WPCSYS, -1 \\ wpoffs, ,,- 0.023 \\ CYLIND, $0.125,0.185,0.004,-0.004,0,360$ \\ WPCSYS, -1 \\ BLOCK,0.030,-0.030,0.2,-0.2,0.2,-0.2, \\ vsbv, 14,16 \\ BLOCK, $0.030,-0.030,0.2,-0.2,0.2,-0.2$, \\ vsbv, 15,14 \\ vsbv, 18,6 \\ vsbv, 14,7 \\ vsbv, 17,8 \\ vsbv, 7,9 \\ vsbv, 19,10 \\ vsbv, 7,11 \\ vsbv, 16,12 \\ vsbv, 7,13 \\ allsel \\ ! MATERIAIS \\ ! TAMBOR - FoFo Cinzento
}

mp,ex,1,160e9
mp,prxy,1,0.28
mp,dens,1,7150
mp,kxx,1,46.861
mp,alpx,1,10.5e-6
mp,c,1,603
! LONA
mp,mu,2,0.4
mp,ex,2,1e9
mp,prxy,2,0.2
mp,dens,2,2000
mp,kxx,2,1.4
mp,alpx,2,1e-5
mp,c,2,900
! SPATAS - Aço
mp,ex,3,200e9
mp,prxy,3,0.3
mp,dens,3,7850
mp,kxx,3,60
mp,alpx,3,12e-6
mp,c,3,434
!
n,1,0,0,0
n,2,0.030,0.155,0
n,3,-0.030,0.155,0
n,4,0.030,-0.155,0
n,5,-0.030,-0.155,0
! Malha do tambor
et,1,226
keyopt,1,1,11
Isel,s,,,1,8,1
LESIZE,all, , ,20, , , , ,0
allsel
Isel,s,,,17,20,1
lesize,all,,,10, , , , ,0
allsel
type,1
mat,1
secnum,1
real,1
vsweep,1
allsel
! Malha das Lonas
et,2,226
keyopt,2,1,11
type,2
mat,2
secnum,2
real,2
esize,0.01
vsweep,2
vsweep,3
! Tambor - Rígido
et,3,170
keyopt,3,2,1
tshap,pilot
type,3
mat,1
secnum,3
real,3
e,1
tshape,quaPOPT,4,2,2,
et,4,174
keyopt,4,1,1
KYP,4,12,5


vsel,s,,,1,,,1

csys, 1

NSEL,r,LOC,X,0.210

csys, 0

type, 4

mat, 1

secnum, 4

real,3

esurf,,bottom

allsel

! Sapata direita - Vinculo

et, 5,170

keyopt,5,2,1

tshap,pilot

type, 5

mat, 5

secnum, 5

real, 5

$\mathrm{e}, 2$

tshape,qua8

et, 6,174

keyopt,6,1,1

KEYOPT,6,4,2

KEYOPT,6,2,2

KEYOPT, 6, 12,5

vsel,s,,,2,,,1

csys, 1

NSEL,r,LOC,X,0.190

csys, 0

type, 6

mat, 6

secnum, 6

real,5

esurf

allsel

! Sapata esq - Vinculo

et, 7,170

keyopt,7,2,1

tshap,pilot

type, 7

mat, 7

secnum, 7

real, 7

e, 3

tshape,qua8

et, 8,174

keyopt,8,1,1

KEYOPT,8,4,2

KEYOPT,8,2,2

KEYOPT, $8,12,5$

vsel,s, ,,3,,,1

csys, 1

NSEL,r,LOC,X,0.190

csys, 0

type, 8

mat, 8

secnum, 8

real, 7

esurf

allse

! Sapata direita - força

et, 9,170

keyopt,9,2,1

tshap, pilot

type, 9

mat, 9

secnum, 9

real, 9

e,4

tshape,qua8

et, 10,174

keyopt, 10,1,1

KEYOPT,10,4,2

KEYOPT,10,2,2

KEYOPT, 10,12,5 vsel,s,,,2,,,1

csys, 1

NSEL,r,LOC,X,0.190

csys, 0

type, 10

mat, 10

secnum, 10

real, 9

esurf

allsel

! Sapata esq - força

et, 11,170

keyopt,11,2,1

tshap,pilot

type, 11

mat, 11

secnum, 11

real, 11

e,5

tshape,qua8

et, 12,174

keyopt, 12,1,1

KEYOPT,12,4,2

KEYOPT,12,2,2

KEYOPT,12,12,5

vsel,s,,,3,,,1

csys, 1

NSEL,r,LOC,X,0.190

csys, 0

type, 12

mat, 12

secnum, 12

real,11

esurf

allsel

CONTATOS

ICOM, CONTACT PAIR CREATION - START

CM, NODECM,NODE

CM,_ELEMCM,ELEM

$\mathrm{CM}, \mathrm{KPCM}, \mathrm{KP}$

CM,_LINECM,LINE

CM,_AREACM,AREA

CM, VOLUCM, VOLU

/GSĀV,cwz,gsav, ,temp

MP,MU,2,0.4

MAT,2

MP,EMIS,2,

$\mathrm{R}, 12$

REAL, 12

ET, 13,170

ET, 14,174

$\mathrm{R}, 12,, 0.1,0.1,0$,

RMORE,,1.0E20,0.0,1.0,

RMORE, $0.0,100000,1.0,1.0,0.5$

RMORE,0,1.0,1.0,0.0,1.0

KEYOPT, $14,4,3$

KEYOPT, $14,5,0$

NROPT,UNSYM

KEYOPT, $14,7,1$

KEYOPT, 14,8,0

KEYOPT, 14,9,0

KEYOPT, 14,10,2

KEYOPT, $14,11,0$

KEYOPT, 14,12,0

KEYOPT,14,2,0

KEYOPT, 13,5,0

KEYOPT, 14,1,1

! Generate the target surface

ASEL,S, , 5

ASEL,A,,,6

CM, TARGET,AREA

TYPE, 13

NSLA,S, 1

ESLN,S, 0

ESLL,U

ESEL,U,ENAME,,188,189 
NSLE,A,CT2

ESURF

CMSEL,S, ELEMCM

$\mathrm{d}, 1$, roty

! Generate the contact surface

$\mathrm{d}, 2, \mathrm{ux}$

$\mathrm{d}, 2$,uy

ASEL,S, , 9

$\mathrm{d}, 2, \mathrm{uz}$

$\mathrm{d}, 2, \operatorname{rot} x$

$\mathrm{d}, 2$, roty

ASEL,A,, 15

$\mathrm{d}, 3, \mathrm{ux}$

d,3,uy

TYPE, 14

NSLA,S, 1

ESLN,S, 0

$\mathrm{d}, 3, \mathrm{uz}$

$\mathrm{d}, 3, \operatorname{rotx}$

NSLE,A,CT2

d,3, roty

ESURF

ALLSEL

ESEL,ALL

ESEL,S,TYPE,,13

$\mathrm{f}, 4, \mathrm{fx}, 13,21 \mathrm{e} 3$

$\mathrm{f}, 4, \mathrm{fy}, 5.34 \mathrm{e} 3$

$f, 5, f x,-13.21 e 3$

$f, 5, f y,-5.34$ e3

ESEL,A,TYPE, 14

ESEL,R,REAL,,12

/PSYMB,ESYS, 1

/PNUM,TYPE, 1

/NUM, 1

EPLOT

ESEL,ALL

ESEL,S,TYPE, 13

ESEL,A,TYPE,, 14

ESEL,R,REAL,,12

CMSEL,A, NODECM

CMDEL,_NODECM

CMSEL, $\bar{A}$, ELEMCM

CMDEL,_ELEMCM

/PSF,CONV,HCOE,2,0,1

tunif,20

tref,20

!Convecção LEVE nas laterais das lonas

asel,s,,, , $7,8,1$

asel, $\mathrm{a},,, 11,14,1$

asel, $\mathrm{a},,, 17,18,1$

sfa,all, 1, conv, $5.3,20$

allsel

!Convecção LEVE no tambor

asel,, , ,, $3,4,1$

sfa,all, 1, conv, $5.3,20$

CMSEL,S,_KPCM

CMDEL, KPCM

allsel

Iswrite, 1

! load2

CMDEL, LINECM

CMSEL,S,_AREACM

TIME,2

NSUBST,200,300,10

CMDEL, AREACM

$\mathrm{f}, 1, \mathrm{mz}, 7 \mathrm{e} 3$

Iswrite,2

CMDEL,_VOLUCM

Issolve, 1,2

/GRES,cwz,gsav

CMDEL,_TARGET

CMDEL,_CONTACT

ICOM, CONTACT PAIR CREATION - END

! plotagem

WPSTYLE,,,,,,, 0

/RGB,INDEX,100,100,100, 0

/RGB,INDEX, 80, 80, 80,13

/RGB,INDEX, 60, 60, 60,14

/RGB,INDEX, 0, 0, 0,15

/REPLOT

/efacet,2

/show,win32c,,,8

/contour,,30, auto

/plopts, date, off

/UDOC, 1,CNTR,left

! CARGAS/SOLVE

/prep7

nlgeom, on

NROPT,UNSYM

finish

/solu

bcsoption, incore

ANTYPE, 0

NLGEOM, 1

OUTRES,ERASE

OUTRES,BASI,ALL

AUTOTS, 1

LNSRCH, 1

$\mathrm{kbc}, 0$

CNVTOL,F, ,0.001,2,0.01,

! load1

TIME,1

NSUBST,200,300,10

$\mathrm{d}, 1, \mathrm{ux}$

$\mathrm{d}, 1, \mathrm{uy}$

$\mathrm{d}, 1, \mathrm{uz}$

$\mathrm{d}, 1$, rotx 



\section{APÊNDICE B - MACRO DA ANÁLISE DO CASO 1 EM AMBIENTE ANSYS V15.0}

finish

/clear

/prep7

/title, EESC-USP: Freio a Tambor-Flexivel

!Criacao dos novos volumes

CYLIND, 0.225,0.210,-0.110,0.110,0,360,

wprota, -60

CYLIND, 0.210,0.190,-0.100,0.100,0,120,

WPCSYS, -1

wprota, ,, 180

wprota, -60

CYLIND, $0.210,0.190,-0.100,0.100,0,120$,

wpcsys, -1

!Sapatas

CYLIND, 0.190,0.185,-0.100,0.100,0,135,

WPCSYS, -1

wprota, ,.,180

wprota, -70

CYLIND, 0.190,0.185,-0.100,0.100,0,135,

WPCSYS, -1

wpoffs, $0.030,-0.155,0.023$

CYLIND, $0.0095,, 0.004,-0.004,0,360$,

WPCSYS, -1

wpoffs, $0.030,0.155,0.023$

CYLIND, 0.0125, ,0.004,-0.004,0,360,

WPCSYS, -1

wpoffs, $-0.030,-0.155,0.023$

CYLIND, 0.0095, ,0.004,-0.004,0,360,

WPCSYS, -1

wpoffs, $-0.030,0.155,0.023$

CYLIND, $0.0125,0.004,-0.004,0,360$,

WPCSYS, -1

wpoffs, $0.030,-0.155,-0.023$

CYLIND, 0.0095, ,0.004,-0.004,0,360,

WPCSYS, -1

wpoffs, $0.030,0.155,-0.023$

CYLIND, $0.0125,, 0.004,-0.004,0,360$,

WPCSYS, -1

wpoffs, $-0.030,-0.155,-0.023$

CYLIND, 0.0095, ,0.004,-0.004,0,360,

WPCSYS, -1

wpoffs, $-0.030,0.155,-0.023$

CYLIND, $0.0125,0.004,-0.004,0,360$,

WPCSYS, -1

wpoffs, ,, 0.023

CYLIND, $0.125,0.185,0.004,-0.004,0,360$

WPCSYS, -1

wpoffs, ,,-0.023

CYLIND, $0.125,0.185,0.004,-0.004,0,360$

WPCSYS, -1

BLOCK,0.030,-0.030,0.2,-0.2,0.2,-0.2,

vsbv, 14,16

BLOCK, $0.030,-0.030,0.2,-0.2,0.2,-0.2$,

vsbv, 15,14

vsbv, 18,6

vsbv, 14,7

vsbv, 17,8

vsbv, 7,9

vsbv, 19,10

vsbv, 7,11

vsbv, 16,12

vsbv, 7,13

allsel

!MATERIAIS

! TAMBOR - FoFo Cinzento

mp,ex, 1,160e9

mp,prxy, $1,0.28$

\author{
mp,dens, 1,7150 \\ $m p, k x x, 1,46.861$ \\ mp,alpx, 1,10.5e-6 \\ $\mathrm{mp}, \mathrm{c}, 1,603$ \\ ! LONA \\ $\mathrm{mp}, \mathrm{mu}, 2,0.4$ \\ $\mathrm{mp}, \mathrm{ex}, 2,1 \mathrm{e} 9$ \\ mp,prxy,2,0.2 \\ mp,dens,2,2000 \\ $\mathrm{mp}, \mathrm{kxx}, 2,1.4$ \\ $\mathrm{mp}$, alpx,2,1e-5 \\ $\mathrm{mp}, \mathrm{c}, 2,900$ \\ !SPATAS - Aço \\ mp,ex,3,200e9 \\ mp,prxy, $3,0.3$ \\ $\mathrm{mp}$,dens, 3,7850 \\ $\mathrm{mp}, \mathrm{kxx}, 3,60$ \\ $\mathrm{mp}$, alpx,3,12e-6 \\ $\mathrm{mp}, \mathrm{c}, 3,434$ \\ $\mathrm{n}, 1,0,0,0$ \\ $\mathrm{n}, 2,0.030,0.155,0$ \\ $\mathrm{n}, 3,-0.030,0.155,0$ \\ $\mathrm{n}, 4,0.030,-0.155,0$ \\ $\mathrm{n}, 5,-0.030,-0.155,0$ \\ ! Malha do tambor \\ et, 1,226 \\ keyopt, 1,1,11 \\ Isel,s, ,, 1,8,1 \\ LESIZE,all, , , 10, , , , , 0 \\ Isel,s, ,45,48, 1 \\ LESIZE,all, , ,10, , , , ,0 \\ Isel,s, ,,53,56,1 \\ LESIZE,all, , ,10, , , , ,0 \\ allsel \\ Isel,s, ,.17,20,1 \\ lesize,all,,,5, , , , ,0 \\ allsel \\ Isel,s, ,,59,64,1 \\ lesize,all,,,1, , , , , ,0 \\ allsel \\ type, 1 \\ mat, 1 \\ secnum, 1 \\ real, 1 \\ vsweep, 1 \\ vsweep, 4 \\ vsweep,5 \\ allsel \\ ! Malha das Lonas \\ et,2,226 \\ keyopt,2,1,11 \\ type, 2 \\ mat,2 \\ secnum,2 \\ real,2 \\ esize, 0.03 \\ vsweep,2 \\ vsweep,3 \\ ! Malha das Sapatas \\ et, 3,226 \\ keyopt,3,1,11 \\ type, 3 \\ mat,3 \\ secnum, 3 \\ real,3
}


Isel,s, ,.,70,71, 1

Isel, $\mathrm{a},,, 68$

Isel,a,,,73

lesize,all,,,20,,,,,0

Isel,s, ,, 75,78,1

lesize,all,,,10,,,,,0

Isel,s, ,,82,83,1

Isel,a,,,80

Isel, $\mathrm{a},,, 85$

lesize,all,,,20,,,,,0

allsel,all

Isel,s, ,,87,90,1

lesize,all,,,10,,,,,0

allsel

vsweep, 6

vsweep, 7

!Malha das almas

SMRTSIZE, 6

vsweep, 9

vsweep, 10

vsweep, 11

vsweep, 15

! Tambor - vínculo Rígido

et, 4,170

keyopt,4,2,1

tshap,pilot

type, 4

mat, 4

secnum, 4

real, 4

tshape,qua8

et, 5,174

keyopt,5,1,1

KEYOPT,5,4,2

KEYOPT,5,2,2

KEYOPT, $5,12,5$

vsel,s, ,,5,,,1

csys, 1

NSEL,R,LOC, $x, 0.185$

csys, 0

type, 5

mat, 5

secnum, 5

real, 4

esurf

allsel

! Sapata direita - Vinculo

et, 6,170

keyopt,6,2,1

tshap,pilot

type, 6

mat, 6

secnum, 6

real, 6

e,2

tshape,qua8

et, 7,174

keyopt,7,1,1

KEYOPT, 7,4,2

KEYOPT,7,2,2

KEYOPT,7,12,5

vsel,s,,,9

vsel, $\mathrm{a},,, 10$

allsel,below,volu

local, 11,1,0.030,0.155,0

NSEL, r, LOC, X, 0.0125

csys, 0

type, 7

mat, 7

secnum, 7

real, 6

esurf

allsel

! Sapata esq - Vinculo

et, 8,170 keyopt,8,2,1

tshap, pilot

type, 8

mat, 8

secnum, 8

real, 8

e,3

tshape,qua8

et, 9,174

keyopt, $9,1,1$

KEYOPT, 9,4,2

KEYOPT, $9,2,2$

KEYOPT, 9,12,5

vsel,s,,,11

vsel, $\mathrm{a}, ., 15$

allsel,below,volu

local, $11,1,-0.030,0.155,0$

NSEL,r,LOC, X, 0.0125

csys, 0

type, 9

mat, 9

secnum, 9

real, 8

esurf

allsel

Sapata direita - força

et, 10,170

keyopt, 10,2,1

tshap,pilot

type, 10

mat, 10

secnum, 10

real, 10

e,4

tshape,qua8

et, 11,174

keyopt, $11,1,1$

KEYOPT,11,4,2

KEYOPT,11,2,2

KEYOPT, $11,12,5$

vsel,s, ,, 9

vsel, $\mathrm{a},,, 10$

allsel,below,volu

local, 11, 1,0.030,-0.155,0

NSEL, r, LOC, X,0.0095

csys, 0

type, 11

mat, 11

secnum, 11

real, 10

esurf

allsel

! Sapata esq - força

et, 12,170

keyopt,12,2,1

tshap,pilot

type, 12

mat, 12

secnum,12

real, 12

e,5

tshape,qua8

et, 13,174

keyopt, $13,1,1$

KEYOPT, 13,4,2

KEYOPT,13,2,2

KEYOPT,13,12,5

vsel,s,,,11

vsel,a,,,15

allsel,below,volu

local, 11,1,-0.030,-0.155,0

NSEL, r, LOC, X,0.0095

csys, 0

type, 13

mat, 13

secnum,13 
real, 12

esurf

allsel

\section{! CONTATOS}

! Almas - Chapa Dir (BONDED)

CM, NODECM,NODE

CM,_ELEMCM,ELEM

$\mathrm{CM}, \mathrm{KPCM}, \mathrm{KP}$

CM, LINECM,LINE

CM,_AREACM,AREA

CM, VOLUCM, VOLU

/GSĀV,cwz,gsav,,temp

MP,MU,3,

MAT,3

MP,EMIS,3,

$\mathrm{R}, 13$

REAL, 13

ET, 14,170

ET, 15,174

$\mathrm{R}, 13,, 1.0,0.1,0$,

RMORE,,.1.0E20,0.0,1.0,

RMORE,0.0,10000,1.0, 1.0,0.5

RMORE, 0,1.0,1.0,0.0, 1.0

RMORE, 10.0

KEYOPT, 15,4,2

KEYOPT, 15,5,0

KEYOPT, 15,7,0

KEYOPT, 15,8,0

KEYOPT, 15,9,0

KEYOPT, 15,10,2

KEYOPT, 15,11,0

KEYOPT,15,12,5

KEYOPT, 15,2,2

KEYOPT, 14,5,0

KEYOPT, 15,1,1

! Generate the target surface

ASEL,S, ,,31

CM,_TARGET,AREA

TYPE, 14

NSLA,S, 1

ESLN,S,0

ESLL,U

ESEL,U,ENAME,,188,189

NSLE,A,CT2

ESURF

CMSEL,S, ELEMCM

! Generate the contact surface

ASEL,S, ,,98

ASEL,A, , 99

ASEL,A,,,108

ASEL,A,,,109

CM, CONTACT,AREA

TYPE, 15

NSLA,S 1

ESLN,S, 0

NSLE,A,CT2

ESURF

ALLSEL

ESEL,ALL

ESEL,S,TYPE,,14

ESEL, A TYPE, 15

ESEL,R,REAL, 13

/PSYMB,ESYS, 1

/PNUM,TYPE,

/NUM, 1

EPLOT

ESEL,ALL

ESEL,S,TYPE,,14

ESEL,A,TYPE, ,15

ESEL,R,REAL,,13

CMSEL,A, NODECM

CMDEL, NODECM

CMSEL,A,_ELEMCM

CMDEL, ELEMCM
CMSEL,S, KPCM

CMDEL,_KPCM

CMSEL,S,_LINECM

CMDEL, LINECM

CMSEL, $\bar{S}$, AREACM

CMDEL, AREACM

CMSEL,S,_VOLUCM

CMDEL, VOLUCM

/GRES,cwz,gsav

CMDEL, TARGET

CMDEL, CONTACT

ICOM, CONTACT PAIR CREATION - END

! Almas - Chapa Esq (BONDED)

ICOM, CONTACT PAIR CREATION - START

CM, NODECM,NODE

CM,_ELEMCM,ELEM

$\mathrm{CM}, \mathrm{KPCM}, \mathrm{KP}$

CM,_LINECM,LINE

$\mathrm{CM}$, AREACM,AREA

CM, VOLUCM, VOLU

/GSĀV,cwz,gsav, ,temp

MP,MU, 3,0

MAT,3

MP,EMIS,3,0

$\mathrm{R}, 14$

REAL, 14

ET, 16,170

ET, 17,174

$\mathrm{R}, 14,,, 1.0,0.1,0$,

RMORE, ,1.0E20,0.0,1.0,

RMORE, $0.0,10000,1.0,, 1.0,0.5$

RMORE, 0,1.0,1.0,0.0,1.0

RMORE, 10.0

KEYOPT, 17,4,2

KEYOPT, $17,5,0$

KEYOPT, 17,7,0

KEYOPT $17,8,0$

KEYOPT 17,9,0

KEYOPT, 17, 10,2

KEYOPT 17,11,0

KEYOPT, 17,12,5

KEYOPT, 17,2,2

KEYOPT, 16,5,0

KEYOPT,17,1,1

! Generate the target surface

ASEL,S,,,37

CM, TARGET,AREA

TYPE, 16

NSLA,S, 1

ESLN,S,0

ESLL,U

ESEL,U,ENAME, ,188,189

NSLE,A,CT2

ESURF

CMSEL S, ELEMCM

! Generate the contact surface

ASEL,S,,,84

ASEL,A, ,.,85

ASEL,A,,,90

ASEL,A, , 91

CM,_CONTACT,AREA

TYPE, 17

NSLA,S, 1

ESLN,S,0

NSLE,A,CT2

ESURF

ALLSEL

ESEL,ALL

ESEL,S,TYPE,,16

ESEL,A,TYPE, 17

ESEL,R,REAL,,14

PSYMB,ESYS, 1

/PNUM, TYPE, 1

/NUM, 1

EPLOT 
ESEL,ALL

ESEL,S,TYPE,, 16

ESEL,A,TYPE,,17

ESEL,R,REAL,, 14

CMSEL,A,_NODECM

CMDEL, NODECM

CMSEL,A,_ELEMCM

CMDEL, ELEMCM

CMSEL,S,_KPCM

CMDEL, KPCM

CMSEL,S, LINECM

CMDEL, LINECM

CMSEL,S, AREACM

CMDEL,_AREACM

CMSEL,S,, VOLUCM

CMDEL, VOLUCM

/GRES,CWZ,gsav

CMDEL,_TARGET

CMDEL,_CONTACT

/COM, CONTACT PAIR CREATION - END

! Chapa - Lona Dir (BONDED)

/COM, CONTACT PAIR CREATION - START

CM,_NODECM,NODE

CM,_ELEMCM,ELEM

$\mathrm{CM}, \mathrm{KPCM}, \mathrm{KP}$

CM,_LINECM,LINE

CM, AREACM,AREA

CM,_VOLUCM,VOLU

/GSĀV,cwz,gsav,,temp

MP,MU, 3,0

MAT,3

MP,EMIS, 3,0

$\mathrm{R}, 15$

REAL, 15

ET, 18,170

ET, 19,174

$\mathrm{R}, 15,,, 1.0,0.1,0$

RMORE,,,1.0E20,0.0,1.0,

RMORE, 0.0,10000,1.0,1.0,0.5

RMORE, 0,1.0,1.0,0.0,1.0

RMORE, 10.0

KEYOPT, 19,4,2

KEYOPT, 19,5,0

KEYOPT, 19,7,0

KEYOPT, 19,8,0

KEYOPT, 19,9,0

KEYOPT,19,10,2

KEYOPT,19,11,0

KEYOPT,19,12,5

KEYOPT, 19,2,2

KEYOPT, 18,5,0

KEYOPT,19,1,

! Generate the target surface

ASEL,S,,,11

CM, TARGET,AREA

TYPE, 18

NSLA,S, 1

ESLN,S,0

ESLL,U

ESEL,U,ENAME,,188,189

NSLE,A,CT2

ESURF

CMSEL,S, ELEMCM

! Generate the contact surface

ASEL,S,,,30

CM,_CONTACT,AREA

TYPE, 19

NSLA,S, 1

ESLN,S,O

NSLE,A,CT2

ESURF

ALLSEL

ESEL,ALL

ESEL,S,TYPE,,18

ESEL,A,TYPE,,19
ESEL,R,REAL, 15

/PSYMB,ESYS, 1

IPNUM,TYPE, 1

/NUM, 1

EPLOT

ESEL,ALL

ESEL,S,TYPE,, 18

ESEL,A,TYPE,,19

ESEL,R,REAL,, 15

CMSEL,A,_NODECM

CMDEL, NODECM

CMSEL,A,_ELEMCM

CMDEL, ELEMCM

CMSEL,S, KPCM

CMDEL,_KPCM

CMSEL,S, LINECM

CMDEL,_LINECM

CMSEL,S, AREACM

CMDEL, AREACM

CMSEL,S,_VOLUCM

CMDEL, VOLUCM

/GRES,cwz,gsav

CMDEL, TARGET

CMDEL,_CONTACT

/COM, CONTACT PAIR CREATION - END

! Chapa - Lona Esq (BONDED)

/COM, CONTACT PAIR CREATION - START

CM,_NODECM,NODE

CM, ELEMCM,ELEM

$\mathrm{CM}, \mathrm{KPCM}, \mathrm{KP}$

CM,_LINECM,LINE

CM, AREACM,AREA

CM,_VOLUCM,VOLU

/GSĀV,cwz,gsav, ,temp

$\mathrm{MP}, \mathrm{MU}, 3,0$

MAT,3

MP,EMIS, 3,0

$\mathrm{R}, 16$

REAL, 16

ET, 20,170

ET, 21,174

$\mathrm{R}, 16,, 1.0,0.1,0$,

RMORE,,,1.0E20,0.0,1.0,

RMORE, $0.0,10000,1.0,1.0,0.5$

RMORE, 0,1.0,1.0,0.0,1.0

RMORE, 10.0

KEYOPT,21,4,2

KEYOPT, 21,5,0

KEYOPT,21,7,0

KEYOPT, 21,8,0

KEYOPT,21,9,0

KEYOPT,21,10,2

KEYOPT,21,11,0

KEYOPT,21,12,5

KEYOPT, 21,2,2

KEYOPT,20,5,0

KEYOPT,21,1,1

! Generate the target surface

ASEL,S, ,,25

CM, TARGET,AREA

TYPE,20

NSLA,S, 1

ESLN,S, 0

ESLL,U

ESEL,U,ENAME,,188,189

NSLE,A,CT2

ESURF

CMSEL,S, ELEMCM

! Generate the contact surface

ASEL,S,,,36

CM,_CONTACT,AREA

TYPE, 21

NSLA,S, 1

ESLN,S, 0

NSLE,A,CT2 
ESURF

ALLSEL

ESEL,ALL

ESEL,S,TYPE,,20

ESEL,A,TYPE,,21

ESEL,R,REAL,,16

/PSYMB,ESYS, 1

/PNUM,TYPE, 1

/NUM, 1

EPLOT

ESEL,ALL

ESEL,S,TYPE,,20

ESEL,A TYPE,,21

ESEL,R,REAL,,16

CMSEL,A, NODECM

CMDEL, NODECM

CMSEL, $\bar{A}$,_ELEMCM

CMDEL, ELEMCM

CMSEL,S,_KPCM

CMDEL, KPCM

CMSEL,S, LINECM

CMDEL, LINECM

CMSEL,S, AREACM

CMDEL, AREACM

CMSEL,S,_VOLUCM

CMDEL, VOLUCM

/GRES,cwz,gsav

CMDEL, TARGET

CMDEL,_CONTACT

ICOM, CONTACT PAIR CREATION - END

! LonaS Tambor (FRICTIONAL)

/COM, CONTACT PAIR CREATION - START

CM,_NODECM,NODE

CM,_ELEMCM,ELEM

$\mathrm{CM}, \mathrm{KPCM}, \mathrm{KP}$

CM,_LINECM,LINE

CM, AREACM,AREA

CM,_VOLUCM,VOLU

/GSĀV,cwz,gsav, ,temp

$\mathrm{MP}, \mathrm{MU}, 2,0.4$

MAT,2

MP,EMIS,2,

$\mathrm{R}, 17$

REAL, 17

ET, 22,170

$\mathrm{ET}, 23,174$

$\mathrm{R}, 17, \ldots, 0.1,0.1,0$,

RMORE,,,1.0E20,0.0,1.0,

RMORE, $0.0,100000,1.0,1.0,0.5$

RMORE, $0,1.0,1.0,0.0,1.0$

KEYOPT, $23,4,3$

KEYOPT, 23,5,0

NROPT,UNSYM

KEYOPT,23,7,1

KEYOPT, 23,8,0

KEYOPT,23,9,0

KEYOPT,23,10,2

KEYOPT,23,11,0

KEYOPT,23,12,0

KEYOPT, 23,2,0

KEYOPT,22,5,0

KEYOPT,23,1,1

! Generate the target surface

ASEL,S, , 5

ASEL,A,,,6

CM,_TARGET,AREA

TYPE,22

NSLA,S, 1

ESLN,S,0

ESLL,U

ESEL,U,ENAME,,188,189

NSLE,A,CT2

ESURF

CMSEL,S,_ELEMCM

! Generate the contact surface
ASEL,S, ,.10

ASEL,A,,,16

CM, CONTACT,AREA

TYPE,23

NSLA,S, 1

ESLN,S, 0

NSLE,A,CT2

ESURF

ALLSEL

ESEL,ALL

ESEL,S,TYPE,,22

ESEL,A,TYPE,,23

ESEL,R,REAL, 17

/PSYMB,ESYS, 1

/PNUM,TYPE, 1

/NUM, 1

EPLOT

ESEL,ALL

ESEL,S,TYPE,,22

ESEL,A,TYPE,,23

ESEL,R,REAL, 17

CMSEL,A,_NODECM

CMDEL, NODECM

CMSEL,A, ELEMCM

CMDEL, ELEMCM

CMSEL,S, KPCM

CMDEL,_KPCM

CMSEL,S, LINECM

CMDEL, LINECM

CMSEL,S, AREACM

CMDEL, AREACM

CMSEL,S, $\bar{S}$,VOLUCM

CMDEL, VOLUCM

/GRES,cwz,gsav

CMDEL,_TARGET

CMDEL, CONTACT

ICOM, CONTACT PAIR CREATION - END

! Acerto da plotagem

WPSTYLE,,,,,,,,0

/RGB,INDEX,100,100,100, 0

/RGB,INDEX, 80, 80, 80,13

/RGB,INDEX, 60, 60, 60,14

/RGB,INDEX, 0, 0, 0,15

/REPLOT

/efacet,2

/show,win32c,,,8

/contour,,30, auto

/plopts, date, off

/UDOC, 1,CNTR,left

ICARGAS e SOLVE

Isolu

bcsoption, incore

ANTYPE, 0

NLGEOM,1

OUTRES,ERASE

OUTRES,BASI,ALL

AUTOTS, 1

LNSRCH,1

$\mathrm{kbc}, 0$

CNVTOL,F, ,0.001,2,0.01,

! Load 1

TIME, 1

NSUBST, 200,300,10

$\mathrm{d}, 1, \mathrm{ux}$

d, 1 ,uy

$\mathrm{d}, 1, \mathrm{uz}$

d, 1 , rotx

d, 1, roty

$\mathrm{d}, 2, \mathrm{ux}$

d,2,uy

$\mathrm{d}, 2, \mathrm{uz}$

$\mathrm{d}, 2$, rotx

d,2, roty 


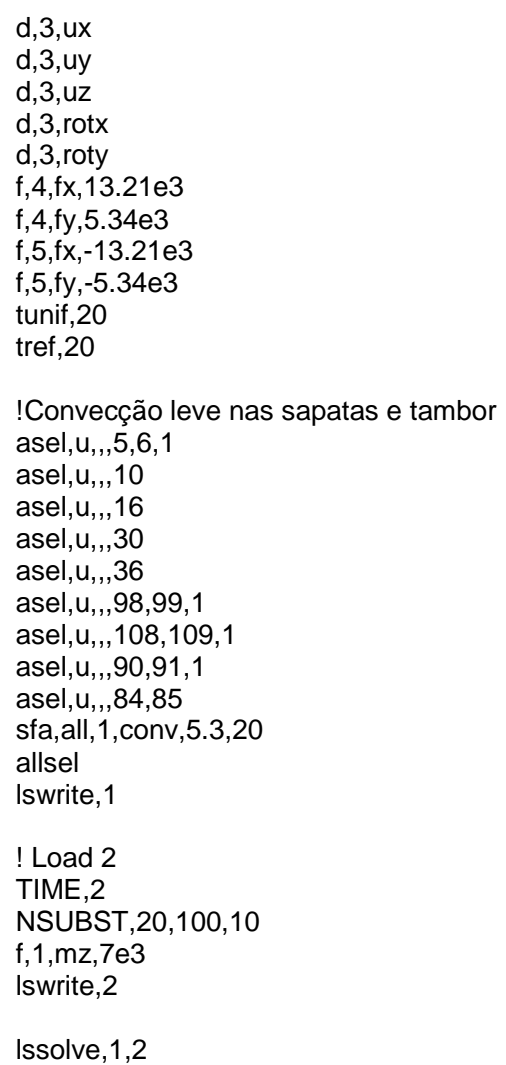




\section{APÊNDICE C - MACRO DA ANÁLISE DO CASO 1 EM AMBIENTE ANSYS V15.0}

\begin{tabular}{|c|c|}
\hline $\begin{array}{l}\text { finish } \\
\text { (clear }\end{array}$ & $\begin{array}{l}\mathrm{mp}, \text { dens, } 1,7150 \\
\mathrm{mp} k \times x, 146,861\end{array}$ \\
\hline $\begin{array}{l}\text { /clear } \\
\text { /prep7 }\end{array}$ & $\begin{array}{l}\mathrm{mp}, \mathrm{kxx}, 1,46.861 \\
\mathrm{mp}, \text { alpx } 1,10.5 \mathrm{e}-6\end{array}$ \\
\hline /title, EESC-USP: Flexivel com Rotacao & $\mathrm{mp}, \mathrm{c}, 1,603$ \\
\hline !Criacao dos novos volumes & ! LONA \\
\hline CYLIND, 0.225,0.210,-0.110,0.110,0,360, & $\mathrm{mp}, \mathrm{mu}, 2,0.4$ \\
\hline wprota,-60 & $\mathrm{mp}, \mathrm{ex}, 2,1 \mathrm{e} 9$ \\
\hline $\begin{array}{l}\text { CYLIND, } 0.210,0.190,-0.100,0.100,0,120 \text {, } \\
\text { WPCSYS - }\end{array}$ & mp,prxy,2,0.2 \\
\hline wprota, ,, 180 & $\begin{array}{l}m p, d e n s, \angle, \angle 000 \\
m p, k x x, 2,1.4\end{array}$ \\
\hline wprota, -60 & $m p$, alpx,2,1e-5 \\
\hline CYLIND, $0.210,0.190,-0.100,0.100,0,120$, & mp,c,2,900 \\
\hline !Sapatas & $\mathrm{mp}, \mathrm{ex}, 3,200 \mathrm{e} 9$ \\
\hline CYLIND, $0.190,0.185,-0.100,0.100,0,135$, & mp,prxy,3,0.3 \\
\hline WPCSYS,-1 & $\mathrm{mp}, \mathrm{dens}, 3,7850$ \\
\hline wprota,,,180 & $m p, k x x, 3,60$ \\
\hline wprota, -70 & $m p$, alpx,3,12e-6 \\
\hline CYLIND, $0.190,0.185,-0.100,0.100,0,135$, & $m p, c, 3,434$ \\
\hline WPCSYS,-1 & $\mathrm{n}, 1,0,0,0$ \\
\hline wpoffs, $0.030,-0.155,0.023$ & $\mathrm{n}, 2,0.030,0.155,0$ \\
\hline CYLIND, $0.0095,, 0.004,-0.004,0,360$, & $n, 3,-0.030,0.155,0$ \\
\hline WPCSYS, -1 & $\mathrm{n}, 4,0.030,-0.155,0$ \\
\hline wpoffs, $0.030,0.155,0.023$ & $n, 5,-0.030,-0.155,0$ \\
\hline CYLIND, $0.0125,, 0.004,-0.004,0,360$, & ! Malha do tambor \\
\hline WPCSYS, -1 & et, 1,226 \\
\hline wpoffs, $-0.030,-0.155,0.023$ & keyopt, $1,1,11$ \\
\hline CYLIND,0.0095, ,0.004,-0.004,0,360, & Isel,s, ,, 1,8,1 \\
\hline $\begin{array}{l}\text { WPCSYS, }-1 \\
\text { wpoffs, }-0.030,0.155,0.023\end{array}$ & $\begin{array}{l}\text { LESIZE,all, , ,10, , , , ,0 } \\
\text { Isel,s,,,45,48,1 }\end{array}$ \\
\hline $\begin{array}{l}\text { CYLIND, } 0.0125,, 0.004,-0.004,0,360 \text {, } \\
\text { WPCSYS }-1\end{array}$ & LESIZE, all, , ,10, , , , ,0 \\
\hline wpoffs $, 0.030,-0.155,-0.023$ & $\begin{array}{l}\text { Isel,S,,,53,56,1 } \\
\text { LESIZE,all, , ,10, , , , } 0\end{array}$ \\
\hline CYLIND, $0.0095,, 0.004,-0.004,0,360$, & allsel \\
\hline WPCSYS,-1 & Isel,s,,,17,20,1 \\
\hline wpoffs, $0.030,0.155,-0.023$ & lesize,all,,,5, , , , ,0 \\
\hline CYLIND, $0.0125,0.004,-0.004,0,360$, & allsel \\
\hline WPCSYS,-1 & Isel,s,,,59,64,1 \\
\hline wpoffs, $,-0.030,-0.155,-0.023$ & lesize,all,,,1, , , , , 0 \\
\hline CYLIND, $0.0095,0.004,-0.004,0,360$, & allsel \\
\hline WPCSYS, -1 & type, 1 \\
\hline wpoffs, $-0.030,0.155,-0.023$ & mat, 1 \\
\hline CYLIND $, 0.0125,, 0.004,-0.004,0,360$, & secnum, 1 \\
\hline WPCSYS, -1 & real, 1 \\
\hline wpoffs, ,,0.023 & vsweep, 1 \\
\hline CYLIND, $0.125,0.185,0.004,-0.004,0,360$ & vsweep, 4 \\
\hline WPCSYS,-1 & vsweep, 5 \\
\hline wpoffs, ,,-0.023 & allsel \\
\hline CYLIND, $0.125,0.185,0.004,-0.004,0,360$ & \\
\hline WPCSYS,-1 & ! Malha das Lonas \\
\hline BLOCK,0.030,-0.030,0.2,-0.2,0.2,-0.2, & et, 2,226 \\
\hline vsbv, 14,16 & keyopt,2,1,11 \\
\hline BLOCK, $0.030,-0.030,0.2,-0.2,0.2,-0.2$, & type,2 \\
\hline vsbv, 15,14 & mat,2 \\
\hline vsbv, 18,6 & secnum, 2 \\
\hline vsbv, 14,7 & real,2 \\
\hline vsbv, 17,8 & esize, 0.03 \\
\hline vsbv, 7,9 & vsweep,2 \\
\hline vsbv, 19,10 & vsweep,3 \\
\hline vsbv, 7,11 & ! Malha das Sapatas \\
\hline vsbv, 16,12 & et, 3,226 \\
\hline vsbv, 7,13 & keyopt,3,1,11 \\
\hline allsel & type, 3 \\
\hline !MATERIAIS & mat,3 \\
\hline ! TAMBOR - FoFo Cinzento & secnum,3 \\
\hline $\mathrm{mp}, \mathrm{ex}, 1,160 \mathrm{e} 9$ & real,3 \\
\hline mp,prxy, $1,0.28$ & Isel, $, \mathbf{s},,, 70,71,1$ \\
\hline
\end{tabular}


Isel,a,,,68

Isel,a,,,73

lesize, all,,,20,,,,,0

Isel,s, ,,75,78,1

lesize,all,,,10,,,,,0

Isel,s, ,,82,83,1

Isel,, ,,, 80

Isel,a,,,85

lesize,all,,,20,,,,,0

allsel,all

Isel,S, ,,87,90,1

lesize,all,,,10,,,,,0

allsel

vsweep,6

vsweep, 7

!Malha das almas

SMRTSIZE,6

vsweep, 9

vsweep, 10

vsweep, 11

vsweep, 15

! Tambor - vínculo Rígido

et, 4,170

keyopt,4,2,1

tshap,pilot

type, 4

mat, 4

secnum, 4

real, 4

$\mathrm{e}, 1$

tshape,qua8

et, 5,174

keyopt,5,1,1

KEYOPT,5,4,2

KEYOPT,5,2,2

KEYOPT,5,12,5

vsel,s,,,5,,,1

CSys, 1

NSEL,R,LOC, $x, 0.185$

csys, 0

type, 5

mat, 5

secnum, 5

real, 4

esurf

allsel

! Sapata direita - Vinculo

et, 6,170

keyopt,6,2,1

tshap, pilot

type, 6

mat, 6

secnum, 6

real, 6

e,2

tshape,qua8

et, 7,174

keyopt,7,1,1

KEYOPT,7,4,2

KEYOPT, 7,2,2

KEYOPT, $7,12,5$

vsel,s,,,9

vsel, a, , 10

allsel,below,volu

local, 11, 1,0.030,0.155,0

NSEL,r,LOC,X,0.0125

csys, 0

type, 7

mat, 7

secnum, 7

real, 6

esurf

allsel

! Sapata esq - Vinculo

et, 8,170

keyopt,8,2,1

tshap, pilot

type, 8

mat, 8

secnum, 8

real, 8

e,3

tshape,qua8

et, 9,174

keyopt, $9,1,1$

KEYOPT, $9,4,2$

KEYOPT, 9,2,2

KEYOPT, 9,12,5

vsel,s,,,11

vsel,a,,,15

allsel,below,volu

local, 11,1,-0.030,0.155,0

NSEL, r, LOC, X, 0.0125

csys, 0

type, 9

mat, 9

secnum, 9

real, 8

esurf

allsel

! Sapata direita - força

et, 10,170

keyopt,10,2,1

tshap,pilot

type, 10

mat, 10

secnum, 10

real, 10

$\mathrm{e}, 4$

tshape,qua8

et, 11,174

keyopt,11,1,1

KEYOPT, $11,4,2$

KEYOPT, 11,2,2

KEYOPT,11,12,5

vsel,s, ,,9

vsel, $a,, 10$

allsel,below,volu

local, 11,1,0.030,-0.155,0

NSEL,r,LOC,X,0.0095

csys, 0

type, 11

mat, 11

secnum, 11

real, 10

esurf

allsel

! Sapata esq - força

et, 12,170

keyopt,12,2,1

tshap,pilot

type, 12

mat, 12

secnum, 12

real,12

e,5

tshape,qua8

et, 13,174

keyopt, $13,1,1$

KEYOPT,13,4,2

KEYOPT,13,2,2

KEYOPT,13,12,5

vsel,s,,,11

vsel,a,,,15

allsel,below,volu

local, 11,1,-0.030,-0.155,0

NSEL,r,LOC, X,0.0095

csys, 0

type, 13

mat, 13

secnum, 13

real, 12 
esurf

allsel

! CONTATOS

! Almas - Chapa Dir (BONDED)

CM,_NODECM,NODE

CM, ELEMCM,ELEM

$\mathrm{CM}$, KPCM,KP

CM,_LINECM,LINE

CM, AREACM,AREA

CM,_VOLUCM,VOLU

/GSAV,cwz,gsav, ,temp

$\mathrm{MP}, \mathrm{MU}, 3$,

MAT,3

MP,EMIS,3,

$\mathrm{R}, 13$

REAL, 13

ET, 14,170

ET, 15,174

$\mathrm{R}, 13,, 1.0,0.1,0$

RMORE,,,1.0E20,0.0,1.0,

RMORE, $0.0,10000,1.0,1.0,0.5$

RMORE, 0,1.0,1.0,0.0,,1.0

RMORE, 10.0

KEYOPT, 15,4,2

KEYOPT,15,5,0

KEYOPT, 15,7,0

KEYOPT, 15,8,0

KEYOPT, 15,9,0

KEYOPT, 15,10,2

KEYOPT, 15,11,0

KEYOPT,15,12,5

KEYOPT,15,2,2

KEYOPT, 14,5,0

KEYOPT, 15,1,1

! Generate the target surface

ASEL,S, ,,31

CM,_TARGET,AREA

TYPE, 14

NSLA,S, 1

ESLN,S,0

ESLL,U

ESEL,U,ENAME,,188,189

NSLE,A,CT2

ESURF

CMSEL,S,_ELEMCM

! Generate the contact surface

ASEL,S, ,,98

ASEL,A,,,99

ASEL,A,.,108

ASEL,A,,,109

CM, CONTACT,AREA

TYPE, 15

NSLA,S, 1

ESLN,S, 0

NSLE,A,CT2

ESURF

ALLSEL

ESEL,ALL

ESEL,S,TYPE, 14

ESEL,A,TYPE,, 15

ESEL,R,REAL, 13

IPSYMB,ESYS, 1

/PNUM,TYPE, 1

/NUM, 1

EPLOT

ESEL,ALL

ESEL,S,TYPE,,14

ESEL,A,TYPE,,15

ESEL,R,REAL, 13

CMSEL,A,_NODECM

CMDEL, NODECM

CMSEL,A, ELEMCM

CMDEL,_ELEMCM

CMSEL,S,_KPCM
CMDEL, KPCM

CMSEL,S,_LINECM

CMDEL, LINECM

CMSEL,S,_AREACM

CMDEL, AREACM

CMSEL,S, VOLUCM

CMDEL,_VOLUCM

GRES,cwz,gsav

CMDEL,_TARGET

CMDEL, CONTACT

ICOM, CONTACT PAIR CREATION - END

! Almas - Chapa Esq (BONDED)

/COM, CONTACT PAIR CREATION - START

CM,_NODECM,NODE

CM, ELEMCM,ELEM

$\mathrm{CM}$, KPCM,KP

CM, LINECM,LINE

CM, AREACM,AREA

CM,_VOLUCM,VOLU

/GSAV,cwz,gsav,,temp

MP,MU, 3,0

MAT,3

MP,EMIS, 3,0

$\mathrm{R}, 14$

REAL, 14

ET, 16,170

ET, 17,174

$\mathrm{R}, 14,,, 1.0,0.1,0$,

RMORE,,,1.0E20,0.0,1.0,

RMORE, $0.0,10000,1.0,1.0,0.5$

RMORE, 0,1.0,1.0,0.0,1.0

RMORE, 10.0

KEYOPT, 17,4,2

KEYOPT, 17,5,0

KEYOPT, 17,7,0

KEYOPT, 17,8,0

KEYOPT $17,9,0$

KEYOPT 17, 10,2

KEYOPT, 17,11,0

KEYOPT, 17,12,5

KEYOPT, 17,2,2

KEYOPT, 16,5,0

KEYOPT,17,1,1

! Generate the target surface

ASEL,S, ,,37

CM,_TARGET,AREA

TYPE, 16

NSLA,S, 1

ESLN,S,0

ESLL,U

ESEL,U,ENAME,,188,189

NSLE,A,CT2

ESURF

CMSEL,S,_ELEMCM

! Generate the contact surface

ASEL,S, ,,84

ASEL,A,,,85

ASEL,A,,,90

ASEL,A,,,91

CM, CONTACT,AREA

TYPE, 17

NSLA,S, 1

ESLN,S, 0

NSLE,A,CT2

ESURF

ALLSEL

ESEL,ALL

ESEL,S,TYPE,,16

ESEL,A,TYPE,,17

ESEL,R,REAL, 14

IPSYMB,ESYS, 1

/PNUM,TYPE, 1

/NUM, 1

EPLOT

ESEL,ALL 
ESEL,S,TYPE,,16

ESEL,A,TYPE,, 17

ESEL,R,REAL, , 14

CMSEL,A,_NODECM

CMDEL, NODECM

CMSEL,A, ELEMCM

CMDEL,_ELEMCM

CMSEL, $\bar{S}$, KPCM

CMDEL, KPCM

CMSEL,S, LINECM

CMDEL, LINECM

CMSEL,S,_AREACM

CMDEL, AREACM

CMSEL,S,_VOLUCM

CMDEL,_VOLUCM

/GRES,cwz,gsav

CMDEL,_TARGET

CMDEL,_CONTACT

/COM, CONTACT PAIR CREATION - END

! Chapa - Lona Dir (BONDED)

/COM, CONTACT PAIR CREATION - START

CM, NODECM,NODE

CM,_ELEMCM,ELEM

$\mathrm{CM}, \mathrm{KPCM}, \mathrm{KP}$

CM, LINECM,LINE

$\mathrm{CM}$,_AREACM,AREA

CM, VOLUCM, VOLU

/GSĀV,cwz,gsav,,temp

MP,MU,3,0

MAT,3

MP,EMIS,3,0

$\mathrm{R}, 15$

REAL, 15

ET, 18,170

ET, 19,174

$\mathrm{R}, 15,,, 1.0,0.1,0$,

RMORE,,,1.0E20,0.0,1.0,

RMORE,0.0,10000,1.0,,1.0,0.5

RMORE,0,1.0,1.0,0.0,,1.0

RMORE, 10.0

KEYOPT, 19,4,2

KEYOPT,19,5,0

KEYOPT, 19,7,0

KEYOPT, 19,8,0

KEYOPT, 19,9,0

KEYOPT,19,10,2

KEYOPT,19,11,0

KEYOPT,19,12,5

KEYOPT,19,2,2

KEYOPT, 18,5,0

KEYOPT, 19,1,1

! Generate the target surface

ASEL,S,,,11

CM,_TARGET,AREA

TYPE, 18

NSLA,S, 1

ESLN,S,0

ESLL,U

ESEL,U,ENAME,,188,189

NSLE,A,CT2

ESURF

CMSEL,S, ELEMCM

! Generate the contact surface

ASEL,S,,,30

CM, CONTACT,AREA

TYPE, 19

NSLA,S, 1

ESLN,S, 0

NSLE,A,CT2

ESURF

ALLSEL

ESEL,ALL

ESEL,S,TYPE, , 18

ESEL,A,TYPE,,19

ESEL,R,REAL,,15
PSYMB,ESYS, 1

/PNUM,TYPE, 1

/NUM, 1

EPLOT

ESEL,ALL

ESEL,S,TYPE, ,18

ESEL,A,TYPE,, 19

ESEL,R,REAL, , 15

CMSEL,A,_NODECM

CMDEL, NODECM

CMSEL,A, ELEMCM

CMDEL,ELEMCM

CMSEL,S, KPCM

CMDEL, KPCM

CMSEL,S,_LINECM

CMDEL, LINECM

CMSEL,S,_AREACM

CMDEL, AREACM

CMSEL,S,_VOLUCM

CMDEL,_VOLUCM

IGRES,cwZ,gsav

CMDEL,_TARGET

CMDEL, CONTACT

/COM, CONTACT PAIR CREATION - END

! Chapa - Lona Esq (BONDED)

ICOM, CONTACT PAIR CREATION - START

CM, NODECM,NODE

CM,_ELEMCM,ELEM

$\mathrm{CM}$, KPCM, KP

CM, LINECM,LINE

CM,_AREACM,AREA

CM, VOLUCM, VOLU

/GSĀV,cwz,gsav, ,temp

$M P, M U, 3,0$

MAT, 3

MP,EMIS,3,0

$\mathrm{R}, 16$

REAL,16

ET, 20,170

ET, 21,174

$\mathrm{R}, 16,, 1.0,0.1,0$,

RMORE,,1.0E20,0.0,1.0,

RMORE, 0.0,10000,1.0,,1.0,0.5

RMORE, 0,1.0,1.0,0.0,,1.0

RMORE, 10.0

KEYOPT,21,4,2

KEYOPT,21,5,0

KEYOPT, 21,7,0

KEYOPT,21,8,0

KEYOPT,21,9,0

KEYOPT,21, 10,2

KEYOPT,21,11,0

KEYOPT,21,12,5

KEYOPT,21,2,2

KEYOPT, 20,5,0

KEYOPT,21,1,1

! Generate the target surface

ASEL,S, ,,25

CM,_TARGET,AREA

TYPE, 20

NSLA,S, 1

ESLN,S,0

ESLL,U

ESEL,U,ENAME, 188,189

NSLE,A,CT2

ESURF

CMSEL,S, ELEMCM

! Generate the contact surface

ASEL,S, ,,36

CM, CONTACT,AREA

TYPE,21

NSLA,S, 1

ESLN,S,0

NSLE,A,CT2

ESURF 
ALLSEL

ESEL,ALL

ESEL,S,TYPE,,20

ESEL,A,TYPE,,21

ESEL,R,REAL,,16

/PSYMB,ESYS, 1

/PNUM,TYPE, 1

/NUM, 1

EPLOT

ESEL,ALL

ESEL,S,TYPE,,20

ESEL,A,TYPE,,21

ESEL,R,REAL, 16

CMSEL,A,_NODECM

CMDEL, NODECM

CMSEL,A, ELEMCM

CMDEL, ELEMCM

CMSEL,S, KPCM

CMDEL,KYCM

CMSEL,S, LINECM

CMDEL, LINECM

CMSEL,S,_AREACM

CMDEL, AREACM

CMSEL,S,_VOLUCM

CMDEL,_VOLUCM

/GRES,cwz,gsav

CMDEL,_TARGET

CMDEL, CONTACT

ICOM, CONTACT PAIR CREATION - END

! LonaS Tambor (FRICTIONAL)

ICOM, CONTACT PAIR CREATION - START

CM, NODECM,NODE

CM,_ELEMCM,ELEM

$\mathrm{CM}, \mathrm{KPCM}, \mathrm{KP}$

CM, LINECM,LINE

CM,_AREACM,AREA

CM, VOLUCM, VOLU

/GSAV,cwz,gsav,,temp

MP,MU,2,0.4

MAT,2

MP,EMIS,2,

$\mathrm{R}, 17$

REAL, 17

$\mathrm{ET}, 22,170$

ET, 23,174

$\mathrm{R}, 17,,, 0.1,0.1,0$,

RMORE,,,1.0E20,0.0,1.0,

RMORE, $0.0,100000,1.0,1.0,0.5$

RMORE, 0,1.0,1.0,0.0,1.0

KEYOPT, 23,4,3

KEYOPT,23,5,0

NROPT,UNSYM

KEYOPT,23,7,1

KEYOPT,23,8,0

KEYOPT,23,9,0

KEYOPT,23,10,2

KEYOPT,23,11,0

KEYOPT,23,12,0

KEYOPT,23,2,0

KEYOPT,22,5,0

KEYOPT,23,1,1

! Generate the target surface

ASEL,S, ,,5

ASEL,A,,,6

CM, TARGET,AREA

TYPE,22

NSLA,S, 1

ESLN,S,0

ESLL,U

ESEL, U,ENAME, 188,189

NSLE,A,CT2

ESURF

CMSEL,S, ELEMCM

! Generate the contact surface

ASEL,S,,,10
ASEL,A , 16

CM,_CONTACT,AREA

TYPE,23

NSLA,S, 1

ESLN,S,0

NSLE,A,CT2

ESURF

ALLSEL

ESEL,ALL

ESEL,S,TYPE,,22

ESEL,A,TYPE,,23

ESEL,R,REAL,,17

/PSYMB,ESYS, 1

PNUM,TYPE, 1

/NUM, 1

EPLOT

ESEL,ALL

ESEL,S,TYPE,,22

ESEL,A,TYPE,,23

ESEL,R,REAL,,17

CMSEL,A, NODECM

CMDEL,_NODECM

CMSEL,A, ELEMCM

CMDEL, ELEMCM

CMSEL, S, KPCM

CMDEL, KPCM

CMSEL,S,_LINECM

CMDEL, LINECM

CMSEL,S,_AREACM

CMDEL, AREACM

CMSEL,S, VOLUCM

CMDEL,_VOLUCM

/GRES,cwz,gsav

CMDEL,_TARGET

CMDEL,_CONTACT

ICOM, CONTACT PAIR CREATION - END

! Acerto da plotagem

WPSTYLE,,,,,,,, 0

/RGB,INDEX,100,100,100, 0

/RGB,INDEX, 80, 80, 80,13

/RGB,INDEX, 60, 60, 60,14

/RGB,INDEX, 0, 0, 0,15

/REPLOT

lefacet,2

/show,win32c, ,.,

/contour,,30,auto

/plopts, date, off

/UDOC, 1, CNTR,left

!CARGAS e SOLVE

Isolu

bcsoption, incore

ANTYPE, 0

NLGEOM, 1

OUTRES,ERASE

OUTRES,BASI,ALL

AUTOTS, 1

$\mathrm{LNSRCH}, 1$

$\mathrm{kbc}, 0$

CNVTOL,F, ,0.001,2,0.01,

! Load 1

TIME, 1

NSUBST,200,300,50

esel,s,type,,22

CM,rotor,ELEM

allsel

d, $1, u x$

d, 1,uy

d, $1, u z$

d, 1 , rotx

d, 1 , roty

d, 2 , ux

d,2,uy

$\mathrm{d}, 2, \mathrm{uz}$ 
$\mathrm{d}, 2$, rotx

d,2, roty

d, 3 ,ux

d,3,uy

d,3,uz

d, 3 , rotx

d, 3 , roty

$\mathrm{f}, 4, \mathrm{fx}, 1.321 \mathrm{e} 3$

$\mathrm{f}, 4, \mathrm{fy}, 0.534 \mathrm{e} 3$

$\mathrm{f}, 5, \mathrm{fx},-1.321 \mathrm{e} 3$

$\mathrm{f}, 5, \mathrm{fy},-0.534 \mathrm{e} 3$

tunif, 20

tref,20

!Convecção leve nas sapatas

vsel,u,,,1 1

vsel,u, , , 4,5,1

allsel,below,volu

asel, $\mathrm{u},,, 10$

asel, $\mathrm{u},,, 16$

asel, $\mathrm{u},,, 30$

asel,u,,,36

asel,u,,,,98,99,1

asel,u,,,108,109,1

asel,u,,,90,91,1

asel, $\mathrm{u},,, 84,85$

sfa,all, 1, conv, 10.6,20

allsel

!Convecção pesada no tambor

vsel,s,,,1

vsel, a, ,, $4,5,1$

allsel,below,volu

asel,u,, $, 5,6,1$

sfa,all,1,conv, 105.2,20

allsel

solve

! Load 2

TIME,2

NSUBST, 300,500,200

d, 1 , rotz

cmrotate, rotor,,, 15

solve 